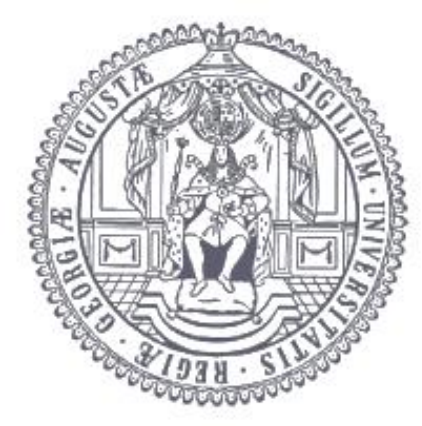

Urbanisation, Land Use and Soil Resource: Spatio-Temporal Analyses of Trends and Environmental Effects in Two Metropolitan Regions of Ghana (West Africa)

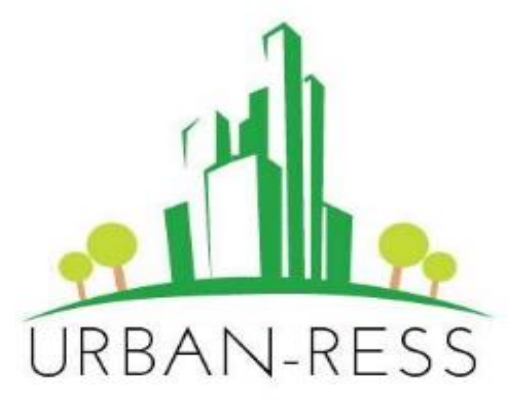

Dissertation

for the award of the degree

"Doctor rerum naturalium" (Dr. rer. Nat.) of the Georg-August-Universität Göttingen

within the doctoral program Geography

of the Georg-August University School of Science (GAUSS)

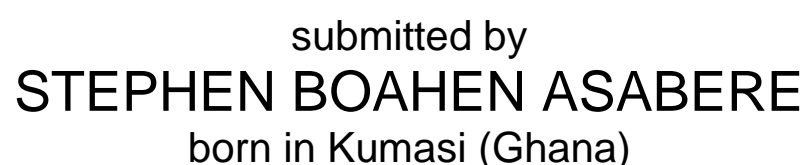

Göttingen, 2020 


\section{Thesis Committee}

Prof. Dr. Daniela Sauer

(Physical Geography Department / Georg-August Universität Göttingen)

Prof. Dr. Jochen Schanze

(Chair of Environmental Development and Risk Management / Technische

Universität Dresden)

Prof. Dr. Heiko Faust

(Human Geography Department / Georg-August Universität Göttingen)

Prof. Dr. Hans Ruppert

(Sedimentology and Environmental Geology Department / Georg-August Universität Göttingen)

Dr. Stefan Erasmi

(Thünen Institute of Farm Economics, Braunschweig)

Dr. Markus Keck

(Human Geography Department / Georg-August Universität Göttingen)

\section{Members of the Examination Board}

Reviewer 1:

Prof. Dr. Daniela Sauer

(Physical Geography Department / Georg-August University of Göttingen)

Reviewer 2:

Prof. Dr. Jochen Schanze

(Chair of Environmental Development and Risk Management / Technische Universität Dresden)

Date of the oral examination: $19^{\text {th }}$ June, 2020 
"There was no doubt about it: the City was the culmination of man's mastery over the environment. Not space travel, not the fifty colonized worlds that were now so haughtily independent, but the City."

Isaac Asimov, The Caves of Steel. 


\section{ACKNOWLEDGMENTS}

Over the past few years, I have had the privilege to interact with many people in both research and non-research capacities, who have contributed immensely to the final realisation of this $\mathrm{PhD}$ thesis, and I am highly indebted to everyone. By far, the most important person in my career has been Prof. Dr. Daniela Sauer, who has literally been my "Doktormutter" in every sense, for this whole journey. Her patience to share her knowledge, trust worthiness, fairness to everyone and keen interest in the understanding of the physical environment has been a great inspiration. Whenever it was possible, she has fully supported my scientific career development, which has gone beyond just the realisation of this $\mathrm{PhD}$ thesis. For all these opportunities, I say "me daase". I also deeply appreciate the support and mentoring from my second supervisor, Prof. Dr. Jochen Schanze, particularly at the beginning of this thesis. I thank Dr. Stefan Erasmi for his friendship and mentorship. I appreciate the support of the Graduate Academy, TU Dresden, and the Gesellschaft von Freunden und Förderern (GFF), TU Dresden for initial grants to develop the proposal for this research.

My appreciation to Prof. Dr. Dagmar Haase and Prof. Dr. Antje Bruns for the initial discussions on potentially supervising my PhD. I especially thank Prof. Dr. Alfred Schultz, who in addition to supervising my master thesis, also encouraged me to embark on this PhD work. I also thank Prof. Dr. Dominic Faust and my former colleagues at the Physical Geography Department-TU Dresden, particularly Christopher, Rico and Sasha. I thank my former colleagues at the Chair of Risk Management and Environmental Development-TU Dresden, particularly Verena with whom I shared the same office, Raphael and Ren. I also thank all my friends in Dresden.

I deeply appreciate the contributions and friendship of my former and current colleagues at the Physical Geography Department-University of Göttingen. In their own small ways, everyone made it easy for me to assimilate well in Göttingen. To former colleagues Rodolfo, Wiebke, Ulf, Thorsten, Daniel, Felix, Stefan, Alex, Jan, Joscha, Hung; and to my current colleagues Nora, Kwabena, Harold, Barbara, Flavia, Florian, Michael, Claudia, Collins, Obaida, Simon and Britta, I say "thank you". I particularly thank Nora for sharing the same office and being an excellent "work partner", and Kwabena for being a "brother from another mother". Thank you to Dr. Grotheer, Anja and Petra for taking the time to explain all the lab equipments to me and answering all my silly questions. I sincerely thank Marie-France Hesse for her support in everything to do with official stuff and the plantain plant. I thank Carola and Raffael who were the first master students I worked with within the context of this PhD project.

Special thanks to the long-lasting friends I have come to have in Göttingen - Amelie and Collins who have always been there for support, Kwame, Noah, Isaac, Issaka, friends from the African Research Network, and friends from the Ghana community Göttingen. I thank my closest friends Theodore and Sandra who have always been there, right from the beginning. Special thanks to all friends in Berlin, Ghana Professionals and Students group, especially Cosmas, Kobla, Kwasi-Addo, Prosper and Emile. A special thank you to George who in diverse ways has been a great 
support right from the beginning. I sincerely thank Harriet, a childhood friend, who after learning about my PhD project, contributed freely by designing a logo for me.

Finally, and most importantly, my deepest appreciation to my family both in Europe and Ghana. I especially appreciate my dear Larissa Awura-Ama, and her parents Tina and Robert, for all the love, emotional support, and the much-needed cheer in those tough times. Thank you to my lovely sister Elizabeth, who has always been my greatest cheerleader, to my brother Daniel and his family, and to all my cousins, nephews and nieces.

This thesis was only made possible because of the endless support of my parents, who have spent their entire life savings to educate me and my siblings. 


\section{TABLE OF CONTENTS}

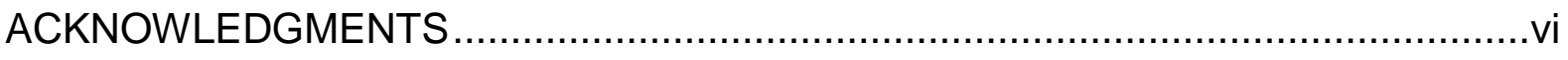

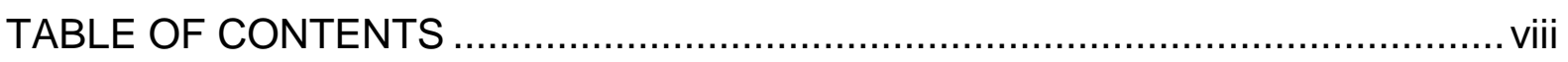

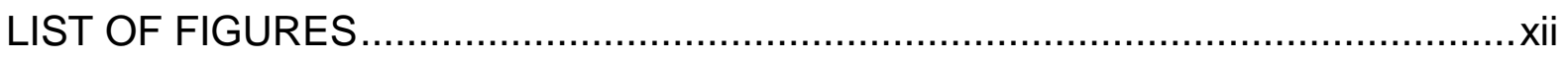

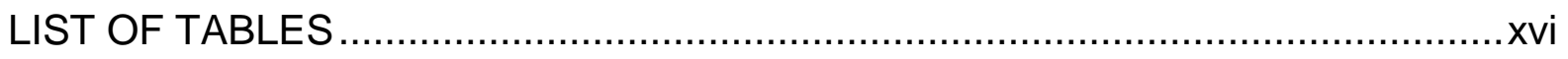

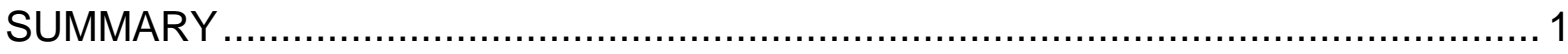

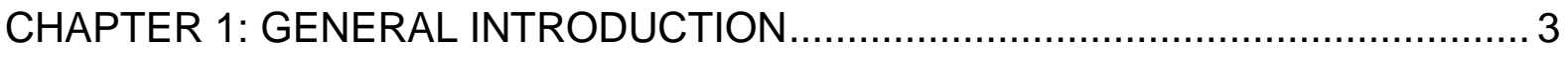

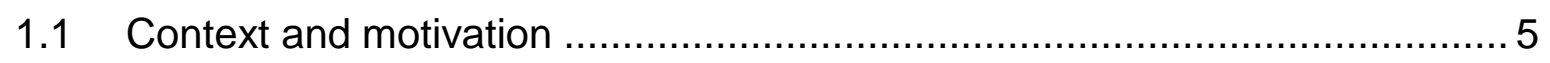

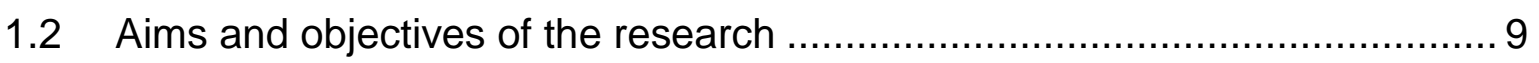

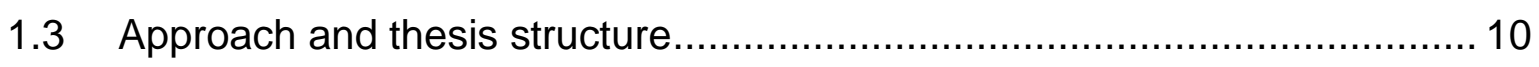

1.4 Contributions to publications and manuscripts ................................. 13

CHAPTER 2: URBANISATION PROCESSES AND IMPACTS ON LANDSCAPE

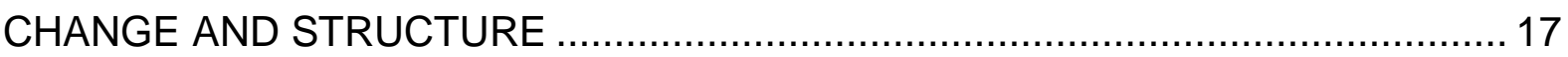

2.1 Study 1: Urbanisation, land use transformation and spatio-environmental impacts: analyses of trends and implications in major metropolitan-regions of

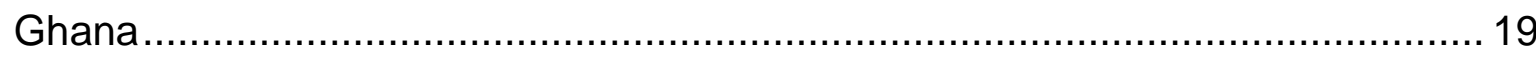

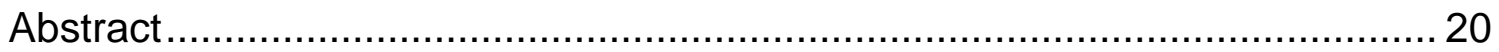

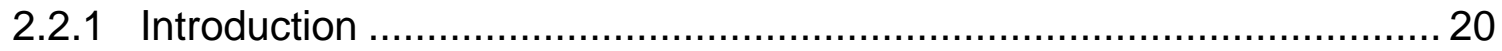

2.1.2 Contextualising land use and landscape transformation in Africa ..........22

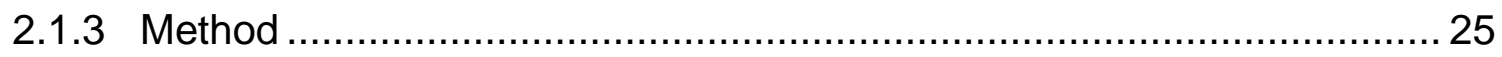

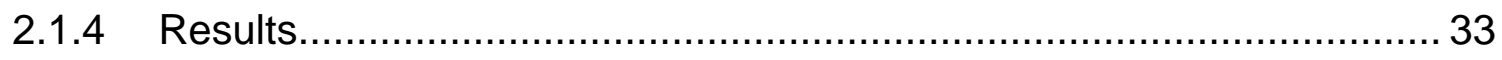

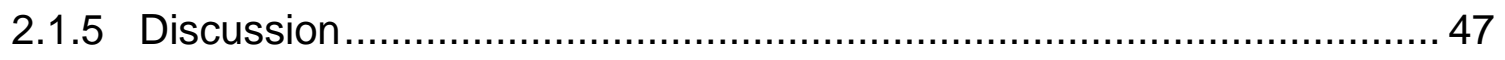

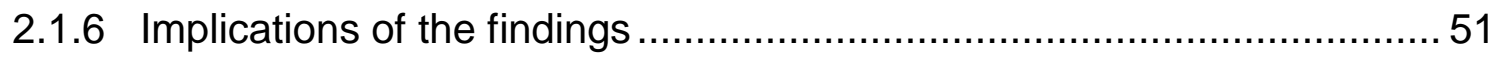


2.1.7 Conclusions

2.2 Study 2: Landscape Transformations in Rapidly Developing Peri-urban Areas of Accra, Ghana: Results of 30 years 57

Abstract 57

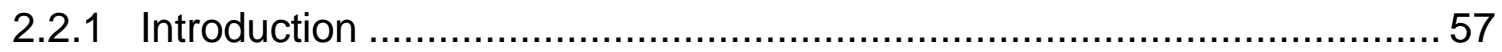

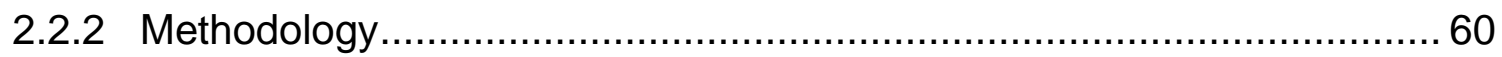

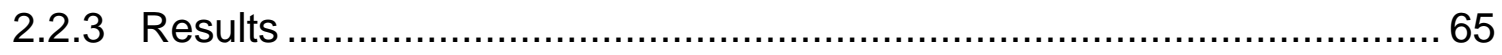

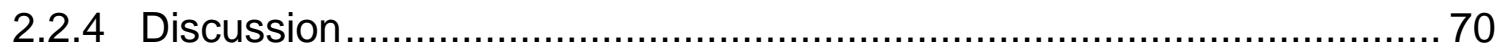

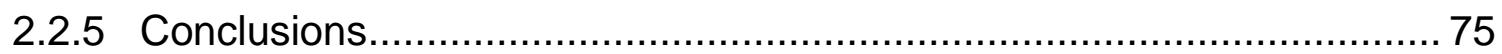

CHAPTER 3: URBANISATION INFLUENCE ON URBAN ARABLE SOILS............ 77

3.1 Study 3: Urbanisation leads to increases in $\mathrm{pH}$, carbonate and soil organic matter stocks of arable soils of Kumasi, Ghana (West Africa) .......................... 79

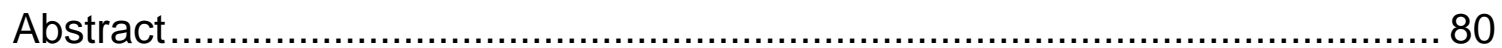

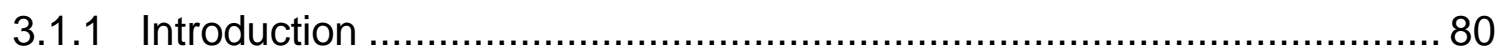

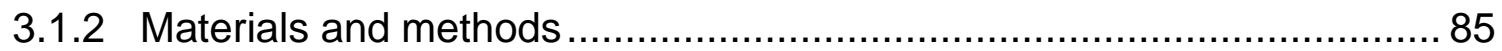

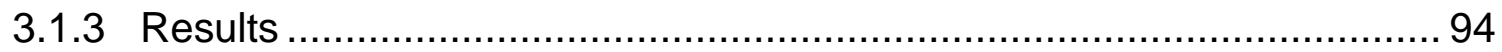

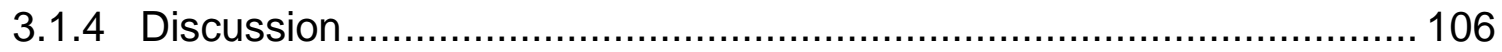

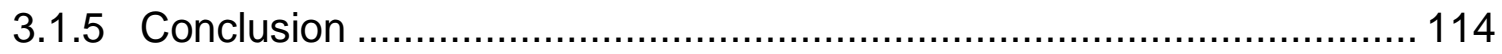

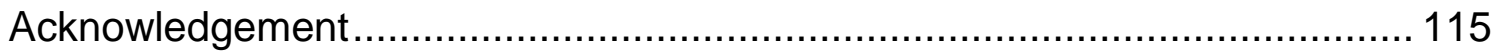

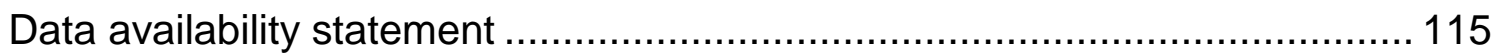

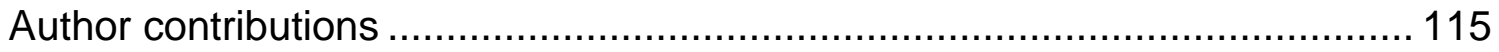


3.2 Study 4: Urbanisation enhances effective cation exchange capacity, stocks of $\mathrm{Ca}$ and $\mathrm{K}$, but reduces stocks of $\mathrm{N}$ and exchangeable $\mathrm{Mg}$ in arable soils of

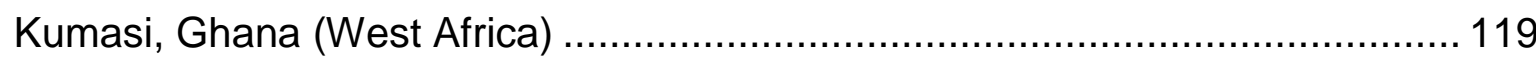

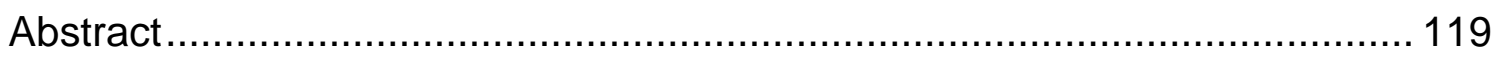

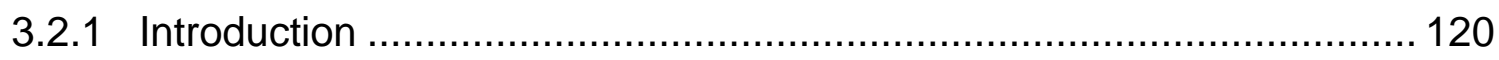

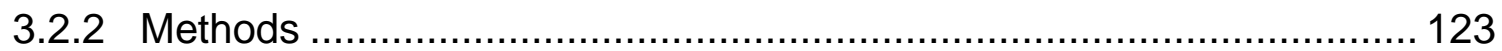

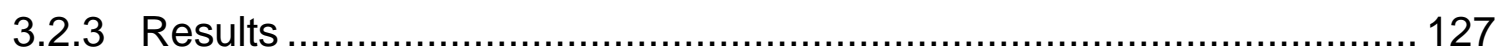

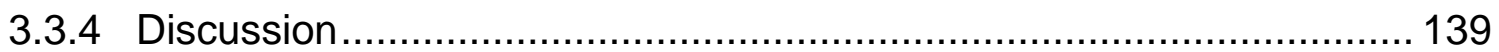

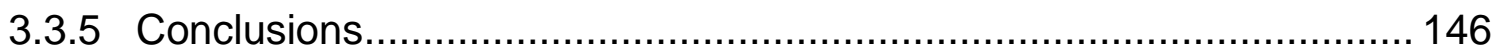

3.3 Study 5: Urbanisation enhances stocks of $P$ fractions in strongly weathered arable soils; a case of Kumasi (Ghana), West Africa................................... 151

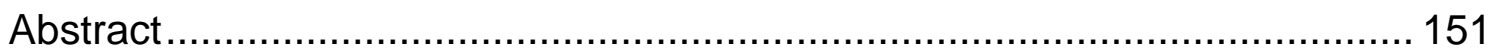

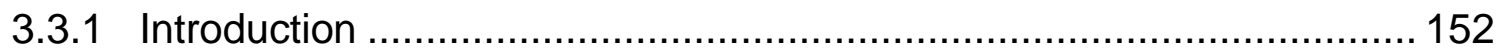

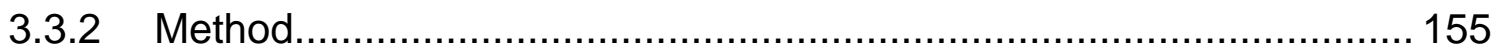

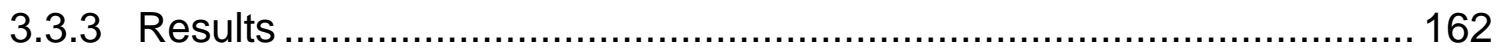

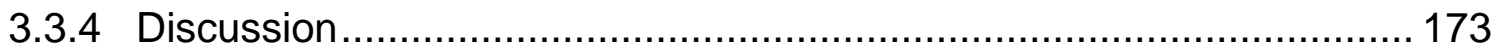

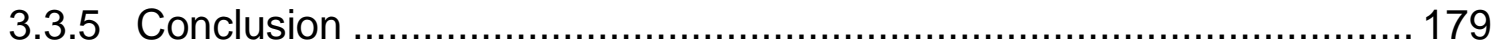

Supplementary materials ................................................................ 180

CHAPTER 4: GENERAL CONCLUSIONS AND IMPLICATIONS ........................ 185

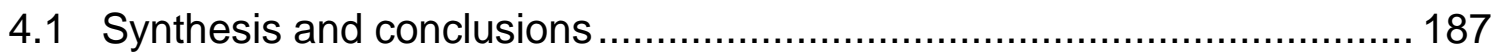

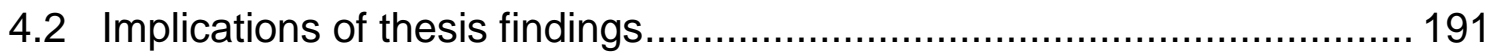

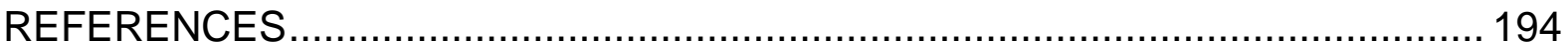




\section{LIST OF FIGURES}

\section{CHAPTER 1}

Figure 1.1.1: Share of global population living in urban areas.............................. 6

Figure 1.1.2: Context map of the studies in this thesis....................................... 9

Figure 1.1.3: Flow chart of thesis working steps. ............................................ 12

\section{CHAPTER 2: Study 1}

Figure 2.1.1: Map of $(\mathrm{A})$ Ghana showing the metropolitan regions of .................... 26

Figure 2.1.2: Conceptual representation of the four dominant classes ................... 31

Figure 2.1.3: Classified land cover maps of Accra City-region (ACR) ..................... 37

Figure 2.1.4: Area proportions of land cover classes .......................................... 37

Figure 2.1.5: Box plots of landscape metrics of the land cover ............................. 39

Figure 2.1.6: Box plots of landscape metrics of the land cover ............................ 41

Figure 2.1.7: Trends of landscape metrics of the land cover ................................ 42

Figure 2.1.8: Trends of landscape metrics of the land cover ............................... 45

Figure 2.1.9: Relationships between absolute increase …................................ 47

\section{CHAPTER 2: Study 2}

Figure 2.2.1: Ghana (insert) showing the 10 administrative regions ......................61 61

Figure 2.2.2: Projected trend of urban expansion from 1985-2050 ........................66

Figure 2.2.3: Changes in land use land cover in the Ga West .............................67 67

\section{CHAPTER 3: Study 3}

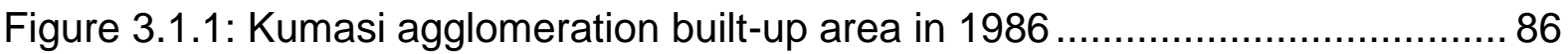

Figure 3.1.2: Some urban farms in Kumasi and their soil conditions....................... 87

Figure 3.1.3: Estimated fixed effects of model coefficients.................................... 95

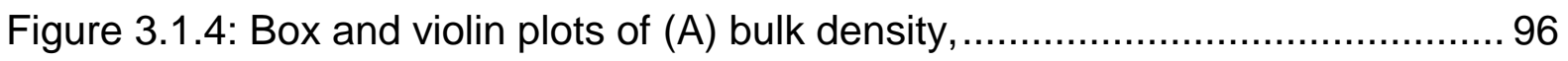

Figure 3.1.5: Comparison of long-term versus short-term urban soils, .................. 98 
Figure 3.1.6: Boxplots comparing rural, forest and urban soils 99

Figure 3.1.7: Boxplots comparing rural, forest and urban soils 100

Figure 3.1.8: Boxplots comparing rural, forest and urban soils 101

Figure 3.1.9: Boxplots comparing rural, forest and urban soils with 103

Figure 3.1.10: Relationships between 104

Figure 3.1.11: Dendrogram showing the hierarchical alignment 105

\section{CHAPTER 3: Study 4}

Figure 3.2.1: (A) Location of Kumasi in Ghana (insert) 124

Figure 3.2.2: (A-C) Box and violin plots comparing rural, forest and urban soils .... 128

Figure 3.2.3: Box and violin plots comparing rural, forest and urban soils 129

Figure 3.2.4: Comparison of long-term versus short-term urban soils, 130

Figure 3.2.5: (A) Bar plots comparing the contributions of cations in percentages. 133

Figure 3.2.6: Box and violin plots comparing rural, forest and urban soils 135

Figure 3.2.7: Relationships between (A) Contents of total N (TN) 136

Figure 3.2.8: Correlation plots indicating the relationships 139

\section{CHAPTER 3: Study 5}

Figure 3.3.1: Study area and sampled locations in Kumasi (Ashanti region). 156

Figure 3.3.2: Some soil properties of KSProfile1 158

Figure 3.3.3: The $P$ sequential fractionation and analysis 160

Figure 3.3.4: Boxplots comparing rural, forest and urban soils 164

Figure 3.3.5: Comparison of long-term versus short-term urban soils, 166

Figure 3.3.6: Comparison of (A)soil organic carbon (SOC)/plant-available P (PPa) 167

Figure 3.3.7: (A) Comparison of contents of soil $P$ fractions. 168

Figure 3.3.8: Linear relationships between contents of $P$ fractions. 170

Figure 3.3.9: Linear relationships between contents 172 
Figure 3.3.10: Causal path diagram depicting the relationships. 173

CHAPTER 4

Figure 4.1.1: Key research findings of all studies in this thesis. 189 


\section{LIST OF TABLES}

\section{CHAPTER: General Introduction}

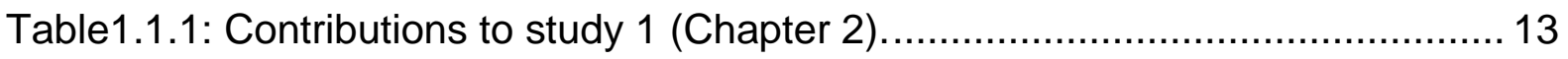

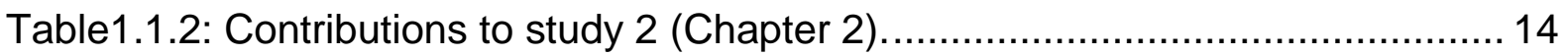

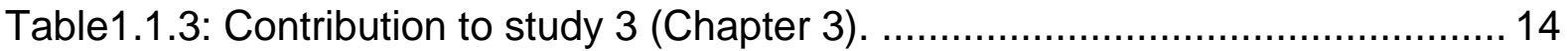

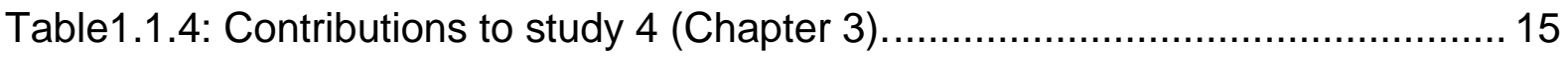

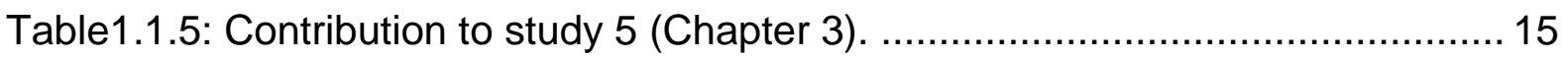

\section{CHAPTER 2: Study 1}

Table 2.1.1: Zone divisions and Population distribution in................................ 28

Table 2.1.2: Characteristics, sampling points and overall accuracies .................... 30

Table 2.1.3: Description of the selected landscape metrics. ................................. 33

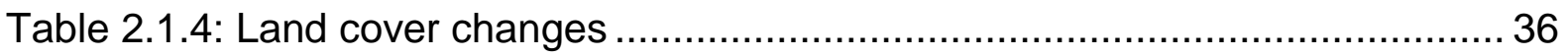

\section{CHAPTER 2: Study 2}

Table 2.2.1: Description of land cover classes identified in the district...................62

Table 2.2.2: Accuracy result of classified 2004 and 2016 images......................... 63

Table 2.2.3: Spatio-temporal analysis of urban expansion................................... 65

Table 2.2.4: Changes in LULC and landscape indices from 1985 to $2015 \ldots \ldots \ldots \ldots . . . .68$

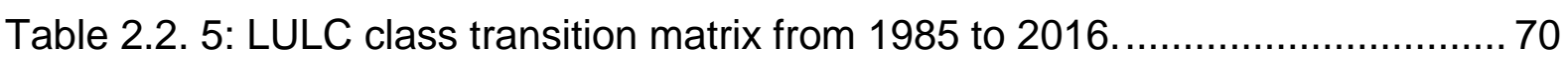

\section{CHAPTER 3: Study 3}

Table 3.1.1: Description of the soil profile KS Profile 1.................................... 90

Table 3.1.2: Mean contents and stocks of SOM variables .................................99 


\section{SUMMARY}

With more than half of the world's population already urbanised, global sustainability is partly hinged on how the urbanisation process is impacting the natural environment. Therefore, it is important to characterise, understand, and monitor the physical manifestation and interaction between the urbanisation process and environmental resources, in order to inform sustainable urban growth and land management strategies. Such information is especially important for urban regions in Asia and Africa, which have, in recent years, become hotspots of urbanisation. In many metropolitan regions of Africa for instance, a nexus of exponential built-up expansion, inadequate infrastructure, and complex land tenure has created heterogenous landscapes that are yet to be understood. One common feature within such landscapes is urban agriculture which is widespread in many African cities, as urbanites rely on it for their livelihood. To date, it is unclear how the resulting environmental effects of rapid urbanisation can be characterised and assessed. In addition, it is largely unknown how the soils that underlie the urban agricultural fields are responding to the sprawling urban trends. The aim of this thesis is to fill these gaps, by characterising the emergent urban landscapes that result from rapid urbanisation, and empirically demonstrate how soil fertility of urban agricultural fields is being shaped, using two typical West African metropolitan regions in Ghana. For this purpose, the thesis is divided into two main objectives as follows: (1) to examine the evolution and spatio-environmental impacts of rapid urbanisation in Accra and Kumasi, the two major metropolitan regions in Ghana, and (2) to assess the influence of rapid urbanisation on urban soil fertility properties of the Kumasi region.

To accomplish the first objective, we relied on optical remote sensing techniques. We used a support-vector-machine learning algorithm to classify retrospective Landsat satellite images spanning three decades from 1985 to 2019, in both Accra and Kumasi metropolitan regions. We then created a detailed land use transition map, and applied landscape and spatial metrics to characterise the emergent landscapes. To accomplish the second objective, we designed a novel grid-based soil sampling stratification that relied on the 1986 satellite image of Kumasi, and embarked on an extensive field campaign in the city, in August-September 2016. The sampling approach involved keeping factors that were not in the focus of the study constant (i.e. parent material, topography, soil type, crop and climate, while differentiating two urbanization categories. These categories were defined as: (1) long-term urban soils, which were areas that were under urbanization in 1986 (i.e. $\geq 30$ years urban influence), and (2) short-term urban soils, which were areas that came under urbanization afterwards ( $<30$ years of urban influence). A total of 636 top-soils (0-10 $\mathrm{cm}$ ) were sampled, and consequently subjected to standard (ISO and DIN) soil preparation and analyses, such as soil organic matter (SOM), soil pH, total $\mathrm{C}$ and $\mathrm{N}$, and effective cation exchange capacity (ECEC). In addition, we developed a novel sequential extraction method for assessing soil $P$ fractions, as the inherent nature of tropical soils makes it especially relevant to examine the plant-available and recalcitrant $P$ pools instead of its total contents.

We found that, for the first objective, built-up areas have substantially increased in the two metropolitan regions of Ghana at the expense of other environmental classes, leading to increased fragmented environments. In Ga West, a peri-urban district of Accra for instance, we found that built-up land increased $>200 \%$ within the recent 30 
years. Such fragmented environments underlie various urban environmental problems like floods and heatwaves. The analysis further indicated that the urban expansion process follows a general trend where the historical-core zones were initially hotspots for land transitions. In recent years however, settlements in the suburban and peripheral zones have expanded, becoming integrated into the conterminous urban areas of the metropolitan regions. The analysis also uncovered and highlighted a complex, unique, dynamic and multidirectional process, which showed that the urbanopen-space class, being in a permanent state of flux, mediates transitions between built-up land and vegetation and vice versa. It was recognised that this process is central to the informal practices that characterise physical development in cities and towns in Ghana and other similar West African countries. For the second objective, the analyses demonstrated that urban arable soils that have been under long-term urbanisation influence have higher contents and stocks of SOM, plant-available and recalcitrant $\mathrm{P}$, carbonates, exchangeable $\mathrm{Ca}^{2+}, \mathrm{K}^{+}$and $\mathrm{Na}^{+}$, soil $\mathrm{pH}$ and ECEC, relative to their short-term counterparts. Both field observations and lab analysis confirmed that these results are attributable to the accumulation of household waste (degradable and non-degradable) and construction materials on the arable fields. In contrast, the stocks of exchangeable $\mathrm{Mg}^{2+}$ and total $\mathrm{N}$ were lower in the long-term compared to the short-term urban soils. We attributed this to the accumulated non-degradable materials, and most likely, to the increased intensity of agricultural use under urban land demand. These findings highlight a diametrically opposite consequence of urban waste management challenges on the wider environment in Kumasi. With these increased soil fertility indicators in the urban agricultural fields, which is an integral part of the urban-open-spaces class, we conclude that management efforts that seek to decrease the environmental impact of the urbanisation process can target this urbanopen-spaces class, as it is the central piece of the land transitions in Ghana.

Based on these findings, we recommend that an integrative urban growth management strategy that brings together spatial planning and environmental resource governance, as well as an improved urban waste management system will be useful to enhance urban sustainability in Ghanaian cities. Given that the two metropolitan regions that were studied in this thesis are typical for West Africa, the findings of this research are also relevant to most other cities in the region. 
CHAPTER 1: GENERAL INTRODUCTION 


\subsection{Context and motivation}

In the 1950s, only one third of the global human population was urban. Since then, urbanisation has progressed rapidly, and for the first time, since 2007, global human demographics have shifted to become predominantly urban (Ritchie and Roser 2020). Projected estimates have suggested that there will be a complete reversal of the 1950 s demographic trend within the century, because the urban population will likely reach two thirds of the human population by 2050 (United Nations, Department of Economic and Social Affairs, Population Division 2019). Spatially, this process of urbanisation leads to the transformation of landscapes into highly dynamic, complex and multifunctional units (Antrop 2004; Benza 2014). An understanding of such transformed spatial dimensions of urban landscapes is an important step to elucidate the idiosyncratic relationships between urban morphology, socioeconomic development and environmental sustainability.

Africa is one of the continents that has been experiencing rapid levels of urbanisation in recent decades. This phenomenon is partly due to its exponential population growth and the increasing concentration of the population in major cities. Although the continent is currently the least urbanised in the world (at $\sim 40 \%$ urban population) (Figure 1.1.1), it is expected that by $2050,60 \%$ ( 1.2 billion people) of Africa's population will be urban (Parnell and Walawege 2011; United Nations, Department of Economic and Social Affairs, Population Division 2014). It can be deduced from the resulting spatial morphologies that a relational trend between income, location and urbanisation exist on the continent. For instance, poorer countries are less urbanised compared to richer ones, while coastal countries are more urbanised compared to landlocked countries with the same income level (United Nations Economic Commission for Africa 2014). Moreover, urban dwellers compared to their rural 
counterparts are better educated and housed, economically stable, and innovative amongst others (Cobbinah et al. 2015a). Thus, these trends strongly suggest that the opportunities of urbanisation are closely tied to the overall development of the African continent.

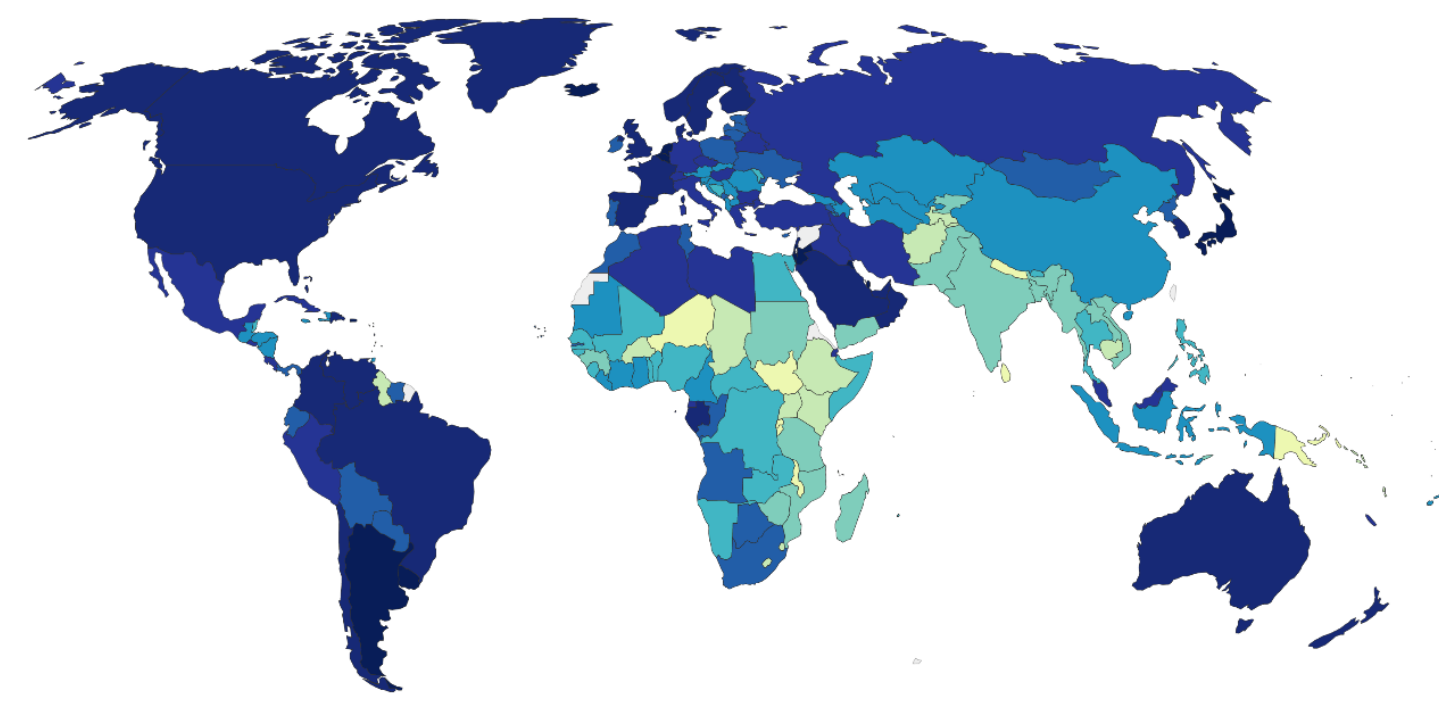

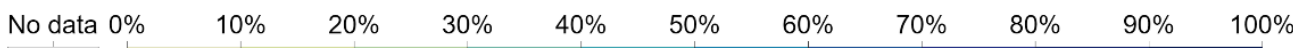

Source: UN World Urbanization Prospects (2018)

Note: Urban populations are defined based on the definition of urban areas by national statistical offices.

OurWorldInData.org/urbanization • CC BY

Figure 1.1.1: Share of global population living in urban areas in 2017 (Ritchie and Roser 2020).

Within this context, the current UN-Sustainable Development Goals (UN-SDG) (United Nations 2016) can be achieved on the African continent with management strategies that rely on an understanding of the ensuing emergent spatial morphologies and associated environmental effects of its cities. In recent years, there has been a growing research interest to characterise, map and quantify the spatial patterns of urban expansion. These efforts have been supported by techniques in remote sensing and GIS, which provide extensive spatial and temporal information on land-surface changes. However, because most of the studies have concentrated exclusively on the built-up land cover class, knowledge on the spatial trends of urban expansion impacts 
on the wider environment is limited. A part of this thesis addresses this limitation, by considering other urban environmental land classes in the analysis.

One common feature within urban landscapes in Africa is urban agriculture, which is widespread in many cities, as urbanites rely on it for their livelihood. Globally, urban agriculture is estimated to support about 800 million people (Smit et al. 2001). For most cities in Africa, the sustenance of urban agriculture is an important component in the provision of livelihood and socioeconomic survival for many of its population, especially the poor (Zezza and Tasciotti 2010). In this regard, it is estimated that 20 million West Africans are fully or partially relying on urban agriculture for food and employment (Cofie et al. 2003; Drechsel and Dongus 2010). The sustenance and management of urban agriculture, are thus an important component in achieving food security ( $2^{\text {nd }}$ UN-Sustainable Development Goal (SDG), defined by the United Nations (2016)) and in making African cities "inclusive, safe, resilient, and sustainable" $\left(11^{\text {th }}\right.$ $\mathrm{SDG})$. It has been highly recommended, for instance, to integrate arable land into urban planning in West African cities (Deelstra and Girardet 2000; van Veenhuizen 2006; McClintock 2010). However, empirical data that can inform such planning and management schemes about the properties of the soils that enable urban farming and provide important urban ecosystem services, are extremely rare. Another part of this thesis will provide a city-wide empirical information on the soil fertility status of urban agricultural fields.

Urban soils have developed under direct and indirect anthropogenic influence, unlike similar soils in the natural and semi-natural environments (Lorenz and Kandeler 2005; Lehmann and Stahr 2007). Direct influences from housing, waste, traffic, construction etc. cause physical and chemical alteration of the urban soils. Additionally, the urban environment indirectly conditions pedogenic factors such as climate (Pouyat et al. 
2010; Bouma 2016; Vasenev and Kuzyakov 2018). Hence, urban soils may be transformed into highly artificialized soils such as Technosols (Lehmann and Stahr 2007; Chesworth 2008), whereas other soils, e.g. those under green areas and arable fields, may remain more similar to natural soils (Edmondson et al. 2014; Joimel et al. 2016; Asabere et al. 2018b). As current global human demographics continue to consolidate in cities, urban soils that provide ecosystem services in urban areas are becoming increasingly relevant for achieving the UN global sustainability agenda (Deelstra and Girardet 2000). However, there are still large knowledge gaps related to the functioning of these urban soils (Byrne 2007; Lorenz and Lal 2009), especially in urbanisation hotspots such as tropical West African cities.

Against this background, cities of the few African countries that have predominant urban populations, can be analysed for practical examples that can be used to support sustainable management schemes in the region. Ghana represents such a quintessential country, as the it is currently one of four in West Africa that have become predominantly urban over the last decade (Figure 1.1.2). In addition, urban agricultural fields are widespread in Ghanaian cities, as it has been estimated that in Kumasi for example, up to $36 \%$ of the total food needed in the city is produced within it. Thus, by using city regions in Ghana, the findings in this thesis will provide important and generalizable lessons to support sustainable urban growth management of cities within the West African region as a whole. 

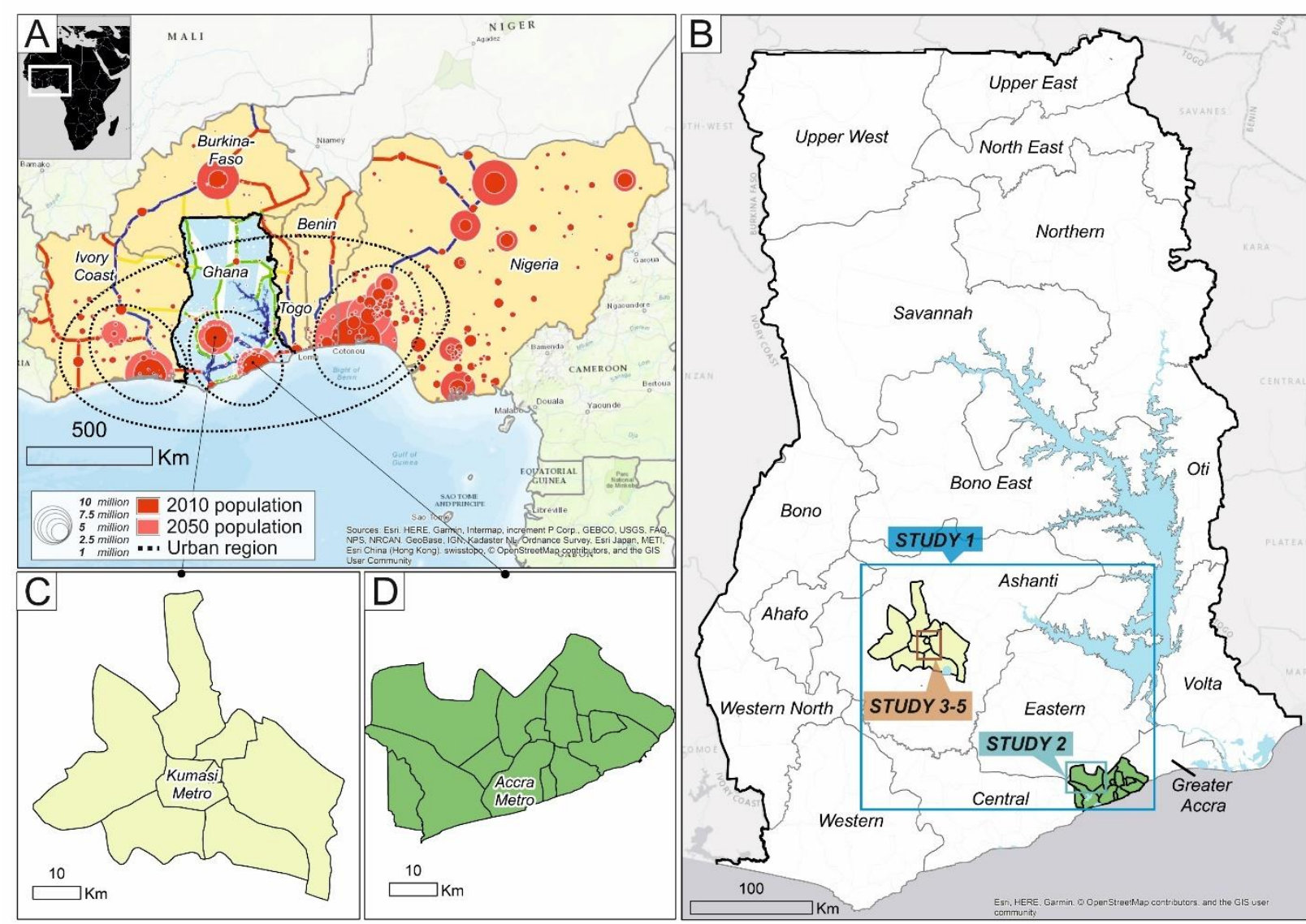

Figure 1.1.2: Context map of the studies in this thesis.

(A) Regional map of West Africa showing key population hotspots for 2010 and estimates for 2050 (source: Government of Ghana 2015). (B) The sixteen administrative regions of Ghana showing location and extents of study areas. (C-D) Administrative units of the two main metropolitan regions, (C) Greater Kumasi Metropolitan sub-region and (D) Accra city region, which were investigated in this thesis.

\subsection{Aims and objectives of the research}

The overall aim for this thesis was to characterise the emergent urban landscapes that result from rapid urbanisation, and empirically ascertain how soil fertility of urban agricultural fields has been shaped by the urbanisation process. For this purpose, two main objectives were undertaken as follows:

1. To quantify the characteristics of spatio-environmental impacts of urban land cover transformations over the last three decades, using Landsat satellite data and landscape metrics in; 
(i) two major metropolitan regions in Ghana, namely, the Accra City Region (ACR) and the Greater Kumasi Sub-Region (GKSR) - Study 1 (Chapter 2.1),

(ii) a rapidly developing peri-urban area of Accra, the capital city of Ghana Study 2 (Chapter 2.2).

2. To investigate the influence of rapid urbanisation on soil fertility properties of arable soils in Kumasi, Ghana (Chapter 3). This objective was further divided into three sub-themes in accordance with relevant indicators for tropical soils as follows;

(i) effects on soil $\mathrm{pH}$, soil organic matter (SOM) and carbonate stocks - Study 3 (Chapter 3.1),

(ii) effects on effective cation exchange capacity (ECEC), stocks of exchangeable base cations and total nitrogen (TN) - Study 4 (Chapter 3.2),

(iii) effects on the stocks of soil phosphorus $(\mathrm{P})$ fractions - Study 5 (Chapter 3.3).

\subsection{Approach and thesis structure}

In order to achieve the two objectives in the thesis, it was important to adopt two broadly different methodologies at different scales of observations, i.e. at a macro level (remote sensing) and micro level (field sampling). For the first objective (Study 1 and 2), techniques in optical remote sensing and geographic information system (GIS), as well as landscape and spatial metrics were used to classify, quantify and examine the retrospective time steps of land cover datasets (i.e. 1985-2019) for the study areas (Module 1-Figure 1.1.3). In Study 1, which was focused on understanding the regional trends of urbanisation, the two main metropolitan regions of Ghana that comprised of the Accra metropolis with its 12 surrounding districts (i.e. ACR), and the Kumasi metropolis with its seven surrounding districts (i.e. GKSR) were used (Figure 1.1.2). 
In Study 2, the geographical extent was decreased to focus on a peri-urban area, and thus the Ga West district, which is one of the rapidly expanding districts of the ACR, was used as a case study district (Figure 1.1.2).

For the second objective (Study 3-5), a field campaign was conducted (in AugustSeptember 2016) to sample top soils $(0-10 \mathrm{~cm})$ from arable fields for different lab analyses (Module 3 in Figure 1.1.3). Considering the nature of enquiry for this objective (Module 4 in Figure 1.1.3), a single study area with generalizable features of urbanisation was adequate. Thus, a onetime field campaign was conducted in the core and peripheral areas of Kumasi (Figure 1.1.2), whereby the sampling approach was based on the 1986 classified Landsat image from Study 1. This general approach which relied on both remote sensing and field sampling, made it possible to relate the findings in the studies from objective 1 with those of objective 2 . 


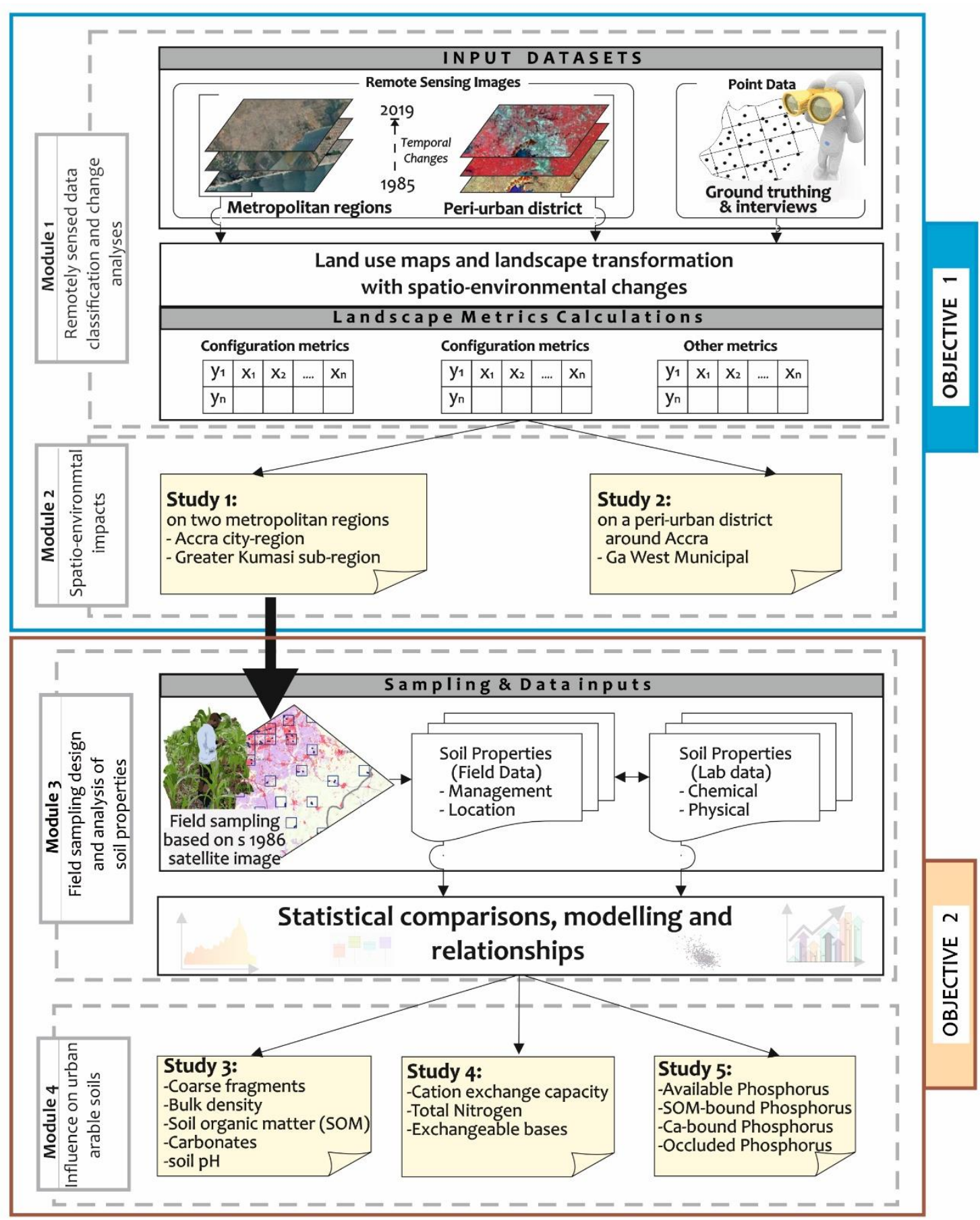

Figure 1.1.3: Flow chart of thesis working steps.

The rest of the thesis is structured as follows: in chapters 2 and 3 , the studies that were conducted for each respective objective are presented. All the studies are presented as scientific manuscripts with their respective conclusions. Consequently, after all studies have been presented, chapter 4 is used to present the synthesis of the five studies, where the main conclusions are drawn. For editorial and formatting 
consistency, figures and layout of texts, fonts, layouts of tables and referencing style of the two studies (Studies 2 and 3) that have been published were formatted to fit those of this thesis.

\subsection{Contributions to publications and manuscripts}

This thesis is a cumulative compilation of five studies. The contributions of various

co-authors to the five studies are described in Table 1.1.1 - 1.1.5 below.

Table1.1.1: Contributions to study 1 (Chapter 2).

Title: Urbanisation, land use transformation and spatio-environmental impacts: analyses of trends and implications in major metropolitan-regions of Ghana

\begin{tabular}{|c|c|}
\hline Authors & Contribution to study \\
\hline Stephen B. Asabere $^{1}$ & $\begin{array}{l}\text { Conceptualized, designed, field campaign, data } \\
\text { organization and analysis, visualizations, } \\
\text { manuscripts structure and writeup and review. }\end{array}$ \\
\hline Ransford A. Acheampong ${ }^{2}$ & Supported structure, reviewed draft manuscript. \\
\hline George Ashiagbor 3 & Supported analysis, reviewed draft manuscript. \\
\hline Sandra C. Beckers ${ }^{1}$ & Reviewed draft manuscript. \\
\hline Markus Keck ${ }^{4}$ & Reviewed draft manuscript. \\
\hline Stefan Erasmi ${ }^{5}$ & Reviewed draft manuscript. \\
\hline Jochen Schanze 6,7 & Reviewed draft manuscript. \\
\hline Daniela Sauer ${ }^{1}$ & Conceptualized,reviewed draft manuscript. \\
\hline
\end{tabular}

Current status: Published DOI: 10.1016/j.landusepol.2020.104707

${ }^{1}$ Department of Physical Geography, Institute of Geography, University of Goettingen, Germany. ${ }^{2}$ Department of Planning and Environmental Management, School of Environment, Education and Development, University of Manchester, England. ${ }^{3}$ Department of Wildlife and Range Management, Faculty of Renewable Natural Resources, Kwame Nkrumah University of Science and Technology, Ghana. ${ }^{4}$ Department of Human Geography, Institute of Geography, University of Goettingen, Germany. ${ }^{5}$ Department of Cartography and Remote Sensing, Institute of Geography, University of Goettingen, Germany. ${ }^{6}$ Chair of Environmental Development and Risk Management, Faculty of Environmental Sciences, Technische Universitaet Dresden, Germany. ${ }^{7}$ Leibniz Institute of Ecological Urban and Regional Development, Germany. 
Table1.1.2: Contributions to study 2 (Chapter 2).

Title: Landscape Transformations in Rapidly Developing Peri-urban Areas of Accra, Ghana: Results of 30 years

\begin{tabular}{|c|c|}
\hline Authors & Contribution to study \\
\hline George Ashiagbor ${ }^{1}$ & $\begin{array}{l}\text { Conceptualized, designed, field campaign, data } \\
\text { organization and analysis, visualizations, } \\
\text { manuscripts structure, writeup and review. }\end{array}$ \\
\hline Clifford Amoako ${ }^{1}$ & Writeup, reviewed draft manuscript. \\
\hline Stephen B. Asabere ${ }^{2}$ & $\begin{array}{l}\text { Design, analysis, writeup, reviewed draft } \\
\text { manuscript. }\end{array}$ \\
\hline Jonathan Quaye-Ballard ${ }^{1}$ & Reviewed draft manuscript. \\
\hline
\end{tabular}

${ }^{1}$ Kwame Nkrumah University of Science and Technology (KNUST), Kumasi, Ghana.

${ }^{2}$ University of Goettingen, Institute of Geography, Department of Physical Geography,

Germany.

Table1.1.3: Contribution to study 3 (Chapter 3).

Title: Urbanisation leads to increases in $\mathrm{pH}$, carbonate and soil organic matter stocks of arable soils of Kumasi, Ghana (West Africa)

\begin{tabular}{|c|c|}
\hline Authors & Contribution to study \\
\hline Stephen B. Asabere ${ }^{1}$ & $\begin{array}{l}\text { Conceptualized, designed, field campaign, lab } \\
\text { analysis, data organization and analysis, } \\
\text { visualizations, manuscripts structure, writeup and } \\
\text { review. }\end{array}$ \\
\hline Thorsten Zeppenfeld ${ }^{1}$ & Reviewed draft manuscript, supported data analysis. \\
\hline Kwabena Abrefa Nketia ${ }^{2}$ & Reviewed draft manuscript. \\
\hline Daniela Sauer ${ }^{1}$ & $\begin{array}{l}\text { Conceptualized, designed, field campaign, reviewed } \\
\text { draft manuscript. }\end{array}$ \\
\hline
\end{tabular}

Current status: Published DOI: 10.3389/fenvs.2018.00119

${ }^{1}$ Department of Physical Geography, Institute of Geography, University of Goettingen, Göttingen, Germany. ${ }^{2}$ Council for Scientific and Industrial Research, Soil Research Institute, Kumasi, Ghana. 
Table1.1.4: Contributions to study 4 (Chapter 3).

Title: Urbanisation enhances effective cation exchange capacity, stocks of $\mathrm{Ca}$ and $\mathrm{K}$, but reduces stocks of $\mathrm{N}$ and exchangeable $\mathrm{Mg}$ in arable soils of Kumasi, Ghana (West Africa)

\begin{tabular}{|c|c|}
\hline Authors & Contribution to study \\
\hline Stephen B. Asabere ${ }^{1}$ & $\begin{array}{l}\text { Conceptualized, designed, lab analysis, data } \\
\text { organization and analysis, visualizations, } \\
\text { manuscripts structure, writeup and review. }\end{array}$ \\
\hline Thorsten Zeppenfeld ${ }^{1}$ & Reviewed draft manuscript, supported data analysis. \\
\hline Kwabena Abrefa Nketia² & Reviewed draft manuscript. \\
\hline Daniela Sauer ${ }^{1}$ & $\begin{array}{l}\text { Conceptualized, designed, reviewed draft } \\
\text { manuscript. }\end{array}$ \\
\hline Current status: & To be submitted to Soil Research \\
\hline
\end{tabular}

Table1.1.5: Contribution to study 5 (Chapter 3).

Title: Urbanisation enhances stocks of $P$ fractions in strongly weathered arable soils; a case of Kumasi (Ghana), West Africa

\begin{tabular}{|c|c|}
\hline Authors & Contribution to study \\
\hline Stephen B. Asabere ${ }^{1}$ & $\begin{array}{l}\text { Conceptualized, designed, methodological } \\
\text { development, lab analysis, data organization and } \\
\text { analysis, visualizations, manuscripts structure and } \\
\text { writeup and review. }\end{array}$ \\
\hline Harold Hughes ${ }^{1}$ & $\begin{array}{l}\text { Supported methodological development, reviewed } \\
\text { draft manuscript. }\end{array}$ \\
\hline Jiangyun Li1 & Supported lab analysis, reviewed draft manuscript. \\
\hline Daniela Sauer ${ }^{1}$ & $\begin{array}{l}\text { Conceptualized, designed, methodological } \\
\text { development, reviewed draft manuscript. }\end{array}$ \\
\hline Current status: & To be submitted to SOIL \\
\hline
\end{tabular}


This chapter presents two studies. Here, we employ optical remote sensing techniques, spatial and landscape metrics to characterise and quantify the emergent landscapes of urbanisation and peri-urbanisation, and their environmental impacts in Ghana. Based on the findings, the studies derive socioeconomic implications for policy and management of urban regions for sustainability in rapidly developing Ghanaian cities.

\subsection{Study 1: Urbanisation, land use transformation and spatio- environmental impacts: analyses of trends and implications in major metropolitan-regions of Ghana}

Stephen Boahen Asabere ${ }^{1}$, Ransford Acheampong ${ }^{2}$, George Ashiagbor ${ }^{3}$, Sandra Carola Beckers ${ }^{1}$, Markus Keck ${ }^{4}$, Stefan Erasmi ${ }^{5}$, Jochen Schanze ${ }^{6}$, Daniela Sauer ${ }^{1}$.

\footnotetext{
${ }^{1}$ Department of Physical Geography, Institute of Geography, University of Goettingen, Germany.

${ }^{2}$ Department of Planning and Environmental Management, School of Environment, Education and Development, University of Manchester, England.

${ }^{3}$ Department of Wildlife and Range Management, Faculty of Renewable Natural Resources, Kwame Nkrumah University of Science and Technology, Ghana.

${ }^{4}$ Department of Human Geography, Institute of Geography, University of Goettingen, Germany.

${ }^{5}$ Thünen Institute of Farm Economics, Braunschweig, Germany.

${ }^{6}$ Chair of Environmental Development and Risk Management, Faculty of Environmental Sciences, Technische Universitaet Dresden, Germany.

${ }^{7}$ Leibniz Institute of Ecological Urban and Regional Development, Germany.
}

- Manuscript published in Land Use Policy as Asabere et al. (2020). Urbanization, land use transformation and spatio-environmental impacts: analyses of trends and implications in major metropolitan regions of Ghana. DOI: $\underline{10.1016 / j . l a n d u s e p o l .2020 .104707}$ 


\begin{abstract}
Urbanisation induces spatial and environmental changes. Monitoring and understanding the nature of these changes is crucial to achieving sustainable urban development imperatives. To this end, this paper examines the evolution and spatioenvironmental impacts of rapid urbanisation in two major metropolitan regions of Ghana-Accra City-Region and the Greater Kumasi Sub-Region. The analysis uses Landsat satellite data and landscape metrics to analyse land use transitions and to characterise the emergent landscapes over the last three decades. The results show that built-up land has increased significantly in these metropolitan regions largely at the expense of environmental land cover classes. The expansion process follows a general trend where the historical-core zones were initially sites of rapid land cover conversion to built-up, with settlements in the suburban and peripheral zones expanding in recent years and becoming integrated into the conterminous urban areas of the metropolitan regions. The analysis also uncovered a unique, dynamic and complex process whereby the urban-open-space class, being in a permanent state of flux, mediates transitions between built-up land and vegetation and vice versa. The metric-based land use transformation analysis shows that the landscapes of the metropolitan regions have fragmented because of an increased expansion and aggregation of patches of built-up land in the core areas and leapfrog, sprawling expansion in the outlying suburban and peripheral zones. The paper concludes on the need for integrative urban growth management strategies that brings together spatial planning and environmental resource governance to avert the negative consequences on the natural environment of unfettered urban expansion.
\end{abstract}

Keywords: Urbanisation; Spatio-environmental impacts; Land use transformation; Sustainability; Ghana

\title{
2.2.1 Introduction
}

Africa has experienced rapid levels of historical urbanisation. This phenomenon has in part, been triggered by overall levels of rapid population growth across the continent, and the increasing concentration of population in major cities (United Nations, Department of Economic and Social Affairs, Population Division 2014). In spatial terms, the urbanisation process manifests in the morphological changes to human settlements, with emergent landscapes that are spatially unique, complex and heterogeneous (Benza 2014). Across Africa and other regions in the Global South, rapid peri-urbanisation, sprawling and fragmented spatial development characterises urban physical development. Through anthropogenic conversion, reduction and division, landscapes are fragmented when they transition from large continuous areas 
into smaller and isolated parts (Jaeger 2000; Jaeger et al. 2011). The resulting extensive consumption of land is linked to environmental degradation, destruction of eco-system services, loss of agrarian livelihood at the urban fringes and increasing levels of urban poverty (Pacione 2009; Abass et al. 2018).

The number of studies examining the impacts of historical urbanisation has increased in recent years. In the spatial sciences, including Urban Geography and Urban Planning, researchers continue to monitor, understand and characterise the spatial and environmental impacts of urbanisation. This in part, has been made possible by the availability of remotely sensed data, which allows to retrospectively analyse morphological changes of settlements of varying sizes at different spatial scales. In Ghana for example, a number of studies have sought to understand and quantify the physical expressions of urbanisation in the country's major urban agglomerations, using remote sensing data (see e.g. Stow et al. (2016), Acheampong et al. (2017), Agyemang et al. (2017), and Korah et al. (2019)). Despite the scientific contributions of these previous studies in helping to understand an important aspect of the urbanisation process that is still underway, they tend to focus exclusively on characterising and quantifying built-up land expansion trends. In doing so, they are unable to provide insights into the wider environmental impacts that results as urban areas expand at the expense of key environmental resources such as farmland, vegetation, open land and water body.

This paper fills the aforementioned gaps in the literature by bringing to the analysis of the impact of urbanisation, a spatio-environmental perspective. The analysis focuses on two major metropolitan regions of Ghana, namely, Accra city-region (ACR) and Greater Kumasi sub-region (GKSR). The paper utilizes temporal series of Landsat satellite images from 1985 to 2019, and landscape composition and configuration 
metrics to characterize land use transformation. This paper, thus, contributes to the literature in two major ways. Firstly, the analysis reveals the increasing landscape fragmentation and the associated environmental pressures exerted by the rapid expansion of built-up land in these metropolitan regions. Secondly, the paper uncovers and highlights a unique characteristic of the on-going spatial transformation by which a land cover class identified as 'urban-open-spaces' mediates the transitions between 'vegetation' and 'built-up' land. Being in a permanent state of flux, 'urban-open-spaces' affects quantities of built-up and vegetation land cover classes at different points in time, implying that failing to account for this phenomenon could result in unreliable estimates of land cover quantities. The policy implications of the findings for sustainable urban growth management are consequently discussed.

The rest of the paper is structured as follows. In section 2.1.2, a brief overview of the relevant literature is provided, followed by an outline of the research methodology in section 2.1.3. The results of the analysis are presented in section 2.1.4. Discussion of the key findings and their implications are presented in sections 2.1.5 and 2.1.6 respectively, followed by our concluding thoughts in section 2.1.7.

\subsubsection{Contextualising land use and landscape transformation in Africa}

Africa is one of the regions in the Global South that has experienced rapid levels of historical urbanisation. In the 1950s, it was estimated that only $14 \%$ of the continent's population lived in cities. By 2015 , the urban population had increased to $40 \%$, and it is projected that by the first half of the 21 st century, about $55 \%$ of the continent's population will be living in cities (United Nations, Department of Economic and Social Affairs, Population Division 2014). In spatial terms, urbanisation manifests in the expansion of the physical size of settlements through the development of land for housing, employment and infrastructure. Different forms of physical expansion may be 
observed. In most African cities, peri-urbanisation typifies the urbanisation process. This phenomenon has been observed as rapid physical development in transition zones between fully urbanised land in cities and areas in predominantly agricultural use (Webster 2002; Simon et al. 2004; McGregor 2012). In a regional context, periurbanisation results from both the outward expansion of established built up areas of major cities in the region, usually the historical origins of growth into the outlying peripheral areas and in situ expansion of small, previously rural settlements.

Spatially, the emergent landscapes of urbanisation tend to be fragmented. Landscape fragmentation could manifest in six distinguishable phases, namely, perforation, incision dissection, dissipation, shrinkage and attrition (Forman 1995; Jaeger 2000). Although one phase may dominate the landscape at a particular time, all phases are largely inseparable in reality (Jaeger 2000). Anthropogenic fragmentation of landscapes is induced by conversion, reduction and division of landscapes, which results in the transition of landscapes from large continuous areas into smaller and isolated parts (Jaeger 2000; Jaeger et al. 2011). Invariably, urban expansion and the resulting fragmentation proceeds at the expense of other key environmental land cover types such as vegetation, open land and water.

In countries of the Global South, including Ghana, spatial transformation and landscape fragmentation occurs within the context of very complex conditions that manifest at the global and local scales. One of the key drivers of land use change in these regions is the rapid population growth that has occurred in the last seven decades in these regions (United Nations, Department of Economic and Social Affairs, Population Division 2014). Population growth and concentration leads to the formation of urban areas. These urban areas continue to attract population, which in turn, generates enormous demand of land for housing, infrastructure and economic 
activities. The very process of physical development and emergent outcomes observed in the landscape are also very much embedded in complex formal and informal processes. Through what has commonly become known as 'informal urbanism' urban transformations, including the development of land for various activities proceed independent of formal frameworks, including state planning and administrative systems (see e.g. Dovey (2012), and Amoako and Frimpong Boamah (2017)). Consequently, a larger share of land development that occurs through the urbanisation process tend not to comply with official rules and regulations.

In Ghana, the practices of informal urbanism coupled with a complex land tenure system (Kasanga and Kotey 2001; Ubink and Quan 2008) and weak spatial planning and governance has resulted in sporadic, often unplanned physical development (Acheampong 2019; Korah et al. 2017a). Under these conditions, the quality of development outcomes not only suffer, but the physical development process also exerts significant negative impact on the environment through unfettered leapfrog, sprawling development and fragmentation. The extent and intensity of fragmentation have implications for urban ecosystem functions, and can lead to the decline of essential services (Haase et al. 2012). For example, landscape fragmentation can result from land surface sealing and vegetation removal, which in turn, can lead to urban floods, soil erosion and heat waves (Oke 2017). Uncontrolled urban expansion and fragmentation also directly influences local climate, water balance and biodiversity losses (Elmqvist et al. 2013).

Monitoring, understanding and quantifying land cover transformation and the extent of fragmentation is therefore crucial to the future sustainability of urban built and natural environments. Using remotely sensed data and landscape metrics, it is possible to quantify the spatial composition and configuration of emergent landscapes (Forman 
1995; Turner and Gardner 2015). The current paper quantifies and examines the spatio-environmental impacts of land cover transitions in two metropolitan regions in Ghana over the last three decades, using landscape metrics and Landsat satellite data.

\subsubsection{Method}

\subsubsection{Study areas-Accra City-Region and Greater Kumasi Sub- Region}

The geographical extent of the analysis of land use transformation are the Accra CityRegion (ACR) and Greater Kumasi Sub-Region (GKSR)-Figure 2.1.1. These metropolitan regions have recently been delineated as functional geographies for purposes of strategic regional planning and growth management under Ghana's new decentralised spatial planning system (Agyemang et al. 2017; Acheampong 2019). ACR comprises the Accra Metropolitan area (AMA), the largest metropolis in Ghana, and 12 neighbouring administrative units. GKSR is made up of the Kumasi Metropolitan Area (KMA), and seven neigbouring adminsitrative units. 

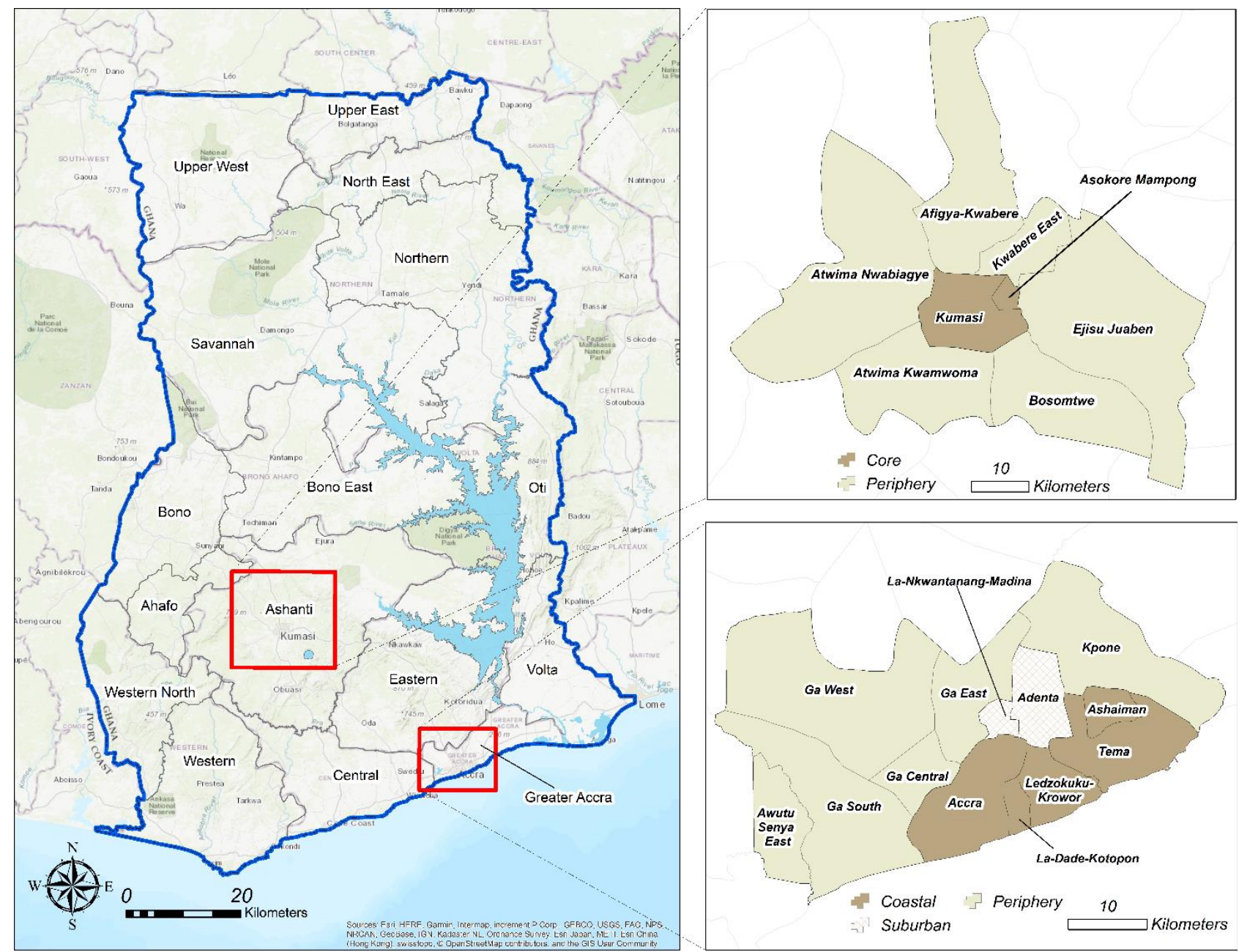

Figure 2.1.1: Map of (A) Ghana showing the metropolitan regions of (B) Greater Kumasi Sub-region (GKSR) and (C) Accra City-region (ACR), and their corresponding administrative districts.

These metropolitan regions can be further sub-divided into broad contiguous spatial untis or zones, using their historical origins of growth and expansion as the reference point. With GKSR, two such broad zones, namely, the 'core-zone' and 'peripheralzone' are identifiable (Figure 2.1.1B). The core marks the historical origins of urban growth and is the most urbanised part of the sub-region. Two administrative units, namely, Kumasi Metropolitan Area and Asokore Mampong Municipality constitute this core zone. The 'peripheral-zone' comprises seven administrative units surrounding the core. As the analysis of built-up land will later show, these peripheral districts have recently become the main fronteir of urban expansion in the sub-region. Regarding ACR, three broad spatial zones are identified, namely, 'historical-core coastal zone', 
'suburban-zone' and the 'peripheral zone' (Figure 2.1.1C). The 'coastal zone' comprises the earliest largest settlements in the region, including Accra which served as the capital of the British Gold Coast Colony in the 1800s and continues to remain the national capital of modern Ghana. The suburban and peri-urban zones have been the main hotspots of rapid urban expansion in recent years, as the region continues to attract population and attendant land use activities, including housing and infrastructure (see e.g. Doan and Oduro (2012), and Ashiagbor et al. (2019)). Table 2.1.1 provides a summary of the physical and demographic information about the GKSR and ACR and their constituent zones. 
Table 2.1.1: Zone divisions and Population distribution in Greater Kumasi Sub-region and Accra city-region.

\begin{tabular}{|c|c|c|c|c|c|}
\hline $\begin{array}{l}\text { Metropoli } \\
\text { tan } \\
\text { region }\end{array}$ & Districts & $\begin{array}{l}\text { Population } \\
\text { in } 2019\end{array}$ & $\begin{array}{l}\text { Area } \\
\left(\mathrm{km}^{2}\right)\end{array}$ & Zones & $\begin{array}{l}\text { Zonal density } \\
\text { (people } \mathrm{km}^{-2} \text { ) }\end{array}$ \\
\hline \multirow{7}{*}{$\begin{array}{l}\text { Greater } \\
\text { Kumasi } \\
\text { Sub- } \\
\text { region }\end{array}$} & $\begin{array}{l}\text { Kumasi } \\
\text { Asokore Mampong }\end{array}$ & $\begin{array}{l}2,105,382 \\
372,222\end{array}$ & $\begin{array}{l}188.3 \\
19.2\end{array}$ & $\begin{array}{l}\text { Historical- } \\
\text { Core } \\
\text { Zone }\end{array}$ & 11939.3 \\
\hline & Atwima Nwabiagya & 180,296 & 771.8 & \multirow{6}{*}{$\begin{array}{l}\text { Peripheral } \\
\text { zone }\end{array}$} & \multirow{6}{*}{314.1} \\
\hline & Ejisu Juaben & 174,482 & 732.6 & & \\
\hline & Kwabre East & 136390 & 130.5 & & \\
\hline & Atwima Kwanwoma & 110,503 & 353.7 & & \\
\hline & Afigya Kwabre & 162,848 & 471.6 & & \\
\hline & Bosomtwe & 116,324 & 344.2 & & \\
\hline \multirow{13}{*}{$\begin{array}{l}\text { Accra } \\
\text { City- } \\
\text { region }\end{array}$} & Accra & $2,087,668$ & 141.0 & \multirow{5}{*}{$\begin{array}{l}\text { Historical- } \\
\text { Coasta- } \\
\text { Core }\end{array}$} & \multirow{5}{*}{8275.5} \\
\hline & Tema & 353,086 & 126.7 & & \\
\hline & Ledzokuku-krowo & 275,239 & 64.2 & & \\
\hline & Ashaiman & 231,096 & 32.5 & & \\
\hline & La-dade-kotopon & 221,284 & 18.5 & & \\
\hline & Adenta & 93,158 & 75.0 & \multirow[b]{2}{*}{$\begin{array}{l}\text { Suburban } \\
\text { Zone }\end{array}$} & \multirow[b]{2}{*}{2453.1} \\
\hline & $\begin{array}{l}\text { La-nkwatanang- } \\
\text { madina }\end{array}$ & 134,837 & 18.0 & & \\
\hline & Kpone & 132,070 & 237.1 & \multirow{6}{*}{$\begin{array}{l}\text { Peripheral } \\
\text { zone }\end{array}$} & \multirow{6}{*}{1254.6} \\
\hline & Ga East & 179,107 & 116.8 & & \\
\hline & Ga Central & 141,070 & 56.3 & & \\
\hline & Ga West & 268,557 & 354.0 & & \\
\hline & Ga South & 521,162 & 242.2 & & \\
\hline & Awutu-senya East & 129,629 & 86.8 & & \\
\hline
\end{tabular}

Note: Population estimates from Ghana Statistical Services webpage (http://www.statsghana.gov.gh) 


\subsubsection{Satellite data acquisition, processing and classification}

Land cover maps of GKSR and ACR were produced by classifying Landsat ( 30m) multispectral images. The Landsat images covered three time steps that span a period of up to 33 years (Table 2.1.2). Satellite data availability and quality considerations such as the absence or minimal presence of clouds, informed the selection of the images. The 1985 image of the ACR had $<5 \%$ cloud cover that was localised at the northwestern corner of the area. Deducing from other studies (e.g. Ashiagbor et al. 2019), we correctly reclassified those areas as vegetation. Image bands were processed to surface reflectance in order to correct for the different images and sensor dates. The support vector machine - a pixel based non-parametric machine-learning algorithm was consequently used to classify the images in R (R Core Team 2018). This classifier has been demonstrated to produce superior accuracies even with smaller sampling points as compared to a probabilistic parametric classifier such as a maximum likelihood algorithm (Foody and Mathur 2006; Awuah 2017). 
Table 2.1.2: Characteristics, sampling points and overall accuracies of the classified images for the study areas. One Landsat tile area per metropolitan region.

\begin{tabular}{clcccc}
\hline Study & Date & Landsat & Spectral & $\begin{array}{c}\text { Number of } \\
\text { sampling }\end{array}$ & Overall \\
Area & $(\mathbf{y} / \mathbf{m} / \mathbf{d})$ & Sensor & Bands & points & \\
& & & & 850 & 90 \\
\hline GKSR & $11 / 01 / 1986$ & TM & $1,2,3,4,5,7$ & 85 [\%] \\
GKSR & $13 / 01 / 2007$ & ETM+ & $1,2,3,4,5,7$ & 884 & 88 \\
GKSR & $22 / 01 / 2019$ & OLI, TIRS & $2,3,4,5,6,7$ & 1056 & 89 \\
ACR & $02 / 04 / 1985$ & TM & $1,2,3,4,5,7$ & 1135 & 91 \\
ACR & $12 / 02 / 2003$ & ETM+ & $1,2,3,4,5,7$ & 1499 & 89 \\
ACR & $15 / 05 / 2017$ & OLI, TIRS & $2,3,4,5,6,7$ & 1758 & 86 \\
\hline
\end{tabular}

Points were systematically sampled for each image based on four dominant land cover classes (strata), namely built-up, water, vegetation, and urban-open-space. Identification of sampling points for each of the four classes was carried out by visualizing different combinations of spectral bands and with the support of highresolution Google earth images. Spectral band values were extracted at each stratified sampled point and used to train the classification algorithm. The sampling points were divided into $70 \%$ for training and $30 \%$ for validating the support vector machine algorithm. To have comparable bands, the thermal (TM, ETM+ and OLI/TIRS), panchromatic (ETM+ and OLI/TIRS), cirrus and coastal (OLI/TIRS) bands were exempted from the point extractions. Accuracy was assessed with the crossvalidation approach (Belousov et al. 2002), and the overall accuracies were calculated to be a satisfactory $>85 \%$ (Table 2.1.2). Visualization and sampling points were generated with ArcGIS 10.6, and the extraction and implementation of the classification was conducted in R (R Core Team 2018), with its extensions "raster" (Hijmans 2018), “e1071” (Meyer et al. 2018), and “caTools” (Tuszynski 2018). 
As conceptually illustrated in Figure 2.1.2, areas of built-up, water bodies and vegetation were clearly differentiated, and the urban-open-space were fuzzy (mixed) areas that were unidentifiable as one of the three before. In addition to water, the three land cover classes are defined as follows: Built-up refers to buildings, concrete surfaces, rooftops, asphalted roads, railroads and other anthropogenically induced surfaces. Vegetation covers forests, shrubs, plantations, riparian forests, and vegetated grasslands. Urban-open-space referred to anthropogenic open and bare lands that were classified as neither built-up, vegetation, nor water. Thus, an urbanopen-space included among others, croplands, non-asphalted roads such as forest and feeder roads, areas cleared for construction and areas that were still under construction. The urban-open-space was therefore regarded as a land cover type with mixed spectral information, and hence, it signified areas with multiple land uses.

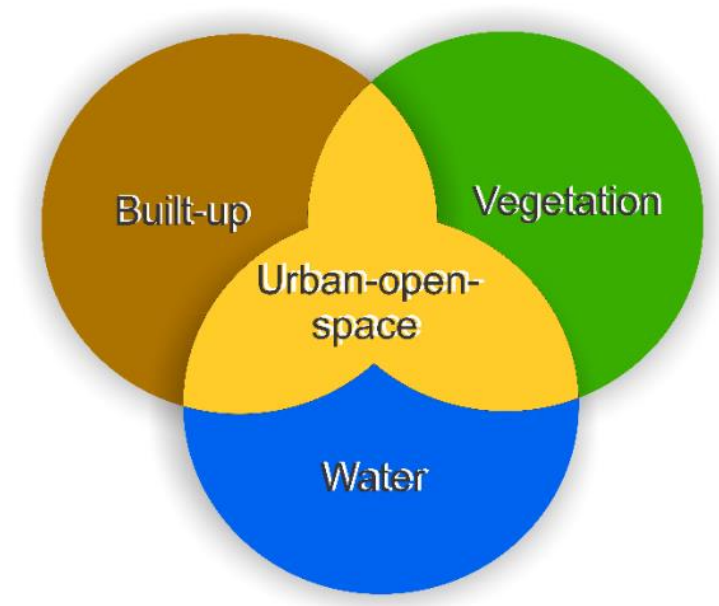

Figure 2.1.2: Conceptual representation of the four dominant classes in the study areas.

\subsubsection{Landscape characterization metrics}

Four complementary landscape metrics (Table 2.1.3) are employed to characterise and quantify the emergent spatial morphologies (i.e. composition and configuration) of each of the metropolitan regions (Forman 1995; Turner and Gardner 2015). The metrics used are: (a) Mean Patch Size (MPS); (b) Patch Density (PD); (c) Edge Density (ED); and (d) Landscape Shape Index (LSI). MPS and PD are used as 
compositional metrics to quantify the size, density, and variety of landscape patches, while ED and LSI are used as configurational metrics to quantify patterns in the spatial arrangement, orientation and shape complexity of the patches (Lausch et al. 2014; McGarigal 2015). MPS and PD decrease and increase respectively as the landscape becomes patchy and fragmented. In addition, a fragmented landscape has increased edges (ED) and spatial complexity (LSI). Thus, the landscape is fragmented when MPS is low and PD, ED and LSI are high. Except the MPS, the three other metrics are spatially normalized (Table 2.1.3), which makes them suitable for comparing landscape characteristics across spatial units of different sizes (McGarigal 2015). 
Table 2.1.3: Description of the selected landscape metrics.

\begin{tabular}{|c|c|c|}
\hline Metric & Description & Equation \\
\hline $\begin{array}{l}\text { Patch } \\
\text { density } \\
\text { (PD) }\end{array}$ & $\begin{array}{l}\text { Measures number of patches relative to the total } \\
\text { landscape area. Increases with increasing } \\
\text { fragmentation in a landscape. (unit: number of } \\
\text { patches }(\mathrm{N}) \text { per } 100 \text { ha }\left[1 \mathrm{~km}^{-2}\right] \text {, range } \geq 0 \text { ). }\end{array}$ & $\frac{N_{i}}{A}(10000 * 100)$ \\
\hline Mean & Summarizes each class as the average of all & $\frac{\sum_{j=1}^{n}\left(\frac{a_{i j}}{10,000}\right)}{N_{i}}$ \\
\hline $\begin{array}{l}\text { patch size } \\
\text { (MPS) }\end{array}$ & $\begin{array}{l}\text { patch areas that belong to that class. Increase } \\
\text { with a decrease in fragmentation. (unit: ha, range } \\
\geq 0 \text { ). PD and MPS can be used complementarily. }\end{array}$ & \\
\hline $\begin{array}{l}\text { Edge } \\
\text { density } \\
\text { (ED) }\end{array}$ & $\begin{array}{l}\text { Sum of all edges of a class relative to the } \\
\text { landscape area. Increases with increasing } \\
\text { fragmentation and shape complexity (unit: } m \text { ha }^{-} \\
1 \text {, range } \geq 0 \text { ). ED gives information on both the } \\
\text { composition and the configuration of a } \\
\text { landscape. }\end{array}$ & $\frac{\sum_{k=1}^{m} e_{i k}^{*}}{A}(10000)$ \\
\hline
\end{tabular}

Landscap Measures the shape complexity of spatial objects $\frac{0.25 \sum_{k=1}^{m} e_{i k}^{*}}{\sqrt{A}}$

e shape in relation to standard geometric objects.

index Increases with increasing shape complexity from

(LSI) a standard geometric unit such as a square or a

circle (no unit, range $\geq 1$ ). An increase in LSI is

an increase in fragmentation.

$A=$ total area of landscape, $a_{i j}=$ patch area, $e_{i k}^{*}=$ total edge length, $N_{i}=$ number of patches

\subsubsection{Results}

In the sections that follow, the results are presented at two spatial scales in the order outlined below: First, the quantities of built-up land cover changes are presented at 
the scale of the metropolitan regions. Next, the metric-based landscape characterization analyses are presented for the whole of each of the metropolitan region first, and subsequently for the broad zonal sub-divisions identified in the two metropolitan regions. Under each step, the results of ACR are presented first, followed by that of GKSR.

\subsubsection{Spatio-temporal analysis of land cover quantities-regional scale}

\section{Accra City-Region}

Over the 32-year period of land cover analysis (1985 to 2017), the data shows that built-up area in ACR increased remarkably by about 4.5 times from 105 to $468 \mathrm{~km}^{2}$. This resulted in a $45.5 \%$ decrease in vegetation land cover from 903 to $492 \mathrm{~km}^{2}$ (Figure 2.1.3; Figure 2.1.4A). The area covered by water $\left(39-43 \mathrm{~km}^{2}\right)$ and urban-openspace $\left(518-562 \mathrm{~km}^{2}\right)$ had small increases over this period. Built-up land has been increasing in all the three spatial zones (i.e. historical-core coastal, suburban and peripheral zones) - Figure 2.13. What this reveal is that lateral expansion of settlements has occurred in each of the zones. For example, built-up land more than doubled (88.3-218.2 $\left.\mathrm{km}^{2}\right)$ in the historical-core zone, mainly through outward expansion. Nonetheless, the analyses reveal a general trend where built-up land expansion has intensified in the outlying suburban and peripheral zones. For example, in 1985 , only $16.5 \mathrm{~km}^{2}$ of the peripheral zone was built-up, but this increased by about 13.5 times to $222.6 \mathrm{~km}^{2}$ by 2017 (Table 2.1.4).

These built-up land expansion trends outlined above have occurred largely at the expense of other land cover types, especially urban-open-space and vegetation. As the detailed analysis of land cover transitions shows, $>50 \%$ of urban-open-space and vegetation land covers transitioned into other land cover types (Figure 2.1.4B). About $46 \%$ of this change occurred because of urban-open-space transitioning to built-up 
land. Urban-open-space class transitioning back to vegetation accounted for the remaining $14 \%$. Transitions between built-up and vegetation accounted for $23 \%$, and between water and vegetation was 13\% (Figure 2.1.4B). There was no transition from water to urban-open-space but the reverse was $4 \%$. Also, the transition from water to built-up was $7 \%$ and the reverse was only $2 \%$ (Figure 2.1.4B).

\section{Greater Kumasi Sub-Region}

Similar to ACR, built-up land has increased significantly in GKSR from 95 to $390 \mathrm{~km}^{2}$ over the 33-year period between 1986 and 2019 (Figure 2.1.3). While built-up land has increased in both the historical-core and peripheral zones, this has occurred intensively in the latter. For example, over the analysis period, built up land in the historical-core zone doubled $\left(68.8-137.9 \mathrm{~km}^{2}\right)$ but that of the peripheral zones increased by nearly ten-fold $\left(26.3-251.8 \mathrm{~km}^{2}\right)$ - Table 2.1.4. These increments were largely at the expense of vegetation, which decreased remarkably from $2518 \mathrm{~km}^{2}$ in 1986 to $1689 \mathrm{~km}^{2}$ by 2019 (Figure 2.1.4C).

The detailed analyses of land cover transitions reveal that over the 33-year period, built-up and water maintained $80 \%$ and $90 \%$ of their land area respectively, whereas urban-open-space and vegetation maintained $44 \%$ and 63\% (Figure 2.1.4D). Transitions between urban-open-space and vegetation represented $26 \%$ and $28 \%$ in both directions respectively. Urban-open-space lost $30 \%$ of its area to built-up, while the reverse was $19 \%$. Vegetation lost only $1 \%$ of its area to built-up, but the reverse was $8 \%$. There were no transitions between water, built-up and urban-open-space, except for a $4 \%$ area transition from water to vegetation. Thus, major land cover transitions in the GKSR were between built-up and urban-open-space (49\%), and between urban-open-space and vegetation (54\%) (Figure 2.1.4D). 
Table 2.1.4: Land cover changes in Accra City-Region (1985, 2003 and 2017) and Greater Kumasi Sub-Region (1986, 2007 and 2019).

\begin{tabular}{|c|c|c|c|c|c|c|c|c|c|c|c|c|c|c|c|c|c|c|}
\hline \multirow{2}{*}{$\begin{array}{l}\text { Regio } \\
\mathrm{n}\end{array}$} & \multirow[t]{2}{*}{ Districts } & \multirow{2}{*}{$\begin{array}{c}\text { Total } \\
\text { Area } \\
{\left[\mathrm{km}^{2}\right]}\end{array}$} & \multicolumn{3}{|c|}{$\begin{array}{c}\text { Built-up } \\
{\left[\mathrm{km}^{2}\right]}\end{array}$} & \multicolumn{3}{|c|}{$\begin{array}{c}\text { Urban-open-space } \\
{\left[\mathrm{km}^{2}\right]}\end{array}$} & \multicolumn{3}{|c|}{$\begin{array}{l}\text { Vegetation } \\
{\left[\mathrm{km}^{2}\right]}\end{array}$} & \multicolumn{3}{|c|}{$\begin{array}{l}\text { Water } \\
{\left[\mathrm{km}^{2}\right]}\end{array}$} & \multirow{2}{*}{$\begin{array}{c}\% \\
\begin{array}{c}\% \\
\text { Change } \\
\text { built-up }\end{array} \\
1985- \\
2017 \\
1986- \\
2019\end{array}$} & \multirow{2}{*}{$\begin{array}{c}\% \\
\text { Change } \\
\text { urban- } \\
\text { open- } \\
\text { space } \\
1985- \\
2017 \\
1986- \\
2019\end{array}$} & \multirow{2}{*}{$\begin{array}{c}\% \\
\text { Chang } \\
\text { e } \\
\text { vegeta } \\
\text { tion } \\
1985- \\
2017 \\
1986- \\
2019\end{array}$} & \multirow{2}{*}{$\begin{array}{c}\begin{array}{c}\% \\
\text { Chan } \\
\text { ge } \\
\text { water }\end{array} \\
1985- \\
2017 \\
1986- \\
2022\end{array}$} \\
\hline & & & $\begin{array}{c}1985 \\
- \\
1986\end{array}$ & $\begin{array}{c}2003 \\
- \\
2007\end{array}$ & $\begin{array}{c}2017 \\
- \\
2019\end{array}$ & $\begin{array}{c}1985 \\
- \\
1986\end{array}$ & $\begin{array}{c}2003 \\
- \\
2007\end{array}$ & $\begin{array}{c}2017 \\
- \\
2019\end{array}$ & $\begin{array}{c}1985 \\
- \\
1986\end{array}$ & $\begin{array}{c}2003 \\
- \\
2007\end{array}$ & $\begin{array}{c}2017 \\
- \\
2019\end{array}$ & $\begin{array}{c}1985 \\
- \\
1986\end{array}$ & $\begin{array}{c}2003 \\
- \\
2007\end{array}$ & $\begin{array}{c}2017 \\
- \\
2019\end{array}$ & & & & \\
\hline \multirow{16}{*}{ ACR } & Accra & 141.0 & 42.1 & 74.7 & 89.0 & 62.5 & 28.2 & 22.9 & 30.9 & 33.5 & 24.9 & 5.2 & 4.3 & 3.9 & 111.5 & -63.3 & -19.4 & -26.2 \\
\hline & Tema & 126.7 & 20.6 & 53.6 & 65.4 & 88.7 & 52.7 & 37.4 & 15.4 & 18.0 & 22.2 & 1.7 & 2.1 & 1.3 & 217.9 & -57.8 & 44.2 & -23.2 \\
\hline & Ledzokuku-krowo & 64.2 & 18.5 & 36.7 & 37.8 & 43.1 & 22.8 & 17.5 & 1.7 & 4.2 & 8.5 & 0.8 & 0.3 & 0.2 & 104.0 & -59.3 & 398.3 & -76.0 \\
\hline & Ashaiman & 32.5 & 2.4 & 9.7 & 15.5 & 26.4 & 17.7 & 11.7 & 3.1 & 3.6 & 3.7 & 0.4 & 1.4 & 1.5 & 543.9 & -55.6 & 18.1 & 227.8 \\
\hline & La-Dade-Kotopon & 18.5 & 4.8 & 8.1 & 10.4 & 10.6 & 5.8 & 4.6 & 3.1 & 4.5 & 3.5 & 0.0 & 0.0 & 0.0 & 119.5 & -56.9 & 11.6 & 120.0 \\
\hline & ${ }^{*}$ Coastal zone & 382.9 & 88.3 & 182.9 & 218.2 & 231.2 & 127.3 & 94.2 & 54.2 & 63.7 & 62.8 & 8.1 & 8.1 & 6.8 & 147.0 & -59.3 & 15.7 & -16.2 \\
\hline & $\begin{array}{l}\text { Adenta } \\
\text { La-Nkwatanang- }\end{array}$ & 75.0 & 0.4 & 12.3 & 19.8 & 41.8 & 43.0 & 42.9 & 32.4 & 19.3 & 11.9 & 0.3 & 0.2 & 0.2 & 5205.1 & 2.8 & $\begin{array}{l}-63.4 \\
\end{array}$ & -32.2 \\
\hline & Madina & 18.0 & 0.2 & 3.4 & 7.8 & 5.4 & 10.2 & 9.2 & 12.3 & 4.4 & 0.9 & 0.0 & 0.0 & 0.0 & 3078.8 & 70.7 & -92.9 & 261.5 \\
\hline & ${ }^{*}$ Suburban zone & 92.9 & 0.6 & 15.6 & 27.7 & 47.1 & 53.2 & 52.1 & 44.7 & 23.7 & 12.7 & 0.3 & 0.2 & 0.2 & 4359.5 & 10.6 & -71.5 & -20.8 \\
\hline & Kpone & 237.1 & 3.4 & 12.4 & 40.6 & 119.7 & 132.0 & 125.5 & 112.2 & 90.8 & 68.8 & 1.1 & 1.2 & 1.5 & 1078.3 & 4.8 & -38.7 & 41.1 \\
\hline & Ga East & 116.8 & 0.3 & 11.3 & 32.4 & 15.9 & 25.1 & 48.4 & 99.3 & 80.1 & 35.7 & 1.1 & 0.1 & 0.0 & 11863.8 & 204.1 & -64.0 & -98.0 \\
\hline & Ga Central & 56.3 & 3.5 & 24.2 & 35.6 & 25.5 & 20.8 & 18.7 & 27.2 & 11.2 & 1.9 & 0.0 & 0.0 & 0.0 & 903.6 & -26.4 & -93.2 & 80.0 \\
\hline & Ga West & 354.0 & 0.9 & 5.7 & 37.8 & 3.3 & 62.0 & 104.9 & 348.1 & 285.3 & 207.5 & 0.9 & 0.2 & 3.1 & 4168.8 & 3053.8 & -40.4 & 243.5 \\
\hline & Ga South & 242.2 & 7.4 & 27.7 & 46.0 & 46.5 & 65.4 & 81.1 & 160.8 & 119.9 & 83.6 & 26.9 & 28.7 & 31.0 & 525.1 & 74.3 & -48.0 & 14.9 \\
\hline & Awutu-Senya East & 86.8 & 1.0 & 14.0 & 30.2 & 28.6 & 52.6 & 37.0 & 57.0 & 19.9 & 19.1 & 0.1 & 0.1 & 0.3 & 3022.4 & 29.5 & -66.4 & 193.9 \\
\hline & ${ }^{*}$ Periphery zone & 1093.3 & 16.5 & 95.3 & 222.6 & 239.5 & 358.0 & 415.6 & 804.6 & 607.1 & 416.6 & 30.1 & 30.3 & 35.9 & 1250.9 & 73.5 & -48.2 & 19.2 \\
\hline \multirow{10}{*}{ GKSR } & Kumasi & 188.3 & 68.0 & 108.6 & 125.5 & 67.6 & 70.1 & 53.4 & 52.7 & 9.6 & 9.4 & & 0.0 & 0.0 & 84.6 & -21.0 & -82.2 & 0.0 \\
\hline & Asokore Mampong & 19.2 & 0.8 & 7.6 & 12.4 & 5.7 & 9.0 & 5.1 & 12.7 & 2.6 & 1.7 & & & & 1449.8 & -10.6 & -86.7 & 0.0 \\
\hline & ${ }^{*}$ Core zone & 207.5 & 68.8 & 116.2 & 137.9 & 73.3 & 79.1 & 58.5 & 65.4 & 12.2 & 11.1 & 0.0 & 0.0 & 0.0 & 100.5 & -20.2 & -83.1 & 0.0 \\
\hline & Atwima Nwabiagya & 771.8 & 5.2 & 22.6 & 43.6 & 101.0 & 194.9 & 223.9 & 663.5 & 551.0 & 500.9 & 1.8 & 3.0 & 3.1 & 742.0 & 121.6 & -24.5 & 69.9 \\
\hline & Ejisu Juaben & 732.6 & 6.2 & 18.0 & 43.5 & 45.1 & 131.0 & 173.0 & 680.7 & 582.9 & 515.4 & & 0.0 & 0.1 & 603.9 & 283.4 & -24.3 & 0.0 \\
\hline & Kwabre East & 130.5 & 3.6 & 14.2 & 38.5 & 22.2 & 44.0 & 52.7 & 104.6 & 72.2 & 39.3 & & 0.0 & 0.0 & 977.7 & 136.9 & -62.5 & 0.0 \\
\hline & Atwima Kwanwoma & 353.7 & 3.2 & 21.4 & 54.7 & 39.1 & 151.3 & 144.9 & 311.2 & 180.7 & 153.6 & & 0.1 & 0.2 & 1633.4 & 270.5 & -50.6 & 0.0 \\
\hline & Afigya-Kwabre & 471.6 & 5.1 & 22.1 & 42.5 & 56.0 & 131.3 & 161.4 & 408.9 & 317.0 & 266.6 & 1.1 & 0.8 & 0.7 & 729.6 & 188.1 & -34.8 & -38.8 \\
\hline & Bosomtwe & 344.2 & 3.1 & 9.7 & 29.0 & 19.1 & 67.4 & 75.1 & 281.9 & 227.5 & 200.9 & 39.9 & 39.3 & 38.9 & 839.9 & 294.1 & -28.7 & -2.4 \\
\hline & *Periphery zone & 2804.4 & 26.3 & 108.0 & 251.8 & 282.5 & 720.0 & 830.9 & 2450.8 & 1931.3 & 1676.7 & 42.8 & 43.2 & 43.1 & 857.6 & 194.1 & -31.6 & 0.5 \\
\hline
\end{tabular}


Accra city-region (ACR):

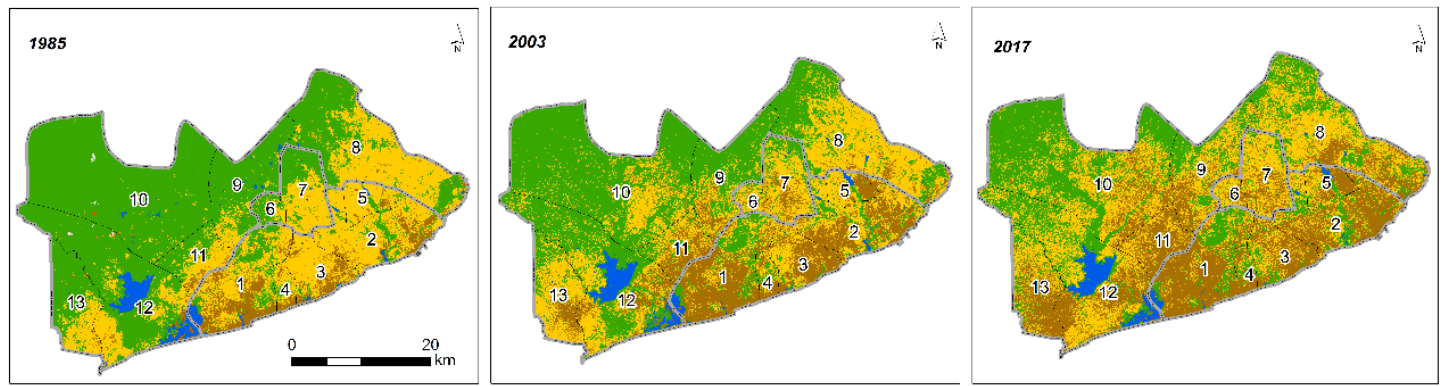

Greater Kumasi sub-region (GKSR):

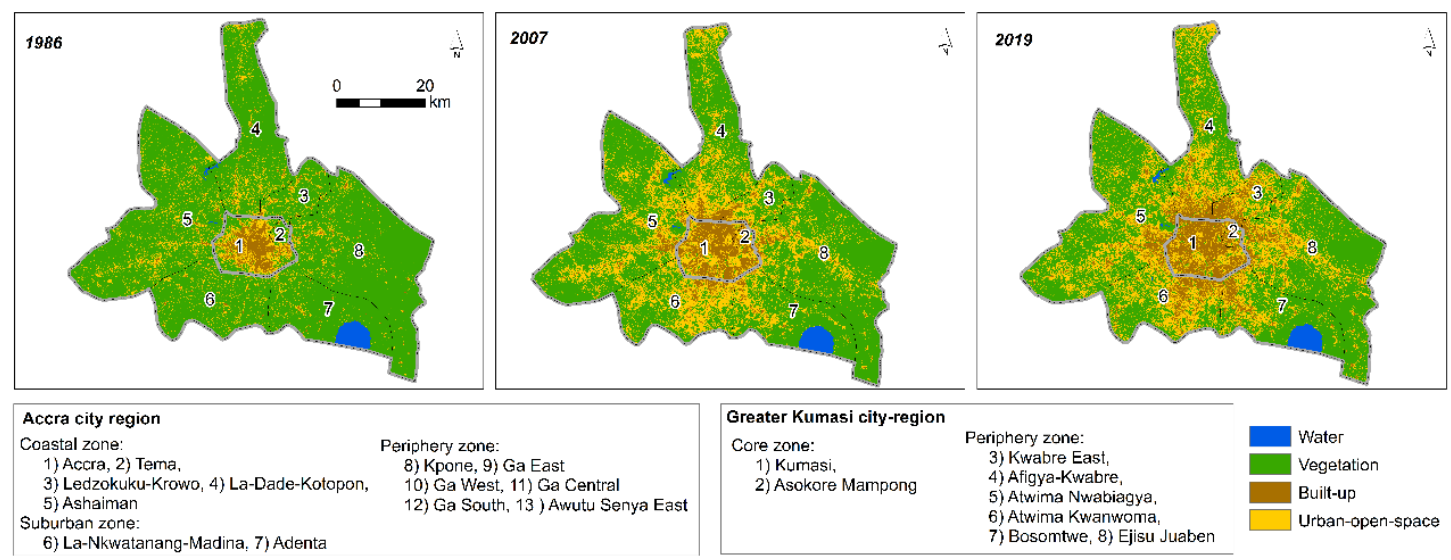

Figure 2.1.3: Classified land cover maps of Accra City-region (ACR) and Greater Kumasi Sub-region (GKSR).
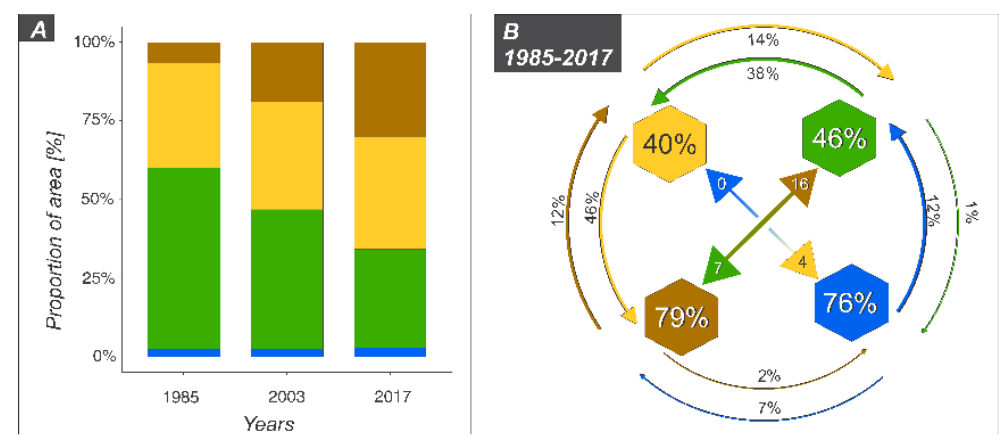

C
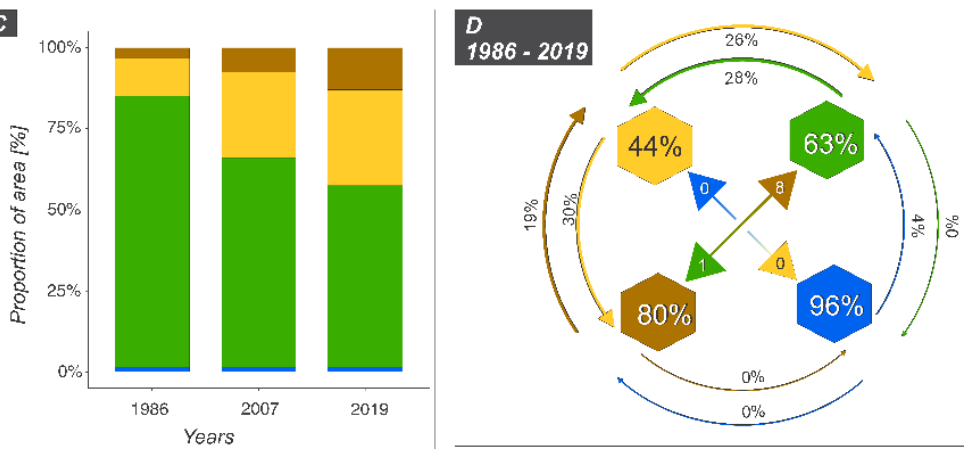

Figure 2.1.4: Area proportions of land cover classes and their temporal transitions for Accra City-region ( $A-B)$ and Greater Kumasi Sub-region (C-D). 


\subsubsection{Metric-based landscape characterization-regional scale}

\section{Accra City-Region}

Outputs from the metric-based analysis of the emergent landscape show that at the city-region scale, mean patch size (MPS) decreased (i.e. 10-3 ha), while patch density (PD) (10-34 $\left.\mathrm{N} \mathrm{km}^{-2}\right)$, edge density (ED) (50-156 $\left.\mathrm{m} \mathrm{ha}^{-1}\right)$ and landscape shape index (LSI) (50-154) all increased. All the zones (coastal, suburban, periphery) had similar trends as those of the city-region as a whole. What these metric-based outputs collectively mean in practice is that, the degree of landscape fragmentation increased in the city-region over the 33-year period of analysis (Figure 2.1.5). At the class level, built-up land increased in MPS even as the other three metrics (i.e. PD, ED and LSI) increased, a trend that contrasts the general trend observed for the city-region as a whole, and those of urban-open-space and vegetation (Figure 2.1.5). In this instance, MPS of the built-up increased due to the enlargement of its patches. Such enlargements happen by converting adjoining patches of other classes and/or by the aggregation of smaller built-up patches. What this means in practice is that while the overall emergent landscape is still largely fragmented, implying a pattern of 'leapfrogging' physical development, the degree of fragmentation appears to slowly minimize over time as patches of adjacent built-up land become consolidated. Metric outputs for water indicate that the landscape structure of this class has remained largely intact within the 32 years. 

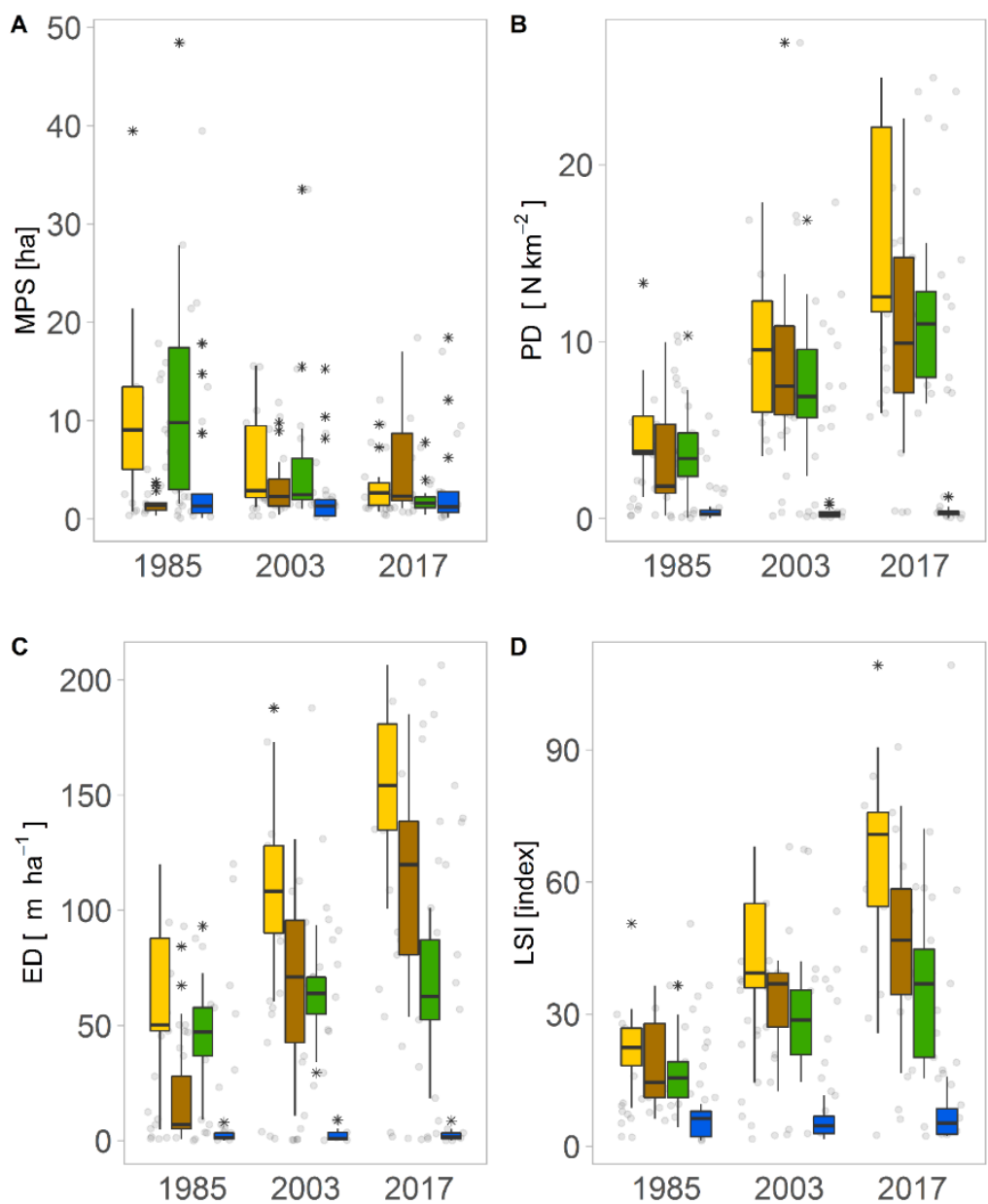

Figure 2.1.5: Box plots of landscape metrics of the land cover classes of districts in Accra City-Region.

Notes: (A) Mean patch size (MPS); (B) Patch density (PD); (C) Edge density (ED); (D) Landscape shape index (LSI). Yellow= urban-open-space, brown= built-up, green= vegetation, and blue= water. Grey points are metric values for each district; black whiskers are outliers. For visualization purpose MPS for Ga West in 1985 (1289 ha) is not included in the plot.

\section{Greater Kumasi Sub-Region}

Regarding GKSR as a whole, MPS initially increased marginally (i.e. 6-8 ha) between 1986 and 2007, but the reverse occurred (i.e. 8 ha) between 2007 and 2019 (Figure 2.1.6A). A corresponding initial marginal decrease and a later increase of PD was also observed (Figure 2.1.6B). However, ED and LSI increased from $66 \mathrm{~m} \mathrm{ha}^{-1}$ and 90 to $103 \mathrm{~m} \mathrm{ha}^{-1}$ and 142, between 1986 and 2019 respectively (Figure 2.1.6C-D). Both the historical-core and periphery zones followed the same trend as the whole of GKSR. The results show that the emergent landscape of the sub-region is fragmented. However, unlike ACR, the degree of landscape fragmentation in the GKSR was only evident in the outputs of configurational metrics but not compositional metrics. 
At the class level, the MPS output trend for built-up remained largely constant, but that of vegetation and water decreased between 1986 and 2019 (Figure 2.1.6A). Moreover, MPS of urban-open-space increased between 1986 and 2007, and then decreased slightly between 2007 and 2019 (Figure 2.1.6A). In contrast, PD of urban-open-space decreased from 1985 to 2007 and then increased from 2007 to 2019, in accordance to that of the general trend (Figure 2.1.6B). The PD of built-up and vegetation increased, while those of water remained the same, between 1986 and 2019 (Figure 2.1.6B). The trend of the ED and LSI increased for both built-up and vegetation over the period, while those of water remained the same (Figure 2.1.6C-D). The ED of urban-open-space increased from 1986 to 2019, and its LSI decreased between 1986 and 2007, and then increased between 2007 and 2019 (Figure 2.1.6C-D). What these results show is a general trend of built-up aggregation and expansion in the GKSR similar to those of ACR. However, the impacts on the degree of fragmentation of the other land cover class, particularly urban-open-space and vegetation, were different from the ACR. For instance, whereas the urban-open-space was the most fragmented in the ACR, it was rather vegetation in the GKSR. 

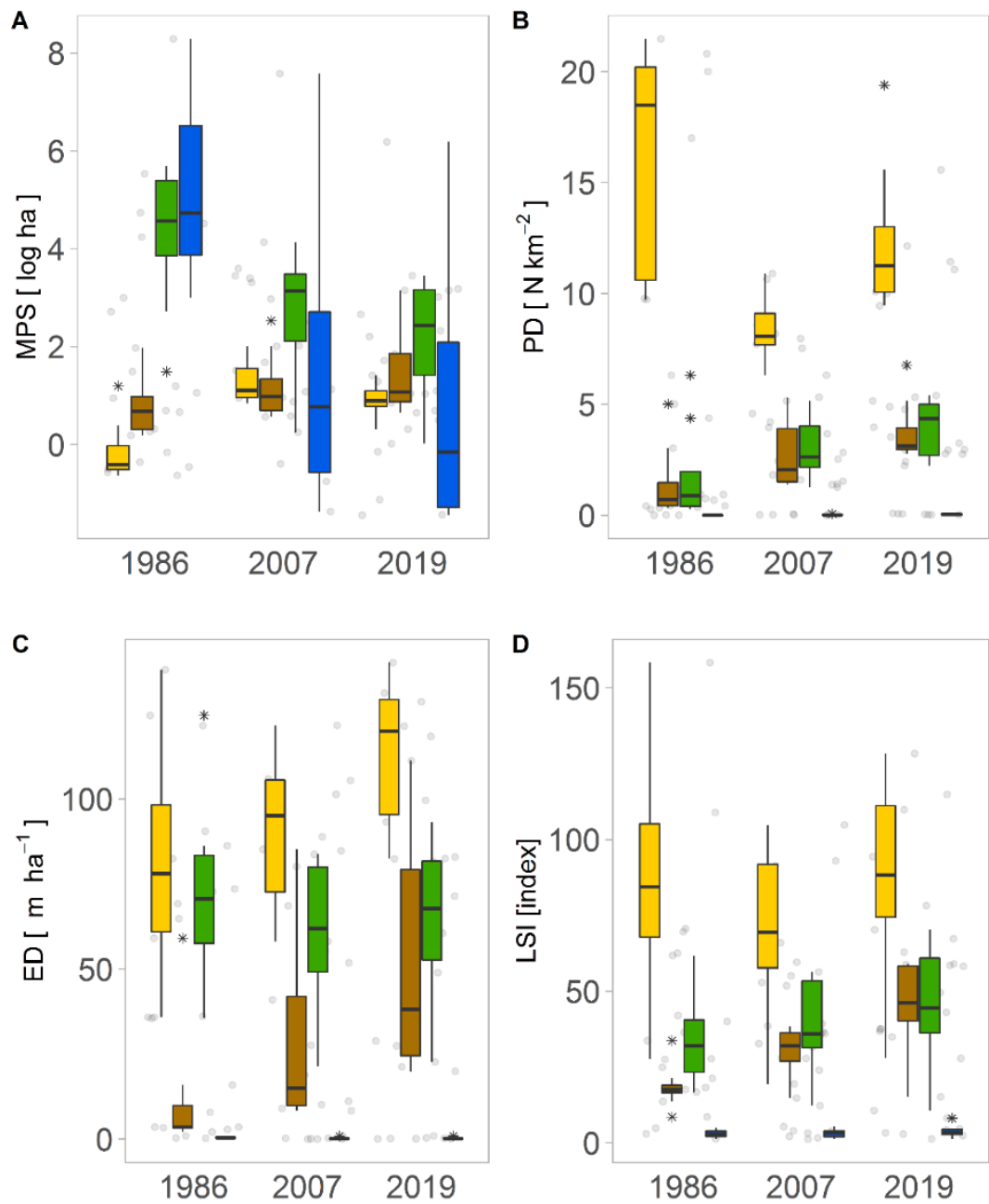

Figure 2.1.6: Box plots of landscape metrics of the land cover classes of districts in Greater Kumasi Sub-region.

Notes: (A) Mean patch size (MPS); (B) Patch density (PD); (C) Edge density (ED); (D) Landscape shape index (LSI). Yellow= urban-open-space, brown= built-up, green= vegetation, and blue= water. Grey points are metric values for each district; black whiskers are outliers.

\subsubsection{Metric-based landscape characterization-zonal sub-division}

\section{scale}

\section{Accra City-Region}

In the historical-core coastal zone of the ACR, an overall trend where MPS, ED and LSI increased as PD decreased for built-up land can be observed (Figure 2.1.7A-D). This means that over time, built-up land in this zone has aggregated and consolidated, becoming stable and less fragmented. In other words, the landscape in this zone was largely fragmented initially with patches of unbuilt land interspersing the built-up land. However, as the zone continues to be developed, the fragmentation, which is typified 
by sprawl and leapfrog development tend to consolidate and disappear. However, a decreased MPS with an increased PD, ED and LSI in urban-open-space and vegetation indicates a high degree of fragmentation in these landscapes.
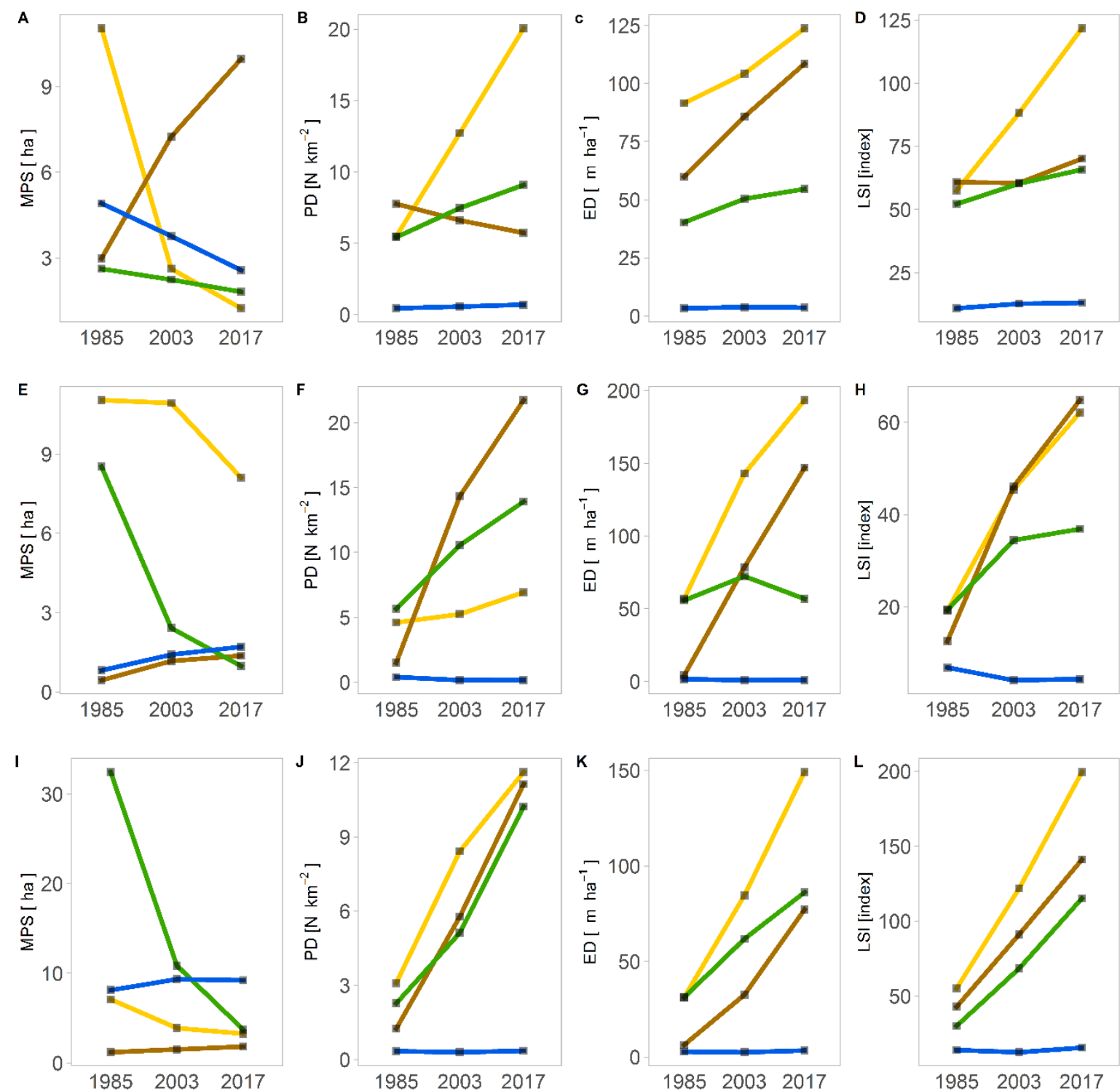

Figure 2.1.7: Trends of landscape metrics of the land cover classes within Historical-core Coastal Zone (A-D); Suburban zone (E-H); and Peripheral zone (I-L) of Accra City-Region.

In the suburban zone, urban-open-space and vegetation decreased in MPS from 11 to 8 ha and 8 to 1 ha respectively, while PD increased for both land cover classes (Figure 2.1.7E-F). In contrast, water and built-up increased in MPS from 0.8 to 1.4 ha and 0.4 to 1.7 ha respectively over the 32 years of analysis. In the same period, the PD of water correspondingly decreased, but that of built-up sharply increased. The 
ED and LSI increased sharply for urban-open-space and built-up, while it decreased slightly for water (Figure 2.1.7G-H). Thus, similar to the coastal zone, built-up patches aggregated and expanded, whereas those of urban-open-space increased in fragmentation. Moreover, ED for vegetation increased in 1985 from $56 \mathrm{~m} \mathrm{ha}^{-1}$ to $72 \mathrm{~m}$ ha $^{-1}$ in 2003 and then decreased to $57 \mathrm{~m} \mathrm{ha}^{-1}$ by 2017 (Figure 2.1.7G). This particular trend was inconsistent with the decreased MPS of the vegetation. These findings suggest that between 2003 and 2017, patches of the vegetation class were converted to other classes. The LSI of vegetation in this period corroborates this result, as it increased from 34 to 37, between 2003 and 2017 compared to an earlier sharp increase between 1985 and 2003 at LSI 19-34.

Trends in the peripheral zone are similar to those of the suburban zone. There was a decreased MPS of vegetation and urban-open-space, and a slightly increased MPS of the built-up and water (Fig 2.1.7I-J). The sharpest decrease was in vegetation, which was from 32 ha in 1985 to 10 ha in 2003, and consequently to 4 ha in 2017 . PD increased sharply in urban-open-space, vegetation, and built-up, while that of water remained fairly constant. ED and LSI correspondingly increased sharply for urbanopen-space, vegetation and built-up while those of water remained largely constant (Fig 2.1.7K-L).

Together, the zonal scale metric-based analyses reflect two important aspects of the overall emergent landscape of the ACR. First, there was aggregation of built-up land without expansion in the coastal zone that strongly affected the urban-open-space in particular. Second, there was both aggregation and expansion of built-up in the suburban and peripheral zones that strongly affected vegetation in particular. Across all the three zones, water was the least impacted despite being slightly fragmented in 
the core zone. However, it aggregated and remained stable in the suburban and periphery zones.

\section{Greater Kumasi Sub-Region}

In the core zone of the GKSR, the MPS of built-up increased sharply from 7 to 21 ha between 1986 and 2019, whereas those of the other classes were initially $>6$ ha and eventually decreased within the same period (Figure 2.1.8A). For instance, MPS for vegetation decreased from 5 to 1 ha by 2007 and remained at $\sim 1$ ha by 2019. PD of built-up decreased in correspondence to the increased MPS (Figure 2.1.8B). Also, ED and LSI of the built-up increased (Figure 2.1.9C-D). This indicate aggregation of builtup land patches at the expense of other land cover types, particularly vegetation. Indeed, this observation is supported by the trend of the decreased MPS, PD, ED and LSI of vegetation, which indicated that vegetation patches were converted to other land classes, including built-up. MPS of urban-open-space decreased slightly between 1986 and 2007 and subsequently increased slightly between 2007 and 2019, a trend which contrasted its PD, ED and LSI. These results indicate that urban-open-space initially fragmented, but later aggregated and expanded over the 33 years. Water had no visible patch in 1986 , but by 2007 , patches of water were visible in the landscape. The extreme fragmentation of vegetation within the historical core zone might explain this, particularly for vegetation around riparian zones and wetlands. 

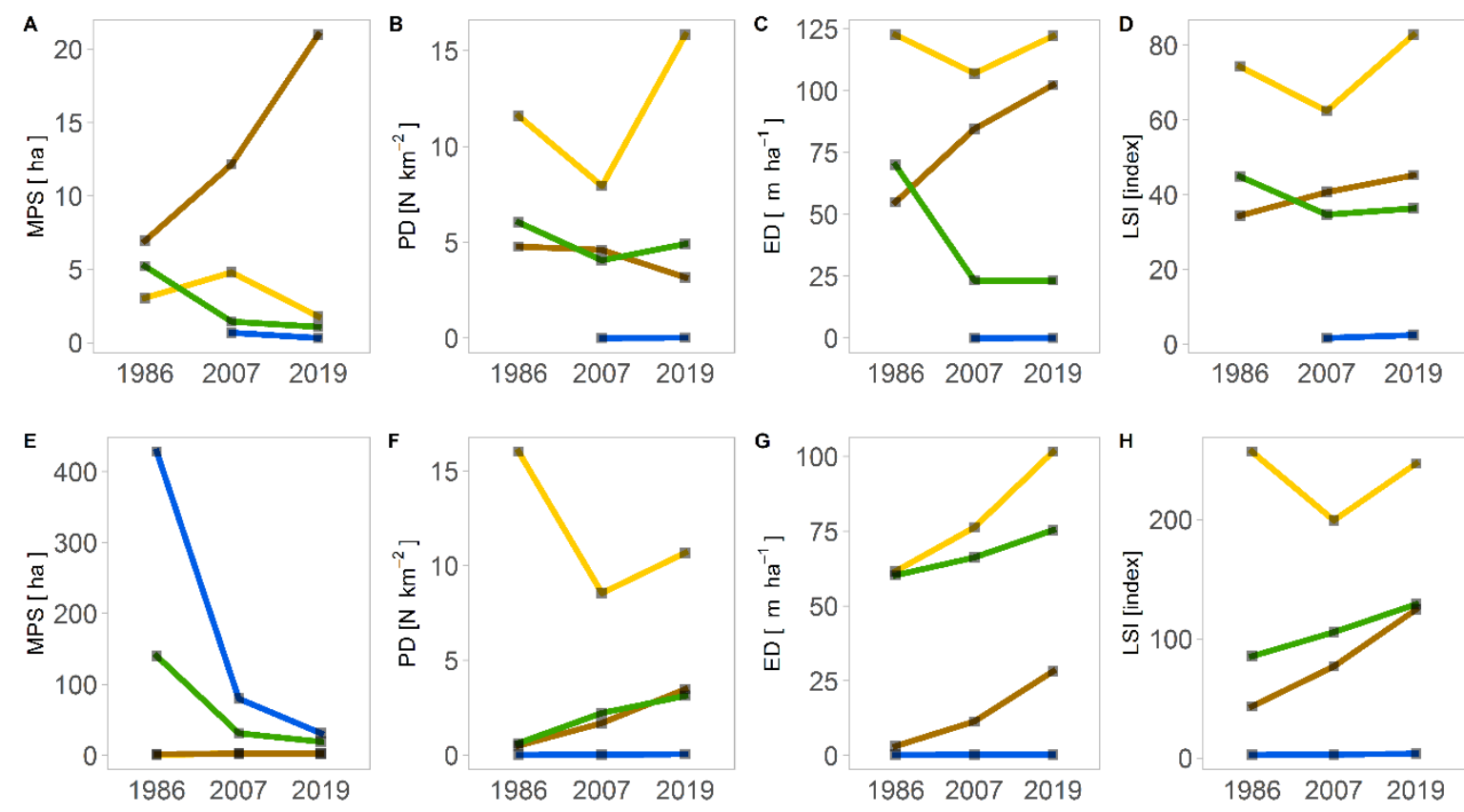

Figure 2.1.8: Trends of landscape metrics of the land cover classes within Historical-core Zone $(A-D)$ and Peripheral Zone $(E-H)$ of Greater Kumasi Sub-region.

In the periphery zone of the GKSR, MPS of water and vegetation decreased sharply from 428 to 31 ha and 140 to 19ha respectively, between 1986 and 2019 (Figure 2.1.8E). Within the same period, MPS of built-up and urban-open space increased slightly from $1-3$ ha and $2-3$ ha respectively. Although the PD, ED, and LSI of vegetation and built-up increased, contrasting patterns were observed from the analysis. For example, whereas vegetation showed extreme fragmentation, built-up showed aggregation and expansion. Water showed constant PD, ED and LSI from 1986 to 2019 , and thus it indicated slight fragmentation (Figure 2.1.8F-H). The PD and LSI of urban-open-space decreased between 1986 and 2007, and then increased between 2007 and 2019. However, its ED increased consistently throughout the 33 years of the study. These trends imply that the patches of urban-open-space went through a dynamic cycle of fragmentation, expansion and shape complexity. 


\subsubsection{Impact of built-up expansion on natural environment landscape}

\section{patches}

The final piece of the analysis explores the impact of built-up land on natural environment landscape patches, by specifying regression models to quantify the relationships between quantities of built-up land and the metrics-based landscape transformation indicators. The results show a positive association between the absolute increases of built-up land and the LSI of urban-open-space in all the districts of the ACR and GKSR (Figure 2.1.9A). Similar linear positive relationships were observed between built-up and LSI $\left(r^{2}=40 \%\right)$ and ED $\left(r^{2}=8 \%\right)$ of vegetation (Figure 2.1.9B and D). However, there was a negative relationship between built-up increase and PD of vegetation $\left(r^{2}=12 \%\right)$. In this instance, the districts clustered according to their metropolitan regions, whereby the districts of the ACR had a noticeably greater impact on the PD (Figure 10E). Furthermore, the results show a positive relationship between built-up land increase and the LSI $\left(r^{2}=12 \%\right)$ and PD $\left(r^{2}=18 \%\right)$ of water, which also reveal some degree of clustering implying greater impacts in ACR districts compared to those of GKSR (Figure 2.1.9C and F).

Together, these results give a clear indication that, built-up expansion has a strong impact on the natural environment land-cover classes, especially vegetation and urban-open-space. They provide important indicators of the presence of landscape fragmentation in the two metropolitan regions and reinforce the observation that builtup land has been increasing and expanding outwards at the expense of natural environmental resources. 


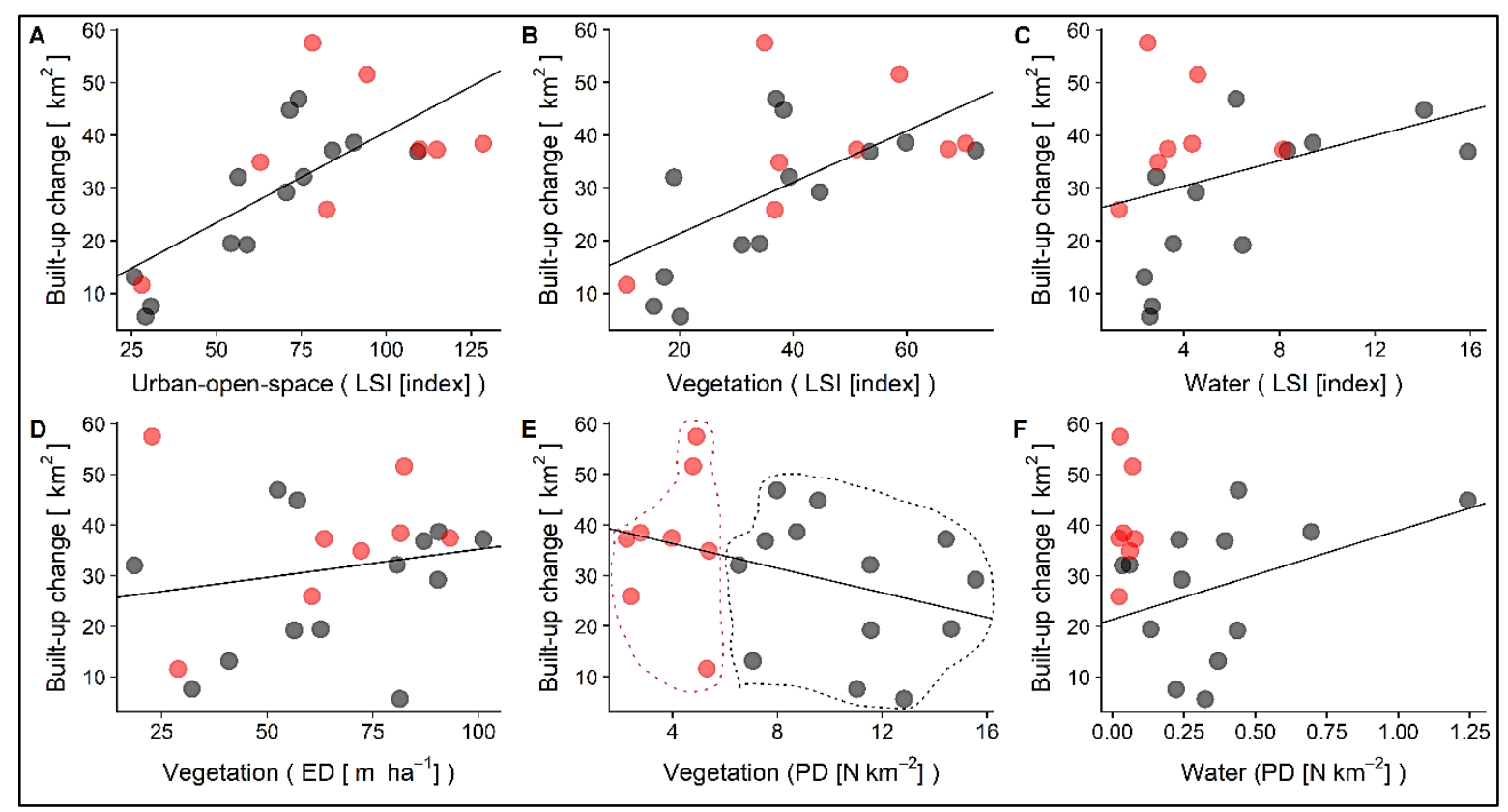

Figure 2.1.9: Relationships between absolute increase of built-up area and (A) LSI of urbanopen-space; (B) LSI of vegetation (C) LSI of water; (D) ED of vegetation; (E) PD of vegetation and $(F) P D$ of water.

\subsubsection{Discussion}

Urbanisation induces spatial and environmental changes. Monitoring and understanding these spatio-environmental changes are crucial to sustainable urban growth management and the preservation of essential ecosystem services. To this end, this paper has examined the evolution and impacts of rapid urbanisation in Ghana's two major metropolitan regions - Accra-City Region (ACR) and the Greater Kumasi Sub-Region (GKSR). Using Landsat satellite data, land cover maps were classified to quantify land transition in these regions over the last three decades. The emergent spatial landscapes in these metropolitan regions have been characterised using a set of complementary metrics. The analysis has also quantified the relationships between quantities of built-up land and metrics-based landscape transformation indicators to explore the impact of fragmentation on natural land cover classes (i.e. vegetation, urban-open-space and water). The results show that in the last three decades, built-up land has increased significantly in the two metropolitan regions. Consistent with the findings of previous studies (e.g. Acheampong et al. 
(2017), Agyemang et al. (2017), Abass et al. (2018), and Korah et al. (2019)), the emergent landscapes show a general pattern where the expansion of built-up land was initially concentrated in the historical-core zones but extended outward in recent years to the outlying suburban and peripheral zones. The rapid increase in population in these metropolitan regions is certainly one of the key drivers of the increased conversion of land to built-up. Currently, the KMA and AMA, the two most urbanised areas in the metropolitan regions, have a resident population of over two million people from an estimated population in the 1970s of about six hundred thousand and three hundred and fifty thousand respectively.

At the same time as these historical-core zones have experienced population influx and expanded, population has increased in erstwhile rural communities, driving new physical development. Thus, previously rural settlements are increasingly becoming spatially integrated into the conterminous urban area of the metropolitan regions. Previous research has shown that formerly small and dominantly rural settlements have attracted population in recent years due to the availability of land at relatively cheaper prices and their proximity to trunk roads that link them to bigger settlements in the core of the metropolitan regions. For example, Doan and Oduro (2012) and Yankson and Bertrand (2012) have shown that hitherto very small settlements in ACR, including Gbawe (Ga South District), Dome (Ga East District), Adenta (Adenta Municipality) and Madina (La-Nkwatanang-Madina District) have had their populations and built-up areas increased largely independent of those of Accra and Tema, the two major cities within the city-region. The analysis presented in this paper also shows that in the last three decades, additional small settlements such as Kasoa (Awutu-Senya East Municipality) have undergone similar trajectory, expanding rapidly outward and becoming part of the conterminous built-up area of the Accra City-Region. 
The detailed analysis of land use transitions reveals that although built-up land increased at the expense of natural environment classes (i.e. vegetation, urban-openspace and water), the process of transformation has been unique, dynamic, multidirectional and complex. The findings suggest that land use transformations were largely through exchanges between vegetation and urban-open-space on the one hand, and urban-open-space and built-up on the other hand. Most importantly, the land cover transitions analysis uncovered a unique process by which urban-openspaces mediate the changes between built-up land and vegetation and vice versa. What this finding means in practice is that, while vegetation removal results in built-up land (e.g. buildings and infrastructure), there appears to be an important time lag that mediates this transition. Within this time lag, the analysis reveal that a number of transitions are plausible. For example, land that was cleared at one point in time, thereby becoming urban-open-space, could revert to vegetation at another. A number of reasons could explain this unique transformation process.

For instance, given that built-up expansion in Ghana is largely a function of residential housing demand (Yeboah 2000; Appiah et al. 2014; Stow et al. 2016), we argue that this process is partly as a direct result of the incremental house building process that is common in towns and cities. By this incremental process, buildings could take several years, sometimes up to 10 years to complete, subject to the financial resources of households and developers (Yeboah and Obeng-Odoom 2010; Afrane and Asamoah 2011). Consequently, it is plausible that an area cleared initially for construction may remain undeveloped (i.e. urban-open-space) for several years. This may result in vegetation regrowth, or the area may be used for urban and peri-urban farming (see e.g. Asabere et al. (2018b)) until such a time that the construction is completed, and ultimately becoming built-up. Moreover, the sites of uncompleted 
structures (e.g. buildings at foundation levels) may regain their vegetation if left unattended for some years.

Furthermore, this study has revealed that in the last three decades, the landscape and environment in the metropolitan regions have fragmented. Landscape fragmentation is characterised by the breaking up of larger areas of natural land cover into smaller, isolated patches. The direct drivers of fragmentation include the construction of building and infrastructure such as roads and railway lines (Forman 1995; Jaeger et al. 2011). In this two case study metropolitan regions, the analysis show that fragmentation of the landscape has occurred at an increased expansion and aggregation of patches of built-up areas. For instance, in the historical-core zones of both ACR and GKSR, built-up area increased by the enlargement of its patches. Builtup land conversion in the suburban zone of ACR, and the peripheral zones in both metropolitan regions further intensified the fragmentation of newer, previously unbuilt areas. There were some striking differences between the environmental fragmentation of the ACR and that of the GKSR though. For instance, whereas the urban-open-space land cover class was the most fragmented in ACR, it was rather vegetation land cover in the GKSR. In addition, the outputs of all the four landscape metrics evidenced that the ACR has increased in fragmentation over the years. In the cases of the GKSR, however, the configurational metrics only clearly evidenced the fragmentation while the picture remained largely unclear for the compositional metrics. Even so, the analysis revealed that the degree of fragmentation for ACR was markedly higher than that of GKSR, as evidenced by the outputs of the edge density and landscape shape index metrics.

Finally, this study found noticeable relationships between the cumulative increase of built-up land and the degree of environmental fragmentation, as measured by the 
various landscape metrics. The impact was found across all areas in both ACR and GKSR. However, the results suggest that areas in ACR showed greater impact on vegetation and water of built-up land expansion compared to GKSR.

\subsubsection{Implications of the findings}

The spatio-temporal analysis and characterization of land cover and land use transformation presented in this study have implications for both theory and policy. The analysis has revealed a unique spatial transformation process by which urbanopen-spaces are in constant flux, mediating the transitions between vegetation and built-up land. As argued in the discussion section, this process is very much embedded in the informal practices that characterise physical development of towns and cities across Ghana, and of which the incremental development of housing is very important. These dynamics are very central to the emergent urban landscapes in Ghana and other regions of the Global South. Thus, the findings of this study provide deep insights and fundamental understanding into the spatial dimensions of the urbanisation process underway in these regions. Most importantly, they provide critical insights for theorizing the urbanisation process and for policy-oriented pursuits such as the development of decision-support systems to simulate the urbanisation process and to aid the design and implementation of sustainable growth management strategies.

Similar to other regions in the Global South, the fragmentation processes uncovered in this study is characterised by scattering, leapfrogging and sprawl. The evidence from previous studies show that fragmentation increases the 'patchiness' and shape complexity of the natural environment, and has direct consequences on the ecological functions and continuous supply of essential ecosystem services (Jaeger et al. 2011). In both metropolitan regions and their zones, our findings point to the increased fragmentation of vegetation, urban-open-space and water areas. As these areas are 
increasingly fragmented by conversion, division and reduction, they produce gradients of environmental effects that threaten the integrity of the ecosystem functions and services. Environmental stresses including loss of biodiversity, urban heat waves, flooding and poor air quality have been linked directly to fragmentation in different regions globally (Haase et al. 2012; Breuste et al. 2013; Elmqvist et al. 2013). Indeed, most of these problems have been reported for the metropolitan regions of this study in recent times, particularly in their main built-up areas (Cobbinah et al. 2017). Seasonal floods in the major cities within the ACR and GKSR (i.e. Accra and Kumasi) have intensified in recent years mainly as a result of vegetation removal, encroachment of wetlands and flood plains, and the overall increase in the degree of imperviousness (Amoako 2016; Owusu-Ansah 2016).

The aforementioned environmental problems that result from unfettered urban expansion and fragmentation of natural landscapes underpin key social issues such as environmental injustice, loss of livelihood, persistence of urban poverty, food insecurity, and exposure to extreme weather events, as well as particulate matter and noise pollution. Thus, policy strategies to avert unsustainable urban development outcomes are crucial. Indeed, the evidence show that unfettered urban expansion at the expense of the natural environment is partly due to the weak spatial planning and governance systems at the regional and local levels in Ghana (see e.g. Acheampong (2019)). By bringing together existing spatial and environmental governance regimes, as well as stakeholders including landowners and traditional authorities, is imperative for strengthening the land use planning system. Thus, such a system, which adopts integrative policy strategies would be crucial to the design and successful implementation of sustainable growth management strategies. 
In practice, the findings of this study also provide useful insight for growth management strategies. It is evident from the findings of this study that such strategies must identify and prioritize integrated spatial and environmental resource planning in the rural and peri-urban areas of the metropolitan regions. This is because, as the results show, these areas are the hotspots of built-up land expansion and environmental fragmentation. Flexible growth management strategies such as the designation and enforcement of urban growth and service boundaries could help ensure balancing the demand for land for housing, infrastructure and economic activities on the one hand, and the preservation of biodiversity and ecosystem services on the other hand. In existing built-up areas in the metropolitan regions' core, urban development planning should plan for and support land use intensification through mixed-use and high-density development supported by green infrastructure. In rural and peri-urban farming areas within the metropolitan regions, cluster-zoning strategies could be implemented through the spatial planning system. This policy tool could ensure that instead of sporadic development of housing, houses are concentrated in designated, planned and serviced areas, leaving the remaining land as open space or making it available for farming.

\subsubsection{Conclusions}

This study has systematically analysed and characterized land cover transitions and its spatio-environmental impacts within the two largest metropolitan regions of Ghana. The results show an increasing trend of outward urban expansion at the expense of the natural environment, resulting in the fragmentation of the landscape. Unfettered urban expansion at the rate uncovered in this analysis is unstainable and has serious implications for biodiversity preservation, continuous supply of essential eco-system services, livelihoods and public health. Thus, integrative growth management 
strategies that bring together spatial planning and environmental resource governance are crucial to avert these negative consequences. Sustainable growth management strategies in these metropolitan regions should prioritize rural and peri-urban areas and promote land use intensification and densification in the established core areas. 


\subsection{Study 2: Landscape Transformations in Rapidly Developing Peri- urban Areas of Accra, Ghana: Results of $\mathbf{3 0}$ years}

George Ashiagbor', Clifford Amoako', Stephen Boahen Asabere ${ }^{2}$, Jonathan QuayeBallard $^{1}$

\section{${ }^{1}$ Kwame Nkrumah University of Science and Technology (KNUST), Kumasi, Ghana ${ }^{2}$ Universität Göttingen, Institute of Geography, Department of Physical Geography, Göttingen, Germany}

- Manuscript is published in Open Geoscience as Ashiagbor et al. (2019). Landscape transformations in rapidly developing peri-urban areas of Accra, Ghana: results of 30 years. DOI: https://doi.org/10.1515/geo-2019-0014

\section{Abstract}

Beyond the loss of peri-urban agricultural and forested land as a result of built-up expansion, not much information exists on the changes in the structure of the periurban landscape in Ghana. The aim of this paper is to examine the extent to which urban expansion is driving changes in landscape structure of the peri-urban fringes of Accra. We submit that rapid peri-urbanisation will fragment the existing agricultural and forested landscape with consequent ecological, socio-economic and urban governance implications. Using Landsat satellite images for the years 1985, 1991, 2002 and 2015, the study area was classified into four land cover classes. The study adopted the use of Urban Intensity Index (UII) and the Annual Rate of Urbanisation (R) as measures of urbanisation. Edge density (ED), largest patch index (LPI) and Aggregation index (Al) were used as proxies to measure landscape structural transformations. The study reveals substantial reductions and fragmentation in agricultural lands, riverine and open forests, while there has been over 200 percent increase in built-up areas. Beyond these revelations in spatiotemporal changes in landscape structure, the paper points to the ecological implications of the changes, and three key socio-economic and urban governance implications.

Keywords: Urbanisation; Peri-urbanisation; Spatial metrics; landscape metrics; Ghana

\subsubsection{Introduction}

\section{Peri-urbanisation and land cover changes}

Over the last two decades, rapid urban explosion, expansion of megacities and secondary metropolitan areas have been discussed in the literature as a metonym of cities in the developing world (Oduro et al. 2014; Roy 2011). The growth in the city implies the land interface between the city and rural areas which comprises valuable forested patches, woodlands, major agricultural lands and important wetlands (Su et 
al. 2014; Lee et al. 2015), is put under immense pressure (Korah et al. 2017b; Kleemann et al. 2017). These peri-urban zones are transient and emergent rather than planned, creating challenging situations for policymakers (Liu et al. 2017; Hedblom et al. 2017).

The phenomenon of peri-urbanisation is complex, and it is characterised by structural changes in the composition and diversity of the peri-urban landscape, significantly rendering it fragile (Budiyantini and Pratiwi 2016; Castro et al. 2016; Roopawula and Bhatt 2017). The growth of urban areas into peripheries is recognised as the cause of loss of agricultural lands and the fragmentation of forests, wetlands and other natural habitats (Vizzari and Sigura 2015). For sustainable management of peri-urban landscape, and for the purposes of conservation, the understanding of landscape dynamics is imperative (Frondoni et al. 2011).

Within African cities, the spatial manifestations of urbanisation are observed in three main ways. Firstly, there is the emergence and concentration of informal socioeconomic and land use activities in the inner parts of the city without approval from city planning authorities (UN-Habitat 2004). Secondly, informal and unapproved settlements grow at "dangerous and ecologically sensitive areas such as floodplains, riverbanks, steep slopes, along railroad tracks, or near waste dumb" (Zhang 2006). The third spatial manifestation of urbanisation occurs at the fringes of cities (Cobbinah and Amoako 2012) and appears to be the most prevalent and difficult to manage and/or control (Butterworth et al. 2007), and hence the central theme of this paper. The main impacts of rapid urban expansion and peri-urbanisation discussed in the existing literature include: land cover and use changes (Cobbinah and Amoako 2012; Wadduwage et al. 2017); uncertainties in peri-urban land markets and tenure arrangements (Gough and Yankson 2000); changing land values (Owusu-Ansah and 
O'Connor 2010); creation of rural-urban interfaces (Simon et al. 2004); peri-urban morphology and typology (Cobbinah et al. 2015b; Budiyantini and Pratiwi 2016) and rural spatial planning (Poerwoningsih et al. 2016), just to mention a few. While periurbanisation is present in almost all African cities, Simon et al. (2004) explains that the process varies from city to city and has been differentiated by demographic patterns; land tenure and management; physical terrain and environmental barriers; and morphology of the city involved.

In Ghana, rapid urban expansion, sprawl, and peri-urbanisation are key features of major cities such as Accra, Tema, Kumasi, and Tamale (Korah et al. 2017b; Cobbinah and Aboagye 2017). Ubink (2006) suggests that most cities in Ghana are experiencing rapid sprawl with rising demand for residential, commercial and other urban land uses. In response to these demands, communal agricultural lands are gradually being lost to high-value urban uses, mainly residential, to the detriment of local agricultural livelihoods in rural-urban fringe communities (Cobbinah and Amoako 2012).

Beyond the loss of active agricultural lands and associated land use changes, not much is known about the changes in the structure of the peri-urban landscape. Quantifying the spatial and temporal characteristics of a peri-urban landscape is an important step in understanding the ecological implications and key socio-economic and urban governance implications of rapid urbanisation in the peri-urban zones. Within the background of urban sprawl, land use dynamics and their related structural changes, it is important to collate reliable information that will inform appropriate policies for the sustainable development of peri-urban zones and to safeguard its ecological integrity (Shen et al. 2017).

The aim of this paper is to examine the extent to which urban expansion is driving changes in landscape structure of the peri-urban fringes of Accra. In doing so, we 
submit that rapid peri-urbanisation will alter existing agricultural and forested landscapes into metropolitan and urbanised land uses with socio-economic and ecological consequences. We discuss; (1) some key socio-economic and urban governance implications; (2) the ecological implications, towards the building of sustainable peri-urban fringes in Ghana; and (3) The way forward towards a more sustainable peri-urban landscape development.

\subsubsection{Methodology}

\subsubsection{Study area}

In line with the aim of the study, the Ga West Municipal Assembly was selected. The Ga West Municipal Assembly is one of the fast-growing peri-urban regions of Accra, the capital of Ghana. It is located on the north-western part of the Accra Metropolitan Area (Figure 2.2.1). It lies within latitude $5^{\circ} 29^{\prime}$ to $5^{\circ} 35^{\prime}$ North and longitude $0^{\circ} 10^{\prime}$ to $0^{\circ} 24^{\prime}$ West. The population of the Municipality according to the 2010 population and housing census stands at 219,788, with 146,520 (66.7\%) migrants (born elsewhere in the Greater Accra Region or other regions in Ghana or outside Ghana) (Ghana Statistical Service 2014a). The major economic activities in the Municipality are agriculture, industry and commerce. The Ga West Municipal Area is also located within the Densu River Basin, making it a very important riparian zone. 


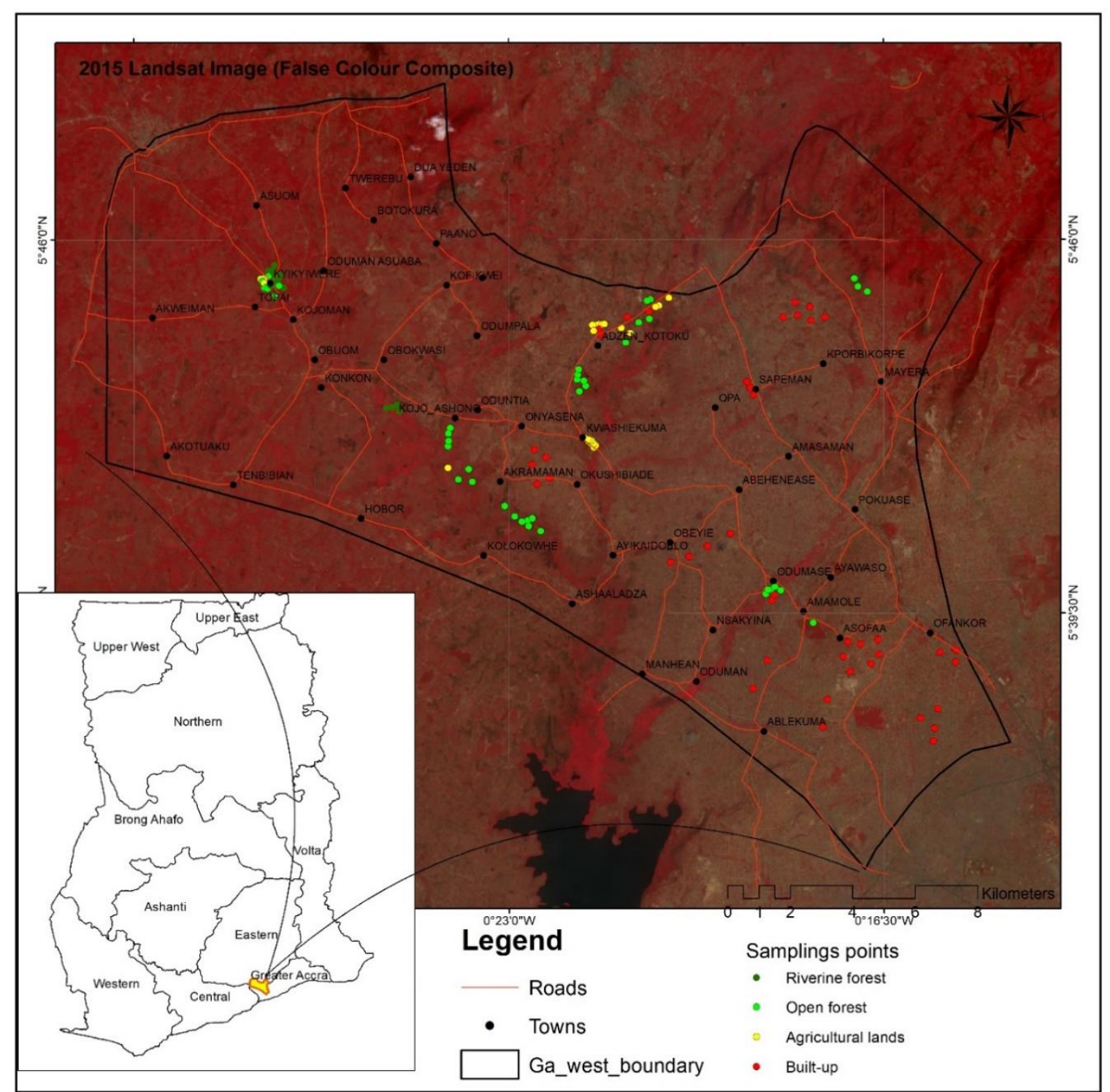

Figure 2.2.1: Ghana (insert) showing the 10 administrative regions (now 16 regions) and the location of study area: The Ga West Municipal Assembly.

\subsubsection{Land cover classification and change analysis}

Historical and current Landsat satellite images for the years 1985 (date: 1985-04-02), 1991 (date:1991-01-10), and 2015 (date: 2015-12-22) were acquired for the study. The images were selected based on availability and $0 \%$ cloud cover. Also, processing techniques e.g. extraction, layer stacking, and geo-referencing were performed on the images. All images were rectified to the same Universal Traverse Mercator (UTM) projection system. 
The GPS coordinates for image training and accuracy assessment were collected in the study area using a stratified random sampling technique. In every land cover, data at even distribution was randomly collected. Google Earth was used to complement referenced data during field observation for the classification and accuracy assessments. The maximum likelihood algorithm was chosen to classify all the images following Asubonteng (2007) and Afrane and Adjei-Poku (2013). The descriptions of the land cover classes are detailed in Table 2.2.1. Kappa and overall accuracies were selected to assess the accuracy of the classified images. Hundred validation GPS points were used in performing the accuracy assessment over the study area. Accuracy assessment for the historical images was performed using GPS points for areas of 'no change' based on local community knowledge.

Table 2.2.1: Description of land cover classes identified in the district.

\section{Land cover categories Descriptions}

Riverine Forest

This is mainly vegetation found along streams and

waterways within the study area. They are moist semideciduous forest and other high tree density patches with tree reaching heights of $15 \mathrm{~m}$.

Open forest Includes thickets and trees (forest trees and fruit trees) with tree heights ranging between $2 \mathrm{~m}$ to about $15 \mathrm{~m}$. The open forest class also includes tree based agriculture where food cropping continues.

Agricultural lands Annual food cropping, Agroforestry and pasture, herbaceous rangelands, grasslands and fallow lands, other agricultural land, Shrub and brush rangelands. Areas with buildings, infrastructure and bare lands. 
Table 2.2.2 shows report of the accuracy assessment for the land cover maps that were generated. The overall classification accuracy for the 2015 image is $88.54 \%$ with a kappa of 0.88 . The 2002, 1991 and 1985 land use maps respectively recorded overall accuracies of $79.28 \%, 86.70 \%$ and $82.58 \%$ with kappa $0.729,0.828$ and 0.782 respectively.

Table 2.2.2: Accuracy result of classified 2004 and 2016 images.

\begin{tabular}{lll}
\hline Land use land cover map & Overall Accuracy (\%) & Kappa statistics \\
\hline 1985 & 82.58 & 0.783 \\
1991 & 86.70 & 0.828 \\
2002 & 79.28 & 0.729 \\
2015 & 88.54 & 0.881 \\
\hline
\end{tabular}

\subsubsection{Analysis of urban expansion}

The Urban Intensity Index (UII) and the Annual rate of urbanisation (R) were chosen as proxies to measure the quantum land cover transformations and urban sprawl. These variables were chosen due to their wide usage and acceptance in similar studies carried out in the recent past (Mosammam et al. 2017; Jaeger 2017; Padmanaban et al. 2017). The UII and R indicate the spatiotemporal dynamics of urban expansion and significantly correlates with commonly used urbanisation indices, i.e. population density and percentage imperviousness. These two indices have been recorded and used to compare spatial differentiation of urban expansion per unit time to detect its evolution (Song et al. 2015). The UII and R for the study area were calculated for the periods: 1985-1991, 1991-2002, 2002-2015 and 1985-2015, using equations 1 and 2 .

$U I I=\frac{U L_{T 2}-U L_{T 1}}{n x T A}$ (Equation 1) 
$R=\sqrt[n-1]{\frac{U L_{T 2}}{U L_{T 1}}}-1$

(Equation 2)

Where, UL is the total urban land in target years T2 and year T1; $\mathrm{n}$ is the time period,

in years; and TA is the total area of landscape.

Consequently, regression analysis was employed to extrapolate the number of years of analysis for the quantum extent of urban expansion for the area. This was done for the year 2020, and a three-time decadal interval until 2050.

\subsubsection{Analysis of spatial patterns of urbanisation- computation of landscape metrics}

Due to the plethora of landscape metrics (LMs) in literature, it has become imperative to stick to one of two decisions a priori when using LMs (Uuemaa et al. 2013; Uuemaa et al. 2011). The first is to select a minimum set of indicators based on ex ante assumptions, and the second is to empirically determine this set of indicators statistically from the abundance of available indices. Sticking to both decisions, 25 landscape metrics were first calculated using the Fragstats software at the class level based on their applicability to this study (McGarigal et al. 2012). The metrics were calculated using the land cover maps and $8 \times 8$ cell rule for patch neighbours. The metrics were further subjected to a Pearson correlation analysis and those with strong correlation $(r>0.75)$ were exempted. This reduced the original number of LMs to 15 metrics that were later subjected to a principal component analysis (PCA) with Varimax and Kaiser Normalization rotations. The PCA revealed the presence of 8 landscape class metrics (keeping PCA factor loadings $>0.8$ ) which indicated a measure of class level/landscape aggregation (McGarigal et al. 2012). Largest patch index (LPI), Edge density (ED) and Aggregation index (AI) were selected from the eight because they were sufficient to quantify the spatiotemporal dynamics in 
landscape structure in the study area (Uuemaa et al. 2011). The selected metrics were also corroborated by other urban studies and found to be sufficient to analyse and extract quantitative information for measuring the dynamic spatial patterns of urban expansion (Larondelle and Haase 2013; Jain et al. 2011).

\subsubsection{Results}

\subsubsection{Spatio-temporal analysis of the urban expansion}

From Table 2.2.3, the period between 1985 and 1991 saw built-up area extending by $13.92 \mathrm{~km}^{2}$ with an annual expansion rate of $2.32 \mathrm{~km}^{2}$ year-1 and Ull value of $0.91 \%$. In 11years, from 1991 to 2002, built-up areas extended by $72.54 \mathrm{~km}^{2}$ with an annual expansion rate of $6.59 \mathrm{~km}^{2}$ year-1 and a UII of 2.58\%. Between 2002 and 2015, builtup land increased by $63.43 \mathrm{~km}^{2}$ with an annual expansion rate of $4.88 \mathrm{~km}^{2}$ year $^{-1}$ and a UII value of $1.91 \%$. Although urban expansion in the region has increased consistently, the epoch between 1991 and 2002 was the highest of all urban expansion indices.

Table 2.2.3: Spatio-temporal analysis of urban expansion in the Ga West district of Ghana.

\begin{tabular}{|c|c|c|c|}
\hline Change Period & Spatial extent $\left(\mathbf{k m}^{2}\right)$ & Annual expansion rates $\left(\mathrm{km}^{2} / \mathrm{y}\right)$ & UII \\
\hline $1985-1991$ & 13.92 & 2.32 & 0.91 \\
\hline $1991-2002$ & 72.54 & 6.59 & 2.58 \\
\hline $2002-2015$ & 63.43 & 4.88 & 1.91 \\
\hline $1985-2002$ & 86.46 & 5.09 & 1.99 \\
\hline $1991-2015$ & 135.98 & 5.67 & 2.22 \\
\hline $1985-2015$ & 149.90 & 5.00 & 1.96 \\
\hline
\end{tabular}

Projections of built-up expansion as depicted in Figure 2.2.2 show built-up increment to $186.6 \mathrm{~km}^{2}$ by 2020 , which will consequently reach $343.5 \mathrm{~km}^{2}$ by 2050 . Hence, urban expansion is expected to constitute about $96 \%$ of the land cover in the district by 2050 . 
This translates into an average annual expansion rate of $5.2 \mathrm{~km}^{2}$ year'-1, which is greater as compared to the 2002-2015 epoch, but still lower as compared to 1991 2002 epoch. On the average, urban expansion from 1985 to 2015 is comparable to the predictions for 2015 to 2050 with approximately $5 \mathrm{~km}^{2}$ year ${ }^{-1}$ added annually for 35 years for each respective period.

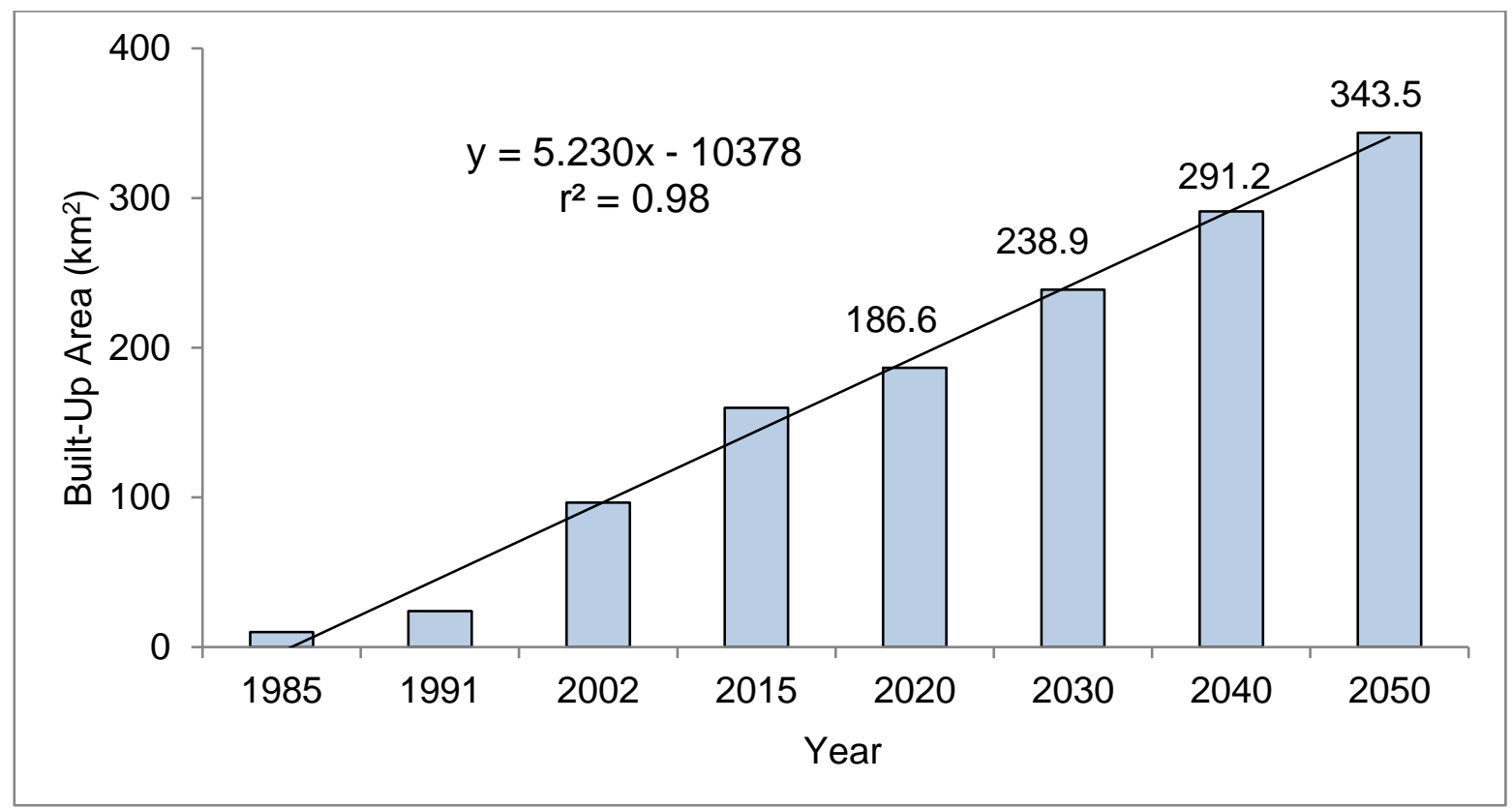

Figure 2.2.2: Projected trend of urban expansion from 1985-2050.

\subsubsection{Spatio-temporal transformations in land use land cover and}

\section{landscape structure}

The study revealed noticeable changes in Land use Land cover (LULC) in the Ga West Municipal area over the study period. Depicted in Figure 2.2.3 and Table 2.2.4, riverine forest, open forest and agricultural lands dominated the 1985 landscape at extents of $97.79 \mathrm{~km}^{2}, 174.29 \mathrm{~km}^{2}$ and $66.3 \mathrm{~km}^{2}$, respectively. By 2015, these areas had substantially reduced to $39.74 \mathrm{~km}^{2}, 88.45 \mathrm{~km}^{2}$, and $60.29 \mathrm{~km}^{2}$, respectively for the riverine forest, open forest and agricultural lands. In contrast, built-up areas increased exponentially at the expense of these land cover types over the same period, from $12.40 \mathrm{~km}^{2}$ in 1985 to $161.52 \mathrm{~km}^{2}$ in 2015 (Table 2.2.3). 


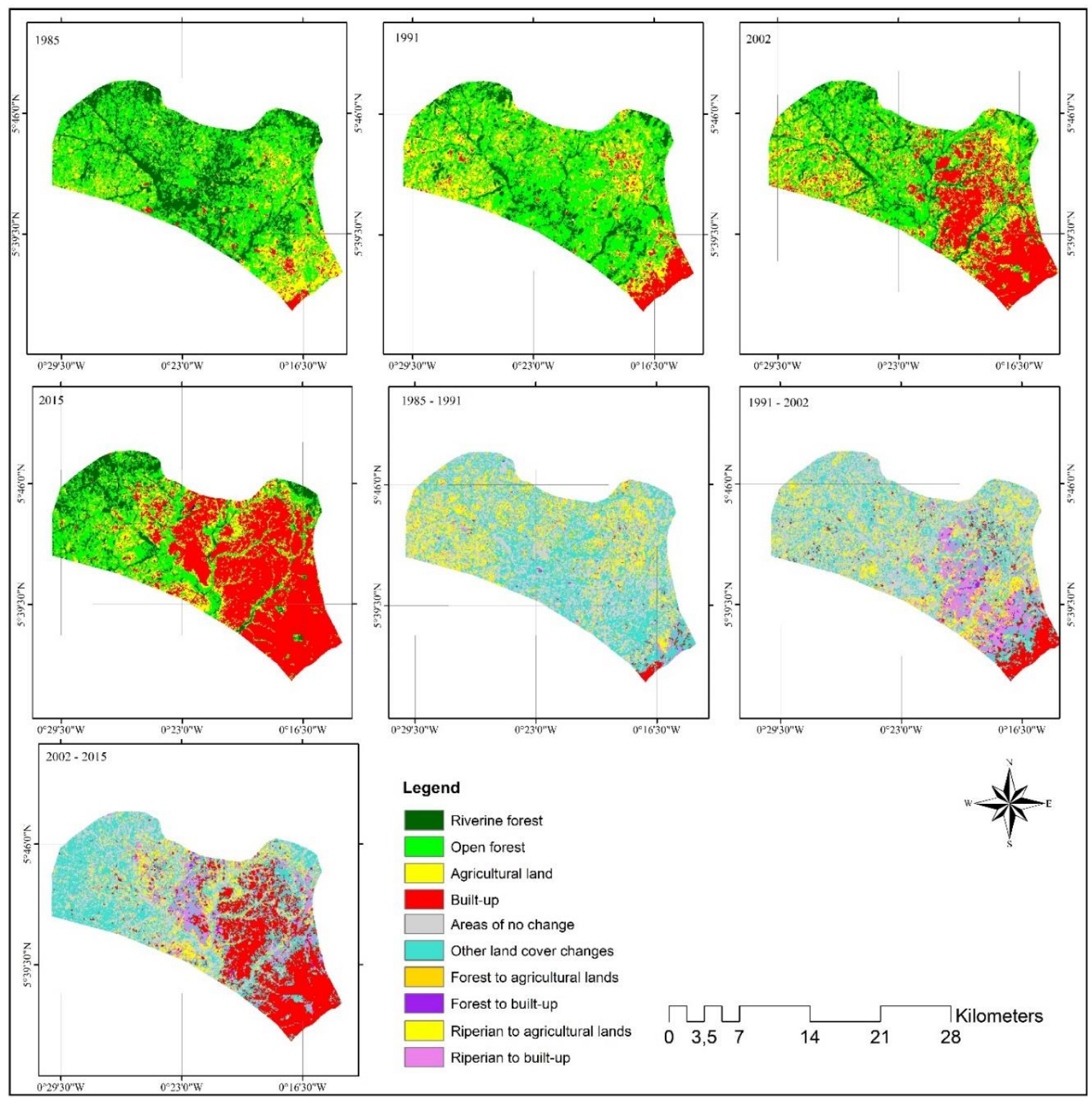

Figure 2.2.3: Changes in land use land cover in the Ga West Municipality from 1985 to 2015. 
Table 2.2.4: Changes in LULC and landscape indices from 1985 to 2015.

\begin{tabular}{lllll}
\hline Landscape Structural Indices & $\mathbf{1 9 8 5}$ & $\mathbf{1 9 9 1}$ & $\mathbf{2 0 0 2}$ & $\mathbf{2 0 1 5}$ \\
\hline Riverine forest area $\left(\mathrm{km}^{2}\right)$ & 97.79 & 48.97 & 37.52 & 39.74 \\
Open forest area $\left(\mathrm{km}^{2}\right)$ & 174.29 & 186.35 & 124.25 & 88.45 \\
Agricultural land area $\left(\mathrm{km}^{2}\right)$ & 66.33 & 89.14 & 90.14 & 60.29 \\
Built-up area $\left(\mathrm{km}^{2}\right)$ & 12.40 & 26.37 & 97.80 & 161.52 \\
Largest Open forest Patch Index (\%) & 23.92 & 27 & 12.62 & 5.89 \\
Largest Riverine forest Patch Index (\%) & 4.87 & 0.9 & 0.61 & 2.73 \\
Largest Agricultural land Patch Index (\%) & 3.14 & 2.06 & 2.09 & 0.51 \\
Largest Built-up Patch Index (\%) & 0.27 & 2.02 & 6.11 & 18.31 \\
Edge density of Open forest (m ha-1) & 67.23 & 56.84 & 49.8 & 35.52 \\
Edge density of Riverine forest (m ha-1) & 37.59 & 21.53 & 17.11 & 15.48 \\
Edge density of Agricultural land (m ha-1) & 34.75 & 42.57 & 50.31 & 37.3 \\
Edge density of Built-up (m ha $\left.{ }^{-1}\right)$ & 4.5 & 7.92 & 23.79 & 21.97 \\
Open forest Aggregation index (\%) & 80.83 & 84.86 & 80.06 & 80.07 \\
Riverine forest Aggregation index (\%) & 80.95 & 78.26 & 77.52 & 80.68 \\
Agricultural land Aggregation index (\%) & 74.01 & 76.32 & 72.31 & 69.35 \\
Built-up Aggregation index (\%) & 78.01 & 83.58 & 87.83 & 93.21 \\
\hline
\end{tabular}

Consistently, the edge density (ED), largest patch index (LPI) and aggregation index (Al) indicated that forest, riparian vegetation and agricultural lands have all changed in composition and structure during the study period in response to built-up expansion (Table 2.2.3). Built-up ED increased more than four times from $4.5 \mathrm{~m} \mathrm{ha}^{-1}$ in 1986 to $21.9 \mathrm{~m} \mathrm{ha}^{-1}$ in 2015 . ED is a measure of the breaking or consolidation of land cover patches, and thus gives quantitative information on both the composition and configuration. LPI is also a measure of landscape composition, and thus demonstrates 
the dominance of a particular land cover type. The built-up LPI increased exponentially from $0.27 \%$ to $18 \%$ between 1985 and 2015 . The increased dominance of the built-up land cover type was further observed in $\mathrm{Al}$, which consistently increased from $78 \%$ to 93\% between $1985-2015$.

As built-up dominated the district's landscape as the years progressed, other land cover types became fragmented by breaking into smaller isolated patches and eventually diminishing in size. Agricultural lands increased in ED values from $34.7 \mathrm{~m}$ $\mathrm{ha}^{-1}$ in 1985 and peaked at $50.3 \mathrm{~m} \mathrm{ha}^{-1}$ in 2002 and then reduced drastically to 37.3 $m \mathrm{ha}^{-1}$ by 2015 . Such an increase and eventual decrease in ED is an indication of anthropogenic disturbance. This general reduction trend was also observed in LPI (from $3.1 \%$ to $0.5 \%$ ) and $\mathrm{Al}(74 \%$ to $69 \%$ ) values within the same change period. Open and riverine forests consistently reduced in ED by almost half of its original values in 1985. That is ED for open forest lands decreased from $67.23 \mathrm{~m} \mathrm{ha}^{-1}$ to $35.52 \mathrm{~m} \mathrm{ha}^{-1}$, and riverine forest also experienced a similar decline from $37.59 \mathrm{~m} \mathrm{ha}^{-1}$ to $15.48 \mathrm{~m} \mathrm{ha}$ 1. Generally, a decrease in ED is an indication of less fragmentation and stability of patches, however, in this instance, it is an indication of increased isolation of vegetation patches and consequent loss of land to built-up. The reduced dominance was observed in LPI, which decreased from $23.9 \%$ to $5.8 \%$ in open forests, and from $4.8 \%$ to $2.7 \%$ in riverine forest in the same study period. Al values were fairly constant for both open and riverine forest, a further indication of integrated isolated patches. Also, as shown in Table 2.2.5, open forest lands generally converted into agricultural lands during the 30 years change period. Between 1985-1991, $48.86 \mathrm{~km}^{2}$ of open forest was converted to agricultural lands. Subsequently, from 1991 to 2002, as the spatial extent of the built-up area increased, $47.69 \mathrm{~km}^{2}$ of open forest lands were 
further converted to agricultural lands. The periods between 2002 and 2015, showed $28.84 \mathrm{~km}^{2}$ of open forest lands converted to agricultural lands.

Table 2.2. 5: LULC class transition matrix from 1985 to 2016.

\section{Area $\left(\mathbf{k m}^{2}\right)$}

\section{Riverine forest Open forest Agricultural land Built-up land}

\begin{tabular}{lllll}
\hline & \multicolumn{5}{c}{$\mathbf{1 9 8 5 - 1 9 9 1}$} & \\
Riverine forest & 24.48 & 57.30 & 14.70 & 1.28 \\
Open forest & 19.82 & 98.43 & 48.86 & 7.18 \\
Agricultural land & 4.04 & 27.37 & 22.94 & 11.96 \\
Built-up land & 0.63 & 3.22 & 2.64 & 3.49 \\
& & $1991-2002$ & & \\
Riverine forest & 20.20 & 19.30 & 5.20 & 4.24 \\
Open forest & 14.54 & 82.25 & 47.69 & 41.84 \\
Agricultural land & 2.47 & 21.57 & 34.30 & 30.81 \\
Built-up land & 0.27 & 1.12 & 2.97 & 19.56 \\
& & $2002-2015$ & & 3.81 \\
Riverine forest & 15.43 & 13.59 & 4.66 & 31.36 \\
Open forest & 18.22 & 45.80 & 28.84 & 40.88 \\
Agricultural land & 5.51 & 24.57 & 19.18 & 83.83 \\
Built-up land & 0.55 & 4.47 & 7.59 & \\
\hline
\end{tabular}

\subsubsection{Discussion}

\subsubsection{Landscape transformations in the Ga West Municipal Assembly}

Over the entire period, the Ga West Municipality have experienced profound development in urban built-up areas exerting pressure on agricultural lands, as well as riverine and open forests lands. Though some changes in land cover were 
expected, the rate and proportions over the thirty-year period present an overwhelming urban expansion rate around Accra. Earlier studies on urbanisation in the Accra Metropolitan Area (AMA) have pointed to rural to urban migration, increasing population densities, housing demands and the growth of informal settlements as reasons for the transformation (Owusu-Ansah and O'Connor 2010).

Several reasons may have accounted for the rapid urbanisation observed in the district. The effect of peri-urban migration as a result of population spill over from neighbouring Accra. The population of Accra grew from 969,195 in 1984 to 1,665,086 in 2014 at $4 \%$ per annum as against a national population growth of about $2.6 \%$ per annum (Yankson and Bertrand 2012). The growth in the population of Accra forced more people to settle in neighbouring municipalities to commute daily to the capital for business. As depicted in the results, built-up expanded from the southern part of the district which is where it borders with the AMA. As discussed by Doan and Oduro (2012) and Yankson and Bertrand (2012), the exponential population growth in the AMA has strongly influenced neighbouring residential towns such as Madina and Gbawe, converting them into remote business districts that have also become hotspots for urban expansion independent of the AMA. The results of this study support such a phenomenon as the capital of the district (Amasaman) has eventually become a peri-urban hotspot for urban expansion within the vicinities of AMA.

The extension of urbanisation trend beyond Accra is accelerated not only by population pressure but also the availability and easy accessibility to the Accra-Kumasi transportation corridors passing through the study municipality (Doan and Oduro 2012). Urban expansion in Ghana and in most African cities has been demonstrated to happen along major road networks (Doan and Oduro 2012). For instance, Doan and Oduro (2012), observed that about $90 \%$ of urban residents in the Greater Accra 
metropolitan region of Ghana were within $4 \mathrm{~km}$ of the trunk roads. Thus, it is plausible that since the Accra-Kumasi trunk road passes through the study area, it is also another way for urban expansion in the district.

In this study, built-up areas expanded into forest and agricultural lands through complete removal of these vegetated areas. As the district continuously receive population spill-over from Accra metropolitan area, land sources of rural livelihood are converted to urban residential areas. Consistent with observations elsewhere in Ghana (Cobbinah et al. 2015b; Cobbinah and Amoako 2012), the high demand for residential housing leads to encroachment of pristine areas like riparian zones. These together with other associated factors such as road network extension and densification led to the observed fragmentation of the fairly connected agricultural and forested peri-urban landscapes in the Ga-West District.

\subsubsection{Socio-economic and urban governance implications of peri-}

\section{urban landscape transformations in Ghana}

The rapid urban expansion over the last thirty years of the Ga West Municipality as revealed by this study points to three key socio-economic and urban governance implications. These implications can be seen and discussed under the following frames of change: (a) community assets and livelihood changes, (b) socio-cultural and value change systems; and (c) urban planning and development management changes.

In the first frame of change, a physical and participatory observation of the communities in the results revealed a transformation of agricultural related activities to small scale industrial, service or commercial activities. Thus, it is deduced that land resources have rapidly reverted from communal ownership held in trust by customary leaders to private ownership; as they have been transferred from agricultural lands to 
residential and industrial properties (built-up). While these appear to alienate indigenes of the area from the collective ownership of their land resources, many of these communities appear to have opened up, with the creation of menial urbanised employment opportunities. As a result, increasing proportions of residents of these communities that were visited were engaged in non-agricultural sectors as their main employment while holding on to the less dominant agricultural sector on a subsistent basis.

The second frame of change points to continuously reduced power of local and traditional decision-making structures. Local chiefs who, hitherto, were the custodians of land resources, in trust for their people are gradually losing grip of the socio-cultural structure of their communities. Substantial proportions of community land resources are now in the hands of private individuals, groups and institutions who have used various processes- approved and unapproved - to obtain and developed them for various purposes. These private individuals who are mostly non-indigenes, having paid for their acquired land, owe no socio-cultural allegiance to the customary set-up. Hence, they do not participate in any communal activities which used to define these affected peri-urban communities. Hence, rapid urbanisation and changes in land use cover have not only had spatial implications for the Ga West Municipality, they have also shaped the current socio-cultural settings of the municipal area.

The two change frames above have shaped the existing urban planning and land management processes - which forms the third implication of the spatiotemporal analysis presented in this study. The rapid urban expansion and peri-urbanisation of Ga West Municipal area present major urban planning and land management challenges between the Accra Metropolitan and the Ga West Municipal Assemblies. For instance, the rapid growth between the two assemblies appears to have blurred 
their boundaries and made development control difficult. As a result, land management and administration for both customary and state institutions between the two local government areas have faced challenges of corruption, uncertainties in acquisition processes, and multiple sales of land to different prospective developers. In many cases, these have led to various conflict situations. There are many such land disputes lodged at various courts in Accra which have taken years to be resolved. Thus, beyond the identification and quantification of LULC changes, peri-urbanisation is key socio-economic, cultural and political issue yet to be properly resolved.

\subsubsection{Ecological implications of peri-urban landscape transformations}

The peri-urbanisation phenomenon is a significant land use planning and management issue that impacts significantly on the ecological function of the landscape. There is increasing consensus among scholars that, ecological implications of landscape transformations should be brought into land use decisions to mitigate environmental degradation and resource misallocation (Du and Huang 2017). Generally, the natural peri-urban ecosystem provides various resources, services, and benefits to local population and wildlife community. However, in the midst of the massive transformations observed in the study landscape, humans have neglected the ecosystem services value which implies a diminished provision of ecosystem services and environmental quality.

Important ecological benefits of the peri-urban green infrastructure are largely related to the provision of habitat, maintenance of biodiversity, improving air quality, climate change and adaptation responds, and the regulation of urban climate etc. As the periurban landscape is increasingly fragmented into more numerous but smaller remnant patches, it produces a gradient of habitat loss. These and associated habitat loss is, considered a threat to biodiversity and ecosystem function which impacts greatly on 
local climate (Buczkowski and Richmond 2012; McKinney 2002; Ricketts and Imhoff 2003). It also alters the biogeochemical cycles and decreases native biodiversity (Barrios 2007). Biodiversity - the underpinning ecological processes that create ecosystem services - is essential in the co-production processes that link the biophysical stocks in ecosystems to human well-being and plays an important role in the global carbon cycle (Hamann 2016). Therefore, the consequent biodiversity loss as a result of the landscape fragmentation observed in the study landscape is a major worry. The loss in biodiversity will also affect the flow of ecosystem services and amongst these services is the role of sequestration of greenhouse gases and climate regulation (Perrings 2010).

\subsubsection{Conclusions}

Using the analysis of satellite remote sensing data, it is evident that urban expansion over the last thirty years of the Ga West Municipality has been rapid. The Ga West Municipality has experienced profound development in urban built-up areas exerting pressure on agricultural lands, riverine and open forests i.e. the green infrastructure of the peri-urban landscape. This increasing dominance of built-up further observed with progressing years, compelled other land cover types to become fragmented by breaking into smaller isolated patches and eventually diminishing in size. Vegetation lost is likely to be intensified if sustainable management interventions are not implemented to safeguard the catchment. A critical analysis of the spatiotemporal changes and the landscape structure revealed fragmentation in forest and agricultural land cover and in some cases, and complete removal other cases. These growing influence of the city on the agricultural and forested lands in the peri-urban fringe as discussed has significant implications on socio-economic and urban governance; and the ecological integrity of the landscape. 
Citizens disregard for urban planning and building regulations, and the existence of a dual urban land market system dominated by customary, indigenous and private actors, operating without the approval of the state's land use planning and administration system are the main reasons that have contributed to the lost and fragmentation of vegetation cover of the peri-urban landscape. As in the case of many African cities, this brings into focus an immediate need for urban land use planning and policy intervention to control the rate of physical expansion and vegetation lost around the Accra metropolis. In the face of plural and/or complex institutional and regulatory framework for land management, wanton disregard for land laws and regulations, uncontrolled peri-urbanisation; urban land use planning has been considered as weak and struggling to keep pace with land use and land cover changes around the city. In order to address this challenge, urban land use planning must reexamine: a) the powers and practices of customary land ownership and b) institutional and legal frameworks for public land administration and land use planning regimes. 


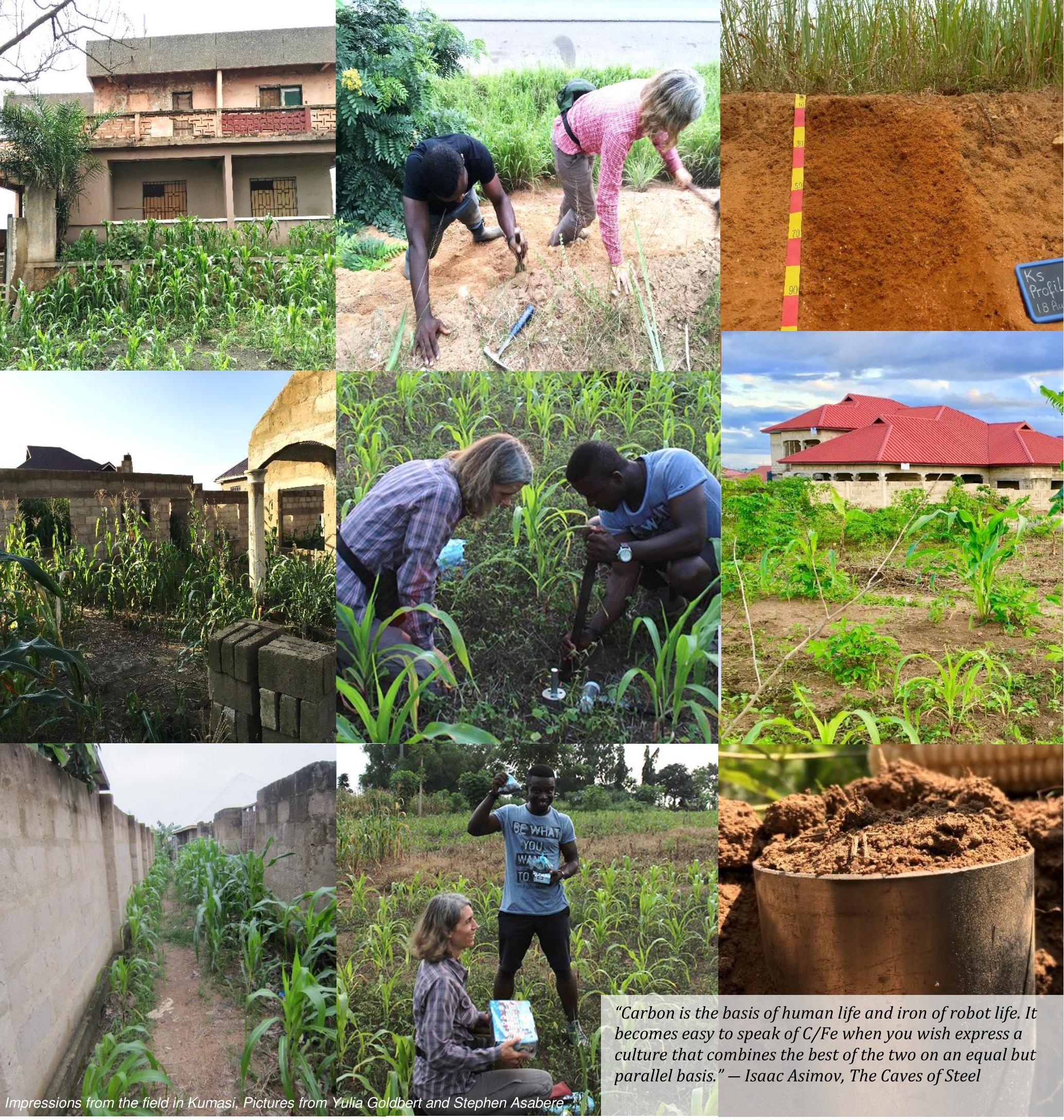

\section{CHAPTER 3: URBANISATION INFLUENCE ON URBAN ARABLE SOILS}


This chapter presents three studies. For these, we investigated the environmental effects of rapid urbanisation in Kumasi on some important soil fertility properties of urban arable fields. It will be shown that in all the three studies, key soil fertility indicators for tropical soils such as soil organic matter contents, soil $\mathrm{pH}$, effective cation exchange capacity and soil phosphorus contents of the urban arable soils were increased with urbanisation. Based on these findings, calls to differentiate the role of urban soils and to integrate the management of urban arable fields in city administration was made for Kumasi, and other Ghanaian and West African cities like it.

\subsection{Study 3: Urbanisation leads to increases in $\mathrm{pH}$, carbonate and soil organic matter stocks of arable soils of Kumasi, Ghana (West Africa)}

Stephen Boahen Asabere', Thorsten Zeppenfeld ${ }^{1}$, Kwabena Abrefa Nketia ${ }^{1,2}$, Daniela Sauer'.

\section{${ }^{1}$ Department of Physical Geography, Institute of Geography, University of Goettingen, Göttingen, Germany \\ ${ }^{2}$ Council for Scientific and Industrial Research, Soil Research Institute, Kumasi, Ghana}

- Manuscript is published in Frontiers in Environmental Science as Asabere et al. (2018). Urbanisation leads to increases in $\mathrm{pH}$, carbonate and soil organic matter stocks of arable soils of Kumasi, Ghana (West Africa). DOI: https://doi.org/10.3389/fenvs.2018.00119

- An abstract based on the manuscript is published in Geophysical Research Abstracts as Asabere et al. (2018). Influence of urbanisation on $\mathrm{pH}$, carbonate and soil organic matter stocks of arable soils of Kumasi (Ghana). [Online] Available at:

//meetingorganizer.copernicus.org/EGU2018/EGU2018-10454-1.pdf. 


\begin{abstract}
Tropical soils typically have low cation exchange capacity and nutrient contents. Both are enhanced by soil organic matter (SOM), which is thus particularly important for the fertility of these soils. In this study, we assessed the influence of urbanisation on SOM, carbonate contents and $\mathrm{pH}$ of arable soils of Kumasi (Ghana, West Africa), since rapid urban sprawl is widespread in West Africa, whereby in many West African cities urban farming is pivotal to the food security of their population. Based on satellite imagery for the year 1986, we defined long-term and short-term urban arable soils, whereby long-term urban soils were urban already in 1986 (thus $\geq 30$ years, as soil sampling took place in 2016), and short-term urban soils became urban afterwards (<30 years). We took 618 undisturbed topsoil samples $(0-10 \mathrm{~cm})$ from 206 urban arable fields. The factors land-use (maize fields) and soil (Ferric Acrisols) were kept largely constant. The fine-earth was analysed for $\mathrm{pH}$ (water), carbonate contents, loss on ignition (LOI), total C (TC) and N (TN). SOM contents were obtained from LOI (SOMLOI). All element contents were transformed to bulk soil element stocks per $\mathrm{m}^{2}$. Differences between short-term and long-term urban soils were identified by a set of linear mixed models. Coarse fragments were more abundant in the long-term (16\%) compared to the shortterm $(10 \%)$ urban soils, because of solid municipal waste that accumulates over time in urban soils. TC and SOMLo concentrations of the fine earth, $\mathrm{pH}$ and $\mathrm{C} / \mathrm{N}$ ratios were all significantly higher in the long-term urban soils. SOC concentrations in the fine earth, as well as bulk soil stocks of TC, SOC and SOMLo were also higher in the longterm urban soils, but at a lower degree of confidence, due to variable bulk densities and contents of coarse fragments. We conclude that dumping of organic and inorganic waste (including ash, bones, egg shells, concrete and mortar) increases SOM stocks and soil $\mathrm{pH}$, but also leads to accumulation of non-degradable solid materials (including plastic, metals etc.). These findings point to the need of an improved urban waste management system, separating degradable and non-degradable waste.
\end{abstract}

Keywords: urbanisation; Ghana; West Africa; tropical soils, urban farming; soil organic matter; soil pH; household waste

\title{
3.1.1 Introduction
}

Soil organic matter (SOM) plays a vital role in soil fertility, biogeochemical cycling and mitigation of climate change (Lal and Augustin 2012; Lal 2004). For instance, SOM strongly influences soil fertility, because it is a major source of multiple plant nutrients (such as $\mathrm{C}, \mathrm{N}, \mathrm{P}$ and exchangeable bases) and hence plays a key role for element cycling in the soil-plant system (Brady and Weil 2017; Blume et al. 2016). SOM also provides energy and habitat for soil fauna, whose activity further enhances soil quality indicators such as soil structure and nutrient availability amongst others (Brock et al. 
2017; Magdoff and Weil 2004). SOM moreover conditions the soils' texture and porosity, thereby improving water and nutrient retention as well as resilience of soils against mechanical stress (Brady and Weil 2017; Brock et al. 2017; Lal 2004). Additionally, dynamics of SOM make soils sources or sinks of atmospheric $\mathrm{CO}_{2}$ (Heitkamp et al. 2012). Hence, the quantity and quality of SOM is a vital indicator of soil quality and soil functioning (Brock et al. 2017).

It is thus of utmost importance to properly manage SOM stocks in soils to ensure crop production, particularly for nutrient-poor tropical soils (Lal 2004). It is well recognized that continued cultivation without sufficient fertilizer input leads to decline of SOM and nutrient supply in tropical soils (Zingore et al. 2008; Bationo et al. 2007; Zingore et al. 2007). In this regard, inherently low soil fertility and depletion of nutrients are identified as major constraints to agriculture in sub-Sahara Africa (Sanchez et al. 1997). For instance, Stoorvogel and Smaling (1990) and Stoorvogel et al. (1993) calculated negative nutrient balances for arable fields in sub-Sahara Africa in the 1980s. Bationo et al. (2007) estimated a mean annual loss of $2-5 \%$ soil organic carbon (SOC) in cultivated soils of West Africa. Application of manure or compost as well as mulching have been identified as pivotal to proper SOM stock management in most tropical arable soils of sub-Sahara Africa (Bationo et al. 2007). Boateng et al. (2006) and Zingore et al. (2008) demonstrated that maize yields increased in response to manure application in Zimbabwe and Ghana. Both studies reiterated the findings of Bationo and Mokwunye (1991) and Bationo et al. (2004), who pointed to the benefit of applying manure to tropical arable fields in sub-Sahara Africa, which enhances multiple soil quality indicators. An increase in SOM stocks thus leads to increased agricultural yields and enhanced functioning of tropical soils as carbon sinks, even at low carbon sequestration rates (Lal 2004; Lopez-Ulloa 2006). 
There are thresholds of SOC concentrations beyond which tropical soils may fail to provide basic ecosystem functions (Lal 2004). Aune and Lal (1997) estimated the threshold of SOC concentration for productive maize fields in the tropics at $1.1 \%$. Yet, it has been a major challenge to increase SOM concentrations of tropical soils. This difficulty is partly attributable to tropical climatic conditions that reduce the residence time of SOM (Amundson 2001). Unlike their temperate counterparts, humid-tropical ecosystems feature temperature and precipitation regimes that enhance the biological, physical and chemical breakdown of SOM (Amundson 2001; Kirschbaum 2000). Amundson (2001) calculated a mean SOM residence time of five years in moist tropical soils compared to 9-14 years residence time in temperate regions, thus, suggesting a faster SOM turnover in tropical ecosystems that is relatively more sensitive to environmental changes, including land-use changes (Lopez-Ulloa 2006). As a global phenomenon, urbanisation is one of the major types of land-use changes. However, its direct influence on SOM stocks of tropical soils is still largely unknown. The influences exerted by the agents of urbanisation such as housing, commerce, traffic, construction and waste, amongst others, differentiate soils in cities from soils in natural, semi-natural and agricultural areas (Lorenz and Lal 2009; Lehmann and Stahr 2007). For instance, soils in cities have developed from anthropogenic parent material and under the influence of the urban island heat effect (Sauer and Burghardt 2006; Lorenz and Lal 2009; Pouyat et al. 2010). Urbanisation may moreover lead to compacted, polluted and sealed soils due to construction and infrastructure development (Lehmann and Stahr 2007). Such extreme anthropogenically altered soils need to be distinguished from soils that even in urbanised areas do not necessarily turn into artificialized soils, which may e.g. underlie urban green infrastructure such as parks, forests and arable fields (Edmondson et al. 2014; Joimel 
et al. 2016). With more than half of the global human population already living in urban environments, functions of urban soils that underlie the provision of various ecosystem services have been investigated in several studies (Baveye et al. 2016). Ecosystem services such as microorganism habitat and carbon sequestration services may be enhanced in urban soils (Liu et al. 2018; Lorenz et al. 2006; Lorenz and Kandeler 2005; Pouyat et al. 2002). Conversely, contamination of urban soils by heavy metals may endanger their potential for the provision of some ecosystem services (Cardoso 2014; Imperato et al. 2003; Anikwe 2002). Waste from households and industry is regarded as one of the key agents of urbanisation that may alter soil properties (Bouma 2016), including enhancement of ecosystem services provision and contamination of urban soils as mentioned above. Against this background, it has been proposed to harness the potentials of organic household waste as compost, particularly for cities in the global south (Drechsel and Kunze 2001). However, many of the interrelations between urbanisation and soil functioning remain unclear (Lorenz and Lal 2009; Byrne 2007), especially for cities in West Africa.

Urbanisation in Ghana like elsewhere in Africa has been associated with unsustainable features such as rapid population growth, extensive land assimilation, environmental degradation and inadequate waste disposal systems (Cobbinah et al. 2015a; Pacione 2009). In particular, rapid urbanisation in Africa has been demonstrated to proceed at the expense of agricultural land (Vermeiren et al. 2013). Still, urban agriculture has persisted and continues to provide food and employment for about 20 million people in West-African cities alone (Drechsel and Dongus 2010; Cofie et al. 2003). These urbanisation features eventually affect stocks of SOM and nutrients directly or indirectly through mechanical and/or chemical disturbance, changed management, environmental changes and pollution (Pouyat et al. 2010; 
Lorenz and Lal 2009). The increased demand on land due to rapid urbanisation has intensified urban agriculture in West African cities (Vermeiren et al. 2013; McGregor et al. 2011). This situation directly affects the dynamics of SOM and nutrients, as fallow periods that are typically needed to balance nutrients in tropical soils drastically decreased (Lal 2004; Bationo et al. 2007). Some urban farmers have responded by irrigation and higher fertilizer inputs, while others continue to depend on rain-fed agriculture with little or no fertilizer inputs, as reported for the city of Kumasi in Ghana (Drechsel 2002; McGregor et al. 2011). Such different management schemes may result in different SOM stocks and nutrient dynamics, especially under a rapidly increasing urban influence. Yet, there is very limited knowledge on how urbanisation is changing the properties of tropical arable soils in West Africa.

Few studies have analysed the nutrient levels of arable soils in some sub-Sahara African cities (Bellwood-Howard et al. 2015; Drechsel 2002). However, they are largely inconclusive on the exact role of urbanisation for these soils. For instance, BellwoodHoward et al. (2015) attributed the observed different soil fertility trends of arable soils of Ouagadougou (Burkina-Faso) and Tamale (Ghana) to their differences in climatic conditions and fertilizer application, which may be independent of the urbanisation process in the respective cities. To our knowledge, no study has yet specifically analysed the role of urbanisation for SOM stocks in tropical arable soils of West Africa. Therefore, in this study we systematically investigated SOM contents and stocks of arable soils of Kumasi in Ghana, West Africa. The aim of this work was to understand the potential of tropical urban soils to support food production, which is an important provisioning ecosystem service of urban soils in Ghana, as well as in West-Africa as a whole. We analysed $\mathrm{pH}$, carbonate and SOM concentrations of arable soils that had been in an urbanised environment for different periods in time $(<30$ years versus $\geq 30$ 
years). Contents of heavy metals and exchangeable cations were analysed as well but are not in the focus of this article. This systematic approach considerably advances the knowledge on the potential of tropical soils for the provision of ecosystem services in West-African cities.

\subsubsection{Materials and methods}

\subsubsection{Study area}

Kumasi (Figure 3.1.1) is the second largest city in Ghana (after Accra, the capital) in terms of population and socioeconomic functionality. Unlike Accra, Kumasi is known for the production of considerable amounts of staples and vegetables in its core and peripheral areas (Drechsel et al. 2007). There are estimates that two out of three households in Kumasi have urban gardens for food production (Drechsel et al. 2007). This situation makes Kumasi particularly suitable for this study, as soils used for urban farming can be sampled in all parts of the city. Like most West-African cities that are undergoing rapid urbanisation, Kumasi's population doubled from $\sim 1$ to $\sim 2$ million people between 2000 and 2010 , exhibiting a rate of $5.6 \%$ population growth per year (Ghana Statistical Service 2014b). This rate has made Kumasi the fastest growing urban agglomeration in Ghana (Acheampong et al. 2017). Consistent with Drechsel (2002), field reconnaissance revealed that the crops that are mainly grown in the city of Kumasi include maize, cassava, plantain and local vegetables. These crops are grown in rain-fed agriculture, either in monoculture or in mixed cropping systems (Figure 3.1.2). In addition, intensively irrigated vegetables (e.g. spring onions and lettuce) are grown in monoculture to some extent.

The city is located in the deciduous forest agro-ecological zone of Ghana with a mean annual precipitation of $1500 \mathrm{~mm}$ and a bimodal rainfall pattern. The peaks of the rainy season occur from May to June and from September to October (Dickson et al. 1988). 
Monthly average temperatures range between 26 and $27^{\circ} \mathrm{C}$. The relief is undulating at an altitude of $250-300 \mathrm{~m}$ above sea level, and the soils are dominated by Ferric Acrisols (IUSS Working Group WRB 2014). Their parent rock is the Cape Coast granite (Adu 1992). The soils are generally strongly acidic with low base saturation and moderate soil organic matter contents (Adu 1992).
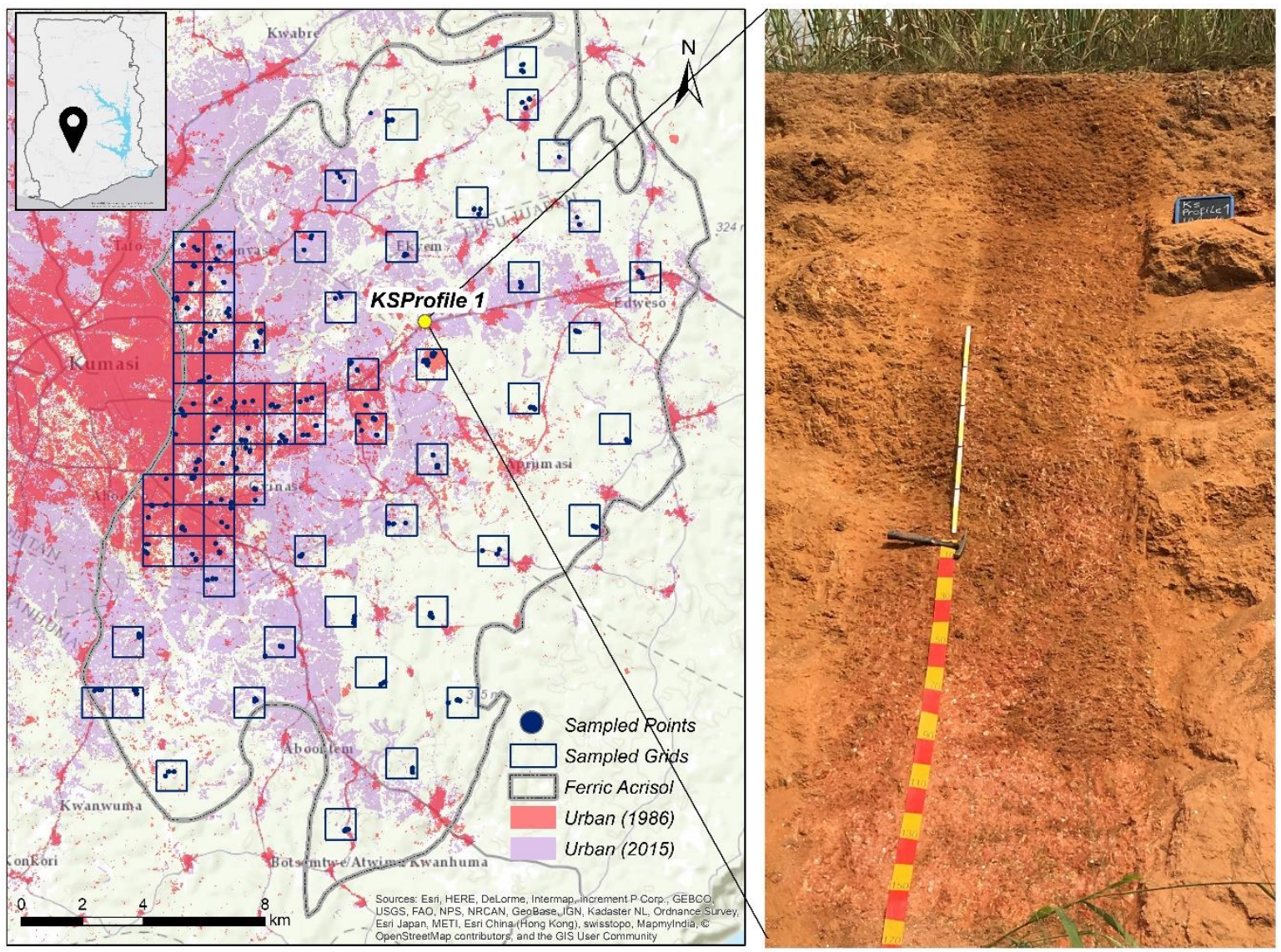

Figure 3.1.1: Kumasi agglomeration built-up area in 1986 showing the stratified grid-based sampling locations of the Ferric Acrisols. Sampling grids $(1 \times 1 \mathrm{~km})$ closer to the core of the city that were already urban in 1986, were denoted as long-term urban soils ( $\geq 30$ years with respect to the sampling year 2016), and those located in the periphery that were not yet urban in 1986, were denoted short-term urban soils. Three fields per grid were sampled, whereby three replicates per field were taken. 

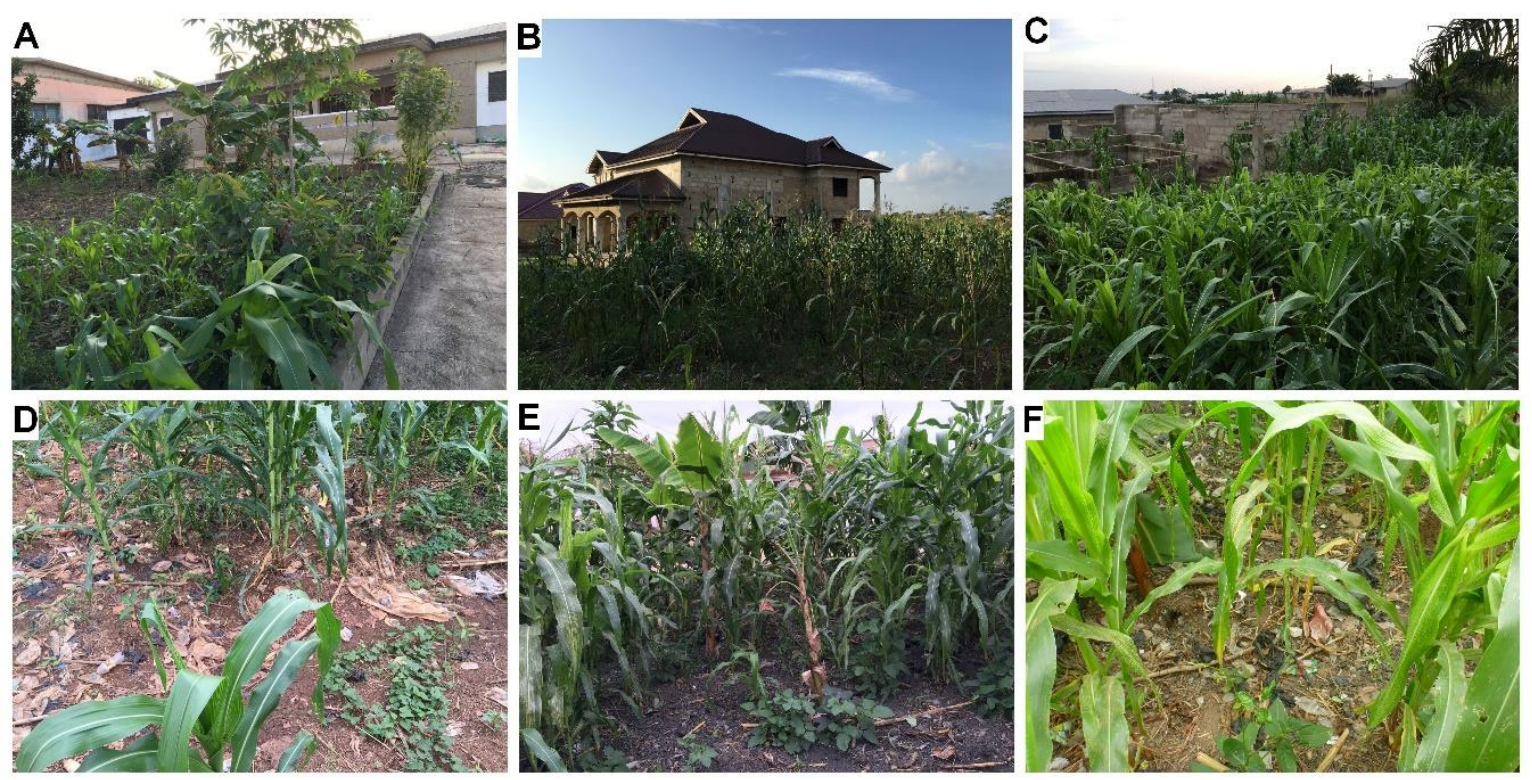

Figure 3.1.2: Some urban farms in Kumasi and their soil conditions. (A) shows a typical urban farm in the front yard of a residential home inside the city, $(B)$ and $(C)$ show urban farms in and around uncompleted residential houses in the outskirts of the city. (D) - (E) show plastic, charcoal, as well as other organic and inorganic wastes that are mostly disposed in these farms. Pictures taken in August to September 2016 by Stephen Asabere and Daniela Sauer.

\subsubsection{Field sampling design and approach}

To investigate the influence of urbanisation on arable soils, a stratified sampling design was employed. In a first step, we defined short-term and long-term strata, which were distinguished based on the built-up class of a 1986 Landsat satellite image of the

Greater Kumasi metropolitan area that was classified by Asabere et al. (in preparation-study 1 of this thesis) (Figure 3.1.1). Field sampling was conducted from August to September 2016. The soils of the inner built-up area that were in an urban environment already in 1986, thus having experienced $\geq 30$ years of continuous urbanisation, were denoted as long-term urban soils (Figure 3.1.1). The soils of the peripheral areas that became urban after 1986, thus having experienced less than 30 years of continuous urbanisation, were denoted as short-term urban soils (Figure 3.1.1). To keep the factor soil type largely constant, a Ferric Acrisol sub-group referenced in the local soil classification as the Bomso-Asuansi/Nta-offin compound association (Adu 1992) was selected, and the boundaries of this mapping unit were 
used to define the study area (Figure 3.1.1). This particular soil unit was selected because it has a wide spatial coverage in both the core and peripheral area of Kumasi. Despite the widespread practice of dumping mixed organic/inorganic household waste on the urban fields and the resulting omnipresence of artefacts, the percentage of artefacts in the soils was still very low, and none of the soils had turned into a Technosol or Anthrosol. A $1 \mathrm{~km} \times 1 \mathrm{~km}$ grid was overlaid within the boundaries of the selected soil unit as shown in Figure 3.1.1.

To keep the factor land use / crop constant, the soil sampling focused only on fields where maize was grown, either in monoculture or mixed cultivation. Three maize fields per $1 \mathrm{~km} \times 1 \mathrm{~km}$ grid cell were sampled as illustrated in Figure 3.1.1. In this way, soils were sampled on altogether 206 maize fields, whereby three replicates per maize field were taken. Thus, 618 soil samples were taken from urban maize fields, including 357 samples from long-term urban fields and 261 samples from short-term urban fields. In addition, top soils of three rural arable maize fields ( 9 samples) and a forest within the city (9 samples) were sampled for comparison. All samples were taken in steel cylinders (length $=10 \mathrm{~cm}$, volume $=255.17 \mathrm{~cm}^{3}$ ) that were vertically inserted from the soil surface, in order to obtain undisturbed top-soil samples from 0-10 cm soil depth. The fields were mostly located in the backyards or front yards of houses, on public land adjacent to roads, open spaces and corners, and building construction sites (Figure 3.1.2). They all appeared to be under rain-fed agriculture without fertilizer inputs. Thus, the factors parent material, soil unit, climate and cultivated crop were all largely kept constant.

In addition to the 636 undisturbed top-soil samples, samples were taken from a soil profile in the central part of the study area. This soil profile, KS Profile 1 (Figure 3.1.1, Table 3.1.1), a Ferric Acrisol, served as a reference profile for the Bomso-Asuansi/Nta- 
offin compound association, since all 636 samples of this study were taken from this soil unit. The profile was exposed in a road cut located along the regional highway N6. The soil has formed in a granitic colluvial deposit, overlying the Cape Coast granite. It was described according to FAO (2006) and classified according to IUSS Working Group WRB (2014). 
Table 3.1.1: Description of the soil profile KS Profile 1.

\section{Horizon Depth (cm) Description}

Ah $0-8 \quad$ Colour: brown (10YR 4/6); Texture: sandy clay loam;

Structure: weak fine granular (very fine and fine); Consistence: non-sticky non-plastic; Rock fragments: few fine quartz stones and gravels; Distinctness: clear and smooth boundary; $\mathrm{pH} 4.3$

ABt 8-15 Colour: brown (10YR 4/6); Texture: sandy clay loam; Structure: weak fine granular (very fine and fine); Consistence: slightly-sticky non-plastic; Rock fragments: few fine quartz stones and gravels; Distinctness: clear and smooth boundary; $\mathrm{pH} 4.4$

Bt1 15-47 Colour: brown (7.5YR 4/6); Texture: clay loam; Structure: moderate subangular blocky (fine and medium); Consistence: slightly-sticky slightly-plastic; Rock fragments: common fine quartz stones and gravels; Distinctness: gradual and smooth boundary; $\mathrm{pH} 4.8$

Bt2 47-67 Colour: bright brown (7.5YR 5/8); Texture: clay loam; Structure: moderate to strong subangular blocky (fine and medium); Consistence: sticky slightly-plastic; Rock fragments: abundant quartz coarse fragments; Distinctness: abrupt and smooth boundary; $\mathrm{pH} 4.5$

2Btg1 67-101 Colour: bright brown (7.5YR 5/8), with distinct medium to abundant reddish brown (5YR 4/4) mottles; Texture: clay loam; Structure: strong angular and subangular blocky (fine and 
medium); Consistence: sticky slightly-plastic; Rock fragments: common to many quartz coarse fragments, common to many muscovite and few ironstone concretions; Distinctness: diffuse and smooth boundary; $\mathrm{pH} 4.9$

2Btg2 101-233 Colour: reddish brown (5YR 4/8) with prominent, abundant reddish brown (5YR 4/4) mottles; Texture: clay loam; Structure: strong sub-angular blocky (fine and medium); Consistence: sticky slightly-plastic; Rock fragments: common to many quartz coarse fragments, common to many muscovite and few ironstone concretions; Distinctness: diffuse and smooth boundary; $\mathrm{pH} 4.7$

2Btg3 233-254 Colour: red (10R 4/6), with distinct abundant reddish brown (5YR 4/4) mottles; Texture: clay loam; Structure: strong angular blocky (fine and medium); Consistence: sticky slightlyplastic; Rock fragments: few quartz coarse fragments, few muscovite; Distinctness: clear and smooth boundary; $\mathrm{pH} 4.3$

2Btg4 254-275 Colour: red (10R 4/6), with distinct abundant reddish brown (5YR 4/4) mottles; Texture: sandy loam; Structure: rocky; Consistence: non-sticky non-plastic; Rock fragments: few quartz coarse fragments, few muscovite; Distinctness: clear and smooth boundary; $\mathrm{pH} 4.4$

2C 275-313 Colour: dark red (10R 3/6); Texture: sandy loam; Structure: strong angular blocky (fine and medium); Consistence: nonsticky non-plastic; Rock fragments: few quartz coarse 
fragments, few muscovite; Distinctness: clear and smooth boundary; $\mathrm{pH} 4.5$

\subsubsection{Laboratory analysis}

The soil samples were dried at $40^{\circ} \mathrm{C}$ and passed through a $2 \mathrm{~mm}$ sieve to separate the coarse fragments from the fine earth. Both were weighed. The coarse fragments included rock fragments and anthropogenic materials such as metal, wood, plastic, leather, textile, charcoal, egg shells, animal bones etc. All analyses were carried out on the fine earth fraction. Fine earth subsamples were pulverized with a planetary ball mill for $\mathrm{C}$ and $\mathrm{N}$ analysis. Total $\mathrm{C}(\mathrm{TC})$ and $\mathrm{N}(\mathrm{TN})$ contents were analysed by dry combustion with a CHN analyser (LecoTruSpec). Soil pH was measured in water at a soil:solution ratio of 1:5 (International 10390). Samples with $\mathrm{pH} \geq 6.0$ were analysed for carbonate contents using the Scheibler method (Blume et al. 2011; Vuong et al. 2013). The carbonate contents were also used for calculating soil inorganic carbon (SIC) contents. Soil organic carbon (SOC) contents were obtained by subtracting SIC from TC. To correct all results for residual water contents of the $40^{\circ} \mathrm{C}$-dried samples, $\sim 10 \mathrm{~g}$ fine earth was dried at $105^{\circ} \mathrm{C}$ to gravimetrically determine the water contents. The samples were then further incinerated at $430^{\circ} \mathrm{C}$ in a muffle furnace for 16 hours to determine SOM by loss on ignition (SOMLoI) (Davies 1974). All element contents were transformed to element stocks per $1 \mathrm{~m}^{2}$, considering bulk density and contents of coarse fragments.

\subsubsection{Statistical analysis}

In order to identify effects of urbanisation on soil properties, we tested all soil variables (analytical data) obtained for the long-term urban soils versus the short-term urban soils with a set of linear mixed models (LMM) (Bates et al. 2015). In each model, a soil 
variable constituted the response, which was explained by a categorical variable indicating whether the sample belonged to a long-term or short-term urban soil. The model estimated a fixed effect, which described the relative difference between the long-term urban soils and the short-term urban soils with respect to the selected soil variable. To account for spatial correlation of data from the field triplicates, a field-level random effect was added to the model. After fitting the models, the residuals were tested for normality prior to further interpretation. 95\% confidence intervals (CI) were estimated around each of the fixed effects by use of 500 parametric bootstrap simulations. Soil variables with a $\mathrm{Cl}$ excluding zero indicated significant influence of urbanisation (i.e. either long-term or short-term). Estimates of the fixed effect above zero indicated that the value of the respective variable was higher in long-term urban soils, whereas estimates below zero indicated that the value of the variable was lower in long-term compared to short-term urban soils. Beyond this inference, the upper and lower limits of the $\mathrm{Cl}$ were used to further characterize the degree of confidence for the models.

A similar modelling approach was used to assess how bulk density was affected by SOM content in these soils in the context of urbanisation, by analysing the relationship between soil bulk density and its predictor SOM content in the fine earth. In the same way, the relationship between $\mathrm{SOC}$ concentration (calculated as $\mathrm{SOC}=\mathrm{TC}-\mathrm{TIC}$ ) and its predictor SOMLo concentration was tested, in order to check, whether the commonly used SOC-SOM conversion factors are applicable to these soils. The goodness of fit for the models was evaluated in both cases by the coefficient of determination $\left(\mathrm{r}^{2}\right)$.

To complement the model-based inferences, an unbiased partitioning (Hothorn et al. 2006) for the binomial response of the short-term and long-term urban soils was 
carried out. The employed algorithm uses the complete dataset and, step by step, splits it into homogenous sub-groups according to the analysed soil properties, thereby identifying the hierarchical levels at which the various soil properties discriminate the dataset. The hierarchical outcome, a dendrogram, finally also shows the proportions of short-term and long-term urban soils that correspond to a certain combination of soil properties. This approach helps to evaluate, which soil variables do most clearly discriminate short-term and long-term urban soils in Kumasi. The dendrogram also showed, at which significant values the classification into sub-groups happened. All statistical analyses were conducted in R (R Core Team 2018), using its extensions 'party' (Hothorn et al. 2006), 'Ime4' (Bates et al. 2015), and 'MuMIn' (Barton 2018).

\subsubsection{Results}

\subsubsection{Bulk density, coarse and fine fractions of the soils}

The bulk densities of the long-term and the short-term urban soils were both $1.39 \pm 0.01$ $\mathrm{g} \mathrm{cm}^{-3}$ (mean \pm standard error). The model estimates of the response coefficients and associated confidence intervals were centred around zero, supporting this result (Figure 3.1.3). The mean bulk density of the rural arable soils $\left(1.33 \pm 0.04 \mathrm{~g} \mathrm{~cm}^{-3}\right)$ was slightly lower, and that of the forest soils was again somewhat lower (mean=1.28 \pm 0.05 $\mathrm{g} \mathrm{cm}^{-3}$ ) (Figure 3.1.4). However, bulk densities of urban soils showed greater variability than those of rural soils, including several outliers (Figure 3.1.4). Some of the urban soils showed very low $\left(<1 \mathrm{~g} \mathrm{~cm}^{-3}\right)$ or high $\left(>1.6 \mathrm{~g} \mathrm{~cm}^{-3}\right)$ bulk densities. Variability was greater in the long-term urban soils $\left(\right.$ range $=1.1 \mathrm{~g} \mathrm{~cm}^{-3}$ ) compared to the short-term urban soils (range $=0.72 \mathrm{~g} \mathrm{~cm}^{-3}$ ).

The long-term urban soils had moreover considerably higher contents of coarse fragments (mean $=16.1 \pm 0.6 \%$ ) compared to the short-term urban soils (mean= $9.6 \pm 0.6 \%$ ) (Figure 3.1.4), whereby the model indicated a strong positive effect (Figure 
3.1.3), reconfirming that the long-term urban soils had significantly more coarse fragments ( $6 \%$ more), compared to the short-term urban soils. Conversely, the amounts of fine earth per $\mathrm{dm}^{-3}$ (providing SOM, CEC, and nutrients) were lower in the long-term compared to the short-term urban soils (Figure 3.1.3). Generally, the constituents of the coarse fragments included a mixture of rock fragments and anthropogenic materials such as metal, wood, plastic, leather, textile, charcoal, egg shells, animal bones etc, which corresponded with field observations in Figure 3.1.2.

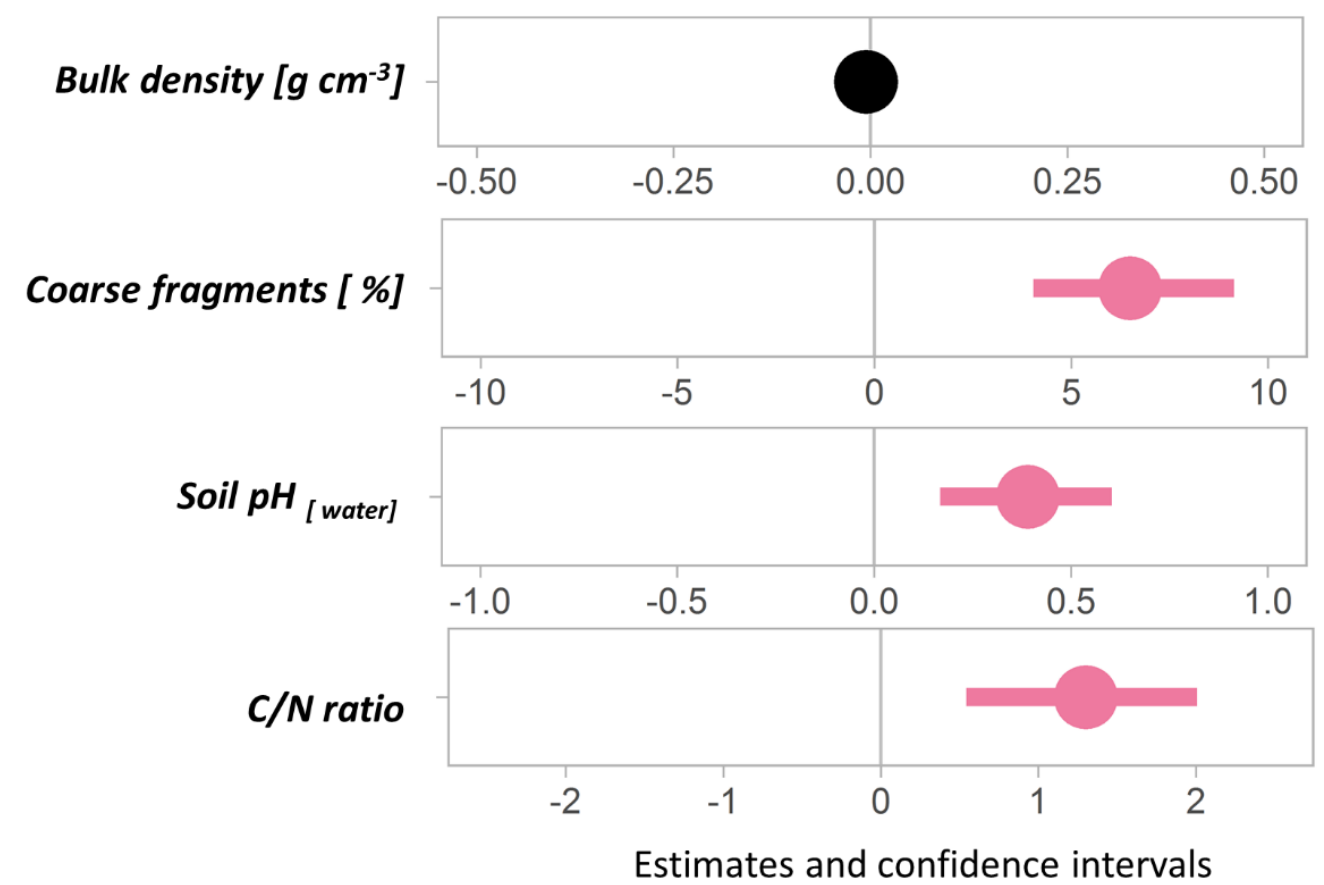

Figure 3.1.3: Estimated fixed effects of model coefficients and 95\% confidence intervals (CI) of the linear mixed models for bulk density, $\mathrm{C} / \mathrm{N}$ ratio, coarse fragment content and soil pHwater, which compares the two urban soil strata. Error bars that do not cross the zero line indicate statistical significance. 

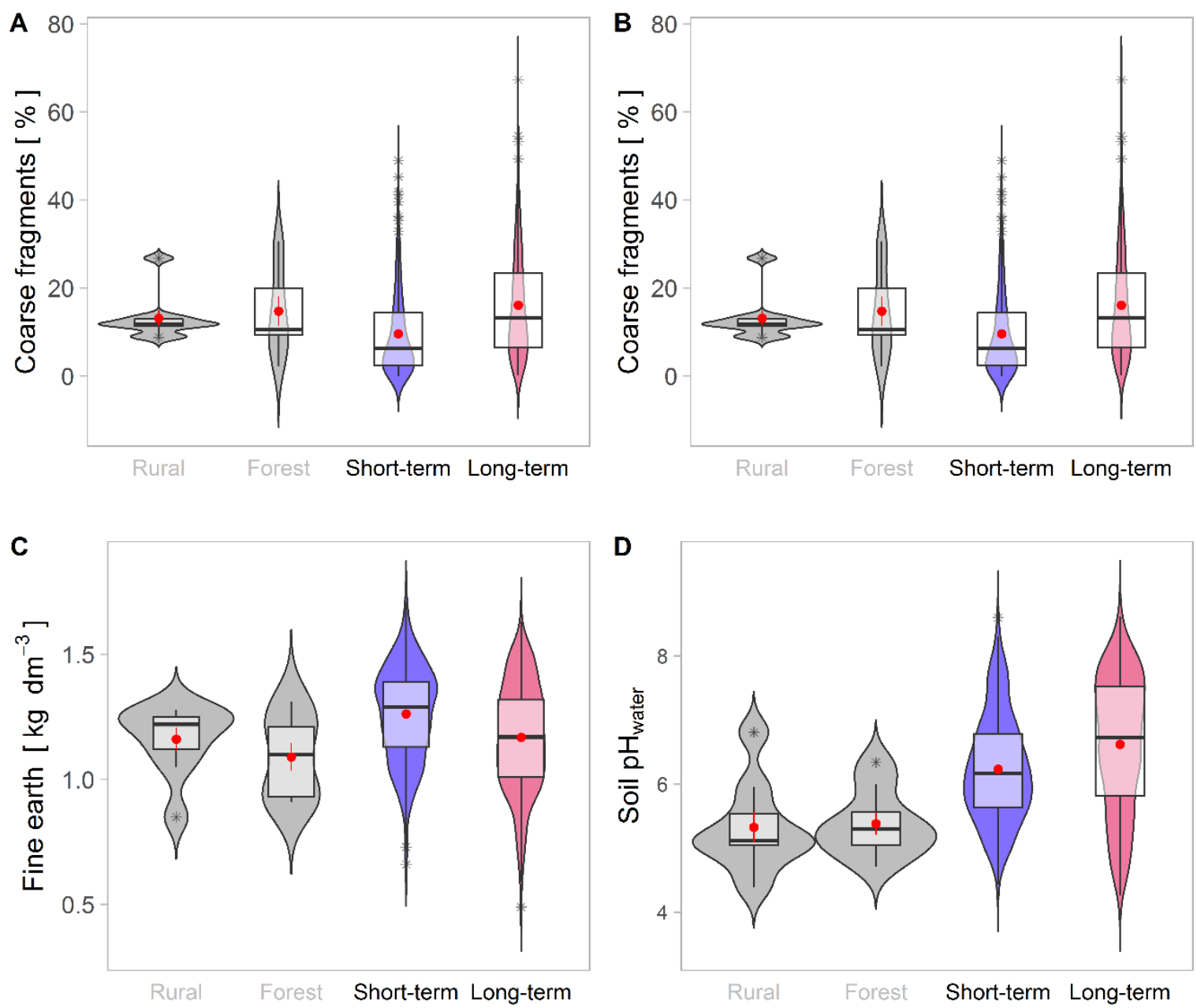

Figure 3.1.4: Box and violin plots of (A) bulk density, $(B)$ coarse fragment content, (C) fine earth content, and (D) soil $\mathrm{pH}$ (water), of rural, forest and urban soils. Statistical analysis focused on relative differences between short-term and long-term urban soils. Arithmetic means (red points), standard errors (red whiskers), medians (bars), ranges (whiskers) and outliers (asterisks) are shown.

\subsubsection{Soil $\mathrm{pH}$}

Mean soil $\mathrm{pH}$ values for the forest soils and the rural arable soils were $\mathrm{pH} 5.7 \pm 0.3$ and pH 6.0 \pm 0.1 , respectively (Figure 3.1.4). The urban soils exhibited substantially higher $\mathrm{pH}$, with means of $\mathrm{pH} 7.4 \pm 0.1$ for the long-term and $\mathrm{pH} 7.0 \pm 0.1$ for short-term urban soils (Figure 3.1.4). Within the urban soils, the $\mathrm{pH}$ of the long-term urban soils was significantly higher (0.4 pH units) compared to their short-term counterparts (Figure 3.1.3). In 197 urban soils, including 155 long-term urban soils, $\mathrm{pH}$ was higher than $\mathrm{pH}$ 7, reaching up to a maximum of $\mathrm{pH} 8.6$ (Figure 3.1.4). 


\subsubsection{Contents, stocks and quality of soil organic matter}

SOMLo contents in the fine earth of the soils were significantly higher $\left(7.0 \mathrm{~g} \mathrm{~kg}^{-1}\right.$ difference) in the long-term compared to the short-term urban soils (Figures 3.1.5 and 3.1.6). SOMLo bulk soil contents and stocks of the long-term urban soils exceeded those of the short-term urban soils, too (Figures 3.1.7 and 3.1.8), however with less confidence, as indicated by inclusion of zero in the output confidence interval of the model (Figure 3.1.5). Further inspection of the descriptive statistics generally supported this decreased confidence, as the mean SOMLo fine earth contents of $50.8 \pm 1.3 \mathrm{~g} \mathrm{~kg}^{-1}$ for the long-term and $43.9 \pm 1.1 \mathrm{~g} \mathrm{~kg}^{-1}$ for the short-term urban soils were more clearly differentiated, compared to their SOMLo stocks of $5.6 \pm 0.1 \mathrm{~kg} \mathrm{~m}^{-2}$ and $5.3 \pm 0.1 \mathrm{~kg} \mathrm{~m}^{-2}$, respectively (Table 3.1.2). The reason for the reduced confidence regarding the differences of SOM stocks compared to SOM contents is that the transformation of element contents to stocks considered the coarse fraction ( $>2 \mathrm{~mm}$ ) of the soils, whereby the soil volume occupied by the coarse fraction was regarded as not contributing to SOM. The proportion of the coarse fraction was increased in the urbanised soils due to artefacts, thus counteracting the general increase of SOM contents in the urbanised soils. The mean SOMLo stock of the forest soils $(5.7 \pm 0.5 \mathrm{~kg}$ $\mathrm{m}^{2}$ ) was comparable to that of the long-term urban soils, whereas the mean SOMLOI stock of the rural arable soils $\left(4.3 \pm 0.2 \mathrm{~kg} \mathrm{~m}^{-2}\right)$ was the lowest of all subsets of soil samples. Thus, the urban arable soils, particularly those under long-term urbanisation, exhibited similar SOM stocks as those of soils under tropical forest conditions in Kumasi.

Total carbon (TC) followed the same trend as SOMLo (Figures 3.1.5-3.1.8), with the long-term urban soils having significantly higher TC contents in their fine earth than the short-term urban soils. Consistently, the contents and stocks of the bulk soils of 
the long-term urban soils also exceeded those of the short-term urban soils, but with less confidence.
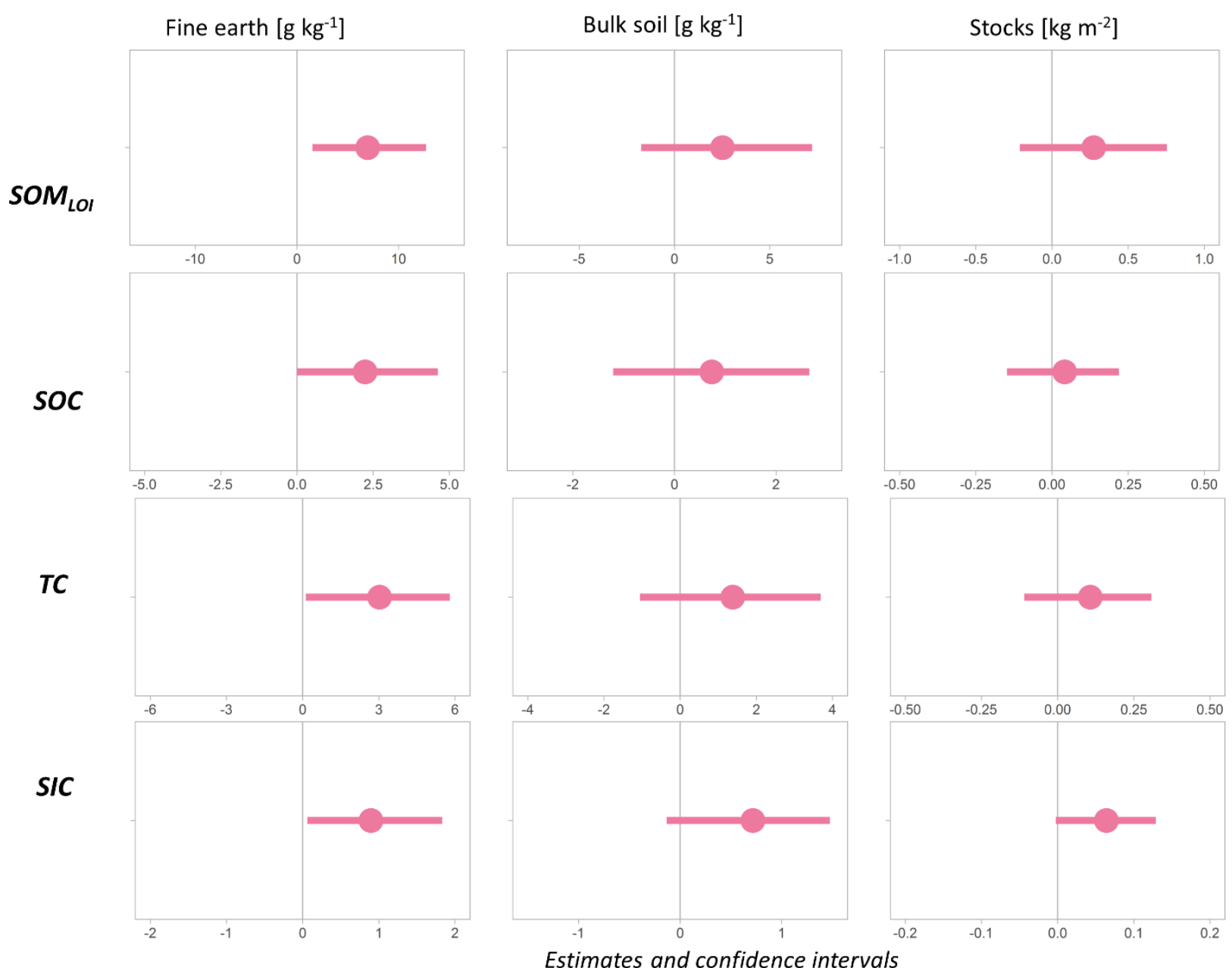

Figure 3.1.5: Comparison of long-term versus short-term urban soils, estimating fixed effects of model coefficients and 95\% confidence intervals (Cl) of the linear mixed models for SOMLOI (soil organic matter obtained from loss on ignition), SIC (soil inorganic carbon), SOC (soil organic carbon), and TC (total carbon). Positive values indicate an increase of the respective soil variable in long-term urban soils, whereas negative values indicate a decrease in long-term urban soils compared to short-term urban soils. Error bars that do not cross the zero line indicate statistical significance. 
Table 3.1.2: Mean contents and stocks of SOM variables in the long-term and the short-term urban soils.

Long-term Short-term

\begin{tabular}{|c|c|c|c|c|c|c|}
\hline $\begin{array}{l}\text { SOM } \\
\text { variables }\end{array}$ & $\begin{array}{l}\text { Fine } \\
\text { earth } \\
\text { contents } \\
\left(\mathrm{g} \mathrm{kg}^{-1}\right)\end{array}$ & $\begin{array}{l}\text { Bulk soil } \\
\text { contents } \\
\left(\mathbf{g ~ k g}^{-1}\right)\end{array}$ & $\begin{array}{l}\text { Stocks in } \\
\text { top } 10 \mathrm{~cm} \\
\left(\mathrm{~kg} \mathrm{~m}^{-2}\right)\end{array}$ & $\begin{array}{l}\text { Fine soil } \\
\text { contents } \\
\left(\mathrm{g} \mathrm{kg}^{-1}\right)\end{array}$ & $\begin{array}{l}\text { Bulk soil } \\
\text { contents } \\
\left(\mathrm{g} \mathrm{kg}^{-1}\right)\end{array}$ & $\begin{array}{l}\text { Stocks in } \\
\text { top } 10 \\
\mathrm{~cm}(\mathrm{~kg} \\
\left.\mathrm{m}^{-2}\right)\end{array}$ \\
\hline SOMLOI & $50.8 \pm 1.3$ & $41.8 \pm 1.1$ & $5.6 \pm 0.1$ & $43.9 \pm 1.1$ & $39.3 \pm 1.0$ & $5.3 \pm 0.1$ \\
\hline TC & $19.3 \pm 0.7$ & $15.9 \pm 0.6$ & $2.1 \pm 0.1$ & $16.3 \pm 0.4$ & $14.5 \pm 0.4$ & $2.0 \pm 0.0$ \\
\hline SOC & $18.2 \pm 0.6$ & $15.0 \pm 0.5$ & $2.0 \pm 0.1$ & $16.0 \pm 0.4$ & $14.2 \pm 0.3$ & $1.9 \pm 0.4$ \\
\hline SIC & $1.6 \pm 0.3$ & $1.3 \pm 0.2$ & $0.2 \pm 0.0$ & $0.5 \pm 0.1$ & $0.5 \pm 0.1$ & $0.1 \pm 0.0$ \\
\hline
\end{tabular}

${ }^{*}$ mean was calculated on a subsample where $n$ for Long-term $=249$, Short-term $=143$.
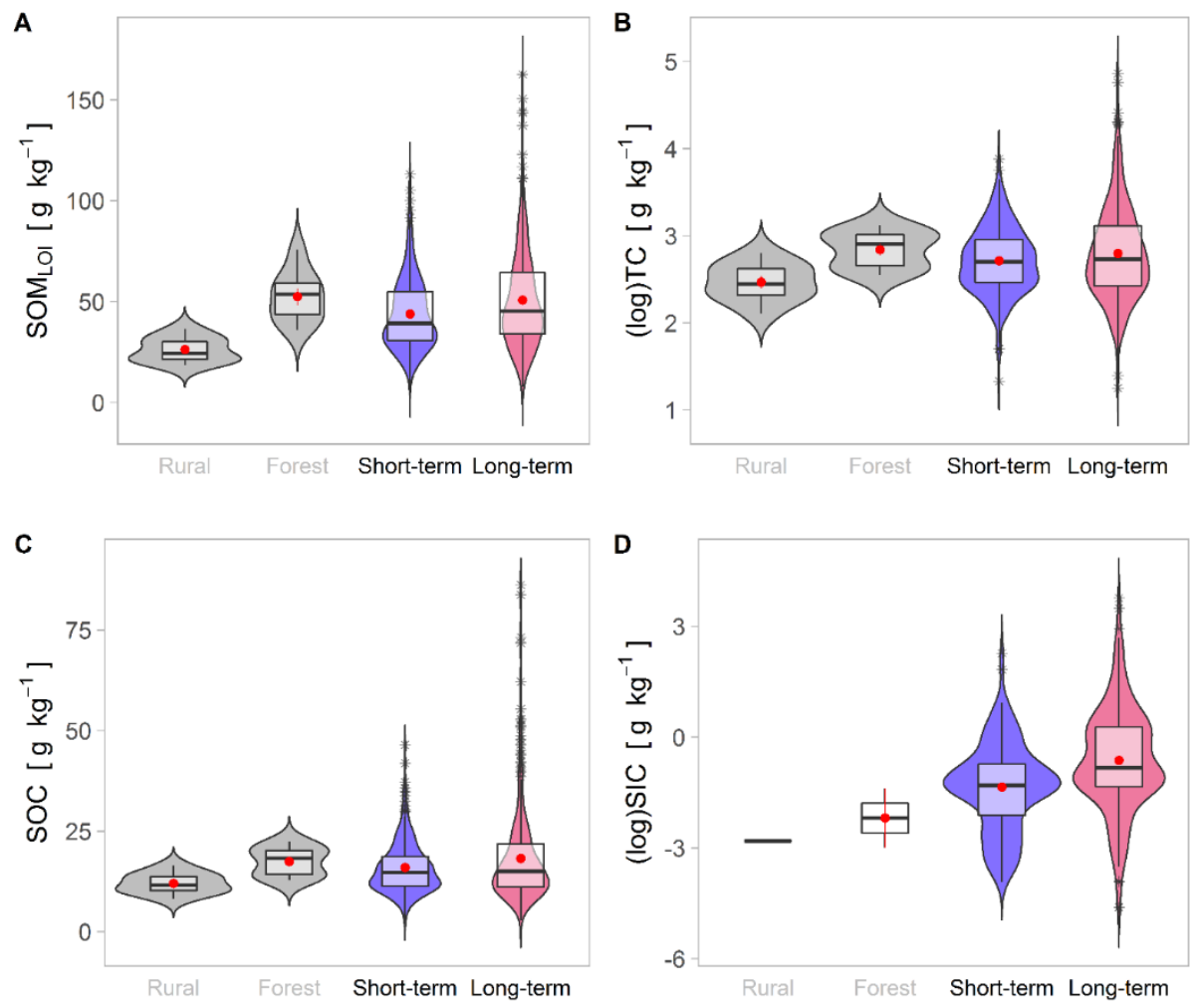

Figure 3.1.6: Boxplots comparing rural, forest and urban soils with respect to fine earth contents of (A) SOM LOI (soil organic matter obtained from loss on ignition), (B) TC (total carbon), (C) SOC (soil organic carbon), (D) SIC (soil inorganic carbon). Arithmetic means (red points), standard errors (red whiskers), medians (bars), ranges (whiskers) and outliers (asterisks) are shown. 

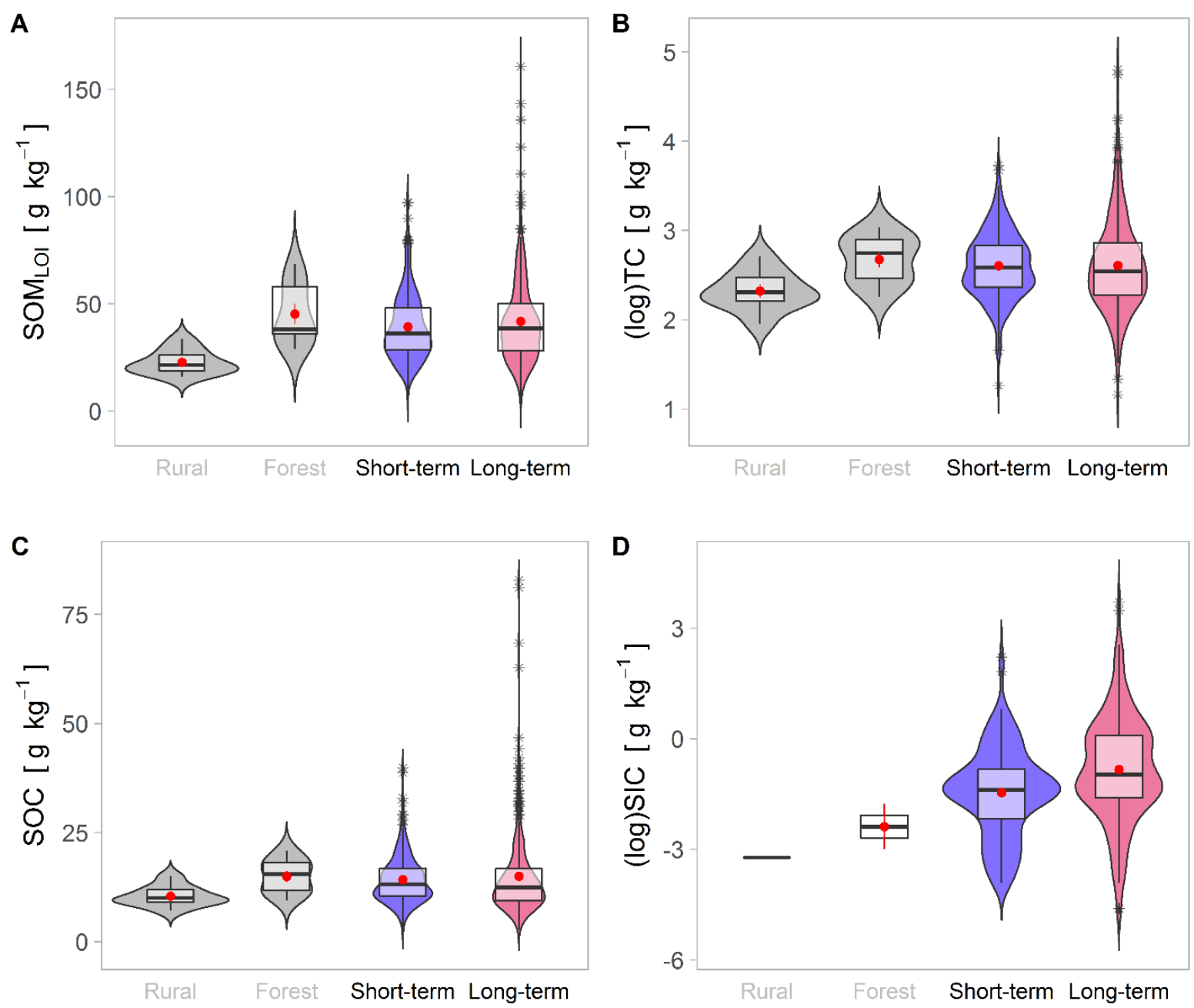

Figure 3.1.7: Boxplots comparing rural, forest and urban soils with respect to bulk soil

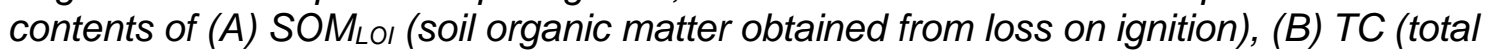
carbon), (C) SOC (soil organic carbon), (D) SIC (soil inorganic carbon). Arithmetic means (red points), standard errors (red whiskers), medians (bars), ranges (whiskers) and outliers (asterisks) are shown. 

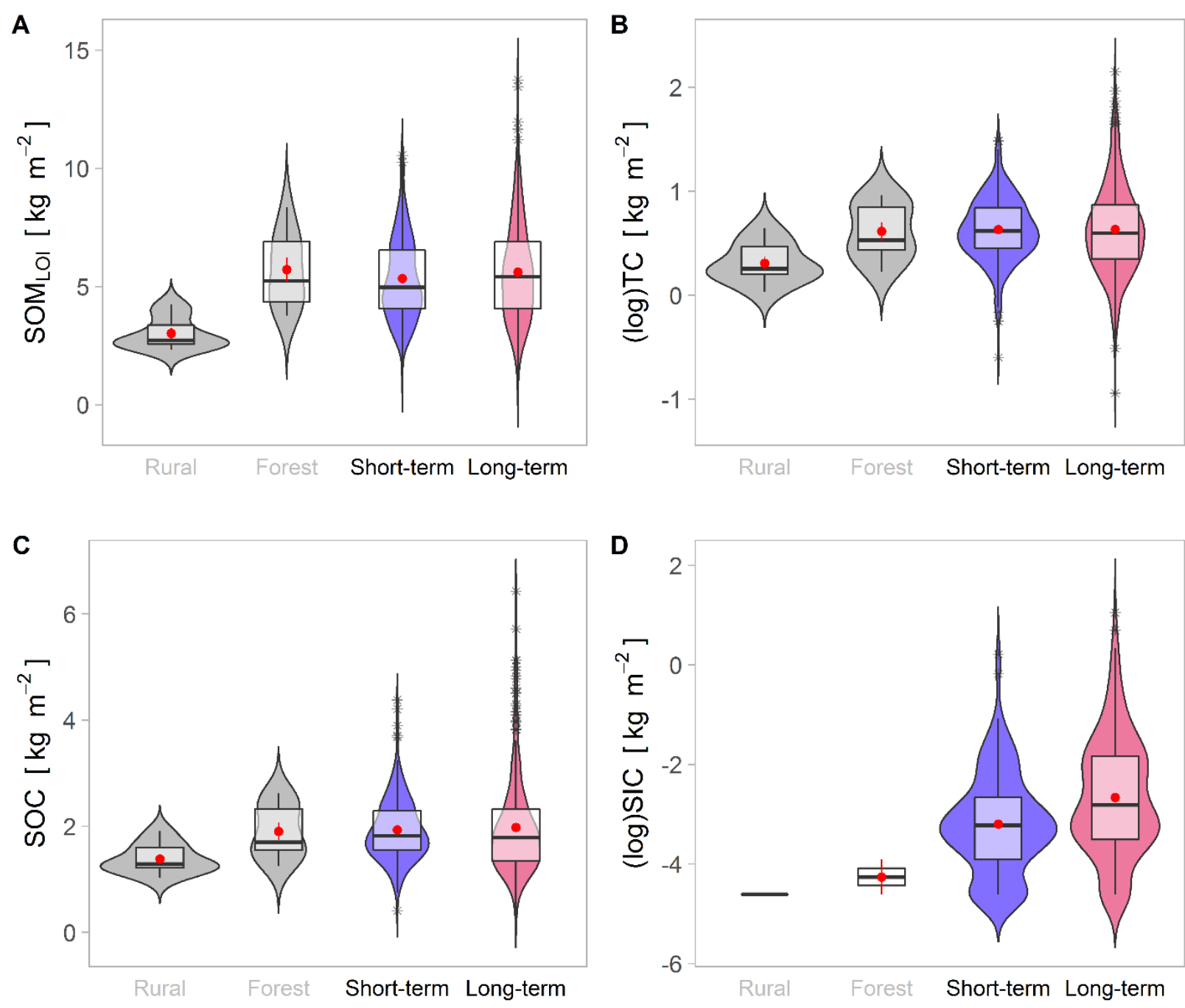

Figure 3.1.8: Boxplots comparing rural, forest and urban soils with respect to their amounts

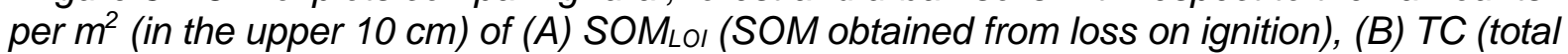
carbon), (C) SOC (soil organic carbon), (D) SIC (soil inorganic carbon). Arithmetic means (red points), standard errors (red whiskers), medians (bars), ranges (whiskers) and outliers (asterisks) are shown.

The contents and stocks of soil inorganic carbon (SIC) in both fine earth and bulk soils of the long-term urban soils significantly exceeded those of the short-term urban soils (Figure 3.1.5, Table 3.1.2). The upper limit of the model estimates might include zero ( 0.1), particularly for the bulk soil contents and stocks (Figure 3.1.5). However, the descriptive statistics such as the means (Table 2) showed that SIC bulk soil contents and stocks in the long-term urban soils were at least twice as high as in the short-term urban soils. 
Also, the soil organic carbon (SOC) contents and stocks of the long-term urban soils exceeded those of the short-term urban soils (Figures 3.1.5-3.1.8; Table 3.1.2). Inspection of the model estimates, however, resulted in a low confidence for both fine earth and bulk soil SOC data (Figure 3.1.5). Mean SOC content and stock of the urban soils (Table 3.1.2) were comparable to those of the forest soils (content $=17.4 \pm 1.2 \mathrm{~g}$ $\mathrm{kg}^{-1}$, stock $=1.9 \pm 0.2 \mathrm{~kg} \mathrm{~m}^{2}$ ), whereas the rural arable soils had much lower mean SOC content and stock (content $=12.0 \pm 1.0 \mathrm{~g} \mathrm{~kg}^{-1}$, stock $=1.4 \pm 0.1 \mathrm{~kg} \mathrm{~m}^{2}$ ). Thus, over all, the SOMLOI, TC and SOC fine earth and bulk soil concentrations, and the corresponding stocks showed a gradual decrease in confidence of the model estimates.

SOC data are commonly used to calculate SOM contents of soils by multiplication with the factor 2.0 or 1.72 (Pribyl 2010). These factors would correspond to SOC/SOM ratios of 0.5 and 0.58 , respectively. However, the SOC/SOMLo ratios of the 636 topsoil soil samples of Kumasi exhibited a very wide range, from 0.03 to 0.72 . Their mean SOC/SOMLo ratio was only $0.36 \pm 0.1$, which corresponds to a SOC-SOM conversion factor of 2.78. One sample showed a SOC/SOMLo ratio of 4.7, which is impossible. For this particular sample, concentrations of the SOC and TC in the fine earth was higher relative to its SOM concentration, and thus the value was attributed to analytical error from the LOI. This value was therefore not included in the calculations. The SOC/SOM ratios of the short-term and long-term urban soils were similar (Figure 3.1.9A). The rural arable soils exhibited the highest mean SOC/SOM ratio of 0.46 , whereas the forest soils showed a mean SOC/SOM ratio of 0.34 (Figure 3.1.9A). The relationship between SOC and SOMLo of all samples from Kumasi (Figure 3.1.10A) can be expressed by the equation $S O C=0.37 S O M_{L O I}\left(r^{2}=0.89\right)$.

$\mathrm{C} / \mathrm{N}$ ratios, commonly used to characterize SOM quality, were calculated as SOC/TN. They ranged from 7.1 to 58.1 , with four samples showing $\mathrm{C} / \mathrm{N}$ ratios above 25 . Out of 
the four samples, two with extreme $\mathrm{C} / \mathrm{N}$ ratios of 55.1 and 58.1 belonged to the shortterm urban soils, and the other two, with $\mathrm{C} / \mathrm{N}$ ratios of 36.4 and 31.2 , belonged to the long-term urban soils. The four maize fields from where these samples were obtained were all characterized by massive household waste dumping. In general, $\mathrm{C} / \mathrm{N}$ ratios were significantly wider (by 1.3 units) in the long-term urban soils, which showed a mean $\mathrm{C} / \mathrm{N}$ ratio of $12.8 \pm 0.2$, compared to the short-term urban soils that exhibited a mean $\mathrm{C} / \mathrm{N}$ ratio of $11.5 \pm 0.2$ (Figures 3.1.3 and 3.1.9B). The mean $\mathrm{C} / \mathrm{N}$ ratio of the rural arable soils was $13.6 \pm 0.5$, and that of the forest soils was $11.5 \pm 0.3$. Thus, the rural arable soils showed the highest $\mathrm{C} / \mathrm{N}$ ratios, whereas the forest soils had $\mathrm{C} / \mathrm{N}$ ratios similar to the short-term urban soils.
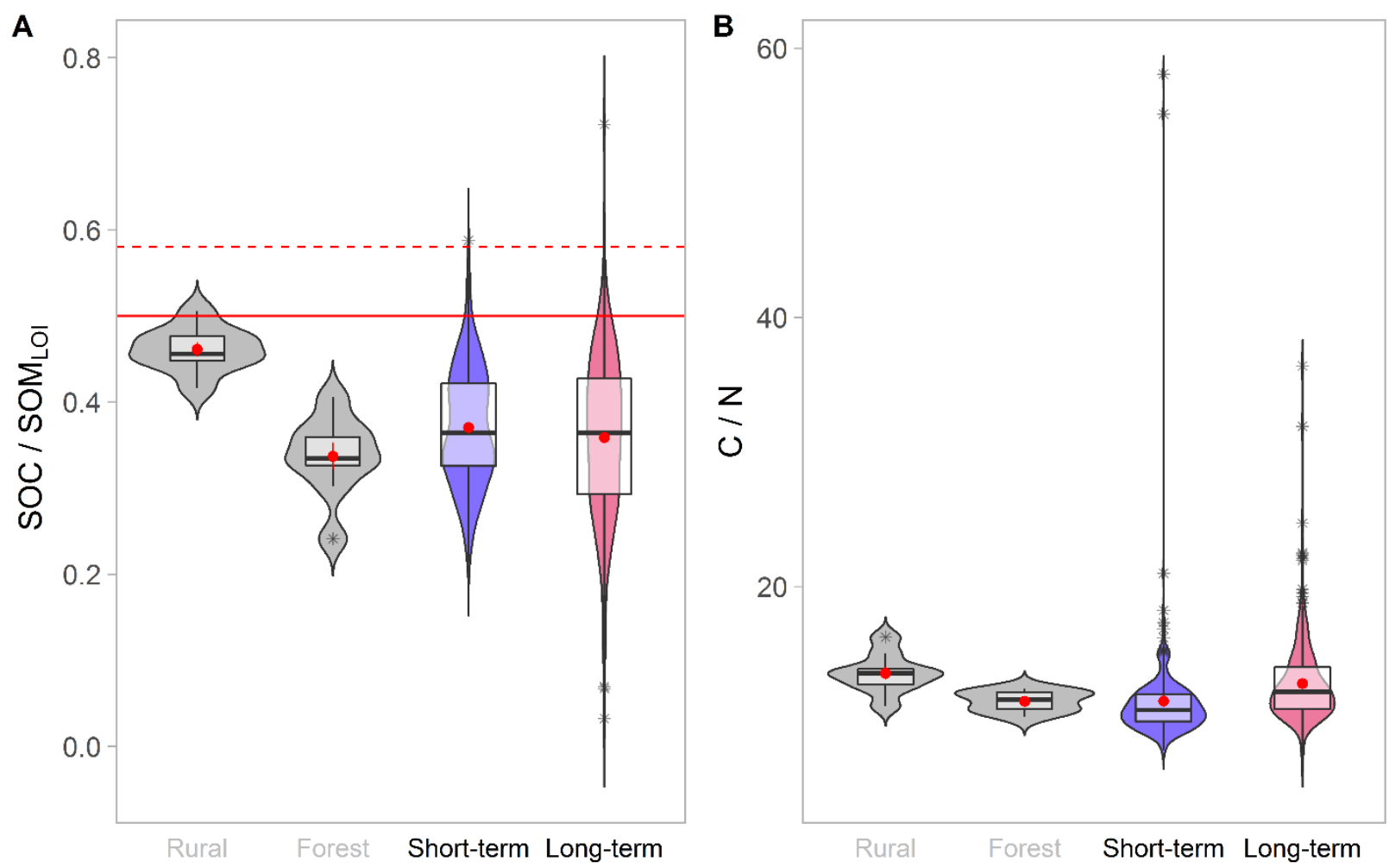

Figure 3.1.9: Boxplots comparing rural, forest and urban soils with respect to their $(A)$ SOC/SOM Lo ratios and (B) C/N ratios. Arithmetic means (red points), standard errors (red whiskers), medians (bars), ranges (whiskers) and outliers (asterisks) are shown. In (A), the thick red line represents the ratio of 0.5 , and the dash red line represents the ratio of 0.58 , which are both commonly used in literature for SOC/SOM conversions. 

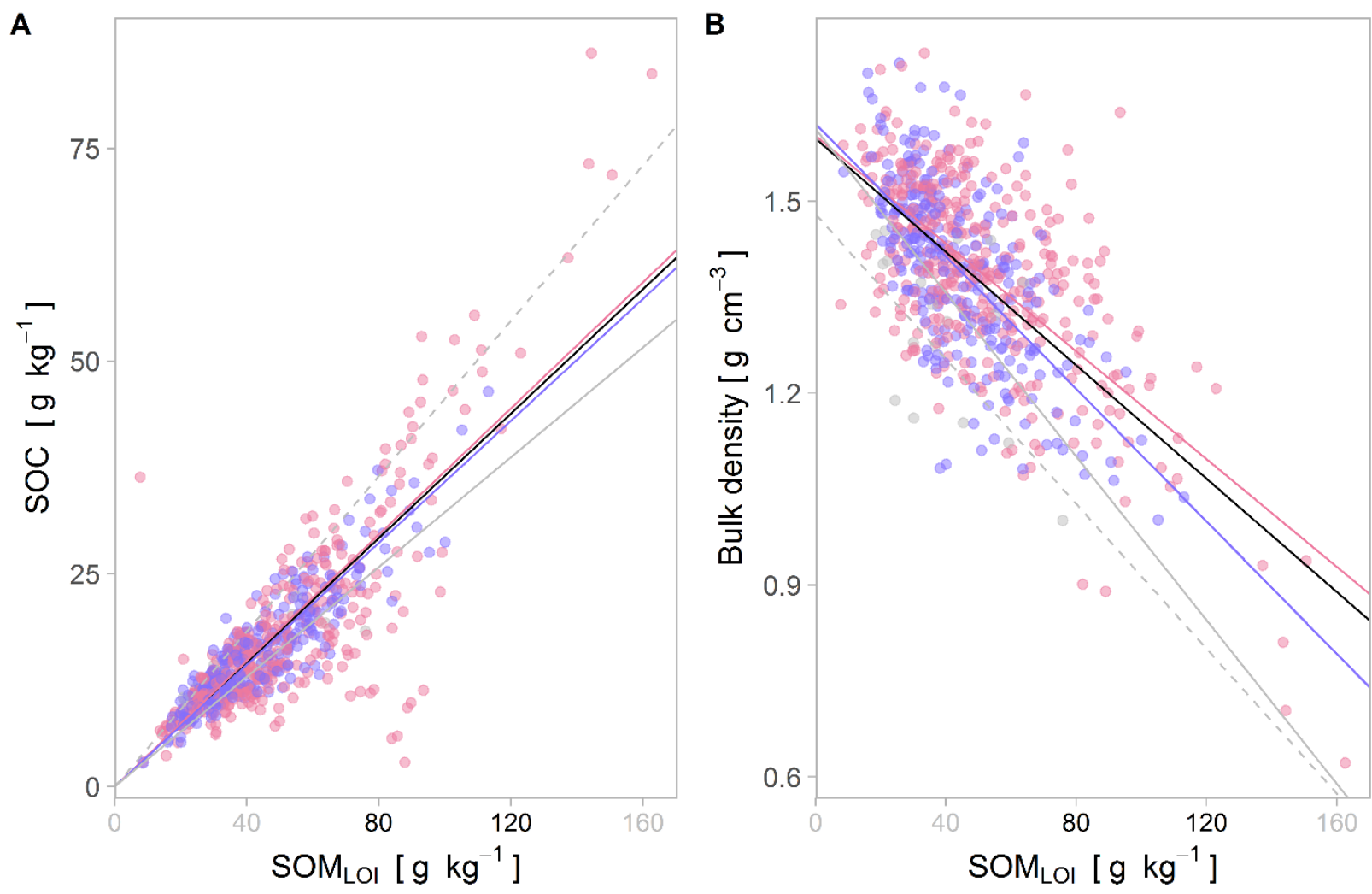

Figure 3.1.10: Relationships between $(A)$ the concentrations of SOC (soil organic carbon) and $S O M L O$ (soil organic matter obtained from loss on ignition) in the fine earth, (B) Bulk density and concentration of $S O M_{\llcorner O}$ in the fine earth. The black line represents the linear relationship for forest, rural and the urban soils, the pink line represents the long-term urban soil, the violet line represents the short-term urban soil, the grey dash line represents rural arable soils and the grey thick line represents forest soils.

\subsubsection{Relationships between bulk density, SOM and other soil}

\section{variables}

As to be expected, bulk density showed a strong negative relationship with SOMLOI concentration in the fine earth (Figure 3.1.10B), which was supported by the model estimates and confidence intervals $(-88.6$ to -71.8$)$. A linear regression equation $B D=$ $1.6-0.004 S O M L O$, was used to express this relationship with $r^{2}=0.74$. Similar model estimates and coefficients were also derived for the long-term and the short-term urban soils (Figure 3.1.10B).

The dendrogram that was obtained from the recursive partitioning (Figure 3.1.11) revealed that out of all variables that were investigated, only six clearly discriminated long-term from short-term urban soils. These variables included (1) contents of coarse 
fragments, (2) soil $\mathrm{pH}$, (3) $\mathrm{C} / \mathrm{N}$ ratios, (4) SOC stocks, (5) SOMLo contents in the fine earth, and (6) SIC contents in the bulk soils. At the highest hierarchical level, the samples were split by the model into samples with $\leq 5.42 \%$ and $>5.42 \%$ coarse fragments. A combination of $>5.42 \%$ coarse fragments and soil $\mathrm{pH}>7$ included predominantly ( $87 \%)$ long-term urban soils. Also, the combination of $>5.42 \%$ coarse fragments, soil $\mathrm{pH} \leq 7, \mathrm{C} / \mathrm{N}>10.09$, and SOMLOI $>59.54 \mathrm{~g} \mathrm{~kg}^{-1}$ included predominantly long-term urban soils. Conversely, the two following combinations included predominantly short-term urban soils: $(A) \leq 5.4 \%$ coarse fragments and $\mathrm{C} / \mathrm{N}$ ratio $\leq$ 10.2, (B) $>5.4 \%$ coarse fragments, soil $\mathrm{pH} \leq 7, \mathrm{C} / \mathrm{N}$ ratio $\leq 10.09$, and $\mathrm{SOC}$ stocks $>$ $1.71 \mathrm{~kg} \mathrm{~m}^{2}$.

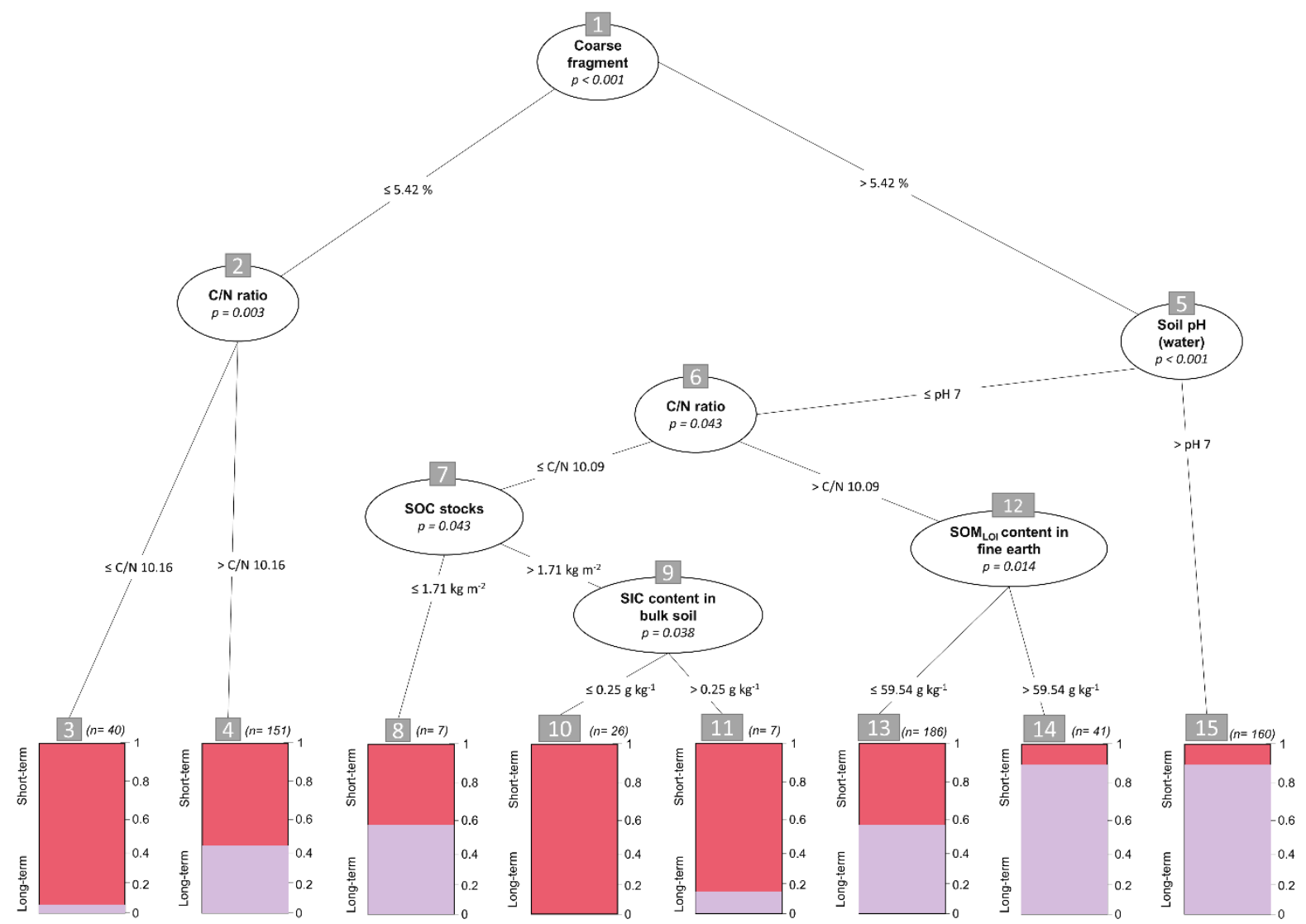

Figure 3.1.11: Dendrogram showing the hierarchical alignment of the six variables that can most clearly discriminate short-term and long-term urban soils. Branches show threshold values for the partitioning referring to the variable shown in the node above together with the test statistics for variable selection. Numbers on top of the nodes indicate the hierarchical level. 


\subsubsection{Discussion}

\subsubsection{Effects of urbanisation on bulk density and coarse fractions of arable soils}

Soil bulk density in both short-term and long-term urban soils was conducive to plant growth (Hazelton and Murphy 2016) and was only slightly higher than in forest and rural arable soils. Thus, the physical conditions of the urban arable soils were still intact, even under prolonged urban influence. The range of bulk density data reported for maize fields in humid tropical regions of Ghana and Zimbabwe were within a similar range as that of the soils under maize in Kumasi (Zingore et al. 2008; Minta 1998). This range is also consistent with bulk density values reported for soils in other cities around the world (Edmondson et al. 2011; Smetak et al. 2007; Lorenz and Kandeler 2005). Thus, contrary to soils investigated e.g. by Jim (1998), Lehmann and Stahr (2007), and Lorenz and Lal (2009), the bulk densities of urban soils of Kumasi are conducive to plant growth.

Bulk density variability was greater in the long-term compared to the short-term urban soils. This finding can be explained by the types of urban activities in the direct vicinity of some of the long-term urban maize fields. For instance, the field, where the highest bulk density $\left(1.73 \mathrm{~g} \mathrm{~cm}^{-3}\right)$ was measured located close to Kumasi airport, a bus station, a concrete block production factory, and a major road, all of which involve human activities that may lead to soil compaction. The field, where the lowest bulk density $\left(0.62 \mathrm{~g} \mathrm{~cm}^{-3}\right)$ was measured located within the confines of an abandoned wood processing factory, near Kaase industrial area. These two situations, though extreme, may serve as examples for the possible influence of urban and industrial activities on soil physical properties in the Kumasi area. Thus, the considerable variability in bulk density that was found particularly for the long-term urban soils, can be attributed to 
the exposure of some of these arable fields to various urban influences, including anthropogenic compaction and deposition, which may also increase surface run-off and erosion, and thus enhance soil degradation (Labrière et al. 2015). Such variability is reminiscent of the general pattern of soil properties in urban soils, as also observed in other cities around the world (Pouyat et al. 2010; Jim 1998; Schleuß et al. 1998). Anthropogenic activities are also reflected in the coarse fraction of the soils, which, in addition to rock fragments, contained also various anthropogenic materials. Whereas some studies highlighted the nutrient contribution of coarse fragments to soils (Corti et al. 2002), it is usually assumed that a high rock fragment content rather has a diluting effect on the fine earth nutrient stocks available to plants (Augustin et al. 1998), as the nutrients are released rather slowly from weathering rock fragments. In the case of the urban maize fields of Kumasi, the nature of the coarse fragments, and their potential to release elements to the soils, is very diverse. In addition to rock fragments, the coarse fraction comprises household and construction waste, including metal, plastics, textiles, etc. The abundance of these materials is the most obvious direct consequence of rapid urbanisation for the arable soils of Kumasi.

It is well recognized that one third to one half of solid waste in most cities in the global south is not collected (Pacione 2009). Likewise, the inadequacy of waste disposal systems in Kumasi is ubiquitous in Ghana (Fuseini and Kemp 2016). This situation was clearly reflected in the on-field observations made during this study, as most of the arable fields also served as household waste disposal sites. Hence, we conclude that the identified and significantly higher coarse fragment contents of the long-term urban soils compared to the short-term urban soils of Kumasi are due to long-term continuous dumping on the fields. 


\subsubsection{Effects of urbanisation on soil pH}

Soil pH has great influence on soil chemical processes that determine the behaviour of nutrients and contaminants (Blume et al. 2016). Hence, it is also an important influencing factor for nutrient availability and plant growth. Whereas acidification is a natural process in most humid tropical soils, anthropogenic activities may lead to alkanisation (Blume et al. 2016). Soil pH in the long-term urban soils of Kumasi was significantly higher, compared to the short-term urban soils. Both, long-term and shortterm urban soils, had higher $\mathrm{pH}($ mean $\mathrm{pH}>7)$ compared to the rural arable soils and the forest soils. Consistent with Adu (1992), the pH values of the rural arable soils and the forest soils were in the usual range for these soils. Boateng et al. (2006) and Quansah (2010) reported pH (water) 4.3-4.6 and pH (water) 6.1-6.3, respectively, for arable maize fields on similar soils in Ghana. Soil pH obtained for the urban arable soils in Kumasi in this study were significantly higher than both (i.e. $\mathrm{pH}$ data from literature and our own $\mathrm{pH}$ data of rural and forest soils). This clear difference indicates that arable soils in Kumasi which become included in the urbanisation process, are influenced by anthropogenic activities that have a similar effect as liming (Blume et al. 2016; Hazelton and Murphy 2016), although intentional liming as part of the management of the fields is usually not done, as confirmed by field observations and farmer interviews.

Possible reasons for the high $\mathrm{pH}(>7)$ in the urban soils include in particular the release of alkaline leachates from calcareous materials (Jim 1998) and decomposing organic waste (Cofie et al. 2009; Boateng et al. 2006). Both field and lab experiments confirmed that decomposition of organic matter may increase the soil $\mathrm{pH}$ of tropical soils (Cofie et al. 2009; Zingore et al. 2008; Boateng et al. 2006). In addition, the formation of alkaline leachate from construction materials such as building sand and 
cement is very likely under the conditions of this study. Similar to the situation in Kumasi, Jim (1998) reported higher soil pH in urban soils of Hong Kong, compared to adjacent natural soils, and attributed the increased $\mathrm{pH}$ to construction waste. Such influence is very likely in Kumasi, too, as most of the sampled arable fields in Kumasi were located within active construction sites. This is a common situation in Ghana, as the construction of a building usually takes at least ten years (Stow et al. 2016; Yeboah and Obeng-Odoom 2010). Thus, many of the urban arable soils were most likely under the influence of a nearby construction site for at least ten years and were possibly used as repositories of construction materials for some time. Carbonates (as contained in various construction materials) in equilibrium with natural systems such as soils are known to exhibit a theoretical pH (water) $\sim 8.5$ (Brady and Weil 2017), and hence the presence of carbonate compounds in the urban soils is another potential source of the high $\mathrm{pH}$. In this regard, various components of household waste that were identified in the urban arable soils during fieldwork provide sources of such carbonate solid phases, including e.g. eggshells, animal bones, batteries, charcoal and ashes. Also, the detection and measurement of carbonates in most of the urban soils with $>\mathrm{pH} 6$ emphasizes this point. For instance, two samples that had the highest SIC stock of $>2.0 \mathrm{~kg} \mathrm{~m}^{-2}$, were also amongst the three samples with $\mathrm{a} \geq \mathrm{pH}$ 8.6. Like the abundance of coarse fragments, the high $\mathrm{pH}$ was another very clear consequence of rapid urbanisation that was identified in this study for the arable soils of Kumasi. However, such high soil pH as observed in the urban arable soils of Kumasi may induce phosphorus and micronutrient deficiency (Jim 1998). It remains, therefore, to be confirmed by further studies, if this is the case for these soils. 


\subsubsection{Effects of urbanisation on SOM}

SOMLo contents and stocks of the long-term urban soils generally exceeded those of the short-term urban soils, although at various degrees of confidence. Considering the nature of the coarse fragments and the observed anthropogenic activities on and near the fields, it was evident that the measured LOI and TC contents included not only typical SOM, but also artificial combustible materials such as fragments of textiles, plastics, and charcoal amongst others. The abundance of SIC in the urban soils strongly supported this assumption. The trends of SIC contents and stocks, which were consistent with the trends of SOMLo and TC contents and stocks, as well as those of soil $\mathrm{pH}$ and coarse fragment contents, stressed the prominent role of household waste on the urban arable soils.

These findings point to two main mechanisms related to rapid urbanisation. The first mechanism is the common practice of dumping of household waste on urban arable fields, and more specifically, the high proportion of organic materials in the household waste of Kumasi, which substantially contributes to SOM stocks of the urban arable soils of Kumasi. The range of SOM contents of urban soils of Kumasi was comparable to the range found for soils under various urban land-use types in the city of Baltimore, USA (Pouyat et al. 2002). Windmeijer and Andriesse (1993) reported $24.5 \mathrm{~g} \mathrm{~kg}^{-1}$ SOC for West African equatorial forests, which is also within the range of the SOC contents of the urban arable soils of Kumasi. Prudencio (1993) reported a range of $11-22 \mathrm{~g} \mathrm{~kg}^{-}$ ${ }^{1} \mathrm{SOC}$ for home gardens in Burkina Faso, which is slightly less, compared to the arable soils of Kumasi. Dicko (2016) reported SOC stocks of $1.02 \mathrm{~kg} \mathrm{~m}^{-2}$ for maize fields in the Upper East region of Ghana, which is markedly lower compared to the mean SOC stocks of the urban arable fields in Kumasi. 
The share of SOC in the SOMLo of the arable soils in Kumasi was about 37\%, which is markedly lower compared to the estimated 50 or $58 \%$ that are usually assumed in the common conversion equations from SOC into SOM data (Pribyl 2010). Further studies are needed to confirm this finding, because in this study, we calculated SOC contents as SOC $=\mathrm{TC}-\mathrm{SIC}$, whereby SIC contents were determined by the Scheibler method, which is less precise than the TC analysis by $\mathrm{CN}$ analyzer. Moreover, SOM contents were calculated based on LOI, and in the case of Kumasi, it is very likely that not only SOM but also the combustion of fine material of disintegrated artificial materials contributed to SOMLo (Vuong et al. 2013; Chatterjee et al. 2009). Despite these uncertainties, the substantial difference in the proportion of SOC in SOM (37\% for Kumasi) suggests that the SOM of the urban arable soils of Kumasi has a considerable lower proportion of SOC than usually assumed for SOM (50\% and 58\%, respectively).

The potential contribution of artificial materials to the soil carbon contents does apparently not lead to an increase in $\mathrm{C} / \mathrm{N}$ ratio, as the rural arable soils showed a mean $\mathrm{C} / \mathrm{N}$ ratio of 13.6 , whereas the short-term urban soils exhibited a mean $\mathrm{C} / \mathrm{N}$ ratio of 11.5 , and the long-term urban soils had a mean $\mathrm{C} / \mathrm{N}$ ratio of 12.8 . Thus, the urban soils exhibited even somewhat lower $\mathrm{C} / \mathrm{N}$ ratios than the rural soils. A possible explanation for this trend might be higher $\mathrm{C} / \mathrm{N}$ ratios in the organic household waste, as the latter is an important source of SOM in the urban soils, in addition to crop residues of the maize plants. In contrast, the SOM of the rural soils under maize has no such source in addition to the maize plant residues. Only four out of the 618 urban soils exhibited $\mathrm{C} / \mathrm{N}$ ratios above 25 , indicating either a lower quality of the SOM (Hazelton and Murphy 2016), or a contribution of charcoal. In general, the $\mathrm{C} / \mathrm{N}$ ratio suggested favourable characteristics of the SOM (Schipper et al. 2004) in all arable 
soils (urban, rural, and forest) of Kumasi. The mean $\mathrm{C} / \mathrm{N}$ ratios of the soils analysed in this study were similar to the $\mathrm{C} / \mathrm{N}$ ratios of $10.1-11.5$ obtained for forest soils of Ghana by Duah-Yentumi et al. (1998), and $14.9 \pm 8.6$ (mean \pm standard deviation) for many humid-tropical soils in general, as reported by (Post et al. 1985). The even slightly lower mean $\mathrm{C} / \mathrm{N}$ ratio of the long-term relative to the short-term urban soils indicates that the quality of SOM in the arable soils of Kumasi is maintained even under the prolonged influence of rapid urbanisation.

Thus, by disposing household waste on their fields (through mostly unplanned efforts), urban farmers in Kumasi cannot only keep the SOM stocks of their soils at higher levels compared to rural arable soils, but they may also maintain suitable $\mathrm{C} / \mathrm{N}$ ratios. Consistent to the explanation of increased SOM stocks and decreased $\mathrm{C} / \mathrm{N}$ ratios in urban soils by dumping of household waste with low $\mathrm{C} / \mathrm{N}$ ratio, Miezah et al. (2015) reported that $67 \%$ of municipal solid waste in Ghana is biodegradable. More specifically, in Kumasi the proportion of biodegradable materials was estimated to be $64 \%$, in addition to $22 \%$ inert materials, which are described to include e.g. ashes, sand and charcoal (Asase et al. 2009). These estimates, therefore, suggest that at least $86 \%$ of urban solid waste in Kumasi, which may be uncollected due to inadequate waste management systems, thus contributes significantly to SOM stocks.

The second main mechanism related to rapid urbanisation, is the accumulation of nonbiodegradable household wastes and construction materials, which dilute SOM and nutrient concentrations measured in the fine earth fraction to varying degree. This effect may explain why the differences between short-term and long-term urban arable soils with respect to SOMLO and SOC stocks were less significant than those with respect to the SOMLO and SOC contents in the fine earth fraction. In a related study, Asabere et al. (in preparation- now Study 1 of this thesis) identified the nucleated 
urban expansion nature of Kumasi, underscoring that areas that are closer to the core of the city have been under longer urbanisation with denser population. Such progressively denser population however leads to enhanced environmental degradation (Cobbinah and Erdiaw-Kwasie 2016), including e.g. enhanced accumulation of municipal solid waste and rock fragments. Thus, we suggest that the long-term urban soils that have been under continuous urbanisation for over 30 years and experienced an increase in population density over this period, accumulated greater amounts of uncollected waste and rock fragments than the short-term urban soils, whereby the accumulation proceeded in a non-linear way but was enhanced as the population density increased. The outcome of the recursive partitioning strongly confirmed the importance of coarse fragments in discriminating short-term and longterm urban soils.

The findings of this study strongly suggest that Kumasi would benefit immensely from an integrated waste management system (Asase et al. 2009). As demonstrated by Miezah et al. (2015), 92\% of urban residents in Ghana are willing to separate their waste in order to benefit from the associated environmental benefits. Thus, a promising way could be that city authorities actively engage urban residents in municipal solid waste management, provide the necessary infrastructure for collecting non-biodegradable waste, allow the urban citizens to separate biodegradable waste from other waste, and to use their biodegradable waste, preferably after composting, as organic fertilizer on their urban arable fields (McGregor et al. 2011; Adamtey et al. 2009; Drechsel and Kunze 2001). Such separation of waste would moreover allow the city of Kumasi to expand the lifespan of their single landfill site for a few more decades (Asase et al. 2009). 


\subsubsection{Conclusion}

The outcomes of this study demonstrate that SOM contents and stocks of long-term urban arable soils in Kumasi have been maintained and even increased, compared to short-term urban arable soils. At the same time, coarse fragments (including various kinds of artificial materials) that are related to rapid urbanisation have considerably accumulated in the long-term urban arable soils. The study suggests that a general notion that rapid urbanisation eventually enhances soil degradation (McGregor et al. 2011) needs to be differentiated. Urban arable soils of Kumasi are different from urban soils in some other cities, which have been described as highly modified, compacted, and of poor quality that compromises ecosystem services provision (Lorenz and Lal 2009; Lehmann and Stahr 2007; Jim 1998). Nevertheless, the findings in this study are in agreement with recent studies such as those of Edmondson et al. (2014), Joimel et al. (2016), Tresch et al. (2018(Tresch et al. 2018; Joimel et al. 2016; Edmondson et al. 2014) which demonstrated that urban arable soils may adequately support ecosystem provision in some European cities.

In this study, direct interrelations between the SOM stocks in urban arable soils and urban household wastes in the rapidly urbanising city of Kumasi have been identified. The obtained knowledge on these interrelations may strengthen the theoretical link between waste and soil sustainability, which is within the broader soil-waste-water nexus framework for sustainable resource management (Bouma 2016; Lal 2014, 2013). As illustrated by Drechsel et al. (2007), Ghanaian cities have become nutrient hubs due to the net import of crop produce from their hinterlands. The study also reconfirms conclusions of other studies, e.g. of Miezah et al. (2015) and Bouma (2016), proposing an integrated waste management system that reincorporates the imported nutrients and organic matter into the urban arable soils as a sustainable 
pathway to improve food security. In a broader sense, the outcomes of this research call for greater attention to urban arable soils, especially in tropical regions, where their provision of multiple ecosystem services is of utmost importance. As Kumasi is a typical rapidly urbanising West-African city, we conclude that the outcomes of this research are also relevant to most other cities in the West-African sub-region.

\section{Acknowledgement}

We thank George Ashiagbor and Martin Manu (Faculty of Renewable Natural Resources, Kwame Nkrumah University of Science and Technology), Eric Asamoah and Alexander Owusu-Ansah (Soil Research Institute, Centre for Scientific and Industrial Research) for the immense support and assistance during sampling in Kumasi. We also thank Dr. Jürgen Grotheer, Petra Voigt, Anja Södje, Raffael Hearth, Johanna Diederich, and Julia Sindermann (Dept. of Physical Geography, University of Göttingen) for their assistance in the lab analysis.

\section{Data availability statement}

The data that is generated for this study is part of the ongoing interdisciplinary UrbanRESS project, hosted at the Physical Geography_University of Goettingen. Data supporting the conclusions of this manuscript will be made available by the corresponding author, upon request to any qualified researcher. Also, all data will be publicly available upon completion of the project.

\section{Author contributions}

SBA and DS contributed conception and design of the study; SBA, DS and KAN organized the field campaign and sampled the soils; SBA analyzed samples and organized the database; SBA and TZ performed the statistical analysis; SBA wrote the first draft of the manuscript; TZ, KAN and DS wrote sections of the manuscript. All authors contributed to manuscript revision, read and approved the submitted version. 


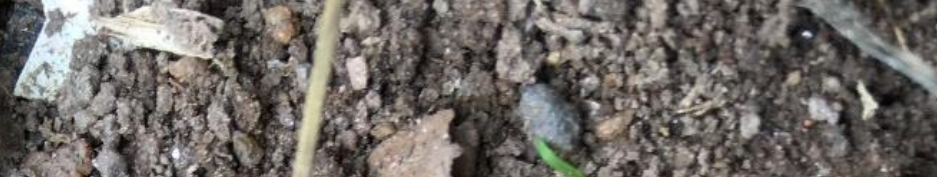

ant

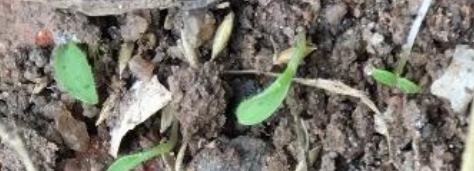

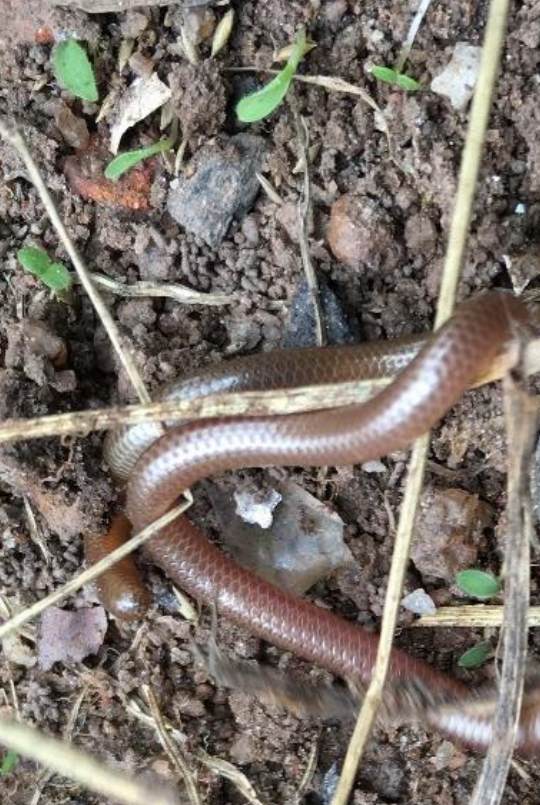

then fse

10.102

Hex 60
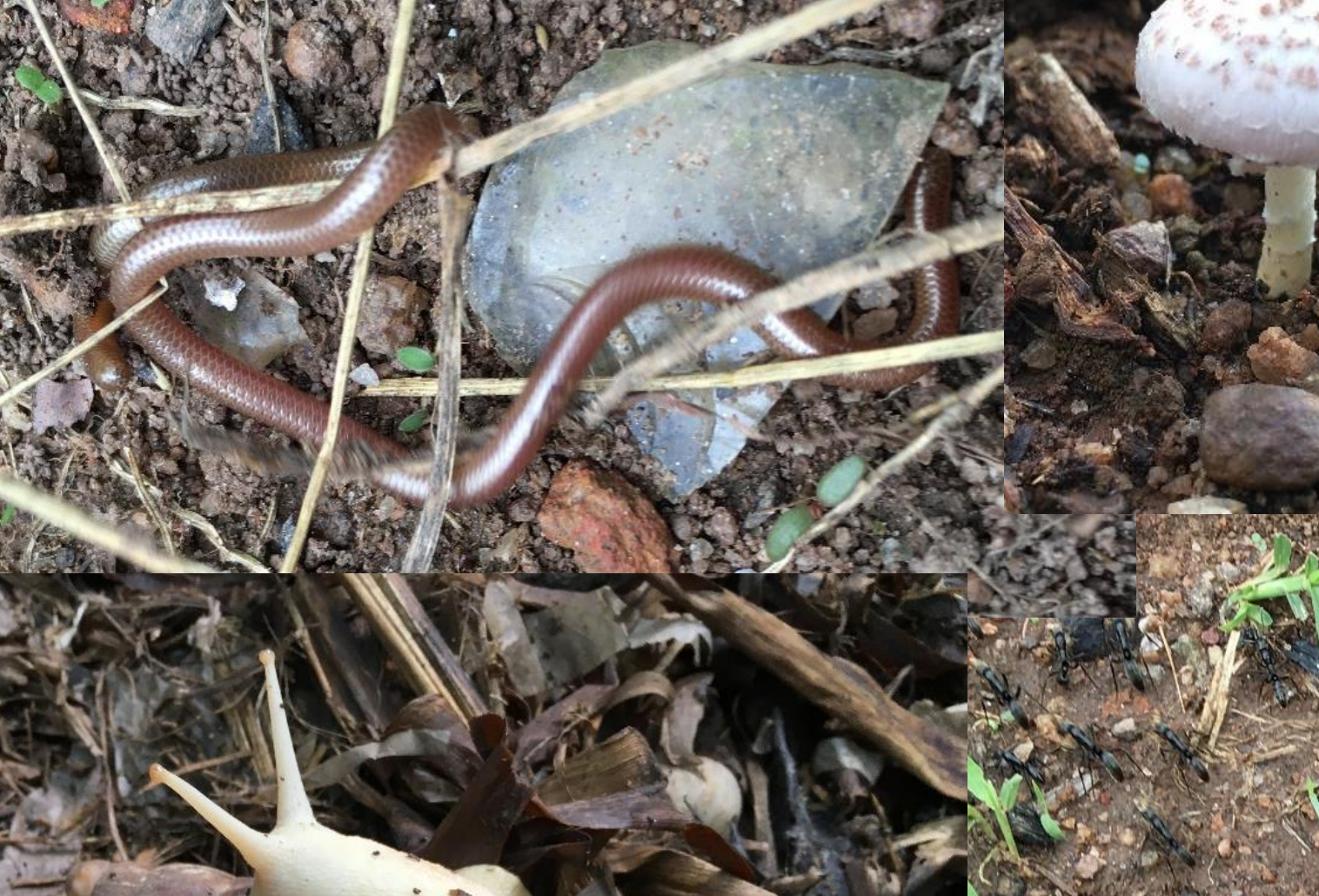


\title{
3.2 Study 4: Urbanisation enhances effective cation exchange capacity, stocks of $\mathrm{Ca}$ and $\mathrm{K}$, but reduces stocks of $\mathrm{N}$ and exchangeable $\mathrm{Mg}$ in arable soils of Kumasi, Ghana (West Africa)
}

\author{
Stephen Boahen Asabere ${ }^{1}$, Thorsten Zeppenfeld ${ }^{1}$, Kwabena Abrefa Nketia ${ }^{1,2}$, Daniela \\ Sauer'.
${ }^{1}$ Department of Physical Geography, Institute of Geography, University of Göttingen, Göttingen, Germany
${ }^{2}$ Council for Scientific and Industrial Research, Soil Research Institute, Kumasi, Ghana
${ }^{3}$ Geschäftsstelle Biosphärengebiet Schwäbische Alb, Germany.

- Manuscript in preparation

- An abstract based on the manuscript is published in Geophysical Research Abstracts as Asabere et al. 2018. Influence of urbanisation on cation exchange capacity and nutrient availability in arable soils of Kumasi (Ghana). [online] Available at: //meetingorganizer.copernicus.org/EGU2018/EGU2018-718-1.pdf.

\begin{abstract}
In most West African cities, urban farming is an important component in ensuring food security and making cities sustainable. We addressed the question, in which way is soil fertility of arable land altered when the land becomes part of an expanding city? We analysed three key parameters of soil fertility, namely effective cation exchange capacity (ECEC), stocks of exchangeable nutrient cations and $\mathrm{N}$, in soils of rain-fed maize fields in the rapidly expanding city of Kumasi (Ghana). Naturally, ECEC and stocks of exchangeable nutrients are low in typical tropical soils of West Africa. Thus, the effect of urbanisation on these soil properties is of relevance. In 2016, we took topsoil samples $(0-10 \mathrm{~cm})$ from 206 maize fields (triplicates $=618$ samples) on Acrisols of the same local soil series. Thereby, we distinguished soils that were urban already in 1986 as long-term ( $\geq 30$ years of urbanisation influence) and soils that became urban after 1986 as short-term ( $<30$ years) urban soils. ECEC and stocks of exchangeable $\mathrm{Ca}^{2+}, \mathrm{K}^{+}$and $\mathrm{Na}^{+}$were significantly higher in the long-term compared to the short-term urban soils. This result can be explained by accumulation of household waste (organic and inorganic) and construction materials on the arable fields, leading to increased soil organic matter stocks and soil pHwater that in turn enhance ECEC and stocks of exchangeable $\mathrm{Ca}^{2+}, \mathrm{K}^{+}$and $\mathrm{Na}^{+}$. However, stocks of exchangeable $\mathrm{Mg}^{2+}$ and total $\mathrm{N}$ were lower in the long-term compared to the short-term urban soils, most likely due to increased intensity of agricultural use under urban conditions. Urban soils in West African cities have the potential to contribute to food security of the local population, but well-coordinated urban planning and waste management are needed to avoid negative effects of urbanisation on arable soils, such as accumulation of nondegradable household waste and pollutants.
\end{abstract}

Keywords: urban soils, West Africa, urbanisation, CEC, nutrient availability 


\subsubsection{Introduction}

Soils of tropical West African cities feature high drainage, conducive temperature and advanced age. Acrisols, Ferralsols, Plinthisols and Lixisols are the most widespread World Reference Based (WRB) soil groups (Jones et al. 2013). Because of an advanced stage of pedogenises, leaching, and the accelerated mineralization of soil organic matter (SOM), these soils lack in weatherable minerals and nutrients, and they have very low cation exchange capacity (CEC) (Mendonça and Rowell 1996; Glaser 2007). In order to balance soil nutrients, tropical regions are naturally dependent on contents of biomass cycling, which is highly influenced by anthropogenic land use changes such as urbanisation (Amundson 2001; Maranguit et al. 2017). In recent years, urbanisation is progressing rapidly in West Africa, but how urban soils in the region are responding to the ensuing changes are still unclear. Moreover, urban farming is widespread and pivotal to the sustainability of inhabitants of the cities in West Africa, and therefore, an understanding of the fertility of urban soils will be useful to support sustainable urban management schemes (Asabere et al. 2018b).

Smallholder farmers in sub-Sahara Africa lack the economic capacity to afford mineral fertilizers for their fields, and thus, in addition to the naturally limiting conditions, the soils in this region often show negative nutrient balances (Stoorvogel et al. 1993; Minde et al. 2008). $\mathrm{N}$ deficiency has been widely reported for about $80 \%$ of the countries in the region (Masso et al. 2017). Moreover, without fallow periods, continuously cultivating on tropical soils quickly diminishes it nutrient levels with every harvest. For instance, Solomon et al. (2007) has shown that the contents of soil organic $\mathrm{C}$ and $\mathrm{N}$ decreased by $85 \%$ from an initial 119 and $10.8 \mathrm{~g} \mathrm{~kg}^{-1}$ respectively after 35 years of continuous cultivation on tropical soils of Kenya. Similarly, Drechsel (2002) has estimated $\sim 58 \mathrm{~kg} \mathrm{ha}^{-1} \mathrm{yr}^{-1} \mathrm{~N}$ losses with time through harvesting, in the 
arable fields of the Ashanti region of Ghana. Considering that rapid urbanisation in African cities is occurring at the expense of arable lands (Vermeiren et al. 2013; Willkomm et al. 2019), urban farmers are subjecting their fields to such continuous cultivation. Thus, it remains to be answered in which state the urban arable soils are, and which conditions may be improved to sustain nutrient levels that can support the provision of various urban ecosystem services.

The CEC is an indicator of the soil's buffering ability to maintain $\mathrm{pH}$ and structural changes, as well as to retain available nutrients and water for plant use (Hazelton and Murphy 2016). CEC can be determined by the nature and contents of cation (acid and base) exchangers (Soares et al. 2005). Contents of the acid cations have net positive charges (i.e. become anion exchangers) at the naturally acidic conditions of tropical soils. The mineral fraction of tropical soils is dominated by contents of oxides (acid cations such as $\mathrm{Fe}, \mathrm{Al}$ and $\mathrm{Mn}$ ) and 1:1-type clays such as kaolinite that have extremely low permanent charge $\left(<2 \mathrm{cmol} \mathrm{kg}^{-1}\right)$ (Soares et al. 2005). Thus, it is important to enhance the contents of base cations in order to increase the overall CEC of tropical soils. Typically, tropical soils have a $2-6 \mathrm{cmol} \mathrm{kg}^{-1} \mathrm{CEC}$ range (Gallez et al. 1976; Oorts et al. 2003). Because of such inherently low CEC, tropical soils are inefficient to utilize mineral fertilizers that may be applied (Zech et al. 1997; Glaser et al. 2002). For instance, in high-input intensively cultivated tropical fields such as those in Mato Grosso (Brazil), it has been estimated that farmers have to apply 2 times the amount of fertilizer to achieve the same crop yields as their temperate counterparts (Roy et al. 2017). Such inherently low CEC is thus attributable to the mineralogy and a low SOM contents of tropical soils.

In contrast to the dominant contents of oxides and kaolinite in tropical soils, SOM contents have a net negative charge even at the acidic conditions (Blume et al. 2016). 
SOM contents, also produce organic anions that complexes with the abundant anion exchangers in tropical soils, and thus further enhances the capacity of the cation exchangers (Gallez et al. 1976; Ramos et al. 2018). In addition, SOM contents enhance the soil structure and water holding capacity (Brock et al. 2017; Lal 2006). Moreover, in tropical soils, SOM content may be the most important source of major plant nutrients $(\mathrm{C}, \mathrm{N}$ and $\mathrm{P})$ and nutrient base cation exchangers such as $\mathrm{Ca}^{2+}, \mathrm{Mg}^{2+}$, $\mathrm{K}^{+}$and $\mathrm{Na}^{+}$. Thus, an important way to enhance the CEC of tropical soils in the naturally acidic conditions is by increasing the SOM contents. In this regard, there are estimates of SOM content contribution by $50-90 \%$ of the CEC of tropical soils (Oorts et al. 2003). For instance, Ramos et al. (2018) has shown in an experiment that when SOM contents were completely removed from a humid-tropical soil, the CEC decreased from 8 to $4 \mathrm{cmol} \mathrm{kg}^{-1}$. Consequently, a properly managed SOM content is a fundamental requirement for soil fertility enhancement without which it is extremely challenging to continuously farm the same piece of land in tropical soils, even if mineral fertilizer is applied (Glaser et al. 2002; Bationo et al. 2007).

As a cost-effective solution to the nutrient depletion challenges in tropical areas of subSahara Africa, SOM contents of arable fields can be improved with compost and manure from organic waste and farm residues (Bationo and Mokwunye 1991; Onduru et al. 1999; Zingore et al. 2008). Such an option is particularly relevant for tropical West African cities that often lack appropriate urban waste management (Pacione 2009) on the one hand, and inherently low soil fertility in its urban arable fields on the other hand. For instance, in a related study in Kumasi (Ghana), Asabere et al. (2018b) has demonstrated that the gradual accumulation of household waste in urban arable soils without any conscious effort by urban farmers, has consequently enhanced their SOM stocks and soil pH. Beyond this finding, the implications of urbanisation on other 
relevant soil fertility indicators such as the CEC and contents of plant available nutrients is still largely unclear.

Thus, the question of the response of urban arable soils to the rapid urbanisation in West African cities remains to be fully answered. In this study, we present empirical findings on the city of Kumasi (Ghana) about the effects of rapid urbanisation on the other relevant soil fertility parameters such as the levels of CEC, contents of exchangeable nutrient bases and total $\mathrm{N}$. These parameters are related to the soil $\mathrm{pH}$ and SOM contents that were reported in Asabere et al. (2018), in order to deepen the understanding of the status of soil fertility of arable soils that are influenced by rapid urbanization in Kumasi, a typical West African city. For this purpose, we systematically analysed the top soils from Kumasi for contents of total $\mathrm{N}(\mathrm{TN})$ and exchangeable base cations, and calculated the effective cation exchange capacity (ECEC). We hypothesized that in the absence of any fertilization, arable soils that have been in an urban environment for a long time ( $\geq 30$ years) have lower contents of exchangeable nutrient base cations and ECEC, compared to arable soils that have been in an urban environment for a shorter period ( $<30$ years) as well as soils in a rural environment.

\subsubsection{Methods}

\subsubsection{Study area and sampling approach}

The study area, Kumasi (Figure 3.2.1), is the second largest city in Ghana, and the capital of the Ashanti region, which is one of the 16 administrative regions of the country. The population of the city increased exponentially from $\sim 480$ thousand to $\sim 2$ million people between 1984 and 2010, and a corresponding land area of $\sim 313 \mathrm{~km}^{2}$ has been assimilated (Acheampong et al. 2017). Such rapid population growth and underlying drivers in Kumasi reflect the general trend of urbanisation in the West Africa region (Henderson et al. 2014). Also, like most West African cities, urban farming is 
common in the core and periphery of Kumasi (Figure 3.2.1), and it serves as an important source of livelihood for some inhabitants. The city is located within the Guinean forests of West Africa, a biodiversity hotspot (Myers et al. 2000), with moist tropical climate conditions. The altitude is between 250-300 m above sea level, with mean monthly temperatures of $27-30^{\circ} \mathrm{C}$. Mean annual precipitation ranges between 1300 and $1800 \mathrm{~mm}$, with two peaks in the rainy, one in May-June and the other in September-October. Ferric Acrisols developed on granite dominate the soils in this area (Adu 1992). Hence, Soil pH, contents of exchangeable base cations, organic $\mathrm{C}$ and $\mathrm{N}$ are generally low in these soils, with kaolinite dominated clay minerals.

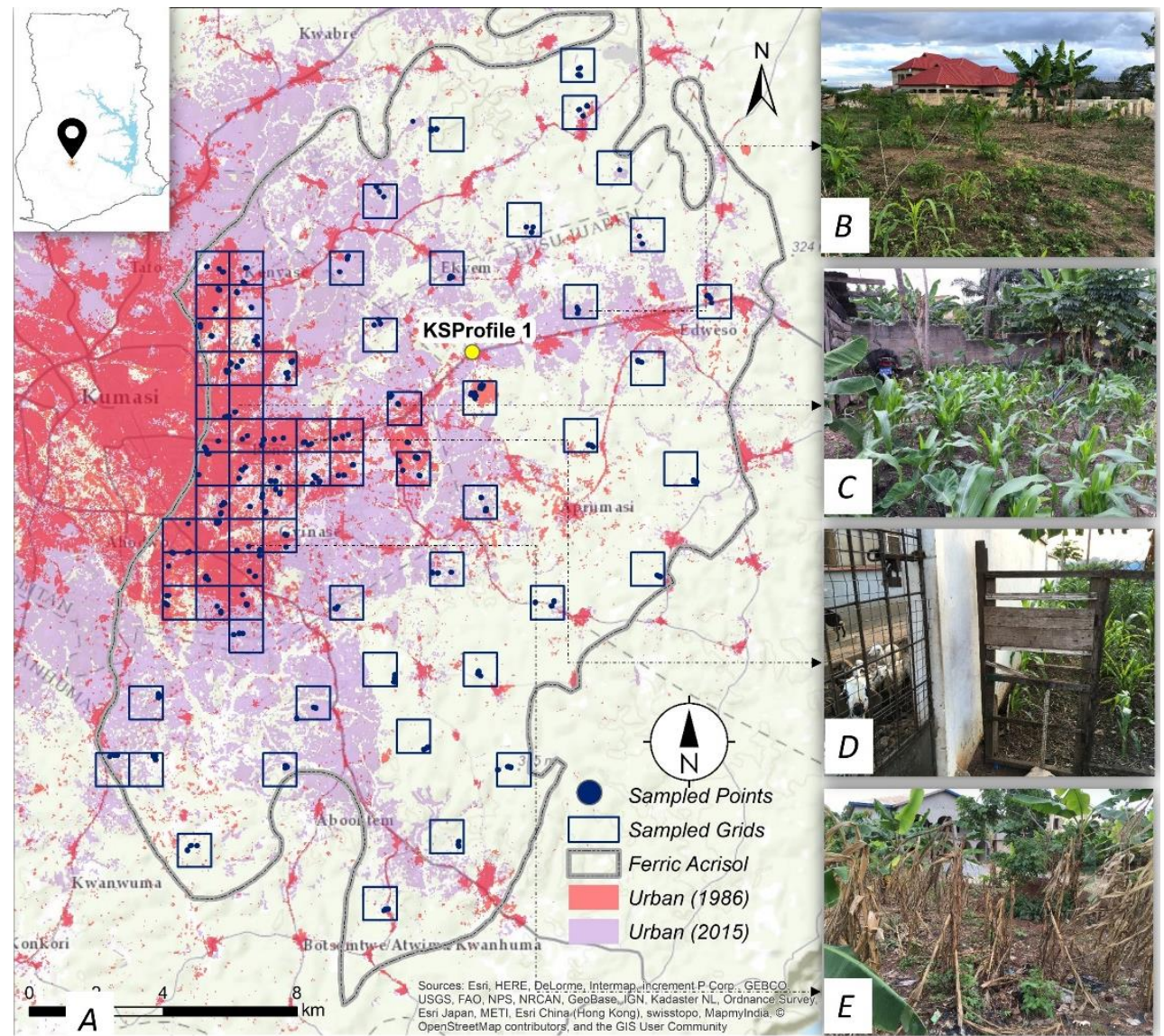

Figure 3.2.1: (A) Location of Kumasi in Ghana (insert) showing the systematic grid-based sampling locations on the Ferric Acrisol in study area, and the chronological urban expansion of the city from 1986 to 2015. (B-E) examples of maize fields that are in back-and front-yard of houses and open areas, which are exposed to on-going construction, urban waste, foot-path, and farm animals (Pictures by Stephen Asabere).

For this study, we made use of soil samples that were extracted from arable fields following a grid-based urbanisation chronosequence approach as detailed in Asabere 
et al. (2018b). In the approach, two categories were defined based a 1986 urban extent that was deduced from a Landsat satellite image, and a field sampling campaign that was conducted in August-September 2016. Sampled fields that were located in the inner urban area according to the 1986 satellite image, and are thus under the influence of urbanisation for $\geq 30$ years were denoted as long-term urban soils (357 samples) (Figure 3.2.1). Similarly, the fields that were located in the areas that became urban after 1986 and are thus under the influence of urbanisation for $\leq$ 30 years were denoted as short-term urban soils (261 samples) (Figure 3.2.1). Three fields were systematically selected based a $1 \mathrm{X} 1 \mathrm{~km}^{2}$ grid as indicated in Figure 3.2.1. For each field, triplicates of top soils $(0-10 \mathrm{~cm})$ were extracted from each maize field, which totalled 206 fields (triplicates= 618 samples). For comparison, a forested area within the city (triplicates $=9$ samples), and three rural maize fields $($ triplicates $=9$ samples) were also sampled.

Figure 3.2.1B-E gives some visual impressions of the sampled maize fields. Consequently, the overall approach ensured that the aim to sample soils with a consistent combination of factors such as parent material, soil unit, climate and cultivated crop(s) was largely achieved.

\subsubsection{Laboratory analyses}

Soil preparation and the analyses of contents of SOM, total C (TC) and total N (TN) are detailed in Asabere et al. (2018b). Content of SOM was determined by the losson-ignition method, and a $\mathrm{CHN}$ analyser was used to determine the contents of TC and TN by the dry combustion method. Exchangeable cations were extracted by the percolation method (Lüer and Böhmer 2000). For this, we percolated a $1 \mathrm{M} \mathrm{NH}_{4} \mathrm{Cl}$ solution through $\sim 2.5 \mathrm{~g}$ of fine earth soil. The difference in $\mathrm{pH}$ of the solution before and after filtration was noted, and the filtrate was analysed for $\mathrm{Ca}^{2+}, \mathrm{Mg}^{2+}, \mathrm{K}^{+}, \mathrm{Na}^{+}$, 
$\mathrm{Al}^{3+}, \mathrm{Fe}^{2+}, \mathrm{Mn}^{2+}$ and $\mathrm{H}^{+}$, by inductively coupled plasma optic emission spectrometry (ICP-OES). The exchangeable cations were calculated by accounting for the $\mathrm{pH}$ differences of the $\mathrm{NH}_{4} \mathrm{Cl}$ that was determined before and after the percolation, and the hydrolysis constant of Al. Thus, we derived the effective cation exchange capacity (ECEC) from the sum of the exchangeable cations, considering their valence. Also, we derived effective base saturation (BS) by dividing the sum of exchangeable bases with the ECEC and multiplying it by $100 \%$. All results were corrected for water contents of the $40{ }^{\circ} \mathrm{C}$ dried samples, and element contents were transformed to element stocks per $1 \mathrm{~m}^{2}$ by considering bulk density and contents of coarse fragments.

\subsubsection{Statistical tests}

We tested all analytical data (i.e. TN, CEC and exchangeable bases) that were obtained for the long-term urban soils against those for the short-term urban soils with a set of linear mixed models. The outcome of the model is an estimated fixed effect, which was described as the relative difference between the long-term and the shortterm urban soils, with respect to the selected soil parameter. We accounted for spatial autocorrelation of data from the field triplicates by adding the field identifier as a random effect to the model. The models with a $\mathrm{Cl}$ that excluded zero indicated a significant influence of the fixed effect for the two categories. Positive estimates of fixed effect indicated that the value of the respective parameter was higher in longterm urban soils, whereas negative estimates indicated that the value of the parameter was higher in the short-term urban soils. The upper and lower limits of the $\mathrm{Cl}$ were used to describe the strength of the model estimates.

To assess how SOM contents within a general urbanisation context influenced TN contents, we used a similar modelling approach to analyse the relationship between TN stocks and its predictor SOM stocks. In the same context and approach, the 
relationship between ECEC and its predictor SOM concentration and soil $\mathrm{pH}$ water was analysed, both independently and as multiple predictors. Also, because of the nonsimple nature of the relationship, the $\mathrm{BS}$ and its predictor soil $\mathrm{pH}_{\text {water }}$ was analysed with a piecewise linear model. Model performances and relationship strengths were evaluated in all cases by the coefficient of determination $\left(r^{2}\right)$ (Barton 2018). Consequently, to assess how each soil fertility parameter relates to others within the large urbanisation influence, we used bivariate correlation plots and assessed the strength of the relationships with the correlation coefficient $(R)$. All statistical analyses were conducted in R (R Core Team 2018), using its extensions 'polynom' (Venables et al. 2016), 'Ime4' (Bates et al. 2015), 'MuMIn' (Barton 2018), and 'segmented' (Muggeo 2017).

\subsubsection{Results}

\subsubsection{Total $\mathbf{N}$ contents and stocks}

Mean ( \pm standard error) fine and bulk TN contents and stocks in the urban soils were comparable to that of the forest soils, but they exceeded those of the rural soils (Figure 3.2.2). For instance, mean $T N$ stocks of the long-term urban soils $\left(0.16 \pm 0.004 \mathrm{~kg} \mathrm{~m}^{-2}\right)$ and that of the short-term urban soils $\left(0.18 \pm 0.004 \mathrm{~kg} \mathrm{~m}^{-2}\right)$ were similar to the that of the forest soils $\left(0.17 \pm 0.02 \mathrm{~kg} \mathrm{~m}^{-2}\right)$, but markedly exceeded that of the rural soils $\left(0.10 \pm 0.01 \mathrm{~kg} \mathrm{~m}^{-2}\right)$. Moreover, the negative estimates of the models indicated that TN contents and stocks in the short-term urban soils were generally higher compared to those of the long-term urban soils (Figure 3.2.3). Because $\mathrm{Cl}$ of the fine earth model had zero, it indicated a low confidence, but the non-zero Cls in the bulk contents and stocks were indications of significant differences. Thus, these results illustrated that urbanisation in Kumasi has decreased the TN contents and stocks of its arable fields. This trend of a greater contents and stocks of TN in the short-term urban soil compared 
to the long-term urban soils, was in contrast to the trend of the SOM contents and stocks as reported in Asabere et al. (2018b).
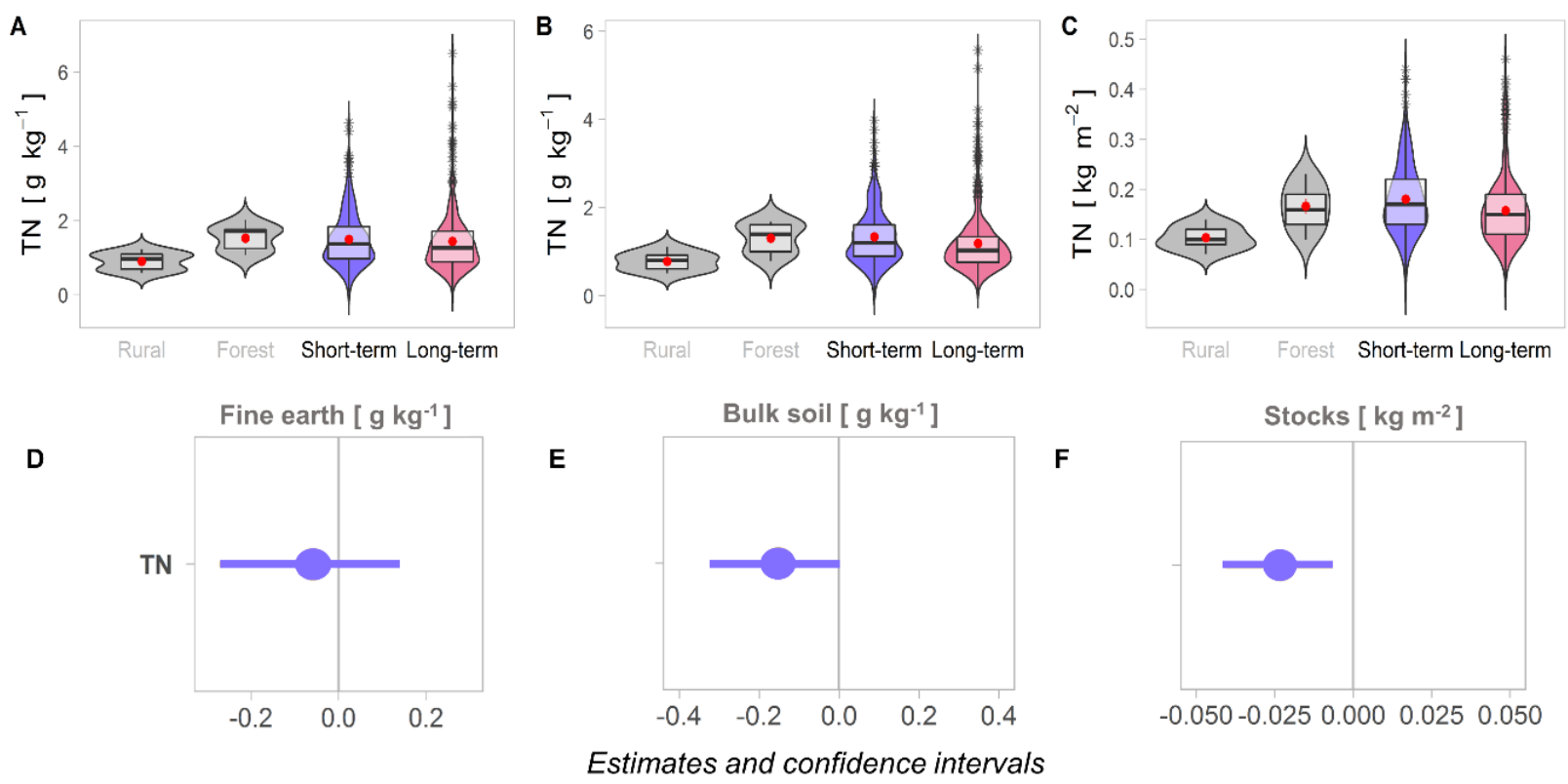

Figure 3.2.2: (A-C) Box and violin plots comparing rural, forest and urban soils with regards to fine earth concentration, bulk contents, and stocks in top $10 \mathrm{~cm}$ of Total N. Arithmetic means (red points), standard errors (red whiskers), medians (bars), ranges (whiskers), and outliers (asterisks) are shown. (D-F): Comparison of long-term versus short-term urban soils, estimating fixed effects of model coefficients and 95\% confidence intervals of the linear mixed models for the contents and stocks of soil organic matter (SOM) and total N (TN). Positive estimates represent higher TN contents and stocks in the long-term urban soils, whereas negative values represent lower parameter relative to the short-term urban soils. Error bars that do not cross the zero line indicate statistical significance. Scale on $x$-axis is different for each model.

\subsubsection{Exchangeable nutrient base cation contents and stocks}

Mean exchangeable $\mathrm{Ca}^{2+}$ concentration of the long-term urban soils $\left(9.8 \pm 0.5 \mathrm{cmol} \mathrm{kg}^{-}\right.$

$\left.{ }^{1}\right)$ exceeded that of the short-term urban soils $\left(5.9 \pm 0.3 \mathrm{cmol} \mathrm{kg}^{-1}\right)$, and both exceeded those of the forest $\left(3.3 \pm 0.5 \mathrm{cmol} \mathrm{kg}^{-1}\right)$ and rural soils $\left(2.4 \pm 0.4 \mathrm{cmol} \mathrm{kg}^{-1}\right)$ (Figure 3.2.3A). Similarly, the mean $\mathrm{Ca}^{2+}$ stocks of the long-term urban soils $\left(210.0 \pm 8.4 \mathrm{~g} \mathrm{~m}^{-}\right.$ $\left.{ }^{2}\right)$ and short-term urban soils $\left(145.2 \pm 6.8 \mathrm{~g} \mathrm{~m}^{-2}\right)$ markedly exceeded those for the forest $\left(71.7 \pm 12.5 \mathrm{~g} \mathrm{~m}^{-2}\right)$ and rural $\left(55.2 \pm 7.7 \mathrm{~g} \mathrm{~m}^{-2}\right)$ soils (Figure $\left.3.2 .3 \mathrm{C}\right)$. Model estimates confirmed that the contents and stocks of exchangeable $\mathrm{Ca}^{2+}$ was significantly higher in the long-term urban soils compared to those of the short-term urban soils (Figure 3.2.4). These trends of marked differences between the urban soils on the one hand, 
and in comparison, to the forest and rural soils on the other hand, reflected similar trends of the soil $\mathrm{pH}_{\text {water }}$ as reported in Asabere et al. (2018b).
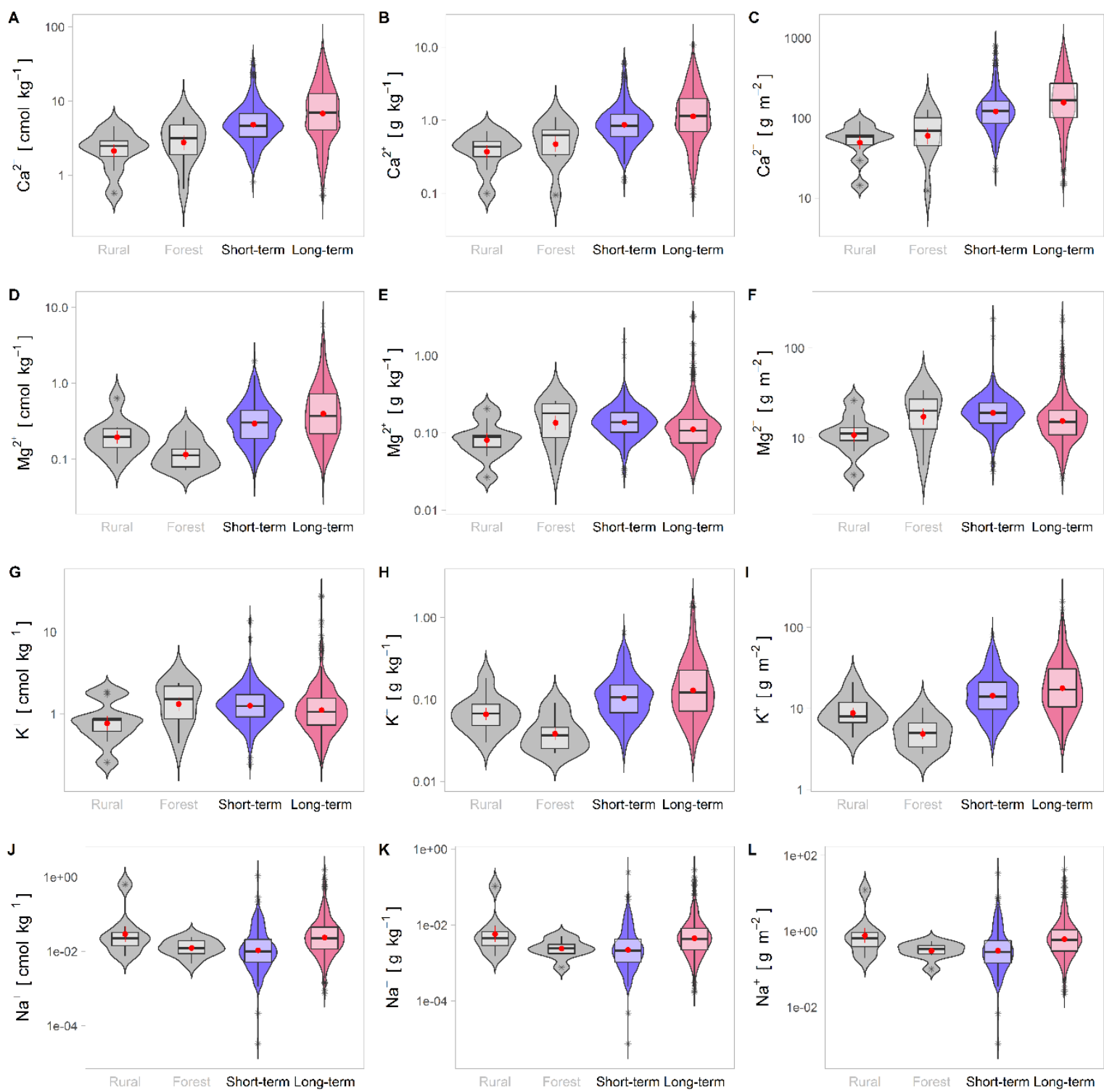

Figure 3.2.3: Box and violin plots comparing rural, forest and urban soils with regards to fine earth concentration, bulk contents, and stocks in top $10 \mathrm{~cm}$ of $(A-C)$ Exchangeable $\mathrm{Ca}^{2+}$; $(D-$ F) Exchangeable $\mathrm{Mg}^{2+}$; (G-I) Exchangeable $\mathrm{K}^{+}$; (J-L) Exchangeable Na+. Arithmetic means (red points), standard errors (red whiskers), medians (bars), ranges (whiskers), and outliers (asterisks) are shown. Note: All data is log (base 10) transformed for visualization. 

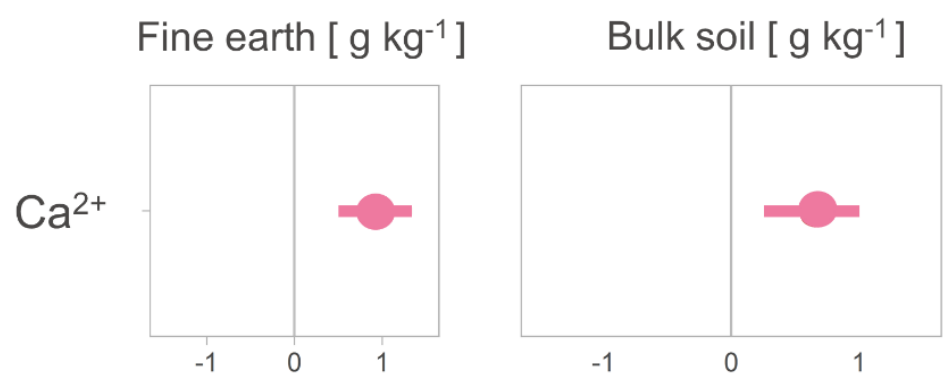

Stock [ $\mathrm{g} \mathrm{m}^{-2}$ ]
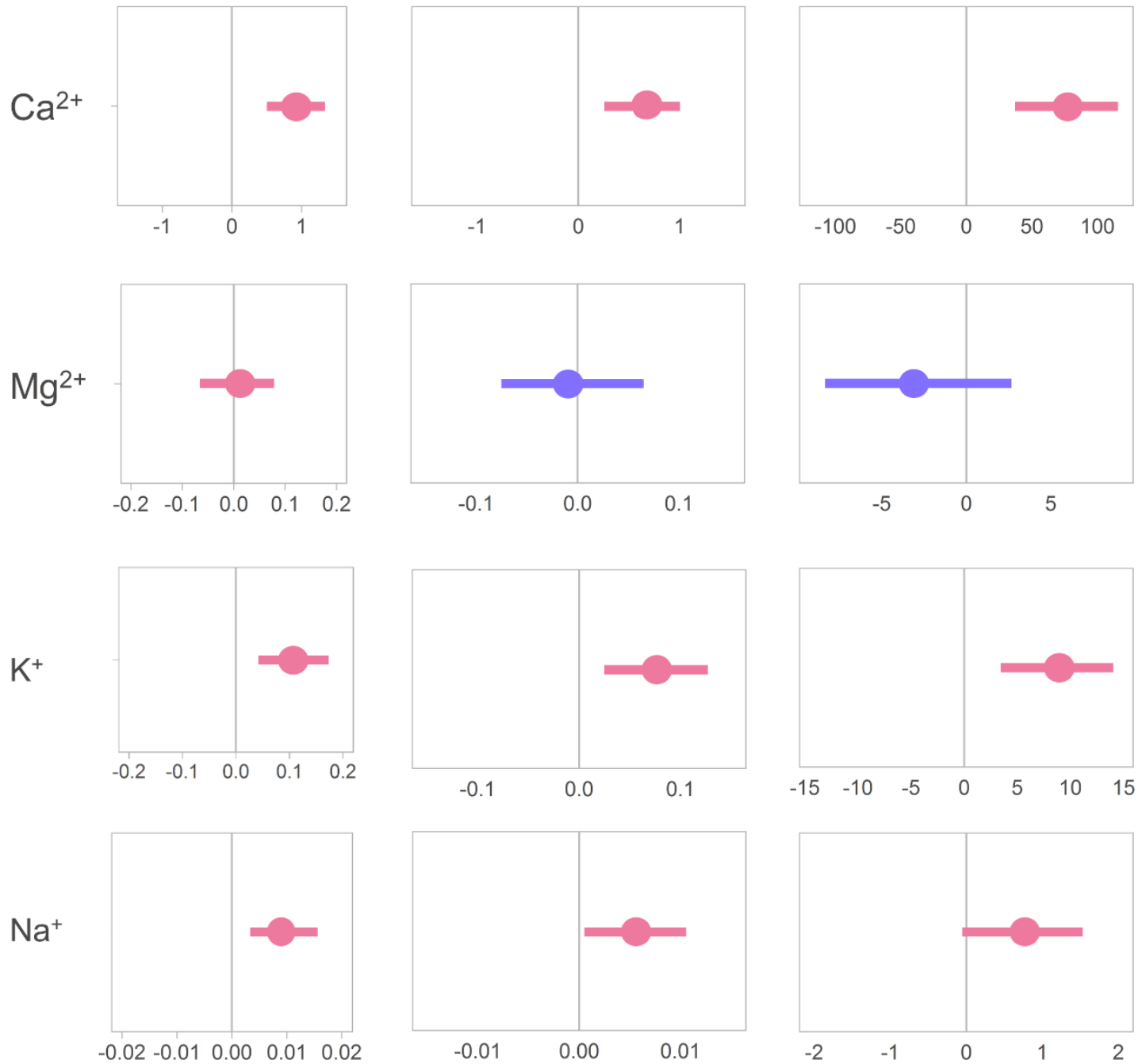

Estimate and confidence intervals

Figure 3.2.4: Comparison of long-term versus short-term urban soils, estimating fixed effects of model coefficients and 95\% confidence intervals of the linear mixed models for the contents and stocks of exchangeable $\mathrm{Ca}^{2+}, \mathrm{Mg}^{2+}, \mathrm{K}^{+}$and $\mathrm{Na}^{+}$. Positive estimates represent higher soil fertility parameter in the long-term urban soils, whereas negative values represent lower parameter relative to the short-term urban soils. Error bars that do not cross the zero line indicate statistical significance. Scale on $x$-axis is different for each model.

Mean exchangeable $\mathrm{K}^{+}$concentration was similar in the urban soils (long-term= $1.5 \pm 0.1 \mathrm{cmol} \mathrm{kg}^{-1}$, and short-term $\left.=1.4 \pm 0.1 \mathrm{cmol} \mathrm{kg}^{-1}\right)$, and they compared positively with that of the forest soils $\left(1.5 \pm 0.2 \mathrm{cmol} \mathrm{kg}^{-1}\right)$ (Figure 3.2.3G). These values exceeded those of the rural soils $\left(0.9 \pm 0.2 \mathrm{cmol} \mathrm{kg}^{-1}\right)$. However, mean exchangeable $\mathrm{K}^{+}$in the bulk contents and stocks of the rural soils $\left(9.7 \pm 1.7 \mathrm{~g} \mathrm{~m}^{-2}\right)$ exceeded that of the forest soils $\left(5.3 \pm 0.8 \mathrm{~g} \mathrm{~m}^{-2}\right)$, and both means compared less to those of the urban soils (long- 
term $=24.5 \pm 1.3 \mathrm{~g} \mathrm{~m}^{-2}$, and short-term $=17.3 \pm 0.7 \mathrm{~g} \mathrm{~m}^{-2}$ ) (Figure 3.2.3G-I). Model estimates were positive without zero in the $\mathrm{Cl}$, and it thus indicated that the contents and stocks of exchangeable $\mathrm{K}^{+}$of the long-term urban soils were significantly higher compared to those of the short-term urban soils (Figure 3.2.4). Similar to these trends, the contents and stocks of $\mathrm{Na}^{+}$were also significantly higher in the long-term urban soils compared to those of the short-term urban soils (Figure 3.2.4).

Mean exchangeable $\mathrm{Mg}^{2+}$ concentration of the long-term urban soils $(0.57 \pm 0.03$ $\left.\mathrm{cmol} \mathrm{kg}{ }^{-1}\right)$ exceeded their short-term $\left(0.36 \pm 0.02 \mathrm{cmol} \mathrm{kg}^{-1}\right)$ counterparts, and both means exceeded those of the forest $\left(0.12 \pm 0.02 \mathrm{cmol} \mathrm{kg}^{-1}\right)$ and rural soils $\left(0.23 \pm 0.05 \mathrm{cmol} \mathrm{kg}^{-1}\right)$ (Figure 3.2.3D). Only Seven long-term urban samples had $>3$ cmol kg-1 exchangeable $\mathrm{Mg}^{2+}$ concentration, while the majority ( $\left.90 \%\right)$ of all samples had $<1 \mathrm{cmol} \mathrm{kg}^{-1}$. The concentrations of these seven samples skewed the overall mean of the long-term urban soils. The seven samples were obtained from three maize fields, which had high amounts of animal droppings and charred wood dust. Because the fields were adjacent to an animal shelter and an abandoned wood processing factory, it was consistent that these were the sources. The concentrations of 559 urban soil samples and all the forest and rural soil samples were $<1 \mathrm{cmol} \mathrm{kg}^{-1}$, and a striking $42 \%$ of these samples were $<0.3 \mathrm{cmol} \mathrm{kg}^{-1}$. The urban and forest soils had similar mean exchangeable $\mathrm{Mg}^{2+}$ concentration in the fine earth $\left(\sim 0.18 \mathrm{~g} \mathrm{~kg}^{-1}\right)$, which markedly exceeded that of the rural soils $\left(0.11 \pm=0.02 \mathrm{~g} \mathrm{~kg}^{-1}\right)$. In the bulk soil, the mean exchangeable $\mathrm{Mg}^{2+}$ stock of the short-term urban soils $\left(21.3 \pm 1 \mathrm{~g} \mathrm{~m}^{-2}\right)$ slightly exceeded that of the long-term urban soils $\left(19.0 \pm 1 \mathrm{~g} \mathrm{~m}^{-2}\right)$. Both means compared positively with that of the forest soils $\left(20.3 \pm 3.5 \mathrm{~g} \mathrm{~m}^{-2}\right)$, but markedly exceeded that of the rural soils $\left(12.17 \pm 2.2 \mathrm{~g} \mathrm{~m}^{-2}\right)$ (Figure 3.2.3F). 
Model estimates and Cls of the contents of exchangeable $\mathrm{Mg}^{2+}$ in the fine earth and bulk soil were centred around zero, and thus suggested similar contents in the urban soils (Figure 3.2.4). In the stocks, even with zero in the Cls, the model estimates were noticeably negative, which indicated that exchangeable $\mathrm{Mg}^{2+}$ stocks in the short-term urban soils were higher compared to the long-term urban soils at low confidence. This result is attributable to the conversion from element contents to element stocks, in which the volume occupied by the coarse fragments contents of the soil was regarded as inert to contribute to contents of $\mathrm{Mg}^{2+}$. As it has been reported in Asabere et al. (2018b), the proportion of the coarse fragment contents was significantly higher in the long-term urban soils compared to the short-term urban soils. Thus, its counteracting effects on the $\mathrm{Mg}^{2+}$ contents in the long-term urban soils were comparatively higher than those of the short-term urban soils.

Consequently, the effects of urbanisation on the exchangeable nutrient base cations of the arable soils of Kumasi were differentiated between the increased contents and stocks of $\mathrm{Ca}^{2+}, \mathrm{K}^{+}$and $\mathrm{Na}^{+}$on the one hand, and the decreased contents and stocks of $\mathrm{Mg}^{2+}$ on the other hand. In addition, as detailed in Figure 3.2.5A, the contributions of the various base cations to BS of the urban, forest and rural soils generally followed a pattern as $\mathrm{Ca}^{2+}>\mathrm{Mg}^{2+}>\mathrm{K}^{+}>\mathrm{Na}^{+}$. Thus, in all soil sample groups, the contribution of $\mathrm{Ca}^{2+}$ content was $>50 \%$, and this contribution was markedly greater in the urban soils (Figure 3.2.5A). 

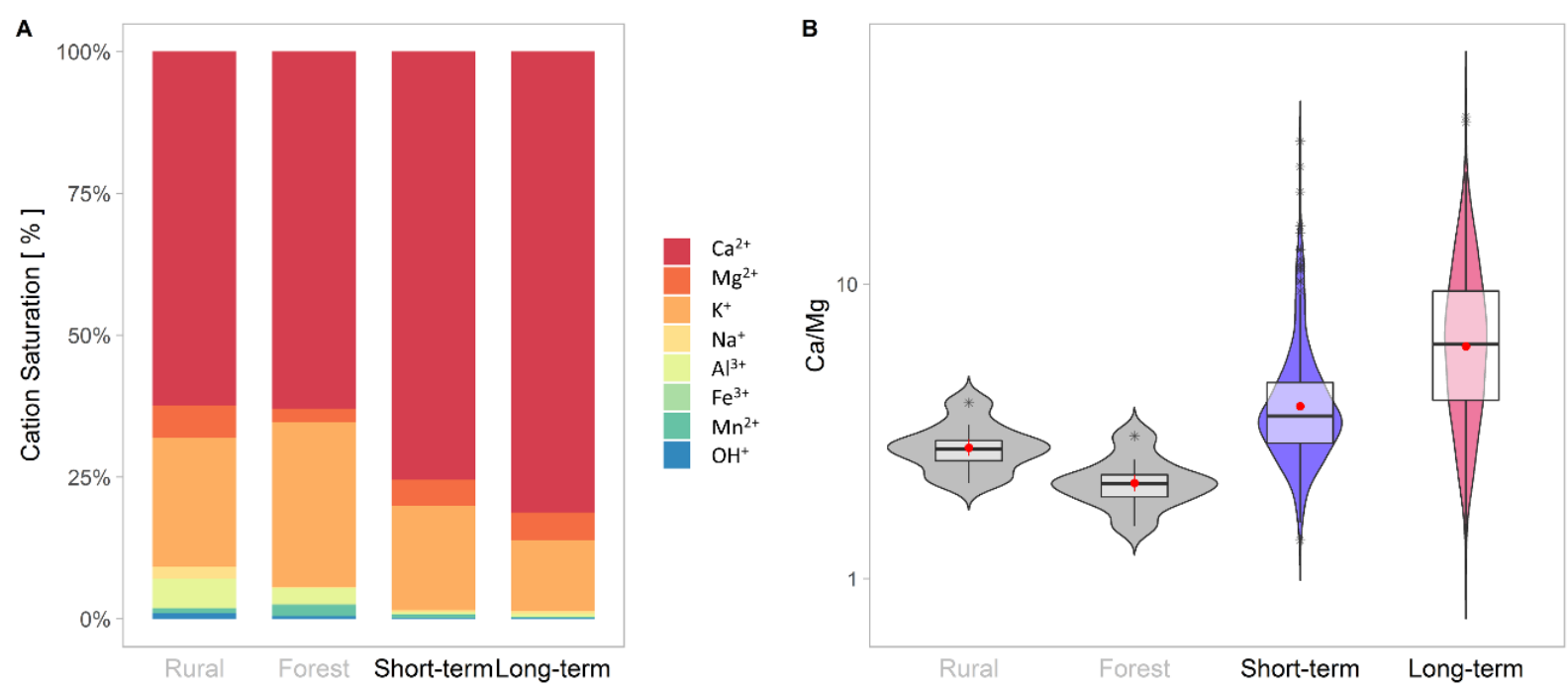

Figure 3.2.5: (A) Bar plots comparing the contributions of cations in percentages of the rural, forest and urban soils. Note: Values on the $y$-axis are scaled to improve the visualization. $(B)$ Boxplots comparing the $\mathrm{Ca} / \mathrm{Mg}$ ratios in the rural, forest and urban soils. Arithmetic means (red points), standard errors (red whiskers), medians (bars), ranges (whiskers), and outliers (asterisks) are shown. Note: $y$-axis is on a log (base 10) scale for visualization.

$\mathrm{Ca} / \mathrm{Mg}$ ratio has been useful to assess the relative proportions of the concentrations of both $\mathrm{Ca}^{2+}$ and $\mathrm{Mg}^{2+}$ in the soil. Because these two cations tend to compete for exchange sites, the concentration increase in one may trigger the concentration decrease in the other (Blume et al. 2016). Generally, a Ca/Mg ratio of $>2$ is arguably adequate for the availability of both cations to plants (Osemwota et al. 2007). In this study, the $\mathrm{Ca} / \mathrm{Mg}$ ratio ranged from 1.2 to 37.1 with a mean ratio $6.0 \pm 0.2$ for all samples (Figure 3.2.5B). The long-term urban soils had a mean $\mathrm{Ca} / \mathrm{Mg}$ ratio $7.4 \pm 0.26$ that was significantly wider $(\mathrm{Cl}=2.1-3.9)$ compared to the short-term urban soils with a mean ratio $4.4 \pm 0.20$ (Figure $3.2 .5 \mathrm{~B}$ ). There were 23 samples of long-term urban soils and four short-term urban soils that had $\mathrm{Ca} / \mathrm{Mg}$ ratio $>15$. All these 27 samples were obtained from arable fields, which were located in close proximity to a construction site (see e.g. Figure 3.2.1 for field conditions). The mean $\mathrm{Ca} / \mathrm{Mg}$ ratio for the rural and the forest soils were $2.8 \pm 0.19$ and $2.2 \pm 0.19$ respectively (Figure 3.2.5B). 


\subsubsection{ECEC and Base saturation}

Mean ECEC of the long-term urban soils was $12.5 \pm 0.5 \mathrm{cmol} \mathrm{kg}^{-1}$, and it exceeded that of the short-term urban soils $\left(9.4 \pm 0.4 \mathrm{cmol} \mathrm{kg}^{-1}\right)$ (Figure 3.2.6A). Both means of the urban soils markedly exceeded the $5.5 \pm 0.8$ and $4.4 \pm 0.5 \mathrm{cmol} \mathrm{kg}^{-1}$ of the forest and rural soils respectively (Figure 3.2.6A). The model output indicated that ECEC of the long-term urban soils was significantly greater (by $3.1 \mathrm{cmol} \mathrm{kg}^{-1}$ units) compared to the short-term urban soils (Figure 3.2.6D). This trend reflected that of the contents and stocks of the exchangeable $\mathrm{Ca}^{2+}, \mathrm{K}^{+}$, and $\mathrm{Na}^{+}$, as well as the soil $\mathrm{pH}_{\text {water }}$ trend as reported by Asabere et al. (2018). Also, there were 184 urban soil samples that had ECEC $\geq 12-55 \mathrm{cmol} \mathrm{kg}^{-1}$, out of which only two samples were within a low $\mathrm{pH}$ range $(<$ $\mathrm{pH}$ 5.5). Mean effective BS of the long-term and short-term urban soils were $97 \pm 0.4$ and $98 \pm 0.3 \%$ respectively, and both also markedly exceeded those of the forest $(91 \pm 4.5 \%)$ and the rural $(88 \pm 5.5 \%)$ soils (Figure $3.2 .6 \mathrm{~B})$. In this instance, the model estimates and confidence indicated effective BS in the urban soils were similar (Figure 3.2.6E). As to be expected, the trends in the BS was diametrically opposite to the trends in the acid saturation (Figure 3.2.6). 


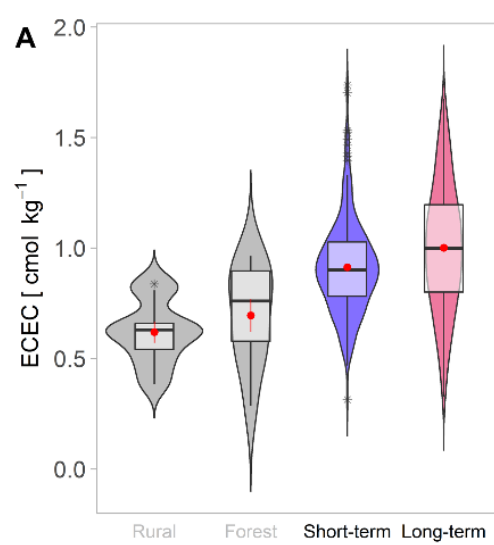

D

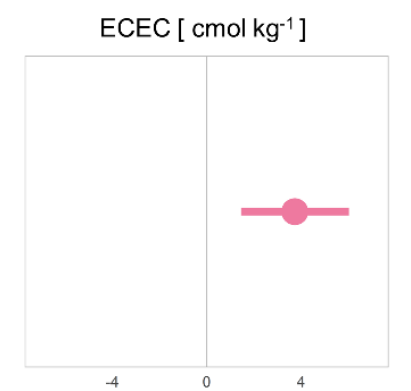

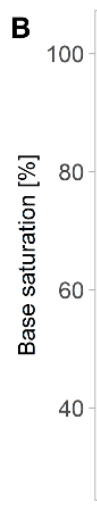

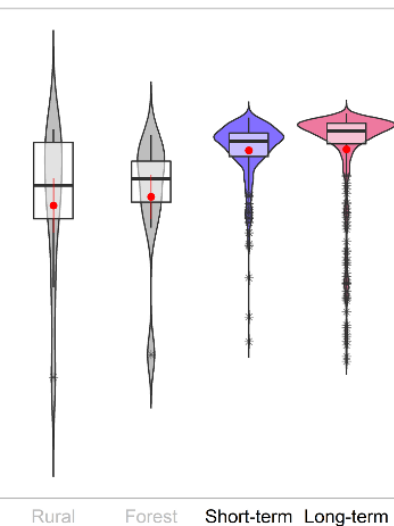

E

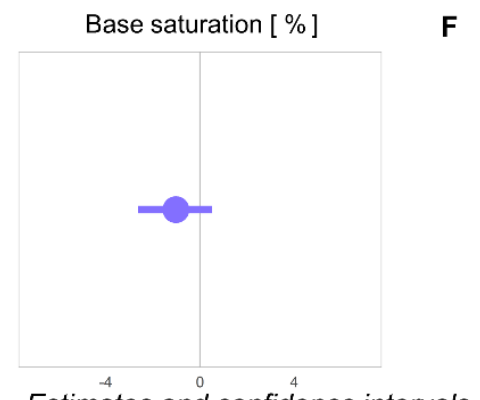

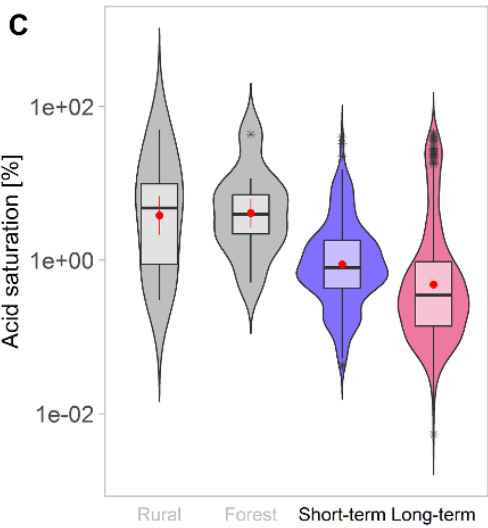

F

Figure 3.2.6: Box and violin plots comparing rural, forest and urban soils with regards to the

(A) ECEC, effective cation exchange capacity; (B) base saturation; (C) acid saturation.

Arithmetic means (red points), standard errors (red whiskers), medians (bars), ranges (whiskers), and outliers (asterisks) are shown. (D-E) Comparison of long-term versus shortterm urban soils, estimating fixed effects of model coefficients and 95\% confidence intervals of the linear mixed models for the contents and stocks. Positive estimates represent higher soil fertility parameter in the long-term urban soils, whereas negative values represent lower parameter relative to the short-term urban soils. Error bars that do not cross the zero line indicate statistical significance. Scale on $x$-axis is different for each model.

\subsubsection{Relationships with SOM contents and Soil $\mathrm{pH}_{\text {water }}$}

There was a generally strong positive linear relationship between bulk contents of TN and SOM, which was described by the function $T N=0.04^{*} \mathrm{SOM}+0.02, r^{2}=0.87$ (Figure 3.2.7A). With similar model coefficients, there were strong relationships in the shortterm urban soils $\left(r^{2}=0.89\right)$, long-term urban soils $\left(r^{2}=0.86\right)$, rural $\left(r^{2}=0.84\right)$ and forest $\left(r^{2}=0.88\right)$ soils that were all comparable. Three long-term urban soil samples were strikingly inconsistent to this generally positive TN-SOM contents relationship. For these samples, their SOM stocks were amongst the highest $\left(>10 \mathrm{~kg} \mathrm{~m}^{-2}\right)$, yet they had low TN stocks $\left(\leq 0.15 \mathrm{~kg} \mathrm{~m}^{-2}\right)$. The surface of the fields from where these samples were 
taken and the soil samples themselves, were unusually reddish in colour, particularly when compared to the dark brownish colour of similar SOM rich samples in this study.
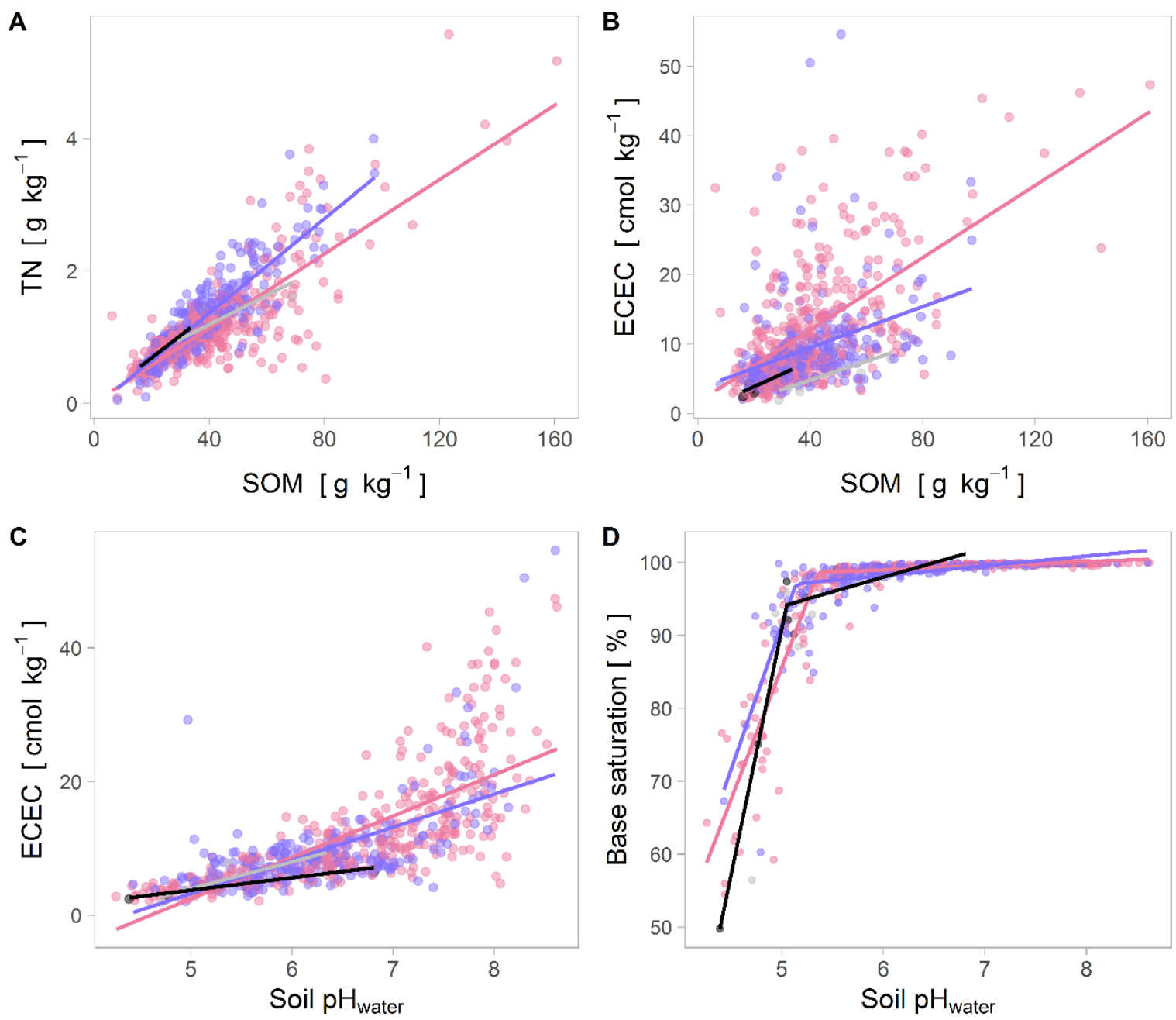

Figure 3.2.7: Relationships between (A) Contents of total $N(T N)$ and soil organic matter (SOM); (B) Effective cation exchange capacity (ECEC) and the contents of SOM; (C) base saturation and soil $\mathrm{pH}_{\text {water }}(\mathrm{D})$ effective cation exchange capacity (ECEC) and soil $\mathrm{pH}$ water. The black line represents the regression line for the urban, forest and rural soils, the dark red line represents the long-term urban soils, the dark yellow line represents the short-term urban soil. Regression line for the forest soils were excluded from the plots because the model failed to find the breaking point due to limited data points.

The relationship between ECEC and SOM contents was also positively linear (Figure 3.2.7B), and it was described generally as $E C E C=0.22 * S O M+1.89, r^{2}=0.66$. With similar coefficients, the relationship was markedly better expressed in the long-term urban soils $\left(r^{2}=0.77\right)$ as compared to their short-term counterparts $\left(r^{2}=0.26\right)$ (Figure 3.2.7B). Also, the coefficients were better expressed in both rural $\left(r^{2}=0.62\right)$ and forest $\left(r^{2}=0.57\right)$ soils compared to those of the short-term urban soils only. This result 
indicated that the importance of SOM contents to ECEC markedly increased with longterm urbanisation influence. Similarly, there was a positive linear relation between ECEC and soil $\mathrm{pH}_{\text {water, }}$ which was described by $\mathrm{ECEC}=5.8^{*} \mathrm{pH}-26.2, r^{2}=0.73$ (Figure 3.2.7C). The model coefficients of this relationship were better expressed in the longterm urban soils $\left(r^{2}=0.78\right)$ compared to those of the short-term urban soils $\left(r^{2}=0.52\right)$. There was a single short-term urban soil sample that showed very high ECEC (29.2 $\left.\mathrm{cmol} \mathrm{kg}^{-1}\right)$, but a low soil $\mathrm{pH}_{\text {water }}(\sim \mathrm{pH} 5.0)$, which contrasted the general trend. This sample was one of two samples with a low soil pH that had ECEC $\geq 12 \mathrm{cmol} \mathrm{kg}^{-1}$. The ECEC-soil $\mathrm{pH}$ water relationship was also strongly expressed in both forest $\left(r^{2}=0.67\right)$ and rural soils $\left(r^{2}=0.79\right)$ with similar coefficients.

Moreover, ECEC was better explained by both SOM contents and soil $\mathrm{pH}_{\text {water }}$ with the function $E C E C=\left(0.13^{*} S O M+5.1^{*} p H\right)-27.9, r^{2}=0.78$, compared to the respective relationships. Here also, the coefficients were better expressed in the long-term urban soils $\left(r^{2}=0.84\right)$ compared to those of the short-term urban soils $\left(r^{2}=0.61\right)$. This particular result indicated that in the short-term urban soils especially, the effect of SOM contents alone was inadequate to explain the ECEC variances. It was, thus, deduced that the effect of SOM contents and soil $\mathrm{pH}_{\text {water }}$ on ECEC of the urban soils increased with urbanisation.

As detailed in Figure 3.2.7D, soil $\mathrm{pH}_{\text {water }}$ generally related to $\mathrm{BS}$ as described by a piecewise linear function $\left(r^{2}=0.81\right)$, with two segments that were nearly perpendicular to each other. The first segment describes a sharp increase in BS with small increase in soil $\mathrm{pH}_{\text {water }}$ until $\sim 5 \mathrm{pH}$, when the slope of the second segment is almost horizontal at which point the BS was largely $\sim 100 \%$. In this relationship, the coefficients were markedly better expressed in the long-term urban soils $\left(r^{2}=0.87\right)$ compared to those of the short-term urban soils $\left(r^{2}=0.65\right)$ (Figure 3.2.7D). Also, whereas the coefficients 
of the model for this relationship were strongly significant for the rural soils $\left(r^{2}=0.97\right)$, those of the forest soils were insignificant. It is plausible that the low forest sample size $(n=9)$ explains this insignificance.

Consistent to these relationships, the correlation plots of the whole dataset also asserted the links between bulk contents of SOM and $\mathrm{TN}$, and soil $\mathrm{pH}$ water on the one hand, and ECEC, bulk contents of exchangeable $\mathrm{Ca}^{2+}, \mathrm{Mg}^{2+}, \mathrm{K}^{+}$and to a weaker extent $\mathrm{Na}^{+}$on the other hand (Figure 3.2.8). With soil $\mathrm{pH}_{\text {water, }} \mathrm{Ca}^{2+}$ contents and ECEC had the strongest correlation ( $R=0.82)$ followed by contents of $K^{+}(R=0.59)>M^{2+}$ $(R=0.36)>\mathrm{Na}^{+}(R=0.22)$. Rather, the trend with the SOM content was contents of $\mathrm{Mg}^{2+}(\mathrm{R}=0.71)>\mathrm{Ca}^{2+}(\mathrm{R}=0.56)>\mathrm{K}^{+}(\mathrm{R}=0.53)>\mathrm{Na}^{+}(\mathrm{R}=0.06)$. The best correlation was between ECEC and $\mathrm{Ca}^{2+}$ contents, which was almost perfectly linear $(\mathrm{R}=0.98)$. Other striking correlations were between contents of $\mathrm{TN}$ and $\mathrm{Mg}^{2+}(\mathrm{R}=0.79)$, as well as contents of TN and those of $\mathrm{Ca}^{2+}(\mathrm{R}=0.57), \mathrm{K}^{+}(\mathrm{R}=0.52)$ and the ECEC $(\mathrm{R}=0.55)$ (Figure 3.2.8). 


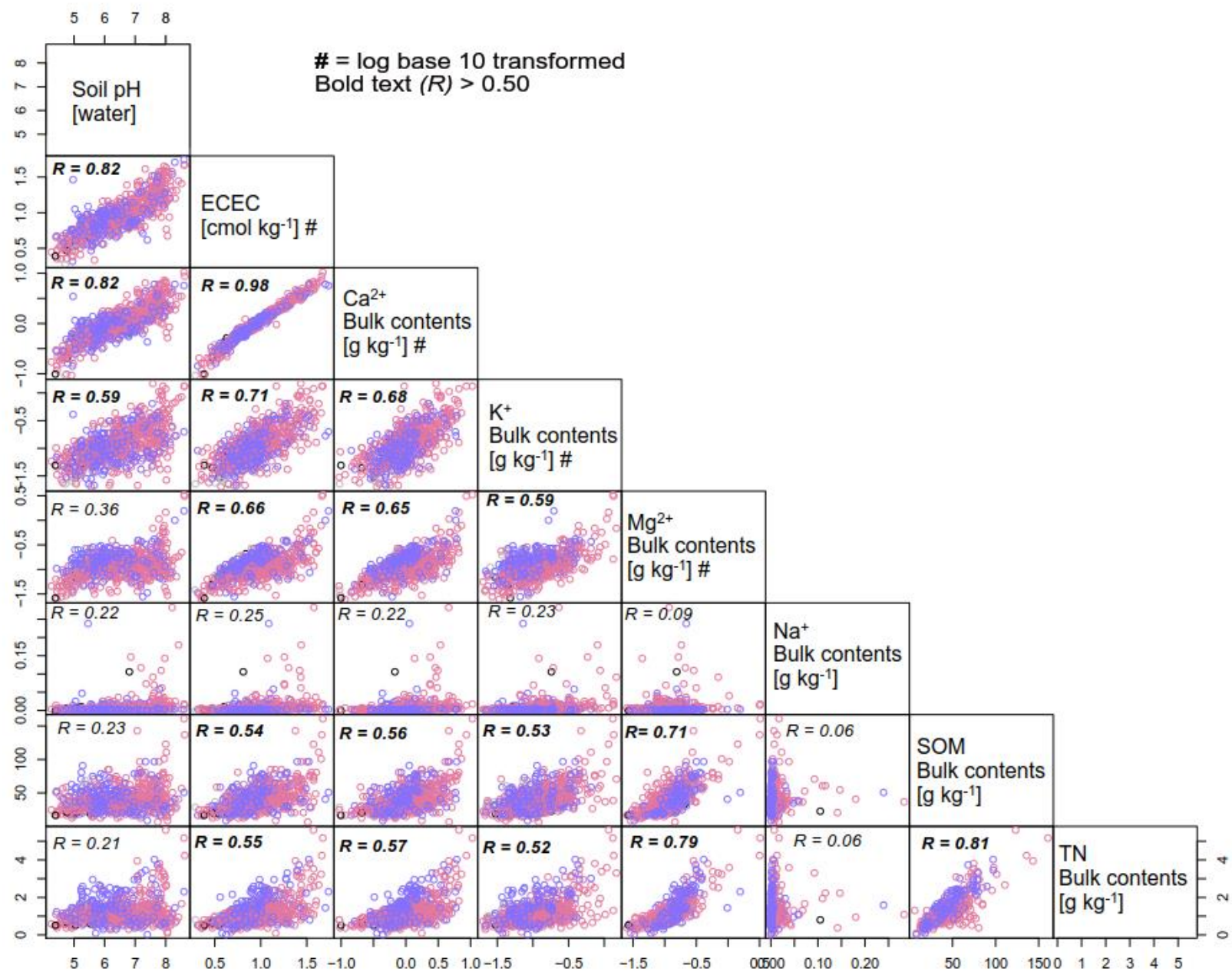

Figure 3.2.8: Correlation plots indicating the relationships between soil pHwater, effective cation exchange capacity (ECEC), bulk contents of exchangeable $\mathrm{Ca}^{2+}, \mathrm{K}^{+}, \mathrm{Mg}^{2+}$, and $\mathrm{Na}^{+}$, SOM and total $N(T N)$.

\subsubsection{Discussion}

\subsubsection{Influence of urbanisation on TN contents and stocks}

The arable fields in Kumasi that were sampled in this study, like most smallholder fields in Africa, largely lack mineral fertilizer application (Minde et al. 2008; Asabere et al. 2018b). Thus, stocks of TN and other nutrients from the tropical soils in this region are derived from SOM mineralization and biomass cycling (Galloway et al. 2003). Consistent in this study, we found a strong positive relationship between TN and SOM stocks in all samples. In addition, we found that TN stocks of the urban soils of Kumasi compared positively to those of the forest soils, but they exceeded those of the rural 
soils. In some maize fields in Ghana, the amount of TN contents $\left(\sim 1 \mathrm{~g} \mathrm{~kg}^{-1}\right)$ that have been reported for similar soils as those investigated in this study (see e.g. Abunyewa and Karbo 2005; Quansah 2010; Mutala 2012) are similar to the mean TN contents of the rural soils but compares less to the urban and forest soils. Also, Nziguheba et al. (2005) and Solomon et al. (2007) have reported 1.5-1.7 $\mathrm{g} \mathrm{kg}^{-1}$ TN bulk contents for soils in the tropical forests of Kenya, which compares positively with those of the urban and forest soils in this study. Moreover, TN stocks of $\sim 0.2-0.6 \mathrm{~kg} \mathrm{~m}^{-2}$ have been reported for some forest soils of Zimbabwe and Ghana (Dawoe et al. 2014; Zingore et al. 2005), which is also in the range of the urban and forest soils of this study. This finding of a positively comparable mean TN stocks of the urban soils and those of forest soils in this and other studies is consistent with similar findings on the SOM stocks for the same soils (Asabere et al. 2018b). Thus, these results further underscore that the sources of SOM stocks are also likely the sources of TN stocks in all the samples of this study. Therefore, the sources of TN stocks in all soil samples of this study have been biomass and farm residues, and in the urban soils particularly, the gradual accumulation of biodegradable household wastes such as food wastes (Asabere et al. 2018b).

Within the urban soils, our results indicated that the TN contents and stocks decreased with increased influence of urbanisation. However, because Asabere et al. (2018b) has demonstrated and reasoned that the accumulation of residual household waste increases with urbanisation, we expected the TN contents and stocks to also increase. This contradicting result suggests two plausible explanations. First, it demonstrates that the quality of SOM stock decreases with regards to TN stock, under increased urbanisation in Kumasi. This finding is consistent with the "non-typical" nature of SOM quality in urban arable soils of Kumasi as it has been observed by Asabere et al. 
(2018b). According to that study, the loss on ignition method that was used to derive the SOM stocks likely included, in addition to the typical SOM, fine fragments of artificial materials (e.g. textile, metal, plastic) that significantly increased under longterm urbanisation in Kumasi. It is thus evident in this study that these artificial materials do not necessarily increase the quality of SOM stocks with regards to the TN stocks. An example that excellently illustrate this contradicting result is the reddish looking fields of the three long-term urban soil samples that had high SOM stocks, and yet low TN stocks. Such reddish colour is inconsistent to the dark brown colours that is typically associated with high SOM stocks (Plice 1943; Vodyanitskii and Savichev 2017).

The second plausible explanation why the TN contents and stocks decreased, instead of increasing under urbanisation influence, is attributable to urban farmers subjecting their arable fields to continuous cultivation in response to rapid urbanisation in Kumasi. With limited fertilizer input, and under the natural constraints of tropical soils, continuous farming leads to accelerated nutrient depletion through harvesting, leaching and erosion as it have been reported for many parts of Ghana, Kenya and Zimbabwe (Zingore et al. 2005; Abunyewa and Karbo 2005; Solomon et al. 2007; Ngoze et al. 2008). For instance, in a long-term study of a tropical soil in Kenya, up to $85 \%$ of the initial $1.5-10.8 \mathrm{~g} \mathrm{~kg}^{-1} \mathrm{~N}$ contents was lost after $\sim 35$ years under maize cultivation (Solomon et al. 2007). Moreover, Drechsel (2002) estimated that $\sim 0.06 \mathrm{~kg}$ $\mathrm{m}^{-2}$ of $\mathrm{N}$ stocks are lost annually on unfertilized arable fields in the Kumasi area through harvesting without nutrient replacement. That study further explained that a fallow period of 20 years is still inadequate to restore soil $\mathrm{N}$ stocks. In this regard, we argue that because the urban arable fields in this study are not actively fertilized with $\mathrm{N}$, and the fallow periods, if any, is far shorter than 20 years, particularly under rapid 
urbanisation conditions, it is extremely challenging to maintain or enhance $\mathrm{N}$ contents and stocks. Thus, urbanisation consequently leads to decreased TN stocks under such conditions.

\subsubsection{Influence of urbanisation on exchangeable nutrient base cations}

As to be expected, contents and stocks of $\mathrm{Ca}^{2+}, \mathrm{K}^{+}$and $\mathrm{Na}^{+}$increased with urbanisation. The mean concentrations of exchangeable $\mathrm{Ca}^{2+}$ and $\mathrm{K}^{+}$in the forest and rural soils of this study compare positively to the $5.5 \mathrm{cmol} \mathrm{kg}^{-1} \mathrm{Ca}^{2+}$ and $0.4 \mathrm{cmol} \mathrm{kg}^{-1}$ $\mathrm{K}^{+}$mean concentrations which have been reported by Asomaning et al. (2009) on three forest soils of southern Ghana. These values compare less to those of the urban soils in this study. Also, Juo and Manu (1996) has reported on the increased concentrations of exchangeable $\mathrm{Ca}^{2+}\left(6-18 \mathrm{cmol} \mathrm{kg}^{-1}\right)$ and $\mathrm{K}^{+}\left(0.4-2.0 \mathrm{cmol} \mathrm{kg}^{-1}\right)$, after a tropical forest area in Ghana was prepared for cultivation by slash-and-burn. This ash induced concentrations compare positively with the means of $\mathrm{Ca}^{2+}$ and $\mathrm{K}^{+}$ concentrations of the urban soils in this study. Moreover, the range of exchangeable $\mathrm{Mg}^{2+}$ concentration of the urban and forest soils in this study compares positively to the $0.5-3.9 \mathrm{cmol} \mathrm{kg}^{-1}$ concentrations that have been reported on Acrisols of southern Togo and Ghana (Poss and Saragoni 1992; Owusu-Bennoah et al. 2000).

The contents of these nutrient base cations were strongly and positively correlated with the contents of $\mathrm{SOM}$ and $\mathrm{TN}$ as well as soil $\mathrm{pH}_{\text {water }}$ in this study. This result strongly suggested that, similar to the TN contents, the sources of the contents of the nutrient base cations is similar to that of the SOM contents and soil $\mathrm{pH}_{\text {water }}$ as it has been reported by Asabere et al. (2018b). Thus, regarding these sources, two specific activities are widespread in Kumasi which have direct effects on the contents of exchangeable base nutrients. These activities, which happen within the vicinity of the arable fields, have been the burning of household waste and the long years it takes to 
complete a building construction (Asabere et al. 2018b). Ash from burnt anthropogenic materials including both biodegradable and non-biodegradable materials, as well as construction materials and waste are particularly rich sources of contents of $\mathrm{Ca}^{2+}$ and $\mathrm{K}^{+}$in particular, as well as $\mathrm{Na}^{+}$and $\mathrm{Mg}^{2+}$ contents. Consequently, since urbanisation in Kumasi has been shown to increase the contents of these anthropogenic materials (Asabere et al. 2018b), it is thus consistent that with the exception of $\mathrm{Mg}^{2+}$ contents, the contents of the exchangeable base nutrients increased.

We found that the effect of urbanisation on the $\mathrm{Mg}^{2+}$ stocks were distinctly different from the nutrient bases. The mean $\mathrm{Mg}^{2+}$ concentration of the urban soils in this study compare markedly less to the $1.1 \mathrm{cmol} \mathrm{kg}^{-1}$ mean concentration that has been reported for tropical soils of north-eastern Australia (Hailes et al. 1997). In addition, when the $\mathrm{Mg}^{2+}$ concentrations are compared to the categorization of Hazelton and Murphy (2016), $90 \%$ of all samples are low and $\sim 42 \%$ of the urban soil samples are deficient (i.e. $<0.3 \mathrm{cmol} \mathrm{kg}^{-1}$ ) in this nutrient. Moreover, among the nutrient bases, only $\mathrm{Mg}^{2+}$ had relatively greater stocks in the short-term urban soils compared to its long-term counterpart, although its concentrations in the fine earth and bulk soils were similar. This trend is a clear indication of the dilution of $\mathrm{Mg}^{2+}$ concentration in the fine earth fraction by the coarse fragment fraction. As it has been demonstrated by Asabere et al. (2018b), non-biodegradable materials from household and construction waste, though limited, tend to also accumulate in the urban arable soils. Because there is no intentional sorting of the waste, with time the areas that have been under long-term urbanisation influence accumulate more of these non-degradable materials. Such a dilution effect, which is one of the major negative influences of rapid urbanisation in Kumasi on the urban arable soils (Asabere et al. 2018b), is also demonstrated to be the reason for the decreased $\mathrm{Mg}^{2+}$ stocks in this study. 
Moreover, similar to the trends in the TN contents and stocks, this particular finding also corroborates the explanation of the non-typical nature of SOM contents in the urban soils of Kumasi. Perhaps, the sensitivity of both $\mathrm{TN}$ and $\mathrm{Mg}^{2+}$ contents to the effect of urbanisation on the urban arable fields of Kumasi is the reason for the strong correlation $(R=0.79)$ that we found in this study. Thus, similarly, it is plausible that the quality of organic materials that accumulate in the urban soils of this study are low in quality regarding $\mathrm{Mg}^{2+}$ contents. This may explain why the three maize fields from where the seven soil samples with the extremely high $\mathrm{Mg}^{2+}$ concentrations, were observed to have enormous amounts of animal faeces and charred wood dust, which are typical SOM materials. In addition, while it may be that because of ion competition, an increase in the $\mathrm{Ca}^{2+}$ content may trigger a decrease in $\mathrm{Mg}^{2+}$ content (Jakobsen 1993; Gransee and Führs 2013), it was not verified in this study. We found that only 27 urban soil samples were out of the normal range of the $\mathrm{Ca} / \mathrm{Mg}$ ratio $1-15$ suitable for plant growth (Hazelton and Murphy 2016; Brady and Weil 2017). Although all the 27 fields were recorded to have contents of accumulated concrete materials, it was all comparable to the other urban arable fields that were sampled. Thus, further examinations are needed to deepen the investigation of such ion competition that leads to decreased $\mathrm{Mg}^{2+}$ contents for arable soils of Kumasi.

\subsubsection{Influence of urbanisation on BS and ECEC}

The nature and contents of cation exchangers determine the CEC of a soil (Soares et al. 2005). Typically, because of a dominant clay mineralogy and contents of oxides (i.e. acid cation contents), tropical soils have extremely low CEC at the naturally acidic soil conditions (Gallez et al. 1976; Mendonça and Rowell 1996). Therefore, an enhancement of the contents of base cation fraction (i.e. base saturation-BS) is an important step towards an overall increase of CEC in tropical soils. In this study, the 
mean BS of the rural and forest soils were markedly higher compared to the $16-25 \%$ BS range that has been reported by Brahene et al. (2015) for tropical soils under an oil palm plantation and a forest in southern Ghana. Thus, mean BS of the urban soils was markedly higher compared to the forest and rural soils of our study and those that are found in the literature.

In response to such enhanced BS, this study found that the ECEC of the urban soils increased with urbanisation. There have been reports of $2-8 \mathrm{cmol} \mathrm{kg}^{-1}$ ECEC for tropical forest soils in Nigeria and Brazil (Oorts et al. 2003; Ramos et al. 2018), which compares positively with the range of the forest and rural soils in this study. However, the values compare markedly lower to the urban soils. Also, Asomaning et al. (2009) have reported $\sim 8 \mathrm{cmol} \mathrm{kg}^{-1} \mathrm{CEC}$ on the tropical soils of southern Ghana. While it compares positively with the range of the forest and rural soils, it is markedly lower compared to the urban soils in this study. Moreover, Abunyewa and Karbo (2005) and Boateng et al. (2006) have reported $1.5-3 \mathrm{cmol} \mathrm{kg}^{-1}$ ECEC for maize arable soils in Ghana, which also compares positively to the mean of the rural soils in this study. Thus, the mean ECEC of the urban soils in Kumasi is markedly higher (at least 2-3 times) compared to background forest and rural arable soils in this and other studies. Considering that the soils in this study are typical tropical soils, the increased ECEC in the urban soils are attributable to anthropogenic activities that have increased the variable charges of the fraction of exchangeable base cation contents at the expense of the exchangeable acid cation contents. The strong correlation ( $R=98 \%)$ between the Ca bulk contents, the most dominant cation, and the ECEC, strongly corroborate this finding. These activities, which have been elaborated in this study and the related study of Asabere et al. (2018b), explain the sources of the contents of SOM, TN, and the exchangeable base nutrients, as well as the soil $\mathrm{pH}_{\text {water. }}$ 
Consistent to these findings, the results in this study also demonstrated that SOM contents and soil $\mathrm{pH}_{\text {water }}$ explained $78 \%$ of the variances in the ECEC of all soil samples and up to $84 \%$ in the urban soils of Kumasi. These results are comparable to those of Oorts et al. (2003) and Ramos et al. (2018), who have demonstrated that SOM stocks and soil pH explained $\sim 85 \%$ of the ECEC variances in the tropical soils of Nigeria and Brazil respectively. SOM content is a key source of exchangeable base cations, and it has is an additional advantage of producing organic anions that can readily bind contents of exchangeable acid cations, and thereby decreasing their counteracting effect (Oorts et al. 2003; Ramos et al. 2018). Thus, SOM content is both an important source and enhancer of the nutrient base cation contents.

\subsubsection{Conclusions}

The most important sources of soil nutrients to the rainfed maize arable fields in the city of Kumasi have been the gradual accumulation of urban household waste and concrete materials (Asabere et al. 2018b). We conclude that in this study, these sources have been demonstrated to also significantly enhance stocks of the exchangeable $\mathrm{Ca}^{2+}, \mathrm{K}^{+}, \mathrm{Na}^{+}$at the expense of acid cation contents, and thereby significantly increasing the ECEC of the urban arable soils. This conclusion is partly consistent with our initial hypothesis that urban arable soils of Kumasi that have been under long-term ( $\geq 30$ years) urban environment receive some fertilization, and therefore, the soils have significantly enhanced nutrient base cations and ECEC. This conclusion highlights the viability of urban arable soils to support crop cultivation in Kumasi, a typical tropical West African city (Asabere et al. 2018b). Also, this conclusion agrees with Edmondson et al. (2014) and Tresch et al. (2018) who found that urban soils under parks and allotment gardens in Leicester (UK) and Zurich 
(Switzerland) are also viable to support different ecosystem services in the respective cities.

Although the urban soils receive some fertilization, this study found that stocks of TN and exchangeable $\mathrm{Mg}^{2+}$ decreased, and thus it partly contradicts our initial hypothesis. This conclusion suggests that there is a depressing effect of rapid urbanisation on urban arable fields which needs to be addressed in order to take full advantage of the benefits of urban farming to sustainable urban management. For urban farmers in Kumasi and other tropical West African cities to overcome such a challenge, it may require an integrated effort by all stakeholders. For instance, leguminous plants could be intercropped in a cycle or mixed with the maize by the urban farmers in an effort to enhance $\mathrm{N}$ stocks (Abunyewa and Kabo 2005). Also, city authorities may encourage (through incentives and participation) urban dwellers to carefully compost their organic waste in order to improve the quality of SOM stocks in the arable soils of the city (Asabere et al. 2018b). Moreover, composted organic household waste can be enriched with dolomite and $\mathrm{N}$-fertilizers as demonstrated by Adamtey et al. (2009), which can be supplied to the urban farmers. As urbanisation rapidly progresses within West Africa, our study demonstrates that for cities like Kumasi, urban arable soils that are influenced under long-term urbanisation are well suited to support food security and urban sustainability of the population. 



\title{
3.3 Study 5: Urbanisation enhances stocks of $P$ fractions in strongly weathered arable soils; a case of Kumasi (Ghana), West Africa
}

Stephen Boahen Asabere', Jiangyun Li ${ }^{1}$, Harold James Hughes ${ }^{1}$, Daniela Sauer ${ }^{1}$.

\author{
${ }^{1}$ Department of Physical Geography, Institute of Geography, University of Goettingen, \\ Göttingen, Germany
}

- Manuscript in preparation

- An abstract based on the manuscript is published in Geophysical Research Abstracts as Asabere et al. (2019). Urbanization enhances stocks of $P$ fractions in strongly weathered arable soils of Kumasi (Ghana), West Africa. [online] Available at:

https://meetingorganizer.copernicus.org/EGU2019/EGU2019-16640.pdf

\begin{abstract}
Tropical soils have naturally low contents of plant-available $P$, and they are characterized by high contents of Fe oxides and mobile $\mathrm{Al}$ that readily fixes $\mathrm{P}$ into unavailable forms. Although urban farming is common and pivotal to the sustainable development of West African cities, the effects of urbanisation on soil $P$ contents and $P$ transformation pathways in the tropical soils are largely unknown. Here, we investigated the effects of urbanisation on four relevant $P$ fractions in urban arable soils of Kumasi (Ghana). We subjected top-soils of maize fields on Acrisols of the same local soil series to a sequential $P$ extraction that included (1) plant-available $P$ ( $\mathrm{PPa}_{\mathrm{Pa}}$, (2) soil organic matter (SOM)-bound $\mathrm{P}$ ( $\left.\mathrm{PsOM}\right)$, (3) Ca-bound P ( $\mathrm{PCa}$ ), and (4) P occluded in pedogenic oxides (Pocc). Top soils were sampled based on a defined urbanisation chrono-category which were (a) long-term urban soils, i.e. >30 years urbanisation, and (b) short-term urban soils, i.e. $<30$ years urbanisation. Forest and rural soil samples were also extracted for comparison. We found that stocks and contents of all $P$ fractions were markedly greater in the long-term urban soils compared to their short-term counterparts. The $\mathrm{P}_{\mathrm{Ca}}$ fraction is naturally absent in most tropical soils, yet 75 out of the 206 urban soils in this study had quantifiable contents of this fraction. Also, the origin of $\mathrm{PPa}$ content was distinguishable for the urban soils compared to the forest and rural soils. Consistent to other studies, these findings suggest that unlike typical tropical forest soils whereby the $\mathrm{P}_{\mathrm{Pa}}$ contents are largely dependent on organic $P$ contents, those of the urban soils in Kumasi are enriched from both organic and inorganic $P$ contents originating from two key sources - household waste and construction. Both have been the source of the enhanced SOM contents, soil $\mathrm{pH}$ and effective cation exchange capacity, which related significantly with the contents of the $\mathrm{P}$ fractions in this study. The findings in this work suggest that it will be beneficial for urban farmers in Kumasi and other West African cities, to engage actively in composting urban household waste for the enhancement of soil P stocks.
\end{abstract}

Keywords: Phosphorus, sequential fractionation, urbanisation; Ghana; West Africa; strongly weathered tropical soils, urban farming; soil organic matter. 


\subsubsection{Introduction}

Plant-available $\mathrm{P}$ in soils is derived from the weathering of parent rock materials (primary $\mathrm{P}$ ), decay of soil organic matter (SOM), fertilizer application, and to a limited extent atmospheric deposition (Kruse et al. 2015). Unlike other major nutrients such as $\mathrm{N}$, the atmospheric return of $\mathrm{P}$ is extremely low (Ryan 2014), and thus the $\mathrm{P}$ removed with harvested crops is mainly replaced by fertilization and weathering (Lauer et al. 2013). Humid tropical soils such as Acrisols, Lixisols and Ferralsols are strongly weathered, and they are characterised by naturally low contents of weatherable minerals and nutrients, and they lack primary P (Solomon et al. 2002; Tiessen 2005). These strongly weathered soils also have low soil $\mathrm{pH}$, dominated by 1:1-type silicate clay minerals (e.g. kaolinite), and are rich in pedogenic Fe oxides and mobile Al that readily sorb P into occluded compounds (Kruse et al. 2015). Because of these characteristics, up to $85 \%$ of total P stocks in strongly weathered tropical soils may be unavailable to plants even when the soils are adequately fertilized (Rodrigues et al. 2016). For instance, a strongly weathered forest soil in the south of Ghana was reported to have $339 \mathrm{mg} \mathrm{kg}^{-1}$ total P content and only $3.5 \mathrm{mg} \mathrm{kg}^{-1}$ (1\%) plant-available P content (Asomaning et al. 2009). Moreover, in the presence of calcium carbonates such as in calcareous soils or lime amended soils, P may be readily precipitated into insoluble crystal Ca-phosphates (Shang and Tiessen 2003; Kruse et al. 2015; Khorshid et al. 2019). Thus, the determination of the relative contents of major soil $P$ fractions is an important step to assess plant-available $\mathrm{P}$ stocks and to optimize fertilization techniques in strongly weathered arable fields.

In the natural environment, humid tropical ecosystems rely on a closed cycle of an accelerated turnover of biomass and SOM stocks to replenish the P stocks and other plant-available nutrients (Solomon et al. 2002; Tiessen 2005). However, 
anthropogenic land use changes, such as urbanisation, have a strong effect on the size and dynamic of soil P pools, as they directly influence the size and distribution of e.g., vegetation cover, biomass production and SOM stocks (Maranguit et al. 2017; Asabere et al. 2018b). The effect of such changes may increase P loss (through erosion and leaching) or transform plant-available $\mathrm{P}$ into increasingly unavailable fractions (Casanova et al. 2002). Thus, the $P$ stocks in humid tropical soils are especially sensitive to land use and associated changes. For instance, Solomon et al. (2002) reported that contents of total $P$ and its available fraction decreased to $~ 39 \%$ and $\sim 77 \%$ in arable fields after 25 years of forest conversion in the southern Ethiopia. Moreover, land preparation by slash-and-burn (or by tropical forest fires) transforms $\mathrm{P}$ into plant-available $\mathrm{P}$, but also renders part of it unavailable to plants by incorporating it into the mineral matrix (Juo and Manu 1996; Maranguit et al. 2017). One of the main land cover changes in tropical West Africa is rapid urban sprawl, driven by the coupled effect of rapid population growth and urbanisation (Henderson et al. 2014). Although this urban sprawling happens at the expense of arable fields, urban farming is still widespread and important to the sustainability and food security of the population (Asabere et al. 2018b). Yet, how urbanisation may affect the stocks of $P$ fractions in tropical urban soils of the rapidly urbanising West African cities is largely unknown. The influence of urbanisation on the evolution of $\mathrm{P}$ stocks are divergent in urban soils. The extent and intensity of urbanisation agents such as construction, commerce, traffic and waste may have remarkably contrasting effects on contents of soil $\mathrm{P}$ fractions. For instance, mineral fertilizer application on public parks and allotment gardens, organic amendments from animal and human excreta, and deposition of dust and sediments from traffic and eroded materials among others, greatly influence the balance in the input and output of the soil P cycle (Zhang 2004). Such effects with positive outcome 
have been used explain the net enrichment of soil P stocks in several cities from China, UK and France have demonstrated because of (Zhang 2004; Joimel et al. 2016; Li et al. 2018; Meng et al. 2018). There may also be neutral outcomes of urbanisation on soil $\mathrm{P}$ contents when both new $\mathrm{P}$ input and output are balanced, as reported for cities in China and Iraq (Yuan et al. 2007; Khorshid et al. 2019). Finally, urbanisation may lead to a decline in soil $\mathrm{P}$ availability as reported for strongly weathered urban soils of Hong Kong city (Jim 1998). Thus, it still remains to be answered what the effect of the ongoing rapid urbanisation in most African cities on urban soil P contents is.

In order to study the functional processes that control plant-available $\mathrm{P}$, previous studies have used various sequential fractionation techniques to separate, identify and quantify the different fractions of $\mathrm{P}$ in the soil (Chang and Jackson 1957; Bowman and Cole 1978; Hedley et al. 1982; Tiessen and Moi 2008). Similar to these studies, we adopted a sequential fractionation procedure in order to investigate the stocks of four relevant $\mathrm{P}$ fractions, namely plant-available $\mathrm{P}\left(\mathrm{P}_{\mathrm{Pa}}\right)$, SOM-bound $\mathrm{P}$ (Psom), Ca-bound $\mathrm{P}(\mathrm{PCa})$, and occluded $\mathrm{P}(\mathrm{Pocc})$ in strongly weathered tropical urban arable soils. To the best of our knowledge, there is no study that has looked into the effects of rapid urbanisation on the stocks of $\mathrm{P}$ fractions in a strongly weathered tropical soil in any West African city. Thus, we employed a systematic approach to analyse the relative amounts of the contents of soil $\mathrm{P}$ fractions in arable fields that have been under longterm ( $>30$ years) compared to short-term ( $<30$ years) urbanisation influence. In addition, we analysed the interrelations within the contents of the $P$ fractions, and with key soil properties in order to assess the effects and transformational pathways that shape the contents of soil P availability in the urban arable soils of Kumasi, Ghana. 


\subsubsection{Method}

\subsubsection{Study area, approach, soil sampling and analyses}

The study was conducted in Kumasi (Figure 3.3.1) which is the second largest city in Ghana, West Africa. Kumasi is also a typical West African city in that it is experiencing rapid urban sprawl on the one hand, and has a widespread presence of arable fields on the other hand (Asabere et al. 2018b). The city's population has increased fivefold from an initial 400 thousand people in 1986 to $>2$ million people in 2019. As a result, Kumasi's built-up area has increased from 68 to $125 \mathrm{~km}^{2}$, while its vegetated area has decreased from 53 to $<10 \mathrm{~km}^{2}$ within the same period (Asabere et al. in review, Land use policy - Study 1). Such negative consequence on vegetation strongly affects biomass and nutrient cycling in its soils. The majority of non-commercial arable fields in the city are largely rain-fed and unfertilized (Drechsel 2002). 


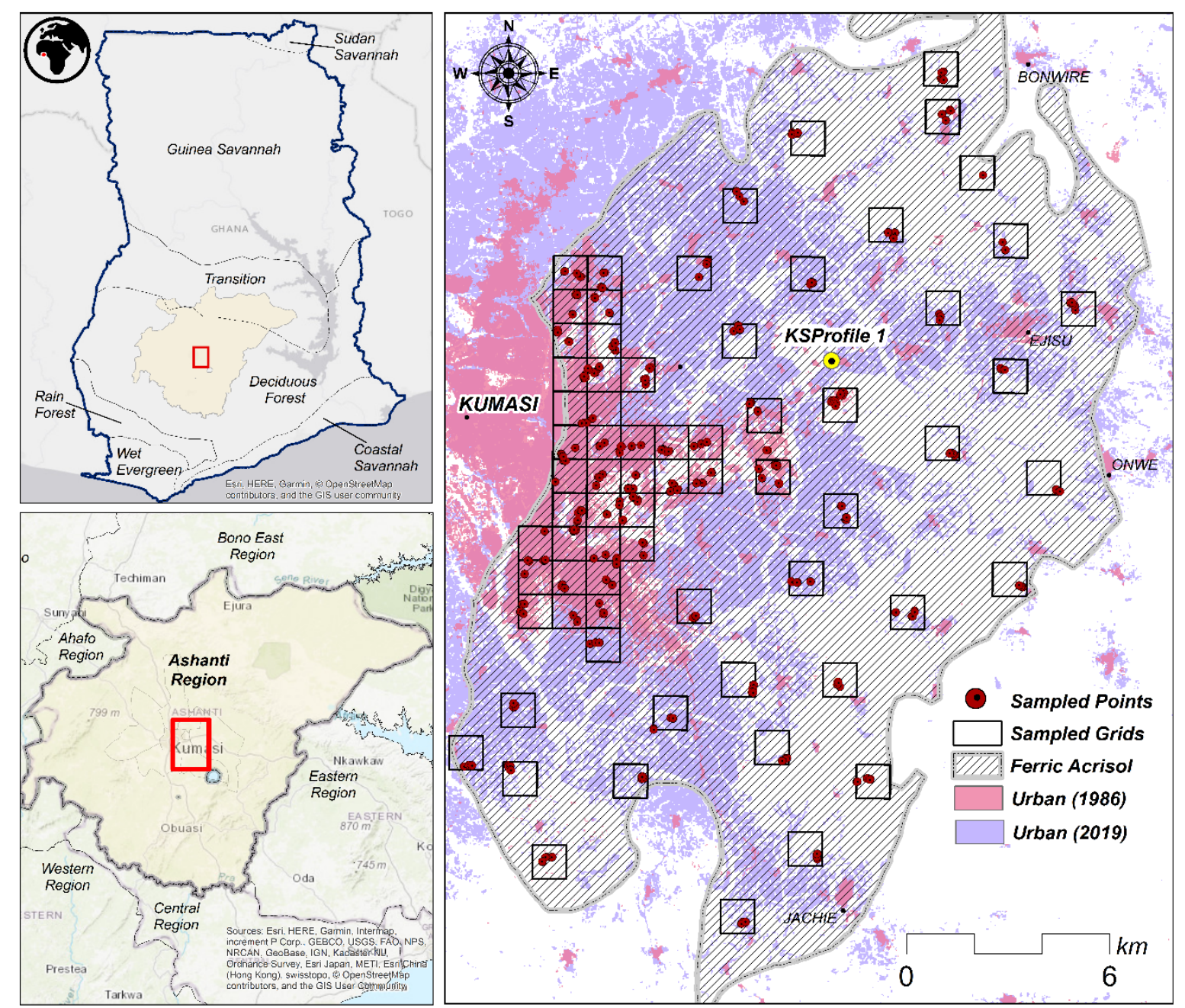

Figure 3.3.1: Study area and sampled locations in Kumasi (Ashanti region). Land use (maize fields), soil type (Ferric Acrisol), parent material, topography and climate (deciduous forest) were kept constant.

In this study, we utilised the sampled top soils $(0-10 \mathrm{~cm})$ from rainfed maize fields in Kumasi (sampling details in Asabere et al. (2018b)). The soil samples were taken by following a satellite based stratified sampling design (Figure 3.3.1). The design included two categories that were predefined using a classified Landsat satellite image of 1986 and the field sampling that was conducted in August-September of 2016. The first category, long-term urban soils, comprised soil samples that were extracted from fields that have been under continuous urbanisation before 1986 (i.e. $\geq 30$ years). The second category, short-term urban soils, comprised samples that were extracted from fields that have been under urbanisation after 1986 (i.e. $<30$ years). A total of 206 
fields were sampled following a $1 \times 1 \mathrm{~km}$ grid that was laid on a Ferric Acrisol map unit (Figure 3.3.1). As detailed in Figure 3.3.2, soil properties of the soil profile (KSProfile 1) that was described and sampled from the centre of the selected soil map unit indicated a strongly weathered tropical soil type, and it fitted the description by Adu (1992) on these soils. In total, 119 fields were located in the long-term area and 87 in the short-term area. For comparison, three rural arable and forest fields were also sampled. Because the sequential P extraction is a long procedure, it was necessary to keep the amount of sample to a manageable size without compromising on the representativeness. Thus, although triplicates of samples were extracted, only one sample per field was randomly selected for this study, except for the rural and forest fields where all triplicates were used. Therefore, a total of 224 samples, which represented all fields were used. With this sampling design, factors such as land use, soil type, parent material, topography and climate were kept constant (Figure 3.3.1). A detailed description of the study area, soil sampling and soil preparation have been reported in Asabere et al. (2018b).

Three key soil properties which have been analysed in the related studies of Asabere et al. $(2018 ; 2018 a)$ were also included in this study, namely, soil organic carbon (SOC) contents, soil $\mathrm{pH}_{\text {water, }}$ and exchangeable cation exchange capacity (ECEC). SOC contents were calculated by subtracting contents of soil inorganic carbon (analysed by the Scheibler method) from total C contents (analysed by a $\mathrm{CHN}$ analyser). Soil $\mathrm{pH}_{\text {water }}$ was determined in a soil:water ratio of 1:5, and ECEC was calculated by summing all exchangeable cations that were measured using the percolation method with a $1 \mathrm{M} \mathrm{NH}_{4} \mathrm{Cl}$ solution. 


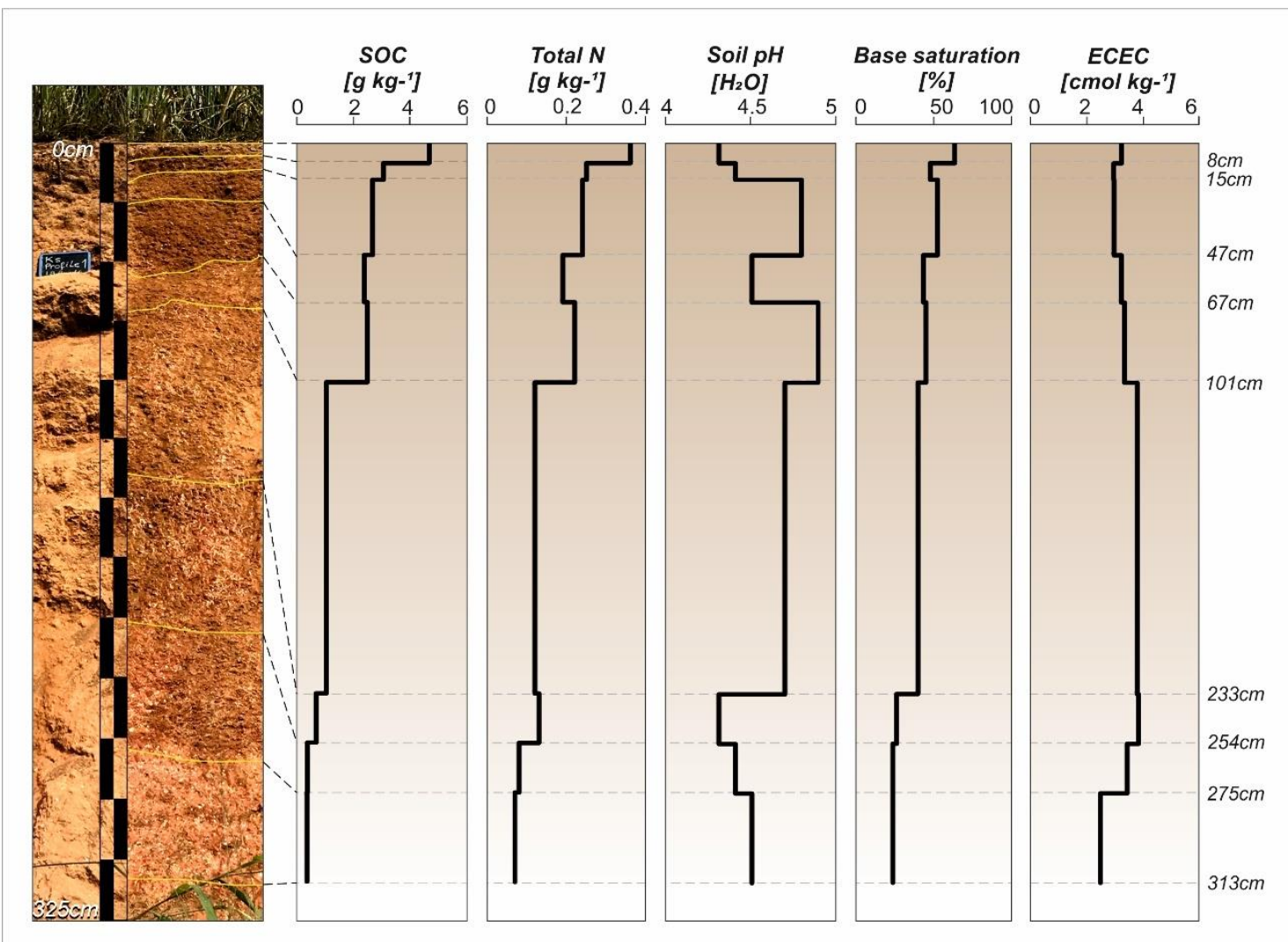

Figure 3.3.2: Some soil properties of KSProfile1, which is centrally located within the Ferric Acrisol unit that was sampled for this study. See Asabere et al. (2018) for the morphological description of this soil profile.

\subsubsection{Sequential P fractionation}

Soil samples were subjected to a sequential P fractionation as depicted in Figure 3.3.3. One gram of fine earth soil ( $<2 \mathrm{~mm}$ sieved) was placed in a $50 \mathrm{ml}$ screw cap centrifuge plastic tube and sequentially extracted in four steps, with an end-over-end shaking at $15 \mathrm{rpm}$. Between every step, samples are washed three times with deionized water and dried for at least 16 hours at $40^{\circ} \mathrm{C}$ before the next step. In step one, $50 \mathrm{ml}$ of 0.5 $\mathrm{M} \mathrm{NaHCO}_{3}$ buffer solution, adjusted to $\mathrm{pH} 8.5$ by adding $0.5 \mathrm{M} \mathrm{NaOH}$, was added to the soil sample, and the solution was shaken for 16 hours before sampling an aliquot for $\mathrm{P}$ analysis. This solution extracted the plant-available $\mathrm{P}\left(\mathrm{P}_{\mathrm{Pa}}\right)$ (Colwell 1963), which includes both the soluble inorganic and organic forms that is available in the soil solution for plant uptake. Considering that Ferric Acrisols are naturally acidic, acid extractions such as Bray 1 (Bray and Kurz 1945) are normally used to determine the 
available $\mathrm{P}$ concentration. However, we adopted this alkaline extraction because the urban soils used in this study were known to have soil pH $>7$ (Asabere et al. 2018). In step two, a $10 \mathrm{ml} 30 \% \mathrm{H}_{2} \mathrm{O}_{2}$ solution was added to the dried soil sample. After the initial frothing, the tube was placed in an $80^{\circ} \mathrm{C}$ water bath for the reaction to continue. This reaction oxidises all organic matter in the soil (SOM) to release the unmineralized P (Psom) (Mikutta et al. 2005). Depending on the amount of $\mathrm{H}_{2} \mathrm{O}_{2}$ solution that was added in order to fully oxidise the SOM (i.e. the lack of visible frothing or bubbles, with only the mineralized soil colour), the solution was topped to $40 \mathrm{ml}$ with deionised water. $10 \mathrm{ml}$ of $0.5 \mathrm{M} \mathrm{Na}$-acetate was added and the solution was shaken for 15 minutes before sampling an aliquot for $\mathrm{P}$ analysis. In step three, $0.5 \mathrm{ml} 10 \% \mathrm{HCl}$ solution was added to the sample. This reaction dissolves calcium phosphates in order to release the Ca-bound $\mathrm{P}(\mathrm{PCa})$. After the reaction settled down, $0.1 \mathrm{M} \mathrm{Na}$ acetate solution was added to top the solution to $50 \mathrm{ml}$. The solution was shaken for $15 \mathrm{mins}$, and eventually sampled for $\mathrm{P}$ analysis. In the final step, $45 \mathrm{ml}$ of $\mathrm{NaHCO}_{3}-\mathrm{Na}$ citrate solution was added to the washed soil sample, and it was placed in an $80^{\circ} \mathrm{C}$ water bath. After 30 minutes, $1 \mathrm{~g}$ of $\mathrm{Na}$ dithionite was added to the solution. This reaction releases $\mathrm{P}$ that is occluded in the Fe-oxides and on the mineral matrix (Pocc). The solution was shook for 15 minutes before sampling for $P$ analysis. 


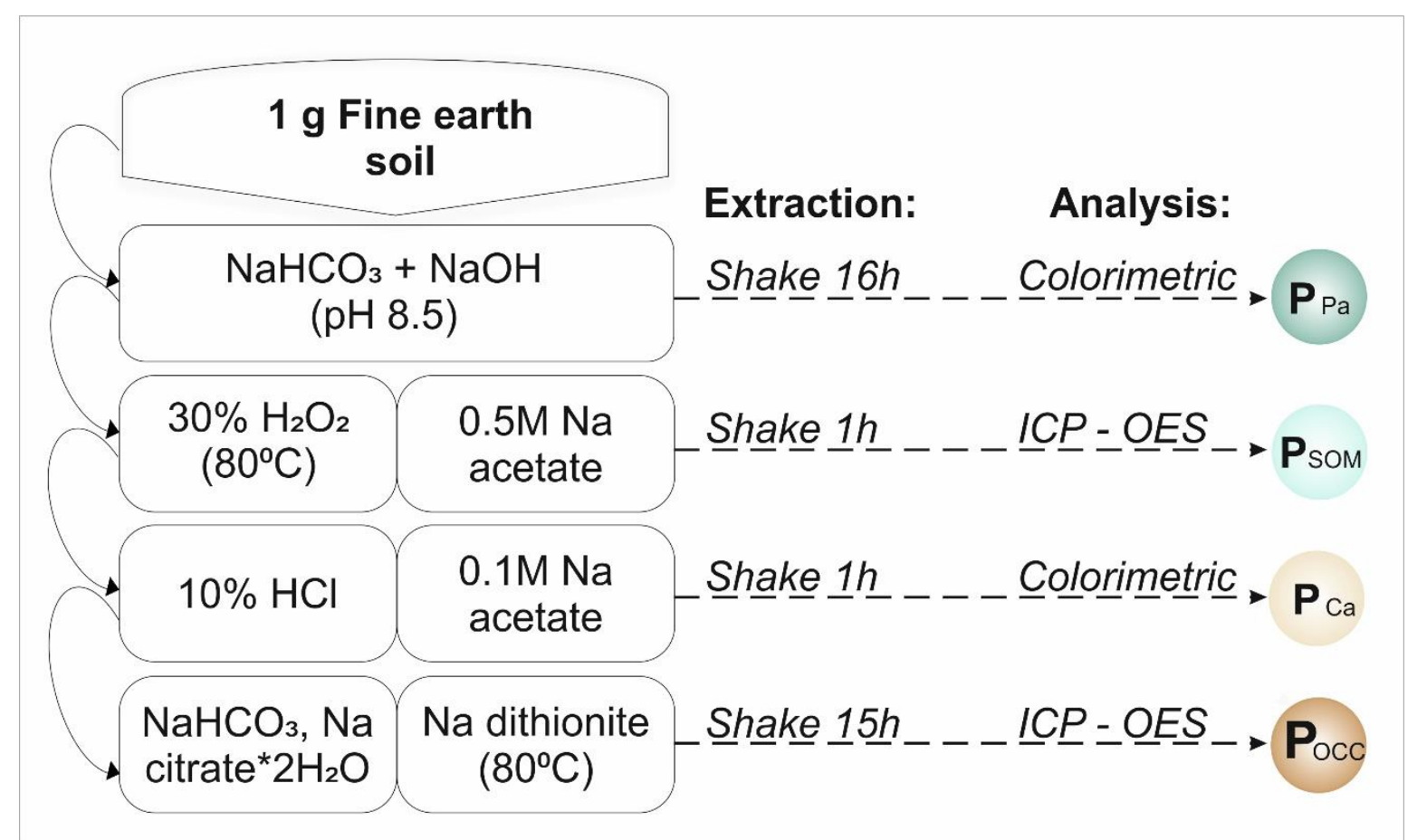

Figure 3.3.3: The $P$ sequential fractionation and analysis adopted for this study.

$\mathrm{P}$ concentrations in the extractions from steps one $(\mathrm{PPa})$ and three $(\mathrm{Pca})$ were determined by the molybdate blue method (Murphy and Riley 1962). P concentrations in the extractions of steps two (Psom) and four (Pocc) were determined with an inductively coupled plasma optic emission spectrometry (ICP-AES). We ensured data quality by adding a blank and two soil samples (from the lab) to every batch (12 in total) of analysis. From these, we calculated the detection and quantification limits of the analysed steps (data in supplementary). Samples that were below the quantification limits were removed from all further analyses. Consequently, the total number of useable analysed samples were 224 in $\mathrm{PPa}_{\mathrm{Pa}} 186$ in $\mathrm{Psom}_{\text {so }} 75$ in $\mathrm{PCa}$, and 186 in Pocc. P stocks per $\mathrm{m}^{2}$ were calculated by considering bulk density and contents of coarse fragments.

Based on the field sampling categories, 56 randomly selected $(n=25$ long-term, 25 short-term, 3 rural, and 3 forest) soil samples were separately analysed for their total P contents by using a multiple acid digestion method. This was done as an analytical control to compare with the sum of the sequentially extracted $\mathrm{P}$ contents. By visual 
inspection of both data distributions, we concluded that the sequential fractionation ( $T P_{\text {fractions }}=$ sum contents of $\mathrm{P}$ fractions) and acid digestion methods were similar (results in supplementary). This result suggested that the sequential extraction was largely exhaustive.

\subsubsection{Statistical modelling}

All analytical data was log (base 10) transformed in order to fulfil the requirements of normality before all statistical analyses and inferences. The effects of urbanisation on the stocks of $\mathrm{P}$ fractions were assessed with linear models to compare the long-term and short-term urban soils. Thus, analytical data on the contents of $\mathrm{P}$ fractions constituted the response variable that was explained by the categorical variable which indicated whether the sample was either long-term or short-term urban soil. Estimated coefficients of each model depicted the relative difference between the long-term and short-term urban soils. Residuals of the models were tested for normality before further interpretation, and 95\% confidence intervals $(\mathrm{Cl})$ were estimated around the coefficients. The strength of a long-term or short-term urbanisation effect was defined by the $\mathrm{Cl}$, whereby those without zero were interpreted as significant. Furthermore, we used similar linear models to assess the pathways of soil $\mathrm{P}$ availability in these strongly weathered soils, by analysing the relationships between contents of the $\mathrm{Pa}$ fraction and those of the three other $\mathrm{P}$ fractions. In the same way, the relationships between contents of all $\mathrm{P}$ fractions and their predictor $\mathrm{SOC}$ contents, soil $\mathrm{pH}$ water, and ECEC were also tested in order to assess the effect of key soil properties on the different soil $\mathrm{P}$ fractions in these soils. The coefficient of determination $\left(\mathrm{r}^{2}\right)$ and the $\mathrm{Cl}$ of the model estimates were used to evaluate the relationships.

To complement the inferences on the relationships within the contents of soil $\mathrm{P}$ fractions and with the soil properties, we employed a structural equation modelling 
(SEM) approach (Grace 2006; Eisenhauer et al. 2015). SEM utilises conventional multivariate regressions and correlations to establish a cause-effect pathway diagram. An important advantage of the SEM approach is its ability to simultaneously test the direct and indirect effect of both multiple dependent (endogenous) and independent (exogenous) variables (Grace 2006). Thus, we were able to combine all the individual linear relationships into a single broad relationships model, which enabled a holistic representation of the causal pathways of $\mathrm{P}$ content transformation in Kumasi's urban soils. In this SEM model, exogenous SOC contents, ECEC and soil $\mathrm{pH}_{\text {water }}$ were specified to explain the endogenous contents of the four $\mathrm{P}$ fractions. In addition, explanatory contents of the $\mathrm{Psom}, \mathrm{P}_{\mathrm{Ca}}$ and $\mathrm{Pocc}$ were specified to explain the $\mathrm{P} \mathrm{Pa}$ contents. Because the focus of this SEM approach was not to test competing hypothesis, the convergence of the model indicated a good representation of the causal relationships between the variables. The output is a path diagram that depicts all the direct and indirect relationships, which explains the variances in the endogenous variables by the exogenous variables. By standardising the coefficients in the model, we were able to evaluate all the relationships with the $r^{2}$. All statistical analyses and modelling were conducted with R (R Core Team 2018), with the packages 'lavaan' (Rosseel 2012), 'semPlot' (Epskamp 2019), 'dplyr' (Wickham et al. 2018).

\subsubsection{Results}

\subsubsection{Contents and stocks of $P$ fractions}

Bulk contents of TPfractions ranged from 37.5 to $15,973.5 \mathrm{mg} \mathrm{kg}^{-1}$, with a mean ( \pm standard error) of $993.1 \pm 160.6 \mathrm{mg} \mathrm{kg}^{-1}$, for all soil samples. There were 19 urban soil samples with $>2500 \mathrm{mg} \mathrm{kg}^{-1} \mathrm{TP}_{\text {fractions }}$ bulk contents, out of which only one sample belonged to the short-term urban soil category. Mean TP fractions stocks was $128.5 \pm 19.4$ 
$\mathrm{g} \mathrm{m}^{-2}$, with a range of 5.4-1835.6 $\mathrm{g} \mathrm{m}^{-2}$. Four long-term urban soils, out of the urban soils with extremely high total $\mathrm{P}$ contents, had $>1000 \mathrm{~g} \mathrm{~m}^{-2}$ stocks. The fields from where these four samples were obtained were commonly characterised by observable accumulated household dumping, burning and concrete materials. Moreover, mean TPfractions bulk contents $\left(1617.4 \pm 290.8 \mathrm{mg} \mathrm{kg}^{-1}\right)$ and stocks $\left(208.1 \pm 35 \mathrm{~g} \mathrm{~m}^{-2}\right)$ of the long-term urban soils were markedly greater compared to those of the short-term urban soils (contents $=348.9 \pm 61.5 \mathrm{mg} \mathrm{kg}^{-1}$, stocks $\left.=46.8 \pm 2.3 \mathrm{~g} \mathrm{~m}^{-2}\right)$ (Figure $3.3 .4 \mathrm{M}$ O). This result is reflected in the model coefficients and Cls of P contents and stocks of all fractions, which were positive and without zeros. Thus, it indicated that all contents and stocks of the long-term urban soils were significantly greater as compared to those of the short-term urban soils (Figure 3.3.5). The urban soils had markedly greater mean TP fractions bulk contents and stocks compared to those of the forest (contents $=157.4 \pm 19.1 \mathrm{mg} \mathrm{kg}^{-1}$, stocks $=20 \pm 7.2 \mathrm{~g} \mathrm{~m}^{-2}$ ) and rural arable soils (contents $=98.5 \pm 13 \mathrm{mg} \mathrm{kg}^{-1}$, stocks $\left.=13 \pm 1.6 \mathrm{~g} \mathrm{~m}^{-2}\right)($ Figure 3.3.4M-O). 

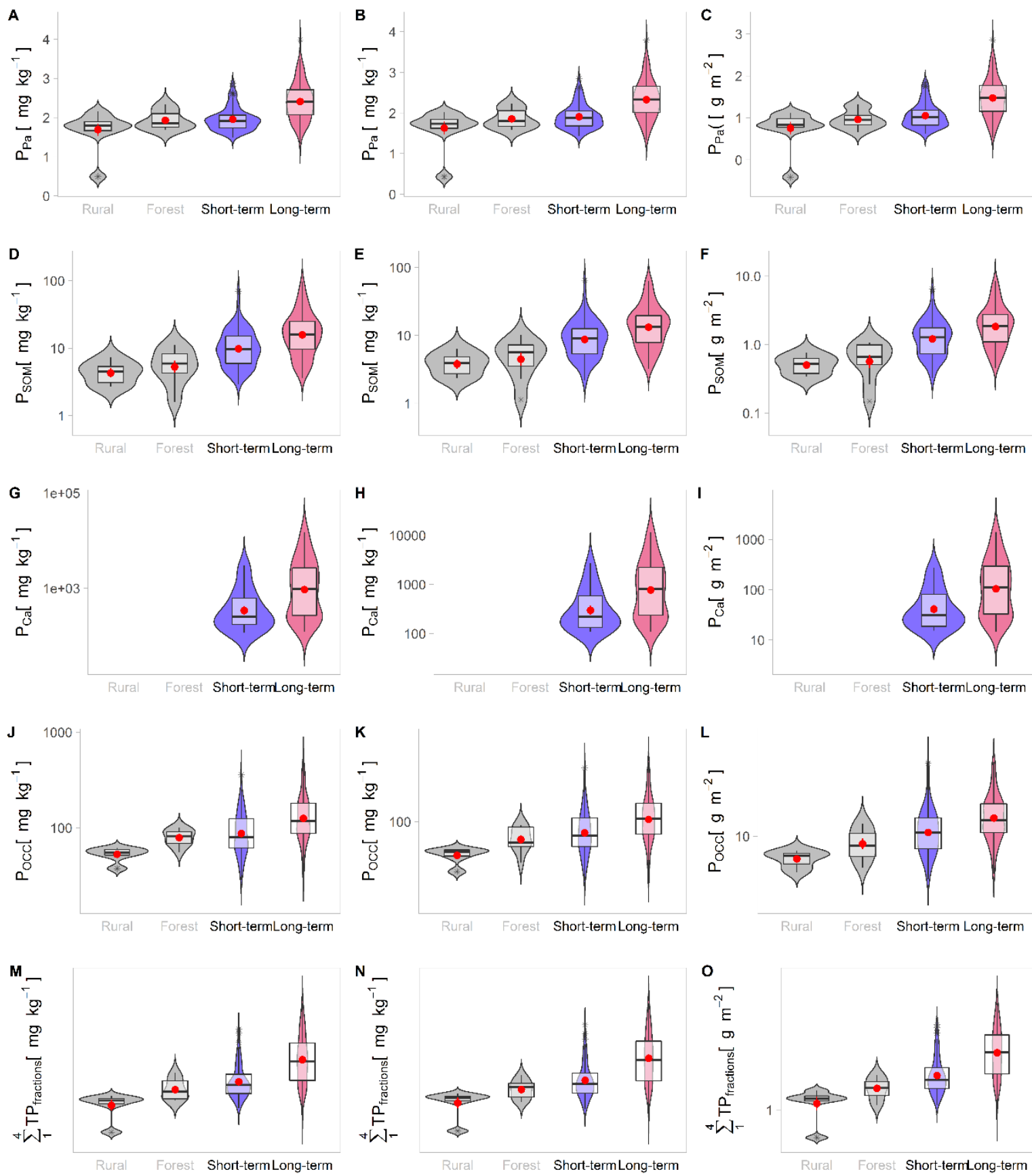

Figure 3.3.4: Boxplots comparing rural, forest and urban soils with respect to their contents and amount per $m^{2}$ of $(A-C)$ plant-available $P(P P a)$; $(D-F)$ soil organic matter- bound $P$ (PSOM); (G-I) Ca-bound P (PCa); (J-L) Occluded P (POCC); (M-O) sum total of $P$ fractions (TPfractions). Arithmetic means (red points), standard errors (red whiskers), medians (bars), ranges (whiskers), and outliers (asterisks) are shown. Note that all plots are log (base10) transformed.

Mean bulk contents of $\mathrm{P} P a, \mathrm{Psom}_{1} \mathrm{P}_{\mathrm{Ca}}$ and $\mathrm{Pocc}$ in the long-term urban soils were $415.5 \pm 64.8 \mathrm{mg} \mathrm{kg}^{-1}, 17.0 \pm 1.3 \mathrm{mg} \mathrm{kg}^{-1}, 1818.5 \pm 363.6 \mathrm{mg} \mathrm{kg}^{-1}$ and $121.0 \pm 6.9 \mathrm{mg} \mathrm{kg}^{-1}$ respectively, and they were greater compared to those of the short-term urban soils which were $107 \pm 11.4 \mathrm{mg} \mathrm{kg}^{-1}, 10.7 \pm 1.0 \mathrm{mg} \mathrm{kg}^{-1}, 498.2 \pm 146.1 \mathrm{mg} \mathrm{kg}^{-1}$ and $89 \pm 6.0$ 
$\mathrm{mg} \mathrm{kg}^{-1}$ respectively. Similarly, mean stocks of all soil $\mathrm{P}$ fractions were also greater compared to those of the short-term urban soils (Figure 3.3.4A-L). These results are reflected in the model estimates and $\mathrm{Cls}$, which indicated significantly greater contents and stocks of long-term urban soils compared to those of short-term urban soils (Figure 3.3.5). The urban soils had markedly greater contents and stocks of all $P$ fractions compared to those of the rural and forest soils (Figure 3.3.4A-J). In P Pa, Psom, and Pocc, forest soils had mean bulk contents and stocks of $82.9 \pm 16.3 \mathrm{mg} \mathrm{kg}^{-1}$ and $10.4 \pm 1.9 \mathrm{~g} \mathrm{~m}^{-2}, 5.3 \pm 0.9 \mathrm{mg} \mathrm{kg}^{-1}$ and $0.7 \pm 0.1 \mathrm{~g} \mathrm{~m}^{-2}$, and $69.2 \pm 6.1 \mathrm{mg} \mathrm{kg}^{-1}$ and $8.9 \pm 0.9$ $\mathrm{g} \mathrm{m}^{-2}$ respectively. These values were greater compared to those of rural arable soils, which were $57.2 \pm 10.1 \mathrm{mg} \mathrm{kg}^{-1}$ and $7.5 \pm 1.3 \mathrm{~g} \mathrm{~m}^{-2}, 4.0 \pm 0.6 \mathrm{mg} \mathrm{kg}^{-1}$ and $0.5 \pm 0.1 \mathrm{~g} \mathrm{~m}^{-2}$, and $47.5 \pm 3.3 \mathrm{mg} \mathrm{kg}^{-1}$ and $6.3 \pm 0.4 \mathrm{~g} \mathrm{~m}^{-2}$ respectively (Figure 3.3.4A-J). Thus, beside the peculiar presence of the $\mathrm{P}_{\mathrm{Ca}}$ contents in the urban soils only, there was an upward increasing trend in contents and stocks of all $\mathrm{P}$ fractions from rural $<$ forest $<$ shortterm urban soils < long-term urban soils (Figure 3.3.4A-J). 


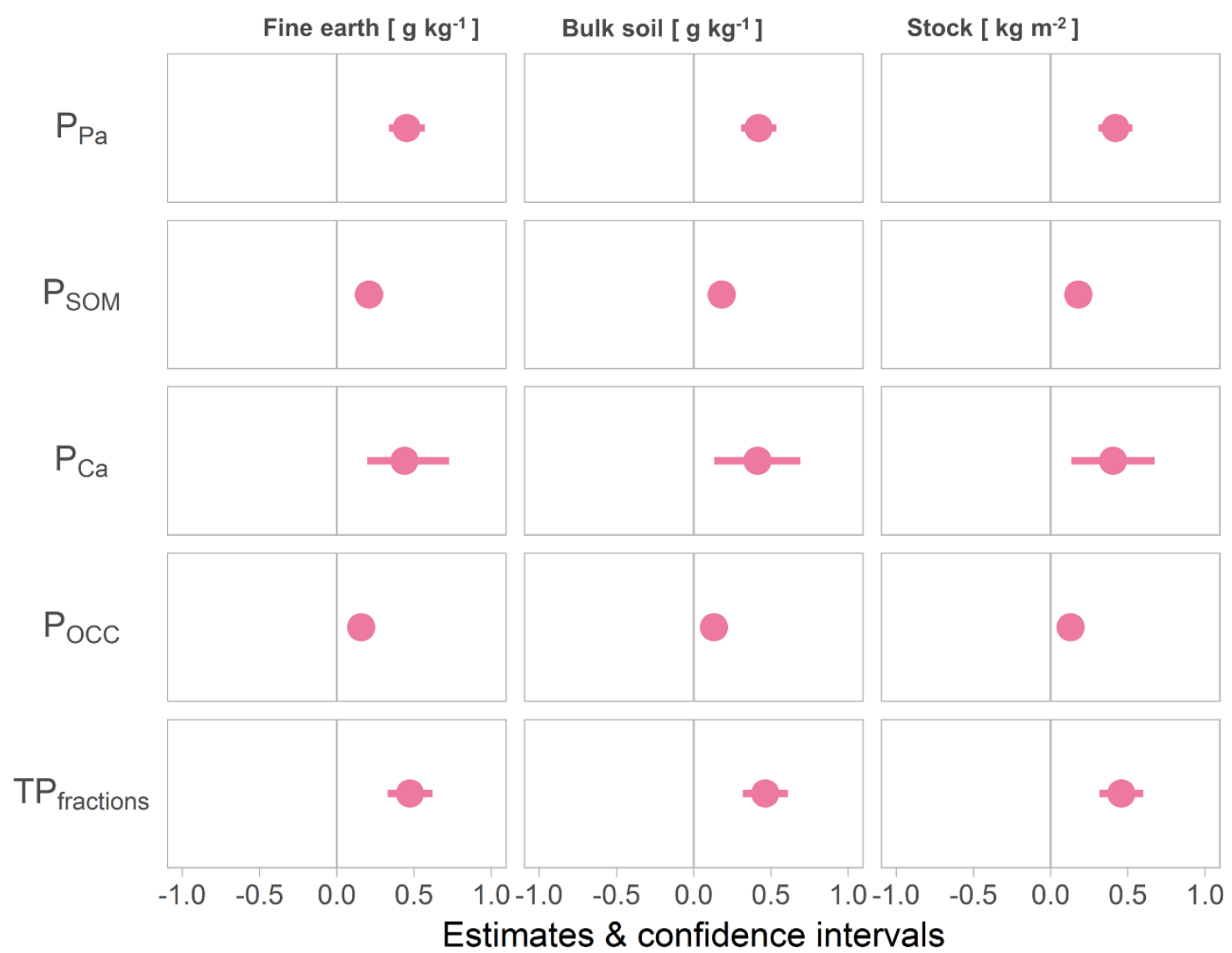

Figure 3.3.5: Comparison of long-term versus short-term urban soils, estimating model coefficients and $95 \%$ confidence intervals (Cl) of the linear models for TPfractions, sum total of contents and stocks of $P$ fractions; $P_{P a}$, plant-available $P$; $P_{\text {Som, }}$, soil organic matter bound $P$; $P_{C a}$, calcium carbonate bound $P$; $P_{0 c c}$, occluded $P$. Positive values indicated an increase of the respective soil $P$ variable in long-term urban soils, whereas negative values indicate a decrease in long-term urban soils relative to short-term urban soils. Error bars that do not cross the zero line indicate statistical significance.

$\mathrm{C}: \mathrm{P}$ ratios are useful to assess the $\mathrm{P}$ nutrient and mineralisation status of a given field. A decreasing C:P ratio $(<200)$ indicates an increasing plant-availability of soil $P$ contents (Dieter et al. 2010). Here, it was calculated as contents of soil organic carbon $(\mathrm{SOC}) / \mathrm{PPa}$, and contents of $\mathrm{SOC} / \mathrm{TP}_{\text {fractions. }}$ Mean SOC/Ppa ratio in the long-term urban soils (90.2 \pm 7.4$)$ was the narrowest compared to the short-term urban soils (192.9 \pm 11.2$)$, forest soils $(215.5 \pm 26)$ and the rural soils $(460.9 \pm 272.7)$ (Figure 3.3.6A). One outlier rural soil sample had a SOC/Ppa ratio of 2636.6. This soil was sampled in a field with stunted and yellowish looking maize plants. Without this particular sample, mean SOC/PPa ratio of the rural soils was $136 \pm 7$, which was less than those of the forest soils (Figure 3.3.6A). Similar to these trends, the mean SOC/TPfractions were long- 
term urban soils $(41.9 \pm 3)<$ short-term urban soils $(77.4 \pm 3.7)<$ forest soils $(98.9 \pm 5.6)$ $<$ rural soil (119.8 \pm 15.2 ) (Figure 3.3.6B). However, both rural and forest soils had median SOC/TP fractions of 102 , which signalled similarities in their ratios. These results corroborate the increased contents and stocks trend of the P Pa fraction particularly of the urban soils of Kumasi. For instance, there was a long-term urban soil sample with the largest $\mathrm{P}_{\mathrm{Pa}}\left(719.6 \mathrm{~g} \mathrm{~m}^{-2}\right)$ and TP fractions $\left(1835.6 \mathrm{~g} \mathrm{~m}^{-2}\right)$ stocks, which also had the lowest C:P ratio $(\leq 5)$. This sample was obtained from a field that was adjacent to a keep (sheep and goat) with visible excreta and burnt waste residues on the whole field.
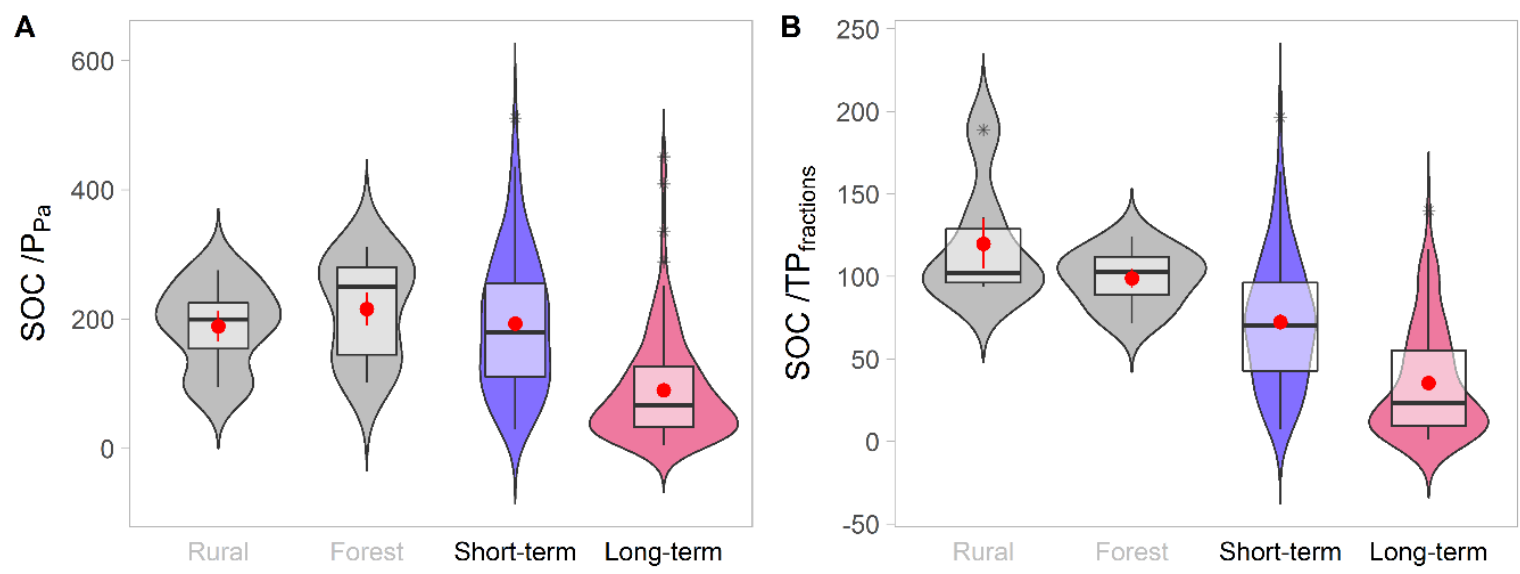

Figure 3.3.6: Comparison of (A)soil organic carbon (SOC)/plant-available $P\left(P_{P a}\right)$ and (B)SOC/sum total of $P$ fractions (TP fractions) ratios of the forest, rural and urban soils.

Arithmetic means (red points), standard errors (red whiskers), medians (bars), ranges (whiskers) and outliers (asterisks) are shown. For visualization in (A), a rural soil sample with ratio 2636.6 was removed from the plot.

\subsubsection{Contributions of contents of soil $P$ fractions in total $P$}

Contents of the $\mathrm{P}_{\mathrm{Ca}}$ fraction were detected and quantified (detection $\geq 37.5 \mathrm{mg} \mathrm{kg}^{-1}$ ) in only 75 urban soil samples, compared to all the 224 for $\mathrm{PPa}$ and 186 for both $\mathrm{Psom}$ and Pocc. Yet the range (108.9-11,551.9 $\left.\mathrm{mg} \mathrm{kg}^{-1}\right)$ and mean content $(1466.4 \pm 277.2 \mathrm{mg}$ $\mathrm{kg}^{-1}$ ) of these samples were extremely high and far greater compared to all other $\mathrm{P}$ fractions (Figure 3.3.7A). All the 19 urban soils that had extremely high $\mathrm{TP}_{\text {fraction }}$ bulk content, also had $\mathrm{P}_{\mathrm{Ca}}$ bulk contents that ranged from $913.5-11,551.9 \mathrm{mg} \mathrm{kg}^{-1}$. Mean 
P Pa bulk contents $\left(268.6 \pm 36.3 \mathrm{mg} \mathrm{kg}^{-1}\right)$ markedly exceeded those of the Pocc $\left(103.4 \pm 4.5 \mathrm{mg} \mathrm{kg}^{-1}\right)$ and Psom $\left(13.6 \pm 0.9 \mathrm{mg} \mathrm{kg}^{-1}\right)$. These trends were reflected in $\mathrm{P}$ stocks of all fractions whereby mean $P_{\text {ca }}$ stocks $\left(186.5 \pm 33.4 \mathrm{~g} \mathrm{~m}^{-2}\right)$ was the greatest, followed by $\mathrm{P}_{\mathrm{Pa}}\left(35.6 \pm 4.4 \mathrm{~g} \mathrm{~m}^{-2}\right)>\mathrm{Pocc}\left(14.1 \pm 0.6 \mathrm{~g} \mathrm{~m}^{-2}\right)>\mathrm{Psom}\left(1.8 \pm 0.1 \mathrm{~g} \mathrm{~m}^{-2}\right)$.

In the urban soils, although the contributions of the $\mathrm{P}$ fractions to their total $\mathrm{P}$ contents varied, they were consistent in a decreasing order of contribution as $\mathrm{P}_{\mathrm{Ca}}>\mathrm{PPa}_{\mathrm{Pa}}>\mathrm{Pocc}$ $>$ Psom (Figure 3.3.7B). Although the contribution of the PPa in both instances was $<40 \%$, it was striking that the contributions of the PCa contents in the long-term urban soils $(61 \%)$ markedly exceeded those of the short-term urban soils (37\%). In contrast, the contributions of the POCC contents in the short-term urban soils (25\%) markedly exceeded those in the long-term urban soils $(7 \%)$. Moreover, in the rural and forest soils, contents of the $\mathrm{PPa}$ contributed $>50 \%$ to their total $\mathrm{P}$ contents, which contrasted the trends in the urban soils (Figure 3.3.7B). These results indicated that while the effects of the $\mathrm{PCa}$ contents increase with urbanisation, its presence in the urban soils strongly decreases the contents of the Pocc particularly and that of the Pra marginally.
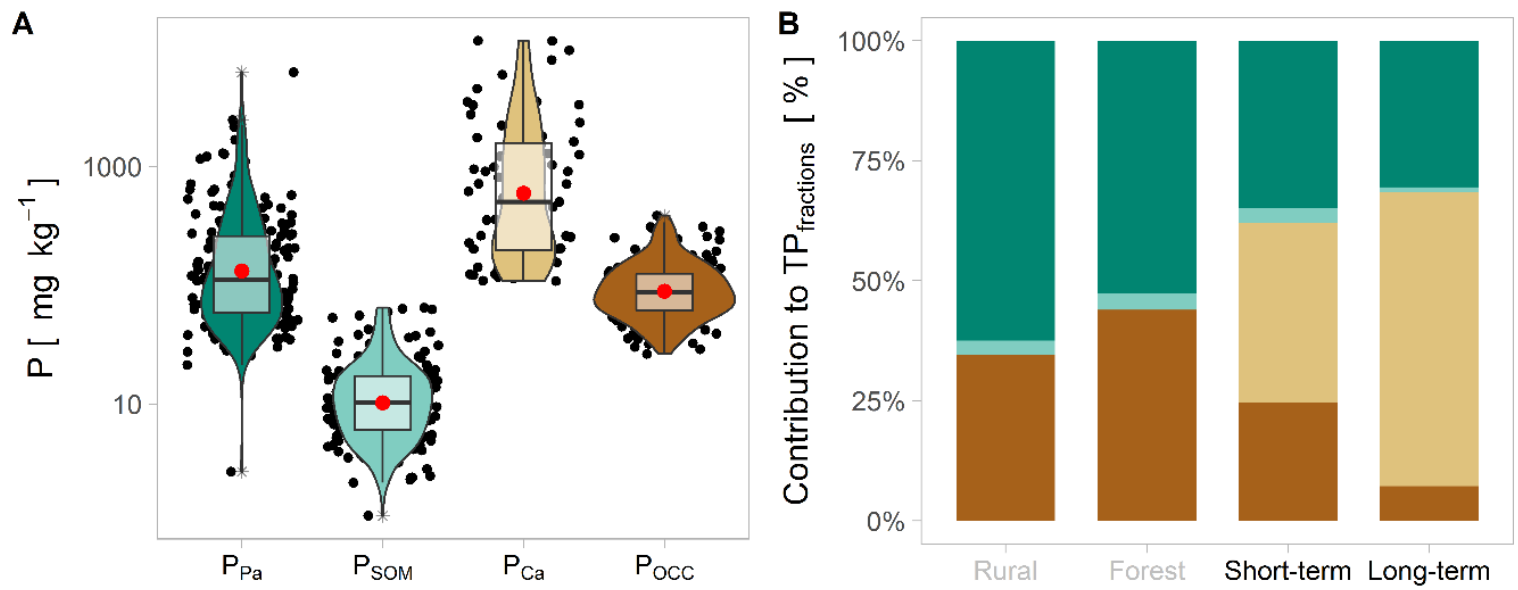

Figure 3.3.7: (A) Comparison of contents of soil $P$ fractions. Note the logarithmic scale. $P_{P a}$, plant-available $P$; $P_{\text {som, }}$ soil organic matter bound $P ; P_{C a}$, calcium carbonate bound $P$; $P_{\text {occ }}$, occluded $P$. Black points indicate soil samples, and asterix show outliers. (B) Comparison of the proportion of each soil $P$ fractions in the total $P$ contents. Dark and light turquoise represent $P_{P_{a}}$ and $P_{s o m}$ respectively, while dark and light brown represent $P_{o c c}$ and $P_{C a}$ respectively. 


\subsubsection{Relationships between fractions of soil $P$ contents and SOC}

contents, soil $\mathrm{pH}_{\text {water }}$ and ECEC

Contents of the soil $\mathrm{P}$ fractions had significantly positive linear relationships with SOC contents, soil $\mathrm{pH}_{\text {water, }}$ and effective cation exchange capacity (ECEC) (Figure 3.3.8AL). With similar coefficients and significant $\mathrm{Cl}$, the explained variances of the $\mathrm{PPa}, \mathrm{Psom}$, Pocc contents by the SOC contents in the forest soils $\left(r^{2}=0.48,0.66,0.64\right.$ respectively) and rural $\left(r^{2}=0.37,0.44,0.68\right.$ respectively) soils were high, and they markedly exceeded those of the long-term urban soils $\left(r^{2}=0.20,0.14,0.18\right.$ respectively $)$ and short-term urban soils $\left(r^{2}=0.12,0.19,0.39\right.$ respectively) (Figure 3.3.8A,D,G,J). Soil $\mathrm{pH}_{\text {water }}$ significantly explained the variances in the contents of the $\mathrm{P}_{\mathrm{Pa}}, \mathrm{Psom}_{\mathrm{s}} \mathrm{P} \mathrm{Ca}$ and Pocc of the long-term urban soils $\left(r^{2}=0.26,0.24,0.26,0.20\right.$ respectively) and shortterm urban soils $\left(r^{2}=0.33,0.45,0.26,0.09\right.$ respectively). However, soil $\mathrm{pH}_{\text {water }}$ was significantly related to Psom in the forest soils $\left(r^{2}=0.51\right)$ and PPa in the rural soils $\left(r^{2}=\right.$ $0.44)$ only. ECEC significantly explained the variances in the $\mathrm{P}_{\mathrm{Pa}}, \mathrm{Psom}_{\mathrm{S}} \mathrm{P}_{\mathrm{Ca}}$ and $\mathrm{Pocc}$ in the long-term urban soils $\left(r^{2}=0.40,0.24,0.28,0.34\right.$ respectively) and short-term urban soils $\left(r^{2}=0.42,0.43,0.22,0.39\right.$ respectively). Also, ECEC related significantly with Psom $\left(r^{2}=0.88\right)$ and Pocc $\left(r^{2}=0.58\right)$ contents of the forest soils, but in the rural soils, it significantly related to the $\mathrm{PPa}$ contents $\left(r^{2}=0.53\right)$ only. The low sample size of the rural and forest soils may be responsible for the instances of statistical insignificance (details in supplementary). Still, these results have shown clear relationships between contents of the $\mathrm{P}$ fractions and $\mathrm{SOC}$ in the forest, rural and urban soils. However, whereas the relationships between contents of the $\mathrm{P}$ fractions with soil $\mathrm{pH}_{\text {water }}$ and ECEC were strong in the urban soils, they were inconsistent for the rural and forest soils. 

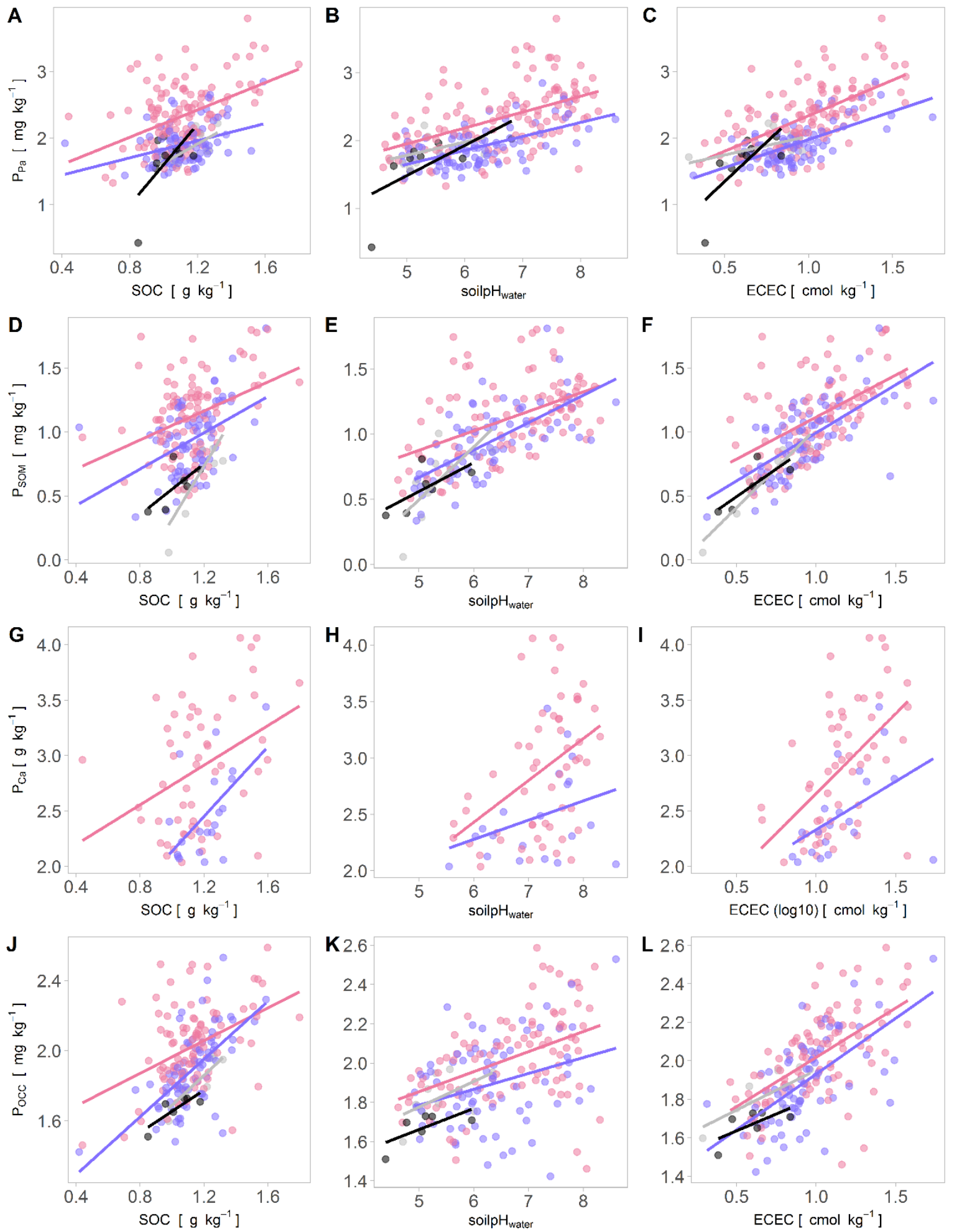

Figure 3.3.8: Linear relationships between contents of $P$ fractions and soil organic carbon

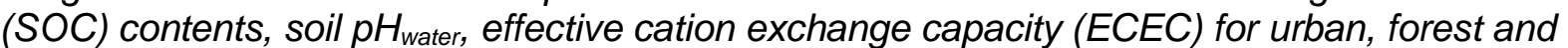
rural soils. Note the logarithmic scale on all units except the soil $\mathrm{pH}$. Lines represent the linear relationships and standard error of the estimates. Dark and light blue points represent long-term and short-term urban soils, grey points represent forest soils, and black points represent soils. 
Contents of the $\mathrm{PPa}$ were positively and significantly related to those of the $\mathrm{Psom}, \mathrm{PCa}$ and the Pocc (Figure 3.3.9A-C). Estimated coefficients and corresponding $\mathrm{Cl}$ indicated greater $\mathrm{P}_{\mathrm{Pa}}-\mathrm{P}_{\text {som }}$ relationship in the long-term urban soils $\left(\mathrm{r}^{2}=0.73\right)$ compared to their short-term counterparts $\left(r^{2}=0.43\right)$. Also, while the $\mathrm{Cl}$ and coefficients of the relationship of the forest soils $\left(r^{2}=0.4\right)$ were significant, those of the rural soils $\left(r^{2}=0.4\right)$ were insignificant. With such high $\mathrm{r}^{2}$, the insignificance of the coefficients of the rural

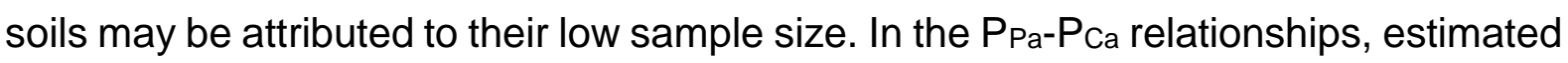
coefficients and their corresponding $\mathrm{Cl}$ indicated similar strengths of the long-term urban soils $\left(r^{2}=0.46\right)$ and short-term urban soils $\left(r^{2}=0.56\right)$ (Figure 3.3.9B). In contrast to these trends, the Cls and coefficients of the $\mathrm{P}_{\mathrm{Pa}}-\mathrm{Pocc}_{\mathrm{O}}$ relationship in the urban soils $\left(r^{2}=\sim 0.20\right)$, though significant, were weaker compared to the $\mathrm{P}_{\mathrm{Pa}}-\mathrm{Psom}_{\mathrm{som}}$ and $\mathrm{P}_{\mathrm{Pa}}-\mathrm{P}_{\mathrm{Ca}}$ relationships. In addition, while the coefficients and $\mathrm{Cl}$ of the forest soils $\left(r^{2}=0.06\right)$ indicated insignificant $\mathrm{PPa}_{\mathrm{Pa}} \mathrm{P}_{\mathrm{O}}$ relationship, those of the rural soils $\left(\mathrm{r}^{2}=0.90\right)$ indicated a remarkable significant relationship. From these results, a clear pattern of the soil P availability pathway was distinguishable for the three main categories. (1) In the forest soils, the $\mathrm{P} P a$ content was strongly related to its $\mathrm{Psom}$ content, (2) in the rural soils, the P Pa content was rather strongly related to its Pocc content, and (3) in the urban soils, the $\mathrm{P}_{\mathrm{Pa}}$ content was strongly related to both the $\mathrm{P}_{\text {som }}$ and $\mathrm{P}_{\mathrm{Ca}}$ contents.
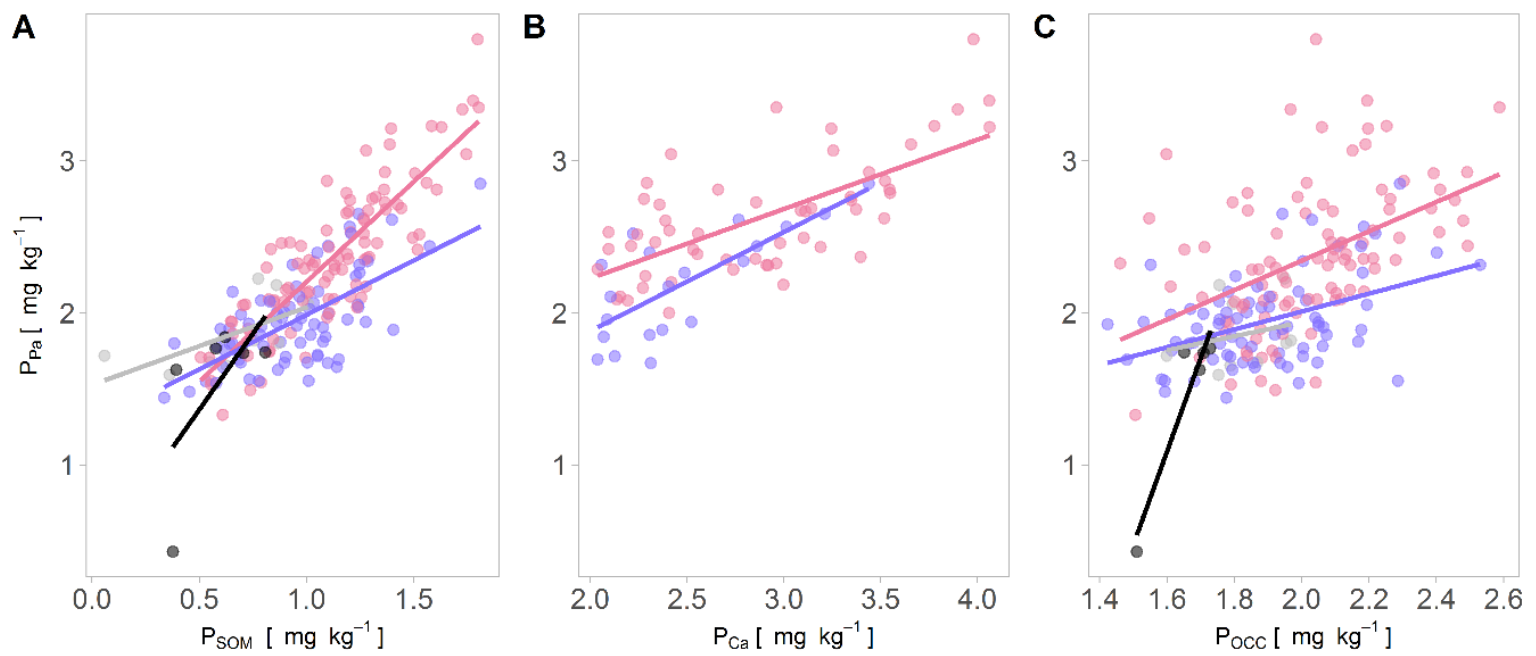
Figure 3.3.9: Linear relationships between contents of plant-available $P(P P a)$ and $(A)$ soil organic matter-bound $P$ ( $\left.P_{\text {Som }}\right)$, $(B)$ Ca-bound $P\left(P_{C a}\right)$ and $(C)$ occluded $P$ ( $\left.P_{O C C}\right)$. Lines indicate the linear models that describe the relationships. Dark and light blue (points and lines) represent long-term and short-term urban soils respectively. Black and grey represent rural and forest soils.

The path diagram of the urban soils (Figure 3.3.10A-B) revealed that the multiple effects of the other $\mathrm{P}$ fractions and soil properties explained $84 \%$ of the variance of the P $\mathrm{Pa}$ contents in the short-term urban soils, which was greater compared to the $72 \%$ in the long-term urban soils. Also, the explained variances in the contents of Psom (65\%), $\mathrm{P}_{\mathrm{Ca}}(47 \%)$ and Pocc $(33 \%)$ by the soil properties were generally greater in the shortterm urban soils compared to the $29 \%, 30 \%$ and $26 \%$ respectively, of the long-term urban soils. In the short-term urban soils, the strength of the direct effects on the $\mathrm{PPa}$ contents indicated a stronger $\mathrm{P}_{\mathrm{Ca}}$ contents compared to the similar strength of $\mathrm{Pocc}$ and $\mathrm{P}_{\text {som }}$ contents. However, in the long-term urban soils, contents of the $\mathrm{P}_{\mathrm{Ca}}$ and Psom particularly, had markedly greater effect on the $\mathrm{P}_{\mathrm{Pa}}$ contents, compared to the marginal effect by the Pocc contents. Moreover, there was a relatively strong direct influence from the soil $\mathrm{pH}_{\text {water }}$ and SOC contents particularly in the short-term urban soils, whereas the strong relationships in the long-term urban soils were from the ECEC and soil $\mathrm{pH}_{\text {water. }}$ Thus, the relative strengths of the interdependent relationships were widely different between the long-term urban soils and their short-term counterparts (Figure 3.3.10A-B).

Consequently, the path diagrams of the urban soils have corroborated the general trends of the respective linear relationships within the contents of the $P$ fractions and with the soil properties. These respective relationships revealed a decreased effect of the strength of SOC contents on the $\mathrm{P}$ fractions in the order of forest $<$ rural $<$ urban soils. In this SEM approach, a similar trend of the decreased effect of SOC contents on the contents of the $P$ fractions from the short-term urban soils to the long-term urban soils was evident. Thus, a forest-rural-urban gradient pattern of the SOC-P 
fractions relationship was deducible as a decreasing trend that followed as forest soils $<$ rural soils $<$ short-term urban soils $<$ long-term urban soils.

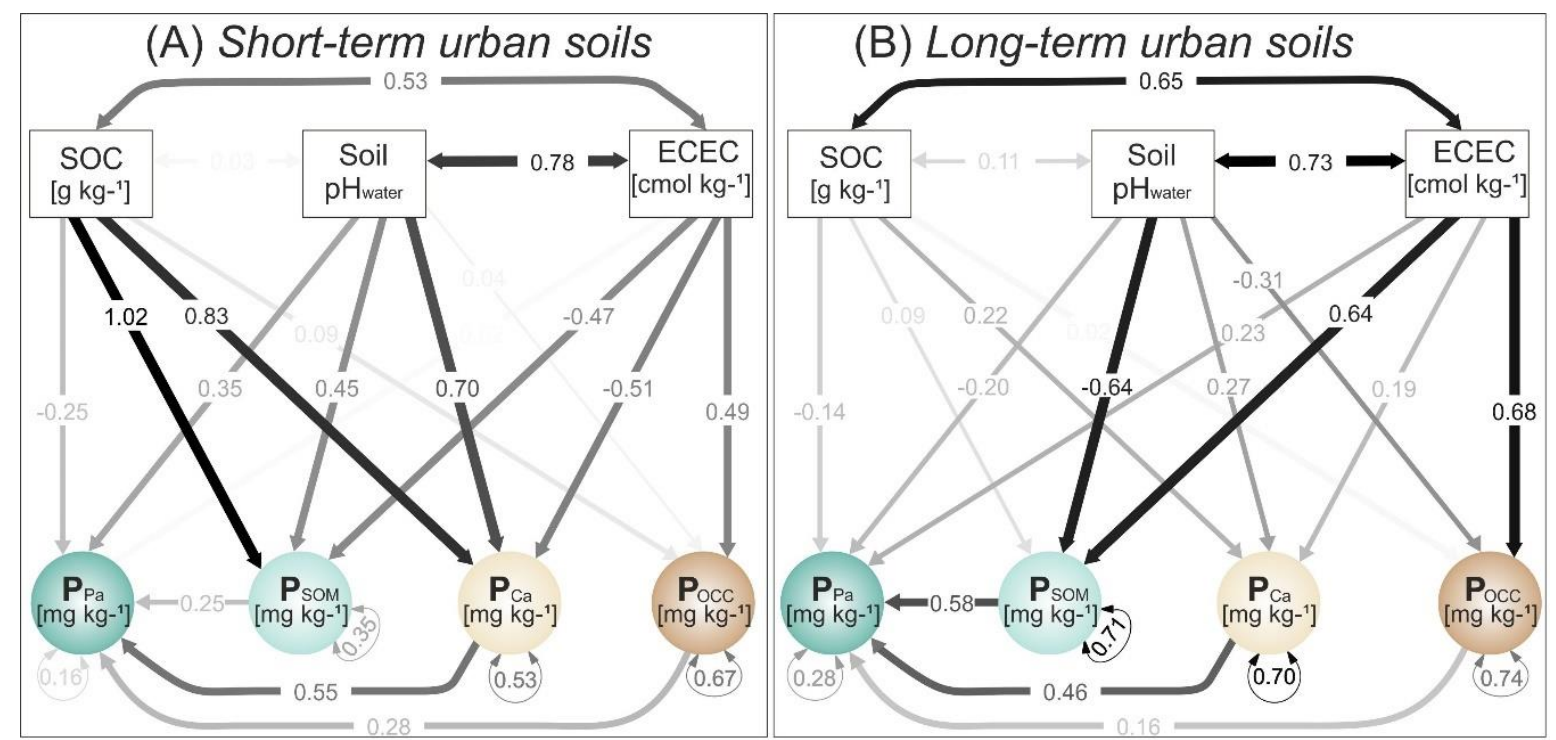

Figure 3.3.10: Causal path diagram depicting the relationships within the contents of the soil $P$ fractions and with the soil properties in the $(A)$ short-term versus $(B)$ long-term urban soils.

Single headed arrows represent the effect (dark= strong, light= weak). Double headed arrows represent unexplained variances. The magnitude of the effect is represented with the intensity of darkness and line thickness. Values on single headed arrow represent the $r^{2}$, and values in the double headed arrows represent unexplained variances

\subsubsection{Discussion}

Available $P$ stocks represent a transient reservoir that can be instantly utilized by plants and other organisms, whereas recalcitrant $\mathrm{P}$ stocks represent a longstanding potential reservoir that may be utilized when available $\mathrm{P}$ is limiting. In this study, we successfully quantified four relevant fractions which represented one available reservoir, plant-available $\mathrm{P}(\mathrm{Paa})$, and three recalcitrant reservoirs, the SOM-bound $\mathrm{P}$ (Psom), Ca-bound $\mathrm{P}$ ( $\mathrm{P}_{\mathrm{Ca}}$ ) and occluded $\mathrm{P}$ (Pocc). Total soil $\mathrm{P}$ stock is usually a poor indicator for soil $\mathrm{P}$ nutrition as the abundance of one reservoir may obscure the limitation of another. In this study, however, total P stock was a useful indicator of all soil $P$ reserves, because the trend of contents and stocks of the sum of all $P$ fractions (TPfractions) reflected the respective trends of $\mathrm{P}_{\mathrm{Pa}}, \mathrm{Psom}_{\mathrm{P}} \mathrm{P} \mathrm{Ca}$ and $\mathrm{Pocc}$. In particular, we found that for all these $\mathrm{P}$ fractions, the contents and stocks of the urban soils 
substantially exceeded those of the rural and forest soils. In addition, we found that soils that have been under long-term urbanisation had significantly greater soil $\mathrm{P}$ contents and stocks compared to their short-term counterparts. The range of total $\mathrm{P}$ stocks of forest and rural soils measured in this study were comparable to the $27-40$ $\mathrm{g} \mathrm{m}^{-2}$ total $\mathrm{P}$ stocks that have been reported for unfertilized arable fields of tropical Kenya (Ngoze et al. 2008). Also, Asomaning et al. (2009) have reported 314-330 mg $\mathrm{kg}^{-1}$ total $\mathrm{P}$ contents in soils of the forest zone of southern Ghana, which compares greater to the mean of the forest and rural soils in this study but compares less to the urban soils. Moreover, Solomon et al. (2002) have reported a range of 874-1426 mg $\mathrm{kg}^{-1}$ total $\mathrm{P}$ in forest soils of sub-tropical Ethiopia, which though is in the range of the urban soils, compares particularly less to the mean of the long-term urban soils in this study. Thus, it is clear that urban arable soils in Kumasi that become part of the urbanisation process, have enriched soil P contents and stocks.

In agreement with these findings, other studies have reported that urbanisation leads to enriched soil P stocks in urban soils around the world (Zhang 2004; Joimel et al. 2016; Li et al. 2018; Meng et al. 2018). The range of total $P$ contents of the urban soils in this study were comparable to the $400-2500 \mathrm{mg} \mathrm{kg}^{-1}$ that have been reported for cities in Iraq, China and England (Zhang 2004; Meng et al. 2018; Khorshid et al. 2019). In all these studies, solid and liquid waste, construction and traffic have been identified as key sources of $P$ in urban soils. Similarly, within the urban environment of Kumasi, the anthropogenic activities which have been identified to shape soil physical and chemical properties of arable soils are accumulated household wastes and construction waste and materials (Asabere et al. 2018b). These activities have been an important source of anthropogenic materials such as food waste, ash, and concrete, which have directly resulted in an increase of SOM stocks, soil $\mathrm{pH}_{\text {water, }}$ 
ECEC and stocks of exchangeable bases in Kumasi's urban arable soils (Asabere et al. 2018a; Asabere et al. 2018b). The trends of these enhanced soil properties reflect similar trends in this study on the enriched soil P contents and stocks. Thus, it is likely that these anthropogenic activities have been the source of the enriched soil $P$ contents and stocks in this study.

Within this context, urban soil $\mathrm{P}$ contents in Kumasi likely have two main origins. Firstly, a woefully inadequate solid and liquid waste collection infrastructure in the city, like most cities in the global south (Pacione 2009; Asabere et al. 2018b), has led to the accumulation of $P$ rich compounds in the urban soils. In Kumasi, only $14 \%$ and $3 \%$ of the solid and liquid wastes respectively are centrally collected (Ghana Statistical Service 2014b). It is, therefore, a widespread practice in Ghanaian cities that several households and communities dump indiscriminately, burn, or bury their solid waste (Miezah et al. 2015). In addition, liquid wastes from households that contain oils, soaps and urine etc. are indiscriminately disposed through open gutters, and thrown into streets and the wider environment (Fuseini and Kemp 2016). There is a strong evidence that urban soils in Kumasi have become repositories of such wastes. Asabere et al. (2018b) have demonstrated that soils that become part of the urbanisation process in Kumasi, exhibits markedly increased contents of coarse fragments that were made of several anthropogenic fragments and charred materials of wood, animal bones, textile etc. Thus, these solid and liquid wastes which have accumulated in the urban arable fields in-situ, or transported by wind and water onto the fields, have been a key source of soil P contents through the enhancement of soil organic matter stocks.

In tropical soils, the effects of soil organic matter turnover are fundamental to soil P cycling. For instance, soil organic matter mineralization is a rich source of available $\mathrm{P}$ 
and other nutrient contents. It is also a source of organic anions that compete for adsorption sites that release P contents. Moreover, by enhancing SOC contents, soil organic matter provides energy for the activities of mycorrhizae and enzymes that mobilizes $P$ from recalcitrant reservoirs and increase available $P$ content. Thus, in this study, we expectably found that the $\mathrm{P}_{\mathrm{Pa}}$ contents of all soil samples strongly correlated with the Psom contents. Contents of $\mathrm{P}_{\mathrm{Pa}}, \mathrm{P}_{\mathrm{SOM}}$, and $\mathrm{P}_{\mathrm{Occ}}$ of forest and rural soils, which represents typical tropical soil conditions, were particularly strongly related to SOC contents compared to those of the urban soils. The relatively weaker SOC-P fractions relationships in the urban soils is attributable to the heterogenous nature of household wastes, whereby the sources of $P$ in the urban soils are likely from non-typical organic matter contents (Asabere et al. 2018b). For instance, sources of P contents are likely from compounds of animal bones and shells, paper, textile, wood, oil and soap amongst others (Levin et al. 2017; Weihrauch 2018). In this regard, the high contents of $\mathrm{PCa}_{\mathrm{Ca}}$ in the urban soils, which is normally uncharacteristic of tropical soils, is partly attributable to these inorganic $\mathrm{P}$ sources. Also, this explanation is consistent with the additionally strong relationships we found between soil $\mathrm{pH}_{\text {water }}$ and ECEC and the contents of the $\mathrm{P}$ fractions in the urban soils only.

Moreover, in anthropogenically influenced tropical soils such as arable fields with limited soil organic matter contents, soil $\mathrm{P}$ availability is also controlled by the strong sorption capacities due to the high clay content and abundant mobile Al and Fe oxides (Maranguit 2017; Owusu-Bennoah et al. 1997). Likewise, we found that in the rural soils, $90 \%$ of the variances in the $\mathrm{P}_{\mathrm{Pa}}$ contents were explained by the Pocc contents alone. This is much more than the $\sim 20 \%$ in the urban soils, and contrasts with that of the forest soils that was uncorrelated. Using the results of the SEM, we found that the 
contribution of the $\mathrm{PCa}_{\mathrm{Ca}}$ fraction present in urban soils decreased the strength of the Pea-Pocc and increased that of the PPa-Psom relationship in the long-term urban soils. Secondly, the other source of $P$ is the accumulation of $P$ rich debris and leachates from concrete (cement) materials such as bricks in the urban soils. Because of the long average construction time ( 10 years) of houses in Ghana (Stow et al. 2016), the arable soils in Kumasi's urban environment have become recipients of these calcareous debris and leachates (Asabere et al. 2018b). As a result, the urban soils of this study have increased soil $\mathrm{pH}_{\text {water }}(>7)$, contents of carbonates and exchangeable Ca (Asabere et al. 2018a; Asabere et al. 2018b). Concrete materials such as cement and bricks are very rich in $\mathrm{P}$, particularly in the form of inorganic $\mathrm{Ca}$ phosphates (Khorshid et al. 2019; Metson et al. 2012). For instance, Nehls et al. (2013) have estimated $200-800 \mathrm{mg} \mathrm{kg}^{-1} \mathrm{P}$ contents in concrete brick debris in urban soils. Thus, for most tropical soils, the presence of the $\mathrm{P}_{\mathrm{Ca}}$ fraction can only have an anthropogenic origin resulting from their higher soil $\mathrm{pH}_{\text {water }}$ and their multiple sources of $\mathrm{Ca}$ phosphates from both household wastes and concrete accumulation.

This particular effect of urbanisation on tropical soils may have negative consequences on soil P availability, as it has been reported for the city of Hong Kong (Jim 1998). At soil pH water of ca. 7.5 and in the presence of abundant $\mathrm{Ca}$, available $\mathrm{P}$ is readily precipitated into insoluble Ca phosphates (Ashman and Puri 2017). In these conditions, tropical soils with naturally low $\mathrm{pH}$ or anthropogenically high $\mathrm{pH}$ conditions may precipitate $\mathrm{PPa}_{\mathrm{Pa}}$ contents into recalcitrant $\mathrm{P}_{\mathrm{Occ}}$ or $\mathrm{P}_{\mathrm{Ca}}$ contents respectively. In the present study, a similar effect of urbanisation may be at stake in the urban soils, because the proportion of $\mathrm{PCa}$ contents and stocks remarkably dominated the total $\mathrm{P}$ contents and stocks in the urban soils. For instance, in each of the four samples with $>1000 \mathrm{~g} \mathrm{~m}^{-2}$ total P stocks, their $\mathrm{P}_{\mathrm{Ca}}$ contents and stocks were substantially greater 
compared to their $\mathrm{PPa}_{\mathrm{Pa}}$ contents and stocks. Considering the possible $\mathrm{P}_{\mathrm{Ca}}$ sources, it is plausible that the contents of fine earth of these specific urban fields were enriched with Ca compounds originating from concrete materials.

Although the recalcitrant $\mathrm{P}$ contents may be enhanced in the urban soils of Kumasi under both acidic and alkaline conditions, our analysis of the C:P ratios suggest that the $\mathrm{P} P a$ contents are sufficient to support plant growth. Soils with adequate $\mathrm{PPa}$ contents tend to exhibit C:P ratios $<200$, whereas those with insufficient $\mathrm{PPa}$ contents exhibit C:P ratios >200 (Maranguit et al. 2017; Dieter et al. 2010; Solomon et al. 2002). In this study, we found that urban soils under long-term urbanisation showed markedly narrower ratios compared to other categories, although all samples had C:P ratios $<200$. Thus, through the combined effect of the accumulated household waste and concrete debris, soil $\mathrm{P}$ availability in the urban arable fields in Kumasi is sufficient to support plant growth.

As indicated in Kirchhof et al. (2008), it is likely that the alkaline extraction method that was employed in this study to extract the $\mathrm{PPa}$ fraction (Collwell-P) may have overestimated the concentration in some of the acidic soil samples. This is because the alkalinity of the extraction solution may have desorbed loosely adsorbed $\mathrm{P}$ from the surfaces of soil minerals and organic matter. This may, therefore partly explain the high (90\%) correlation between $\mathrm{PPa}$ and $\mathrm{Pocc}$ contents, in the rural soils of this study. Nevertheless, the mean $\mathrm{PPa}$ contents of the forest and rural soils $\left(67.1 \mathrm{mg} \mathrm{kg}^{-1}\right)$ of this study compares well with values reported in other studies. For example, Kirchhof et al. (2008) reported a value of $68 \pm 23.3 \mathrm{mg} \mathrm{kg}^{-1} \mathrm{PPa}$ (mean \pm standard deviation) for the tropical highland soils of Papua New Guinea. Also, the mean $\mathrm{P}_{\mathrm{Pa}}$ contents of the urban soils in this study were comparable to the $400 \mathrm{mg} \mathrm{kg}^{-1}$ available $\mathrm{P}$ (Olsen) in the fertilized urban vegetable garden soils of France (Joimel et al., 2016). Moreover, 
Asomaning et al. (2009) have reported $2.5-3.5 \mathrm{mg} \mathrm{kg}^{-1}$ available $\mathrm{P}$ (Bray-1) in strongly weathered forest soils of southern Ghana, which is markedly less than the range measured in urban and forest soils in this study. Thus, to our knowledge this bias was not evident in this study.

\subsubsection{Conclusion}

The findings in this study have shown that through agents such as household waste and construction, rapid urbanisation in Kumasi have directly enhanced both available and recalcitrant soil $\mathrm{P}$ contents and stocks. In addition, because of the enhanced $\mathrm{P}$ contents in the urban soils, especially the enrichment of the $\mathrm{P}_{\mathrm{Ca}}$ contents, the pathway of soil $\mathrm{P}$ cycling has been different from that of typical tropical forest and rural soils. For instance, while all $\mathrm{P}$ fractions were significantly related to SOM contents, the strength of these relationships decreased with increased urbanisation. In contrast, the strength of the relationship between $\mathrm{P}$ fractions and both soil $\mathrm{pH}_{\text {water }}$ and effective cation exchange capacity increased with increased urbanisation. Moreover, the sources of $\mathrm{P}_{\mathrm{Pa}}$ content was different for the urban soils ( $\mathrm{Psom}_{\mathrm{S}}$ and $\mathrm{P}_{\mathrm{Ca}}$ dependent) compared to the forest (Psom dependent) and rural (Pocc dependent) soils. These findings resonate with those of cities from other parts of the world, which have shown similar P enhancements through several anthropogenic activities.

Therefore, our findings suggest that cities have an exclusive role to play in the global sustainable $\mathrm{P}$ management efforts, which seek to recycle $\mathrm{P}$ from $\mathrm{P}$-rich urban waste back into food production (Metson and Bennett 2015). We have shown that even without a deliberate effort by urban farmers in Kumasi to reincorporate organic urban waste into their fields as a means of $P$ recycling, there is still a clear positive urbanisation effect on soil P cycling and stocks in the urban arable fields. Thus, it will be beneficial for urban farmers in Kumasi and other West African cities, to actively 
engage in composting urban household waste for the enhancement of soil P stocks. The results of our study, thus, elucidates the critical role that urban arable fields in tropical West African cities may play in recycling $P$ in order to support urban sustainability and food security. This is a highly relevant issue, as peak $\mathrm{P}$ exploitation will be reached in the next decade, thereby initiating an increase in global $P$ fertilizer prices (Cordell et al. 2009), which is already unaffordable for many West African farmers (Minde et al. 2008).

\section{Supplementary materials}

Appendix 3.3.1: Data on blank samples that were used for ensuring analytical quality of the sequential $P$ fractionation.

\begin{tabular}{lcccc} 
Sample number & $\begin{array}{c}\text { PPa } \\
{[\mathbf{p p m}]}\end{array}$ & $\begin{array}{c}\text { Psom } \\
{[\mathbf{p p m}]}\end{array}$ & $\begin{array}{c}\text { Pca } \\
{[\mathbf{p p m}]}\end{array}$ & $\begin{array}{c}\text { Pocc } \\
\text { [ppm] }\end{array}$ \\
\hline BK1 & 0.06 & $8.54^{*}$ & 0.04 & -0.01 \\
BK2 & 0.03 & $8.03^{*}$ & 0.03 & 0.26 \\
BK3 & 0.06 & 0.00 & 0.00 & -0.01 \\
BK4 & 0.15 & 0.20 & 0.74 & 0.01 \\
BK5 & -0.15 & 0.00 & -0.01 & -0.04 \\
BK6 & 0.13 & -0.01 & 0.00 & -0.02 \\
BK7 & 0.12 & 0.00 & 0.06 & -0.03 \\
BK8 & 0.14 & 0.00 & -0.01 & 0.00 \\
BK9 & -0.08 & 0.00 & -0.02 & 0.01 \\
BK10 & -0.17 & -0.01 & 0.03 & 0.00 \\
BK11 & 0.04 & 0.01 & 0.00 & 0.01 \\
BK12 & -0.06 & 0.01 & 0.00 & 0.01 \\
Mean & 0.02 & 0.02 & 0.08 & -0.01 \\
Standard deviation (SD) & 0.11 & 0.06 & 0.22 & 0.02 \\
Detection limit (3 SD) & 0.35 & 0.20 & 0.75 & 0.04 \\
Quantification limit (10 SD) & 1.10 & 0.61 & 2.30 & 0.16 \\
\hline SD= standard deviation, ${ }^{*}$ Data removed due to contamination &
\end{tabular}



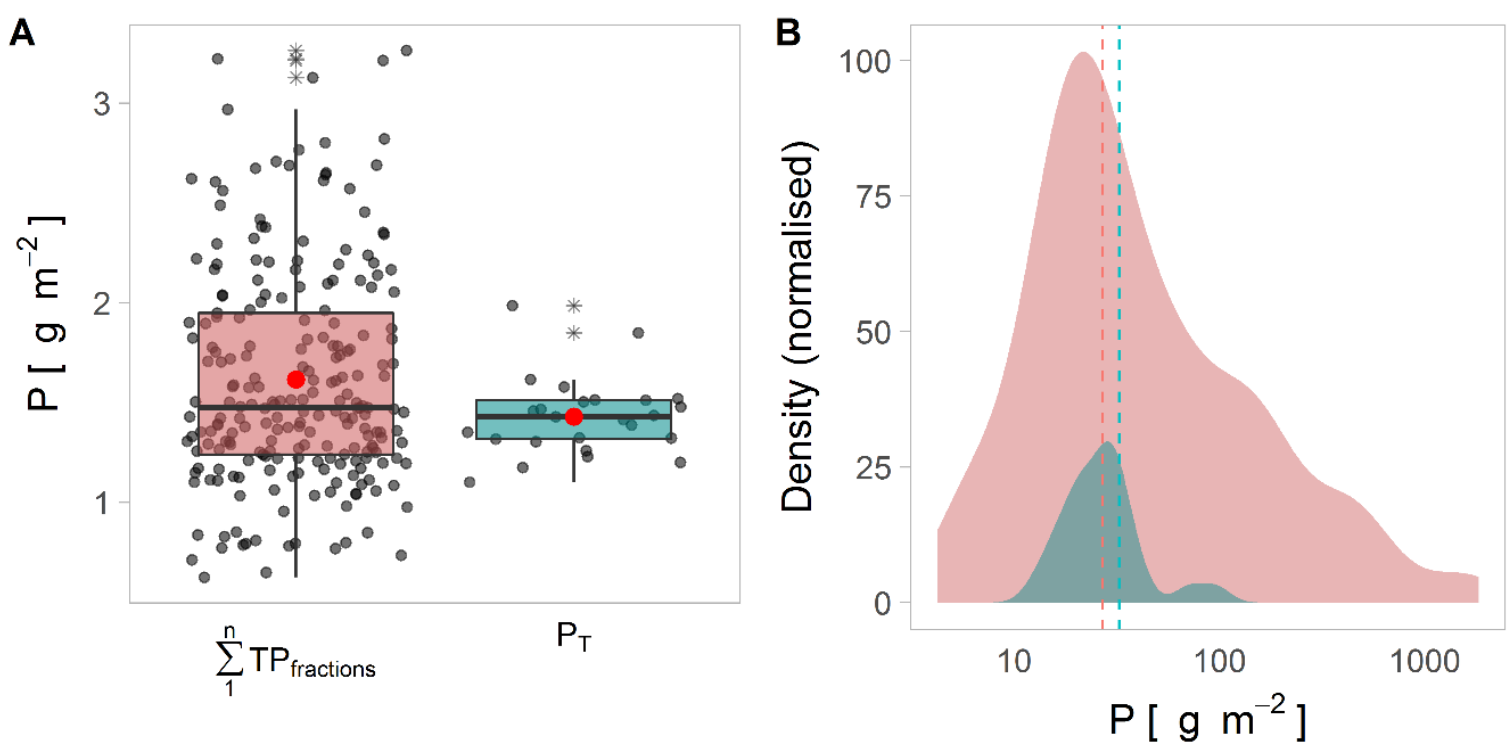

Appendix 3.3.2: Comparable datasets of stocks of the sum of $P$ fractions by sequential extraction (TPfractions) vs those of the total $P(P T)$ from the acid digestion shown as $(A)$ boxplots with black datapoints and red mean points, $(B)$ density plots with dashed lines as medians. Note the logarithmic scale.

Appendix 3.3.3: Coefficients and confidence intervals $(\mathrm{Cl})$ of the linear equations that described the relationships between contents of plant-available $P$ and other soil $P$ fractions, as well as the $P$ fractions and the contents of soil organic carbon (SOC), soil $p H_{\text {water }}$ and effective cation exchange capacity (ECEC).

\begin{tabular}{|c|c|c|c|}
\hline Category & Relationships & $\mathbf{r}^{2}$ & Cl \\
\hline \multirow{15}{*}{$\begin{array}{l}\text { Long-term } \\
\text { urban soils }\end{array}$} & $\mathrm{P}_{\mathrm{Pa}}=1.31\left(\mathrm{P}_{\mathrm{SOM}}\right)+0.89$ & 0.73 & $1.20-1.50$ \\
\hline & $\mathrm{P}_{\mathrm{Pa}}=0.46\left(\mathrm{P}_{\mathrm{Ca}}\right)+1.31$ & 0.46 & $0.32-0.59$ \\
\hline & $P_{P a}=0.97\left(P_{\text {occ }}\right)+0.41$ & 0.22 & $0.59-1.34$ \\
\hline & $P_{P a}=1.03(S O C)+1.19$ & 0.20 & $0.65-1.40$ \\
\hline & $\mathrm{P}_{\mathrm{Pa}}=0.23$ (soil $\mathrm{pH}$ water $)+0.78$ & 0.26 & $0.16-0.31$ \\
\hline & $P_{P a}=1.07(E C E C)+1.27$ & 0.40 & $0.83-1.31$ \\
\hline & $P_{\text {SOM }}=0.57(\mathrm{SOC})+0.49$ & 0.14 & $0.29-0.84$ \\
\hline & $P_{\text {som }}=0.15$ (soil pH water $)+0.13$ & 0.24 & $0.09-0.20$ \\
\hline & $P_{\text {SOM }}=0.66(E C E C)+0.46$ & 0.31 & $0.46-0.85$ \\
\hline & $\mathrm{P}_{\mathrm{Ca}}=0.89(\mathrm{SOC})+1.84$ & 0.14 & $0.28-1.51$ \\
\hline & $\mathrm{P}_{\mathrm{Ca}}=0.23$ (soil $\left.\mathrm{pH}_{\text {water }}\right)+0.78$ & 0.26 & $0.16-0.31$ \\
\hline & $\mathrm{P}_{\mathrm{Ca}}=1.44(\mathrm{ECEC})+1.22$ & 0.28 & $0.81-2.08$ \\
\hline & $P_{O C C}=0.47(S O C)+1.50$ & 0.18 & $0.26-0.67$ \\
\hline & Pocc $=1.53$ (soil pH $\left.\mathrm{H}_{\text {water }}\right)+0.77$ & 0.21 & $0.92-2.14$ \\
\hline & PocC $=0.51(E C E C)+1.51$ & 0.34 & $0.37-0.66$ \\
\hline & $P_{P a}=0.72\left(P_{S O M}\right)+1.27$ & 0.43 & $0.50-0.90$ \\
\hline
\end{tabular}




\begin{tabular}{|c|c|c|c|}
\hline Short-term & $\mathrm{P}_{\mathrm{Pa}}=0.65\left(\mathrm{P}_{\mathrm{Ca}}\right)+0.58$ & 0.56 & $0.36-0.93$ \\
\hline \multirow[t]{13}{*}{ urban soils } & $P_{P a}=0.59\left(P_{o c c}\right)+0.83$ & 0.19 & $0.30-1.87$ \\
\hline & $\mathrm{P}_{\mathrm{Pa}}=0.65(\mathrm{SOC})+1.19$ & 0.12 & $0.28-1.02$ \\
\hline & $\mathrm{P}_{\mathrm{Pa}}=0.21$ (soil $\mathrm{pH}$ water $)+0.62$ & 0.34 & $0.14-0.27$ \\
\hline & $P_{P a}=0.84(E C E C)+1.13$ & 0.42 & $0.63-1.06$ \\
\hline & $P_{\text {som }}=0.71(\mathrm{SOC})+0.14$ & 0.19 & $0.37-1.05$ \\
\hline & $P_{\text {SOM }}=0.21$ (soil $\left.\mathrm{pH}_{\text {water }}\right)-0.38$ & 0.45 & $0.16-0.26$ \\
\hline & $P_{S O M}=0.75(E C E C)+0.24$ & 0.42 & $0.55-0.96$ \\
\hline & $\mathrm{P}_{\mathrm{Ca}}=1.57(\mathrm{SOC})+0.57$ & 0.33 & $0.46-2.67$ \\
\hline & $P_{\mathrm{Ca}}=0.21\left(\right.$ soil $\left.\mathrm{pH}_{\text {water }}\right)+0.62$ & 0.34 & $0.14-0.27$ \\
\hline & $P_{C a}=0.87(E C E C)+1.46$ & 0.22 & $0.30-1.67$ \\
\hline & $P_{\mathrm{OCC}}=0.82(\mathrm{SOC})+0.97$ & 0.40 & $0.58-1.06$ \\
\hline & Pocc $=1.14\left(\right.$ soil $\left.p H_{\text {water }}\right)+0.98$ & 0.09 & $0.31-1.97$ \\
\hline & PocC $=0.58($ ECEC $)+1.35$ & 0.39 & $0.40-0.74$ \\
\hline \multirow{11}{*}{ Forest soils } & $\mathrm{P}_{\mathrm{Pa}}=0.51\left(\mathrm{PSOM}_{\mathrm{SO}}\right)+1.53$ & 0.40 & $-0.05-1.07$ \\
\hline & $P_{P a}=0.46\left(P_{o c c}\right)+1.02$ & 0.06 & $-1.20-2.16$ \\
\hline & $\mathrm{P}_{\mathrm{Pa}}=1.44(\mathrm{SOC})+0.19$ & 0.48 & $0.11-2.76$ \\
\hline & $\mathrm{P}_{\mathrm{Pa}}=0.19($ soil $\mathrm{pH}$ water $)+0.81$ & 0.18 & $-0.17-0.57$ \\
\hline & $\mathrm{PPa}_{\mathrm{Pa}}=0.57(\mathrm{ECEC})+1.13$ & 0.28 & $-23-1.37$ \\
\hline & $P_{S O M}=2.08(S O C)-1.77$ & 0.66 & $0.75-3.41$ \\
\hline & $P_{\text {SOM }}=0.40$ (soil pH $\left.\mathrm{H}_{\text {water }}\right)-1.52$ & 0.51 & $0.05-0.76$ \\
\hline & $\mathrm{PSOM}=1.24(\mathrm{ECEC})-0.21$ & 0.88 & $0.83-1.64$ \\
\hline & $P_{\text {OCC }}=0.85(\mathrm{SOC})+0.84$ & 0.64 & $0.28-1.41$ \\
\hline & Pocc $=1.71$ (soil $\left.\mathrm{pH}_{\text {water }}\right)+0.58$ & 0.33 & $0.46-3.89$ \\
\hline & Pocc $=0.35($ ECEC $)+1.54$ & 0.58 & $0.09-0.73$ \\
\hline \multirow{7}{*}{ Rural soils } & $P_{P a}=1.99\left(P_{S O M}\right)+0.36$ & 0.40 & $-1.40-5.4$ \\
\hline & $\mathrm{P}_{\mathrm{Pa}}=6.13(\mathrm{Pocc})-8.73$ & 0.90 & $3.30-8.90$ \\
\hline & $\mathrm{PPa}_{\mathrm{Pa}}=3.05(\mathrm{SOC})-1.44$ & 0.37 & $-0.48-6.57$ \\
\hline & $\mathrm{P}_{\mathrm{Pa}}=0.44$ (soil pH $\left.\mathrm{H}_{\text {water }}\right)-0.73$ & 0.44 & $0.00-0.89$ \\
\hline & $\mathrm{PPa}_{\mathrm{Pa}}=2.37(\mathrm{ECEC})+0.16$ & 0.53 & $0.36-4.38$ \\
\hline & $P_{S O M}=0.99(S O C)-0.44$ & 0.44 & $-0.55-2.54$ \\
\hline & $P_{\text {SOM }}=0.22$ (soil pH water $)-0.54$ & 0.46 & $-0.11-0.55$ \\
\hline
\end{tabular}




\begin{tabular}{|c|c|c|}
\hline Psom= 0.08 (ECEC) - 0.25 & 0.53 & $-0.03-1.85$ \\
\hline Pocc $=0.60(\mathrm{SOC})+1.05$ & 0.68 & $0.02-1.17$ \\
\hline Pocc $=1.34($ soil pH $\mathrm{pHater})+0.73$ & 0.50 & $-0.51-3.19$ \\
\hline Pocc $=0.35(E C E C)+1.46$ & 0.43 & $-0.21-0.91$ \\
\hline
\end{tabular}


CHAPTER 4: GENERAL CONCLUSIONS AND IMPLICATIONS 


\subsection{Synthesis and conclusions}

The rapid urbanisation that is underway in West Africa has transformed isolated urban areas into regional urbanisation patterns, such as the emergence of urban corridors, city regions and mega-urban regions (United Nations Economic Commission for Africa 2014; Agyemang et al. 2017). These patterns are interacting at multiple spatial and temporal scales, making it complex and heterogeneous, and thus requiring integrated perspectives to characterise, monitor and understand it. Within this context, the overall aim in this thesis was to characterise the emergent urban landscapes that result from rapid urbanisation, and empirically ascertain how soil fertility of urban agricultural fields has been shaped by the urbanisation process. For this purpose, we have conducted five studies which have been organised to achieve the two main objectives in this thesis (Chapter 2 and 3). For the first objective (Study 1-2), we have presented results on the evolution and spatio-environmental impacts of rapid urbanisation in the metropolitan regions of Accra and Kumasi. For the second objective (Study 3-5), we have systematically assessed the influence of rapid urbanisation on urban soil fertility properties of the Kumasi region. This thesis has therefore risen-up to the challenge to integrate the needed different spatial and temporal perspectives in assessing the rapid urbanisation process and associated environmental impacts.

As summarized in Figure 4.1.1, the approach and methods that were used to achieve the objectives are different, but they complement each other in ways that reflect the multiple spatial and temporal interactions of the on-going rapid urban expansion patterns, i.e. from macro to micro scales. From the macro scale, we were able to ascertain the full extent of the rapid urbanisation process, as it is common in Ghana and other West African countries that most cities and towns sprawl over their administrative boundaries. By analysing at the wider metropolitan region, our findings 
can be used to support proactive management schemes, instead of the typical reactive schemes that is ineffective at managing rapidly changing urban land transformation. In this regard, remote sensing and GIS techniques have been appropriately applied to develop systematic land use transition maps that uncovered the unique urbanisation process and the spatio-environmental impacts in the metropolitan regions (Figure 4.1.1). With this, we have provided empirical evidence to underpin key socio-economic features of the on-going rapid urbanisation in Ghana, as it has been reported in other studies. For instance, the impact of the time lag in building construction, a common feature in cities and towns in Ghana and other African countries, can be explained by the mediating role of the urban-open-space class between built-up and vegetation lands (Study 1, Figure 4.1.1). Because of the spatio-temporal complexity of this urbanopen-space class, it has eluded clear identification and quantification until now. Some studies such as Abass et al. (2018) have misidentified it as agricultural fields, making their conclusion that urbanisation leads to loss of arable land inconsistent to parts of their land transition maps. While agricultural fields are part of the urban-open-space class, as this thesis has also shown, it is woefully inadequate to explain some temporal urban landscape changes. Thus, one of the main contributions of this thesis, has been to characterise and highlight the central role of this urban-open-space class, which is important to improve theorising and modelling the rapid urbanisation process occurring in Ghana and other West African countries.

Furthermore, by assessing the landscape fragmentation from the macro scale, we provided plausible explanations to some socioeconomic challenges such as land use conflict, erosion of social structure, and loss of agrarian livelihoods by indigenes, as well as environmental challenges such as floods and heatwaves that have been reported (Study 1-2, Figure 4.1.1). 


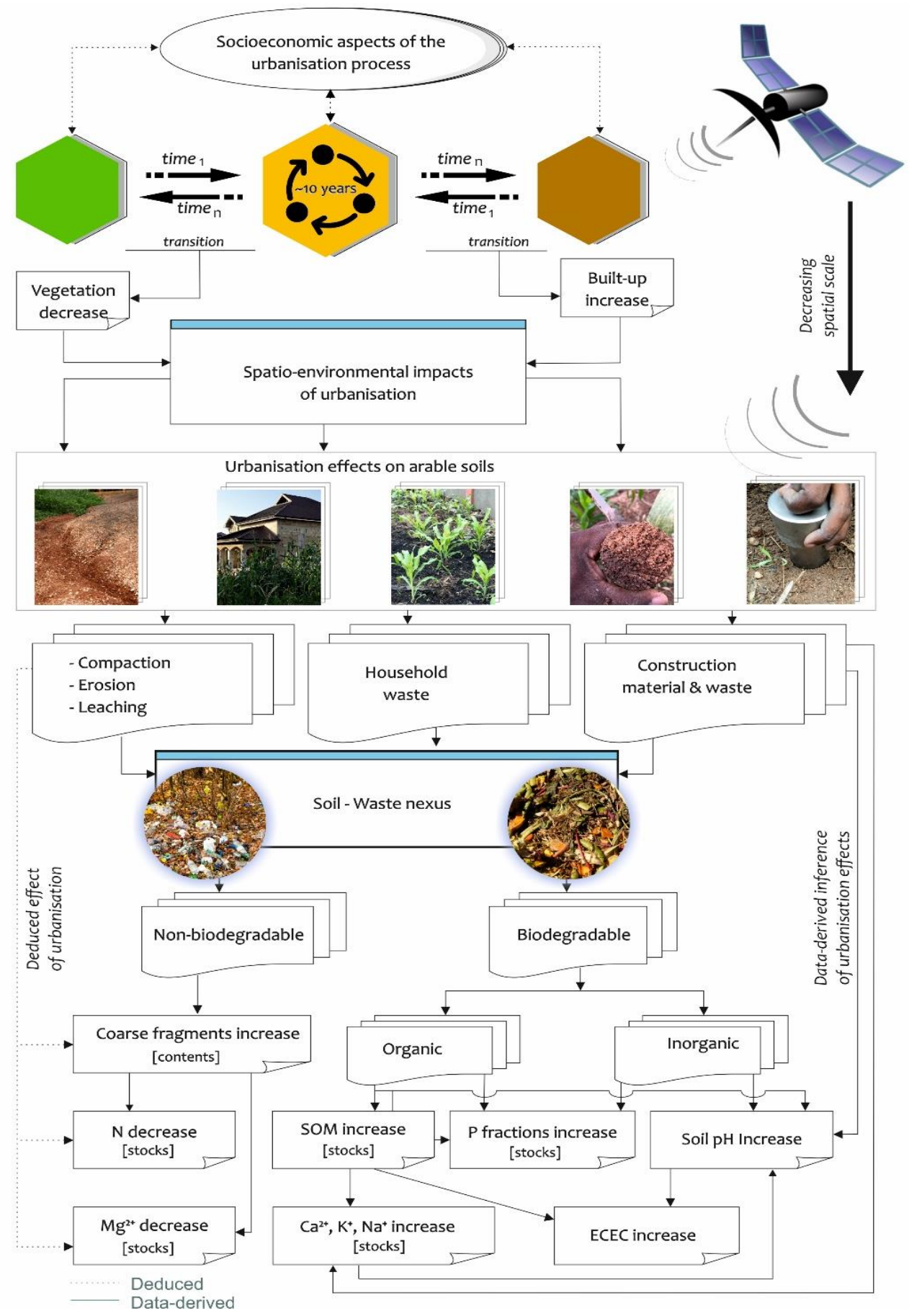

Figure 4.1.1: Key research findings of all studies in this thesis.

The summary in Figure 4.1.1 further illustrates the transition from the macro to micro scale. To show the fractal relationships regarding urbanisation effect on environmental resources, i.e. between the first and second objective, it was important that the spatial and temporal definition of the urbanisation process is kept constant. Thus, the outcome, which is a novel grid-based soil sampling design that relied on the 1986 
Landsat satellite image (Study 3-5), is another important contribution of this thesis. Relying on the remote sensing output for 1986 as the reference year, long-term and short-term urban soils were delineated. Considering cost and time in conducting soil sampling, it was impossible to keep both city regions at this field scale in this thesis. Yet, the extent of coverage of the design and the 636 top-soils that have been sampled, and subsequently analysed, provides an excellent database for future projects.

To keep factors that were not in the focus of objective two constant (i.e. parent material, topography, soil type, crop and climate), in order to assess the effect of urbanisation on the soils, we kept to sampling only rain-fed arable fields. These fields form an integral part of the urban-open-space land class. For example, consistent with the definition of this class (Study 1), the sampled arable fields were located in places such as back and front yard of houses, public lands adjacent to roads, open spaces, corners, and building construction sites (Study 3). It therefore suggests that findings on the nature of the soils have wider implications for other land uses that are part of this class, as they are likely exposed to similar effects.

Within this context, clear fractal relationships can be drawn between the key findings of objective two and those of objective one, with regards to the effect of urbanisation. For instance, it is consistent that because the urban-open-space class mediates land transitions (Study 1), the urban soils that have been under long-term urbanisation had increased contents of coarse fragments (Study 3), which in addition to rock fragments included anthropogenic materials (e.g. plastic, metals, textile, charcoal). Also, in Study 3 and 4 , we deduced that because fallow periods may be missing or substantially decreased for cultivation in urban arable fields, contents and stocks of total $\mathrm{N}$ and exchangeable $\mathrm{Mg}^{2+}$ decreased with urbanisation. Consistent to this finding, the urban- 
open-space class has been described to be in a constant state of flux, as it mediates the land transitions (Study 1). Thus, these findings highlight the robustness of our gridbased sampling design as an important contribution to the urbanisation process.

The studies in this thesis have demonstrated that the influences of urbanisation, i.e. as captured through the multidirectional, complex and dynamic land transformation processes, have not only led to fragmented environments (Objective 1) but also influenced urban soils at varying degrees (Objective 2). Given that the soil fertility indicators in the urban agricultural fields increased with urbanisation, and that the fields are intricately part of the urban-open-spaces class, we conclude that management efforts that seek to decrease the environmental impact of the urbanisation process can target this urban-open-spaces class, as it is the central piece of the land transitions in Ghana.

While these findings have enhanced our understanding of this rapidly changing process, there is still a lot to unravel, including improving the characterisation of the elusive urban-open-space class. For this, future studies should use finer resolution satellite images, especially those that have $<1 \mathrm{~m}$ spatial resolution. In addition, although the soil analysis has provided us with an understanding of the urbanisation influence on soils, future analysis should strive to deepen these analyses such as to characterise the quality of SOM contents in the urban soils. For tropical soils that largely rely on SOM contents for vital soil functions, it will be of great interest. Finally, considering the varying effects of the urbanisation process, it will be interesting to analyse the soils for heavy metals and organic pollutants.

\subsection{Implications of thesis findings}

This thesis, through the various specific studies, has outlined insights for a sustainable urban growth strategy that can identify and prioritise integrated spatial and 
environmental resource planning for metropolitan regions of Ghana and the wider West African region. Based on the findings in this thesis, several practical recommendations have been proposed to city administrators in Ghana, and the wider West African region. These recommendations can be grouped as:

- Develop an integrated urban growth management strategy that brings together spatial planning and environmental resource governance to avert the negative consequences of uncontrollable urban expansion on the natural environment. Practically, such a scheme will involve the designation and support for urban land use intensification through densification in the historical-core zones of the metropolitan regions, on the one hand. On the other hand, cluster-zones within the wider metropolitan region can be supported in order to promote rural and peri-urban farming.

- Develop an integrated waste management strategy where city authorities actively engage urban residents in municipal solid waste management, provide the necessary infrastructure for collecting non-biodegradable waste, allow urban citizens to separate biodegradable waste from other waste, and to use their biodegradable waste, preferably after composting, as organic fertilizers on their urban arable fields.

In both recommendations, it is extremely important for urban administrators to develop such an integrated scheme with the involvement of urban dwellers. Particularly, as informal practices in the form of spontaneous self-organisation is prevalent and widespread in Ghanaian cities (Korah 2017b), a rigid 'top-down' scheme is bound to fail. 


\section{REFERENCES}

Abass K; Adanu SK; Agyemang S (2018): Peri-urbanisation and loss of arable land in Kumasi Metropolis in three decades: Evidence from remote sensing image analysis. In Land Use Policy 72, pp. 470-479. DOI: 10.1016/j.landusepol.2018.01.013.

Abunyewa AA; Karbo KN (2005): Improved fallow with pigeon pea for soil fertility improvement and to increase maize production in a smallholder crop-livestock farming system in the subhumid zone of Ghana. In LAND DEGRADATION \& DEVELOPMENT 16 (5), pp. 447454. DOI: $10.1002 / \mathrm{ldr} .672$.

Acheampong RA (2019): Spatial Planning in Ghana. Cham: Springer International Publishing, checked on $5 / 11 / 2018$.

Acheampong RA; Agyemang FSK; Abdul-Fatawu M (2017): Quantifying the spatio-temporal patterns of settlement growth in a metropolitan region of Ghana. In GeoJournal, pp. 1-18. DOI: 10.1007/s10708-016-9719-x.

Adamtey N; Cofie O; Ofosu-Budu GK; Danso SKA; Forster D (2009): Production and storage of N-enriched co-compost. In Waste management (New York, N.Y.) 29 (9), pp. 2429-2436. DOI: 10.1016/j.wasman.2009.04.014.

Adu SV (1992): Soils of the Kumasi region, Ashanti Region, Ghana. $1^{\text {st }}$ ed. Kwadaso-Kumasi, Ghana: Soil Research Institute (Memoir, no. 8).

Afrane S; Asamoah PKB (2011): Housing situation in Kumasi. In Kwasi Kwafo Adarkwa (Ed.): Future of the Tree - Towards Growth Development of Kumasi. Kumasi: University Printing Press - KNUST, pp. 92-110.

Agyemang FSK; Amedzro KK; Silva E (2017): The emergence of city-regions and their implications for contemporary spatial governance. Evidence from Ghana. In Cities 71 (July), pp. 70-79. DOI: 10.1016/j.cities.2017.07.009.

Amoako C (2016): Brutal presence or convenient absence. The role of the state in the politics of flooding in informal Accra, Ghana. In Geoforum 77, pp. 5-16. DOI: 10.1016/j.geoforum.2016.10.003.

Amundson R (2001): The Carbon Budget in Soils. In Annu. Rev. Earth Planet. Sci. 29 (1), pp. 535-562. DOI: 10.1146/annurev.earth.29.1.535.

Anikwe M (2002): Long term effect of municipal waste disposal on soil properties and productivity of sites used for urban agriculture in Abakaliki, Nigeria. In Bioresource Technology 83 (3), pp. 241-250. DOI: 10.1016/S0960-8524(01)00154-7.

Appiah DO; Bugri, JT; Forkuo EK; Boateng PK (2014): Determinants of Peri-Urbanization and Land Use Change Patterns in Peri-Urban Ghana. In Journal of Sustainable Development 7 (6), pp. 95-109. DOI: 10.5539/jsd.v7n6p95.

Asabere SB.; Zeppenfeld T; Nketia KA; Sauer D (2018): Influence of urbanisation on pH, carbonate and soil organic matter stocks of arable soils of Kumasi (Ghana). In: Geophysical Research Abstracts, vol. 20. EGU General Meeting 2018. Vienna, 9-12th April. European Geoscience Union. 20 volumes. Vienna, Austria: EGU Copernicus, p. 1. Available online at https://meetingorganizer.copernicus.org/EGU2018/EGU2018-104541.pdf. 
Asabere SB; Zeppenfeld T; Nketia KA; Haering V; Sauer D (2018a): Influence of urbanisation on cation exchange capacity and nutrient availability in arable soils of Kumasi (Ghana). In: Geophysical Research Abstracts, vol. 20. EGU General Meeting 2018. Vienna, 9-12 ${ }^{\text {th }}$ April. European Geoscience Union. 20 volumes. Vienna, Austria: EGU Copernicus, p. 1. Available online at https://meetingorganizer.copernicus.org/EGU2018/EGU2018-7181.pdf.

Asabere SB; Zeppenfeld T; Nketia KA; Sauer D (2018b): Urbanization leads to increases in $\mathrm{pH}$, Carbonate and Soil Organic Matter Stocks of Arable Soils of Kumasi, Ghana (West Africa). In Front. Environ. Sci. 6, p. 119. DOI: 10.3389/fenvs.2018.00119.

Asabere SB; Li J; Hughes HJ; Sauer D (2019): Urbanization enhances stocks of P fractions in strongly weathered arable soils of Kumasi (Ghana), West Africa. In: European Geoscience Union 2019 - Geophysical Research Abstracts, EGU2019-16640. Available online at https://meetingorganizer.copernicus.org/EGU2019/EGU2019-16640.pdf.

Asabere SB; Acheampong RA; Ashiagbor G; Beckers SC; Keck M; Erasmi S; Sauer D (2020): Urbanization, land use transformation and spatio-environmental impacts: Analyses of trends and implications in major metropolitan regions of Ghana. In Land Use Policy 96, p. 104707. DOI: 10.1016/j.landusepol.2020.104707.

Asase M; Yanful EK; Mensah M; Stanford J; Amponsah S (2009): Comparison of municipal solid waste management systems in Canada and Ghana. A case study of the cities of London, Ontario, and Kumasi, Ghana. In Waste Management 29 (10). DOI: 10.1016/j.wasman.2009.06.019.

Ashiagbor G; Amoako C; Asabere SB; Quaye-Ballard JA (2019): Landscape Transformations in Rapidly Developing Peri-urban Areas of Accra, Ghana: Results of 30 years. In Open Geosciences 11 (1), pp. 172-182. DOI: 10.1515/geo-2019-0014.

Ashman MR; Puri G (2017): Essential soil science. A clear and concise introduction to soil science. Malden, Mass.: Blackwell.

Asomaning SK; Abekoe MK; Owusu-Bennoah E (2009): Phosphate rock dissolution and availability in some soils of semi-deciduous Rainforest Zone of Ghana. In West African Journal of Applied Ecology 10 (1). DOI: 10.4314/wajae.v10i1.45715.

Augustin S; Schall P; Schmieden U (1998): Modelling aspects of forest decline in Germany. I. Theoretical aspects and cause-effect relationships. In Chemosphere 36 (4-5), pp. 965970. DOI: 10.1016/S0045-6535(97)10156-4.

Awuah KT (2017): Effects of Spatial Resolution, Land-Cover Heterogeneity and Different Classification methods on Accuracy of Land-Cover Mapping. Master thesis (Unpublished). Swedish University of Agricultural Sciences, Sweden, checked on 12/9/2018.

Barrios E (2007): Soil biota, ecosystem services and land productivity. In Ecological Economics 64 (2), pp. 269-285. DOI: 10.1016/j.ecolecon.2007.03.004.

Barton K (2018). MuMln: Multi-Model Inference. CRAN. R - Project. Available online at https://CRAN.R-project.org/package=MuMln.

Bates D; Mächler M; Bolker B; Walker S (2015): Fitting Linear Mixed-Effects Models Using Ime4. In J. Stat. Soft. 67 (1). DOI: 10.18637/jss.v067.i01.

Bationo A; Mokwunye AU (1991): Role of manures and crop residue in alleviating soil fertility constraints to crop production. With special reference to the Sahelian and Sudanian zones of West Africa. In Fertilizer Research 29 (1), pp. 117-125. DOI: 10.1007/BF01048993. 
Bationo A; Kihara J; Vanlauwe B; Waswa B; Kimetu J (2007): Soil organic carbon dynamics, functions and management in West African agro-ecosystems. In Agricultural Systems 94 (1), pp. 13-25. DOI: 10.1016/j.agsy.2005.08.011.

Baveye PC; Baveye J; Gowdy J (2016): Soil "Ecosystem" Services and Natural Capital. Critical Appraisal of Research on Uncertain Ground. In Front. Environ. Sci. 4 (10), p. 609. DOI: 10.3389/fenvs.2016.00041.

Bellwood-Howard I; Haering V; Karg H; Roessler R; Schlesinger J; Shakya M (2015): Characteristics of urban and peri-urban agriculture in West Africa. Results of an exploratory survey conducted in Tamale (Ghana) and Ouagadougou (Burkina Faso). International Water Management Institute. Colombo, Sri Lanka (9789290908210).

Benza M (2014): Population dynamics throughout the urban context. A case study in subSaharan Africa utilizing remotely sensed imagery and GIS. PhD Thesis. San Diego State University; University of California Santa Barbara, San Diego.

Blume H-P; Brümmer GW.; Fleige H; Horn R; Kandeler E; Kögel-Knabner I; Kretzschmar R; Stahr K; Wilke B-M (2016): Scheffer/Schachtschabel soil science. Heidelberg: Springer.

Blume H-P; Stahr K; Leinweber P (2011): Bodenkundliches Praktikum. Eine Einführung in pedologisches Arbeiten für Ökologen, insbesondere Land- und Forstwirte, und für Geowissenschaftler. 3., neubearb. Aufl. Heidelberg: Spektrum Akademischer Verlag.

Boateng SA; Zickermann J; Kornahrens M (2006): Poultry Manure Effect on Growth and Yield of Maize. In West African Journal of Applied Ecology 9, pp. 1-11. DOI: 10.4314/wajae.v9i1.45682.

Bouma J (2016): Implications of the Nexus Approach When Assessing Water and Soil Quality as a Function of Solid and Liquid Waste Management. In Hiroshan Hettiarachchi (Ed.): Environmental resource management and the nexus approach. Managing water, soil, and waste in the context of global change. New York NY: Springer Berlin Heidelberg, pp. 179_ 209.

Bowman RA; Cole CV (1978): An Exploratory Method for Fractionation of Organic Phosphorus from Grassland Soils. In Soil Science 125 (2), pp. 95-101.

Brady NC; Weil RR (2017): The nature and properties of soils. Global edition. Boston: Pearson.

Bray RH; Kurz LT (1945): Determination of total, organic, and available forms of phosphorus in soils. In Soil Science 59 (1), pp. 39-46. Available online at https://journals.Iww.com/soilsci/Fulltext/1945/01000/DETERMINATION_OF_TOTAL,_OR GANIC,_AND_AVAILABLE.6.aspx.

Breuste J; Haase D; Elmqvist T (2013): Urban Landscapes and Ecosystem Services. In: Ecosystem Services in Agricultural and Urban Landscapes: John Wiley and Sons, pp. 83104.

Brock C; Oberholzer H-R; Franko U (2017): Soil organic matter balance as a practical tool for environmental impact assessment and management support in arable farming. In European Journal of Soil Science 68 (6), pp. 951-952. DOI: 10.1111/ejss.12495.

Buczkowski G; Richmond DS (2012): The effect of urbanization on ant abundance and diversity: a temporal examination of factors affecting biodiversity. In PLOS ONE 7 (8), e41729. DOI: 10.1371/journal.pone.0041729. 
Budiyantini Y; Pratiwi V (2016): Peri-urban Typology of Bandung Metropolitan Area. In Procedia - Social and Behavioral Sciences 227, pp. 833-837. DOI: 10.1016/j.sbspro.2016.06.152.

Butterworth J; Ducrot R; Faysse N; Janakarajan S (Eds.) (2007): Peri-urban water conflicts. Supporting dialogue and negotiation. AGRIS, Food and Agriculture Organization of the United Nations: IRC International Water and Sanitation Centre.

Byrne LB (2007): Habitat structure. A fundamental concept and framework for urban soil ecology. In Urban Ecosyst 10 (3), pp. 255-274. DOI: 10.1007/s11252-007-0027-6.

Cardoso RBSM (2014): The Fate of Contaminants in Urban Soils and Sediments. Novel Assessments and Implications for Risks. PhD. Machester Metropolitan University, Manchester.

Casanova E; Salas AM; Toro M (2002): Evaluating the Effectiveness of Phosphate Fertilizers in some Venezuelan soils. In Nutr Cycl Agroecosyst 63 (1), pp. 13-20. DOI: 10.1023/A:1020582513441.

Castro P; Azeiteiro UM; Bacelar-Nicolau P; Leal FW; Azul AM (2016): Biodiversity and Education for Sustainable Development. Cham: Springer International Publishing.

Chang SC; Jackson ML (1957): Fractionation of Soil Phosphorus. In Soil Science 84 (2), pp. 133-144.

Chatterjee A; Lal R; Wielopolski L; Martin MZ; Ebinger MH (2009): Evaluation of Different Soil Carbon Determination Methods. In Critical Reviews in Plant Sciences 28 (3), pp. 164-178. DOI: $10.1080 / 07352680902776556$.

Cobbinah PB; Amoako C (2012): Urban sprawl and the loss of peri-urban land in Kumasi, Ghana. In International Journal of Social and Human Sciences 6 (1), pp. 388-397.

Cobbinah PB; Aboagye HN (2017): A Ghanaian twist to urban sprawl. In Land Use Policy 61. DOI: 10.1016/j.landusepol.2016.10.047.

Cobbinah PB; Erdiaw-Kwasie MO (2016): Urbanization in Ghana. Insights and Implications for Urban Governance. In Umar G. Benna, Shaibu Bala Garba (Eds.): Population Growth and Rapid Urbanization in the Developing World, vol. 4: IGI Global, pp. 82-104.

Cobbinah PB; Erdiaw-Kwasie MO; Amoateng P(2015a): Africa's urbanisation. Implications for sustainable development. In Cities 47 (April), pp.62-72. DOI: 10.1016/j.cities.2015.03.013.

Cobbinah PB; Gaisie E; Owusu-Amponsah L (2015b): Peri-urban morphology and indigenous livelihoods in Ghana. In Habitat International 50, pp.120-129. DOI: 10.1016/j.habitatint.2015.08.002.

Cobbinah PB; Poku-Boansi M; Peprah C (2017): Urban environmental problems in Ghana. In Environmental Development 23, pp. 33-46. DOI: 10.1016/j.envdev.2017.05.001.

Cofie O; Kone D; Rothenberger S; Moser D; Zubruegg C (2009): Co-composting of faecal sludge and organic solid waste for agriculture. Process dynamics. In Water research 43 (18), pp. 4665-4675. DOI: 10.1016/j.watres.2009.07.021.

Cofie O; van Veenhuizen R; Drechsel P (2003): Contribution of Urban and Peri-Urban Agriculture to Food Security in Sub-Saharan Africa. In Water Management, pp. 1-12. 
Colwell JD (1963): The estimation of the phosphorus fertilizer requirements of wheat in southern New South Wales by soil analysis. In Aust. J. Exp. Agric. 3 (10), p. 190. DOI: 10.1071/EA9630190.

Cordell D; Drangert J-O; White S (2009): The story of phosphorus: Global food security and food for thought. In Global Environmental Change 19 (2), pp. 292-305. DOI: 10.1016/j.gloenvcha.2008.10.009.

Corti G; Ugolini FC; Agnelli A; Certini G; Cuniglio R; Berna F; Fernández SMJ (2002): The soil skeleton, a forgotten pool of carbon and nitrogen in soil. In European Journal of Soil Science 53 (2), pp. 283-298. DOI: 10.1046/j.1365-2389.2002.00442.x.

Davies BE (1974): Loss-on-Ignition as an Estimate of Soil Organic Matter1. In Soil Science Society of America Journal 38 (1), p. $150 . \quad$ DOI: 10.2136/sssaj1974.03615995003800010046x.

Dawoe EK; Quashie-Sam JS; Oppong SK (2014): Effect of land-use conversion from forest to cocoa agroforest on soil characteristics and quality of a Ferric Lixisol in lowland humid Ghana. In Agroforest Syst 88 (1), pp. 87-99. DOI: 10.1007/s10457-013-9658-1.

Dickson KB; Benneh G; Essah RR (1988): A new geography of Ghana. Rev. ed / revised and updated with the assistance of R.R. Essah. Harlow: Longman.

Dieter D; Elsenbeer H; Turner BL (2010): Phosphorus fractionation in lowland tropical rainforest soils in central Panama. In Catena 82 (2), pp. 118-125. DOI: 10.1016/j.catena.2010.05.010.

Doan P; Oduro CY (2012): Patterns of population growth in peri-urban accra, ghana. In International Journal of Urban and Regional Research 36 (6), pp. 1306-1325. DOI: 10.1111/j.1468-2427.2011.01075.x.

Drechsel P (Ed.) (2002): Comparing soil nutrient depletion in typical urban, peri-urban and rural farming systems in Ghana. Mini-symposium on practices and constraints of land and water resources management in urban and peri-urban agriculture. Bangkok, 12/03/2002. International Water Management Institute. Bangkok: International Water Management Institute.

Drechsel P; Dongus S (2010): Dynamics and sustainability of urban agriculture. Examples from sub-Saharan Africa. In Sustainability Science 5 (1), pp. 69-78. DOI: 10.1007/s11625009-0097-x.

Drechsel P; Graefe S; Fink M (2007): Rural-Urban Food, Nutrient and Virtual Water Flows in Selected West African Cities. In Water Management 115 (9789290906698), pp. 1-39. DOI: $10.3910 / 2009.115$.

Drechsel P; Kunze D (2001): Waste composting for urban and peri-urban agriculture. Closing the rural-urban nutrient cycle in sub-Saharan Africa / edited by Pay Drechsel, Dagmar Kunze. Columbo, Sri Lanka, International Water Management Institute, Wallingford: CABI Pub.

Du X; Huang Z (2017): Ecological and environmental effects of land use change in rapid urbanization: The case of hangzhou, China. In Ecological Indicators 81, pp. 243-251. DOI: 10.1016/j.ecolind.2017.05.040.

Edmondson JL; Davies ZG; Gaston KJ; Leake JR (2014): Urban cultivation in allotments maintains soil qualities adversely affected by conventional agriculture. In The Journal of applied ecology 51 (4), pp. 880-889. DOI: 10.1111/1365-2664.12254. 
Edmondson JL; Davies ZG; McCormack SA; Gaston KJ; Leake JR (2011): Are soils in urban ecosystems compacted? A citywide analysis. In Biology letters 7 (5), pp. 771-774. DOI: 10.1098/rsbl.2011.0260.

Eisenhauer N; Bowker MA; Grace JB; Powell JR (2015): From patterns to causal understanding: Structural equation modeling (SEM) in soil ecology. In Pedobiologia 58 (23), pp. 65-72. DOI: 10.1016/j.pedobi.2015.03.002.

Elmqvist T; Fragkias M; Goodness J; Gueneralp B; Marcotullio PJ; McDonald RI; Parnell S; Schewenius M; Sendstad M; Seto KC; Wilkinson C (Eds.) (2013): Urbanization, Biodiversity and Ecosystem Services: Challenges and Opportunities. Challenges and Opportunities. Dordrecht, Heidelberg, New York, London: Springer; Springer Netherlands.

Epskamp S; Stuber S; Nak J; Veenman M; Jorgensen TD (2019): semPlot. Path Diagrams and Visual Analysis of Various SEM Packages' Output. Available online at https://CRAN.Rproject.org/package $=$ semPlot.

Foody GM; Mathur A (2006): The use of small training sets containing mixed pixels for accurate hard image classification. Training on mixed spectral responses for classification by a SVM. In Remote Sensing of Environment 103 (2), pp. 179-189. DOI: 10.1016/j.rse.2006.04.001.

Forman RTT (1995): Land mosaics. The ecology of landscapes and regions. Cambridge, New York: Cambridge University Press.

Frondoni R; Mollo B; Capotorti G (2011): A landscape analysis of land cover change in the Municipality of Rome (Italy): Spatio-temporal characteristics and ecological implications of land cover transitions from 1954 to 2001. In Landscape and Urban Planning 100 (1-2), pp. 117-128. DOI: 10.1016/j.landurbplan.2010.12.002.

Fuseini I (2016): Urban governance and spatial planning for sustainable urban development in Tamale, Ghana.

Fuseini I; Kemp J (2016): Characterising urban growth in Tamale, Ghana. An analysis of urban governance response in infrastructure and service provision. In Habitat International 56 (May), pp. 109-123. DOI: 10.1016/j.habitatint.2016.05.002.

Gallez A; Juo ASR; Herbillon AJ (1976): Surface and Charge Characteristics of Selected Soils in the Tropics. In Soil Science Society of America Journal 40 (4), p. 601. DOI: 10.2136/sssaj1976.03615995004000040039x.

Galloway JN; Aber JD; Erisman JWN; Seitzinger SP; Howarth RW; Cowling EB; Cosby BJ (2003): The Nitrogen Cascade. In BioScience 53 (4), p. 341. DOI: 10.1641/00063568(2003)053[0341:TNC]2.0.CO;2.

Ghana Statistical Service (2014a): 2010 Population \& Housing Census. District Analytical Report. Ga West Municipality. Available online at http://www2.statsghana.gov.gh/docfiles/2010_District_Report/Greater\%20Accra/GA\%20 WEST.pdf, checked on 1/9/2020.

Ghana Statistical Service (2014b): 2010 Population and Housing Census. District Analytical Report. Kumasi Metropolitan. Accra, checked on 2/1/2018.

Glaser B (2007): Prehistorically modified soils of central Amazonia. A model for sustainable agriculture in the twenty-first century. In Philosophical transactions of the Royal Society of London. Series B, Biological sciences 362 (1478), pp. 187-196. DOI: 10.1098/rstb.2006.1978. 
Glaser B; Lehmann J; Zech W (2002): Ameliorating physical and chemical properties of highly weathered soils in the tropics with charcoal - a review. In Biol Fertil Soils 35 (4), pp. 219230. DOI: $10.1007 / \mathrm{s} 00374-002-0466-4$.

Gough KV; Yankson PWK (2000): Land Markets in African Cities: The Case of Peri-urban Accra, Ghana. In Urban Studies 37 (13), pp. 2485-2500. DOI: 10.1080/00420980020080651.

Grace JB (2006): Structural Equation Modeling and Natural Systems. Cambridge: Cambridge University Press.

Gransee A; Führs H (2013): Magnesium mobility in soils as a challenge for soil and plant analysis, magnesium fertilization and root uptake under adverse growth conditions. In Plant Soil 368 (1-2), pp. 5-21. DOI: 10.1007/s11104-012-1567-y.

Haase D; Schwarz N; Strohbach M; Kroll F; Seppelt R (2012): Synergies, Trade-offs, and Losses of Ecosystem Services in Urban Regions: an Integrated Multiscale Framework Applied to the Leipzig-Halle Region, Germany. In E\&S 17 (3). DOI: 10.5751/ES-04853170322.

Hailes KJ; Aitken RL; Menzies NW (1997): Magnesium in tropical and subtropical soils from north-eastern Australia. I. Magnesium fractions and interrelationships with soil properties. In Soil Res. 35 (3), p. 615. DOI: 10.1071/S96081.

Hamann M (2016): Exploring connections in social-ecological systems. The links between biodiversity, ecosystem services, and human well-being in South Africa. Stockholm: Stockholm Resilience Centre, Stockholm University.

Hazelton PA; Murphy BW (2016): Interpreting soil test results. What do all the numbers mean? Third edition. Clayton, South VIC, Australia: CSIRO Publishing.

Hedblom M; Andersson E; Borgstrom S (2017): Flexible land-use and undefined governance: From threats to potentials in peri-urban landscape planning. In Land Use Policy 63, pp. 523-527. DOI: 10.1016/j.landusepol.2017.02.022.

Hedley MJ; Stewart JWB; Chauhan BS (1982): Changes in Inorganic and Organic Soil Phosphorus Fractions Induced by Cultivation Practices and by Laboratory Incubations 1. In Soil Science Society of America Journal 46 (5), p. 970. DOI: 10.2136/sssaj1982.03615995004600050017x.

Heitkamp F; Jacobs A; Jungkunst HF; Heinze S; Wendland M; Kuzyakov Y (2012): Processes of Soil Carbon Dynamics and Ecosystem Carbon Cycling in a Changing World. In R. Lal (Ed.): Recarbonization of the biosphere. Ecosystems and the global carbon cycle. Dordrecht: Springer, pp. 395-428.

Henderson JV; Storeygard A; Deichmann U (2014): 50 Years of Urbanization in Africa. Examining the role of climate change (June).

Hijmans RJ (2018): raster. Geographic Data Analysis and Modeling. Available online at https://CRAN.R-project.org/package=raster.

Hothorn T; Hornik K; Zeileis A (2006): Unbiased Recursive Partitioning. A Conditional Inference Framework. In Journal of Computational and Graphical Statistics 15 (3), pp. 651-674. DOI: 10.1198/106186006X133933.

Imperato M; Adamo P; Naimo D; Arienzo M; Stanzione D; Violante P (2003): Spatial distribution of heavy metals in urban soils of Naples city (Italy). In Environmental pollution (Barking, Essex: 1987) 124 (2), pp. 247-256. DOI: 10.1016/S0269-7491(02)00478-5. 
IUSS Working Group WRB (2014): World reference base for soil resources 2014. International soil classification system for naming soils and creating legends for soil maps. Food and Agriculture Organization of the United Nations. Rome (World soil resources reports).

Jaeger J (2000): Landscape division, splitting index, and effective mesh size. New measures of landscape fragmentation. In Landscape Ecology 15 (2), pp. 115-130. DOI: 10.1023/A:1008129329289.

Jaeger J (2017): Exponential increase of urban sprawl in Montreal in Exponential increase of urban sprawl in Montreal in the last 60 years should be taken into consideration in decisions about future urban development. Concordia University. Montreal. Available online at http://ocpm.qc.ca/sites/ocpm.qc.ca/files/pdf/P85/9.63_jochen_jaeger.pdf, checked on $1 / 9 / 2020$.

Jaeger J; Soukup T; Madrinan LF; Schwick C; Kienast F (2011): Landscape Fragmentation in Europe. In European Union (9789292132156). DOI: 10.2800/78322.

Jain S; Kohli D; Rao RM; Bijker W (2011): Spatial Metrics to Analyse the Impact of Regional Factors on Pattern of Urbanisation in Gurgaon, India. In Journal of the Indian Society of Remote Sensing 39 (2), pp. 203-212. DOI: 10.1007/s12524-011-0088-0.

Jakobsen ST (1993): Interaction between Plant Nutrients: III. Antagonism between Potassium, Magnesium and Calcium. In Acta Agriculturae Scandinavica, Section B - Soil \& Plant Science 43 (1), pp. 1-5. DOI: 10.1080/09064719309410223.

Jim CY (1998): Urban soil characteristics and limitations for landscape planting in Hong Kong. In Landscape and Urban Planning 40 (4), pp. 235-249. DOI: 10.1016/S01692046(97)00117-5.

Joimel S; Cortet J; Jolivet CC; Saby NPA; Chenot ED; Branchu P; Consales JN; Lefort C; Morel JL; Schwartz C (2016): Physico-chemical characteristics of topsoil for contrasted forest, agricultural, urban and industrial land uses in France. In The Science of the total environment 545-546, pp. 40-47. DOI: 10.1016/j.scitotenv.2015.12.035.

Jones A; Breuning-Madsen H; Brossard M; Dampha A; Deckers J; Dewitte O; Gallali T; Hallett S; Jones R; Kilasara M; Le Roux P; Micheli E; Montanarella L; Spaargaren O; Thiombiamo L; van Ranst E; Yemefack M; Zougmore R (Eds.) (2013): Soil atlas of Africa. European Commision. Luxembourg: Published by the Publications Office of the European Union (JRC soil atlas series), checked on 2/11/2018.

Juo SR; Manu A (1996): Chemical dynamics in slash-and-burn agriculture. In Agriculture, Ecosystems \& Environment 58 (1), pp. 49-60. DOI: 10.1016/0167-8809(95)00656-7.

Kasanga K; Kotey NA (2001): Land Management in Ghana. Building on Tradition and Modernity. London (February).

Khorshid MSH; Kruse J; Semella S; Vohland M; Wagner J-F; Thiele-Bruhn S (2019): Phosphorus fractions and speciation in rural and urban calcareous soils in the semiarid region of Sulaimani city, Kurdistan, Iraq. In Environ Earth Sci 78 (16), p. 3835. DOI: 10.1007/s12665-019-8543-2.

Kirschbaum MUF (2000): Will changes in soil organic carbon act as a positive or negative feedback on global warming? In Biogeochemistry 48, pp. 21-51, checked on 3/14/2018.

Kleemann J; Inkoom JN; Thiel M; Shankar S; Lautenbach S; Fürst C (2017): Peri-urban land use pattern and its relation to land use planning in Ghana, West Africa. In Landscape and Urban Planning 165, pp. 280-294. DOI: 10.1016/j.landurbplan.2017.02.004. 
Korah PI; Cobbinah PB; Nunbogu AM (2017a): Spatial Planning in Ghana: Exploring the Contradictions. In Planning Practice \& Research 32 (4), pp. 361-384. DOI: 10.1080/02697459.2017.1378977.

Korah PI; Cobbinah PB; Nunbogu AM; Gyogluu S (2017b): Spatial plans and urban development trajectory in Kumasi, Ghana. In GeoJournal 82 (6), pp. 1113-1134. DOI: 10.1007/s10708-016-9731-1.

Kruse J; Abraham M; Amelung W; Baum C; Bol R; Kühn O; Lewandowski H; Niederberger J; Oelmann Y; Rueger C; Santner J; Siebers M; Siebers N; Spohn M; Vestergren Johan; Vogts A; Leinweber P (2015): Innovative methods in soil phosphorus research: A review. In J. Plant Nutr. Soil Sci. 178 (1), pp. 43-88. DOI: 10.1002/jpln.201400327.

Labrière N; Locatelli B; Laumonier Y; Freycon V; Bernoux M (2015): Soil erosion in the humid tropics. A systematic quantitative review. In Agriculture, Ecosystems \& Environment 203, pp. 127-139. DOI: 10.1016/j.agee.2015.01.027.

Lal R (2004): Soil carbon sequestration impacts on global climate change and food security. In Science 304 (5677), 1623-1627 ST - Soil carbon sequestration impacts. DOI: 10.1126/science.1097396.

Lal R; Augustin BJ (2012): Carbon sequestration in urban ecosystems. Dordrecht, New York: Springer.

Lal R (2013): Climate-strategic agriculture and the water-soil-waste nexus. In Journal of Plant Nutrition and Soil Science 176 (4), pp. 479-493. DOI: 10.1002/jpln.201300189.

Lal R (2014): The Nexus Approach to Managing Water, Soil and Waste under Changing Climate and Growing Demands on Natural Resources. In Mathew Kurian, Reza Ardakanian (Eds.): Governing the Nexus. New York: Springer, pp. 39-60.

Larondelle N; Haase D (2013): Urban ecosystem services assessment along a rural-urban gradient. A cross-analysis of European cities. In Ecological Indicators 29, pp. 179-190. DOI: 10.1016/j.ecolind.2012.12.022.

Lauer F; Paetzold S; Gerlach R; Protze J; Willbold S; Amelung W (2013): Phosphorus status in archaeological arable topsoil relicts-Is it possible to reconstruct conditions for prehistoric agriculture in Germany? In Geoderma 207-208 (1), pp.111-120. DOI: 10.1016/j.geoderma.2013.05.005.

Lausch A; Blashke T; Haase D; Herzog F; Ralf-Uwe S; Tischendorf L; Walz U (2014): Understanding and quantifying landscape structure. A review on relevant process characteristics, data models and landscape metrics. In Ecological Modelling 295, pp. 3141. DOI: 10.1016/j.ecolmodel.2014.08.018.

Lee Y-C; Ahern J; Yeh C-T (2015): Ecosystem services in peri-urban landscapes: The effects of agricultural landscape change on ecosystem services in Taiwan's western coastal plain. In Landscape and Urban Planning 139, pp.137-148. DOI: 10.1016/j.landurbplan.2015.02.023.

Lehmann A; Stahr K (2007): Nature and significance of anthropogenic urban soils. In Journal of Soils and Sediments 7 (4), pp. 247-260. DOI: 10.1065/jss2007.06.235.

Levin MJ; Kim K-H; Morel JL; Burghardt W; Charzyński P; Shaw RK (2017): Soils within cities. Global approaches to their sustainable management - composition properties and functions of soils of the urban environment. Stuttgart, Stuttgart: Catena imprint of 
Schweizerbart Science Publishers; E. Schweizerbart'sche Verlagsbuchhandlung (Nägele u. Obermiller) (GeoEcology Essays).

Li T; Zheng W; Zhang S; Jia Y; Li Y; Xu X (2018): Spatial variations in soil phosphorus along a gradient of central city-suburb-exurban satellite. In Catena 170, pp. 150-158. DOI: 10.1016/j.catena.2018.06.011.

Liu H; Huang X; Wen D; Li J (2017): The Use of Landscape Metrics and Transfer Learning to Explore Urban Villages in China. In Remote Sensing 9 (4), p. 365. DOI: $10.3390 /$ rs9040365.

Liu R; Wang M; Chen W (2018): The influence of urbanization on organic carbon sequestration and cycling in soils of Beijing. In Landscape and Urban Planning 169, pp. 241-249. DOI: 10.1016/j.landurbplan.2017.09.002.

Lopez-Ulloa RM (2006): Soil ecosystem services in different land use types in coastal Ecuador. PhD Thesis. Georg-August Universität Göttingen, Göttingen.

Lorenz K; Preston CM; Kandeler E (2006): Soil organic matter in urban soils. Estimation of elemental carbon by thermal oxidation and characterization of organic matter by solid-state 13C nuclear magnetic resonance (NMR) spectroscopy. In Geoderma 130 (3-4), pp. 312323. DOI: 10.1016/j.geoderma.2005.02.004.

Lorenz K; Kandeler E (2005): Biochemical characterization of urban soil profiles from Stuttgart, Germany. In Soil Biology and Biochemistry 37 (7), pp. 1373-1385. DOI: 10.1016/j.soilbio.2004.12.009.

Lorenz K; Lal R (2009): Biogeochemical C and N cycles in urban soils. In Environment International 35 (1), pp. 1-8. DOI: 10.1016/j.envint.2008.05.006.

Magdoff F; Weil RR (2004): Soil organic matter in sustainable agriculture. Boca Raton: CRC Press (Advances in agroecology).

Maranguit D (2017): Land-use Control on Abiotic and Biotic Mechanisms of P Mobilization. Doctoral thesis. Georg-August Universität Göttingen, Göttingen, checked on 7/18/2018.

Maranguit D; Guillaume T; Kuzyakov Y (2017): Land-use change affects phosphorus fractions in highly weathered tropical soils. In Catena 149, pp.385-393. DOI: 10.1016/j.catena.2016.10.010.

Masso C; Baijukya F; Ebanyat P; Bouaziz S; Wendt J; Bekunda M; Vanlauwe B (2017): Dilemma of nitrogen management for future food security in sub-Saharan Africa: a review. In Soil Research 55, pp. 425-434. DOI: 10.1071/SR16332.

McGarigal K (2015): FRAGSTATS help. Amherst: University of Massachussets.

McGarigal K; Cushman SA; Ene E (2012): FRAGSTATS v4. Spatial Pattern Analysis Program for Categorical and Continous Mpas. Amherst, USA: University of Massachussets.

McGregor D (2012): The Peri-Urban Interface: Routledge.

McGregor D; Adam-Bradford A; Thompson D; Simon D (2011): Resource management and agriculture in the periurban interface of Kumasi, Ghana. Problems and prospects. In Singapore Journal of Tropical Geography 32, pp. 382-398. DOI: 10.1111/j.14679493.2011.00438.x.

McKinney ML (2002): Urbanization, Biodiversity, and Conservation. In BioScience 52 (10), p. 883. DOI: 10.1641/0006-3568(2002)052[0883:UBAC]2.0.CO;2. 
Mendonça ES; Rowell DL (1996): Mineral and Organic Fractions of Two Oxisols and Their Influence on Effective Cation-Exchange Capacity. In Soil Science Society of America Journal 60 (6), p. 1888. DOI: 10.2136/sssaj1996.03615995006000060038x.

Meng Y; Cave M; Zhang Ch (2018): Spatial distribution patterns of phosphorus in top-soils of Greater London Authority area and their natural and anthropogenic factors. In Applied Geochemistry 88, pp. 213-220. DOI: 10.1016/j.apgeochem.2017.05.024.

Metson GS; Bennett EM (2015): Phosphorus cycling in Montreal's food and urban agriculture systems. In PLoS ONE 10 (3), e0120726. DOI: 10.1371/journal.pone.0120726.

Metson GS; Hale RL; Iwaniec DM; Cook EM; Corman JR; Galleti CS; Childers DL (2012): Phosphrus in Phoenix. A budget and spatial representation of phosphorus in an urban ecosystem. In Ecological Applications 22 (2), pp. 705-721.

Meyer D; Dimitriadou E Hornik K; Wingessel A; Liesch F (2018): e1071. Misc Functions of the Department of Statistics, Probability Theory Group (Formerly: E1071), TU Wien. Available online at https://CRAN.R-project.org/package=e1071.

Miezah K; Obiri-Danso K; Kádár Z; Fei-Baffoe B; Mensah MY (2015): Municipal solid waste characterization and quantification as a measure towards effective waste management in Ghana. In Waste management (New York, N.Y.) 46, pp. 15-27. DOI: 10.1016/j.wasman.2015.09.009.

Mikutta R; Kleber M; Kaiser K; Jahn R (2005): Review. In Soil Science Society of America Journal 69 (1), p. 120. DOI: 10.2136/sssaj2005.0120.

Minde I; Jayne TS; Crawford E; Ariga J; Govereh J (2008): Promoting fertilizer use in Africa. Current issues and emperical evidence from Malawi, Zambia, and Kenya. Working paper No. 13. International Crops Research Institute for the Semiarid Tropics (ICRISAT), International Food Policy Research Institute (IFPRI) and International Water Management Institute (IWMI) (Regional Strategic Analysis and Knowledge Support System (ReSAKSS) Working Paper, 13).

Minta P (1998): Effect of Mucuna pruriens mulch on the growth and yield of maise (Zea mays L.). Master. University of Ghana, Accra, Ghana, checked on 3/24/2018.

Mosammam HM; Nia JT; Khani H; Teymouri A; Kazemi M (2017): Monitoring land use change and measuring urban sprawl based on its spatial forms. In The Egyptian Journal of Remote Sensing and Space Science 20 (1), pp. 103-116. DOI: 10.1016/j.ejrs.2016.08.002.

Muggeo VMR (2017): Interval estimation for the breakpoint in segmented regression: a smoothed score-based approach. In Aust. N. Z. J. Stat. 59 (3), pp. 311-322. DOI: 10.1111/anzs. 12200 .

Murphy J; Riley JP (1962): A modified single solution method for the determination of phosphate in natural waters. In Analytica chimica acta 27, pp. 31-36.

Myers N; Mittermeier R; Mittermeier CG; da Fonseca GB; Kent J; Fonseca GAB (2000): Biodiversity hotspots for conservation priorities. In Nature 403 (6772), pp. 853-858. DOI: $10.1038 / 35002501$.

Ngoze S; Riha S; Lehmann J; Verchot L; Kinyangi J; Mbugua D; Pell A (2008): Nutrient constraints to tropical agroecosystem productivity in long-term degrading soils. In Global Change Biology 14, pp. 2810-2822. DOI: 10.1111/j.1365-2486.2008.01698.x. 
Oduro CY; Ocloo K; Peprah C (2014): Analyzing Growth Patterns of Greater Kumasi Metropolitan Area Using GIS and Multiple Regression Techniques. In Journal of Sustainable Development 7 (5), pp. 13-31. DOI: 10.5539/jsd.v7n5p13.

Oke TR (2017): Urban climates. Cambridge: Cambridge University Press.

Onduru DD; Gachini GN; Jager A; Diop J-M (1999): Participatory research on compost and liquid manure in Kenya. Networking on soil fertility management: improving soil fertility in Africa-Nutrient networks \& stakeholder perceptions. Nottingham (Managing Africa's soils, 8). Available online at https://library.wur.nl/isric/fulltext/isricu_i34188_001.pdf, checked on $11 / 27 / 2018$.

Oorts K; Vanlauwe B; Merckx R (2003): Cation exchange capacities of soil organic matter fractions in a Ferric Lixisol with different organic matter inputs. In Agriculture, Ecosystems \& Environment 100 (2-3), pp. 161-171. DOI: 10.1016/S0167-8809(03)00190-7.

Osemwota IO; Omueti JAI; Ogboghodo Al (2007): Effect of Calcium/Magnesium Ratio in Soil on Magnesium Availability, Yield, and Yield Components of Maize. In Communications in Soil Science and Plant Analysis 38 (19-20), pp. 2849-2860. DOI: $10.1080 / 00103620701663081$.

Owusu-Ansah JK; O'Connor KB (2010): Housing demand in the urban fringe around Kumasi, Ghana. In J Hous and the Built Environ 25 (1), pp. 1-17. DOI: 10.1007/s10901-009-9173$\mathrm{x}$.

Owusu-Ansah JK (2016): The influences of land use and sanitation infrastructure on flooding in Kumasi, Ghana. In GeoJournal 81 (4), pp. 555-570. DOI: 10.1007/s10708-015-9636-4.

Owusu-Bennoah E; Awadzi TW; Boateng E; Krogh L; Breuning-Madsen H; Borggaard OK (2000): Soil properties of a toposequence in the moist semi-deciduous forest zone of Ghana. In West African Journal of Applied Ecology 1 (1). DOI: 10.4314/wajae.v111.40565.

Owusu-Bennoah E; Szilas C; Hansen HCB; Borggaard OK (1997): Phosphate sorption in relation to aluminum and iron oxides of oxisols from Ghana. In Communications in Soil Science and Plant Analysis 28 (9-10), pp. 685-697. DOI: 10.1080/00103629709369821.

Pacione M (2009): Urban geography. A global perspective / Michael Pacione. $3^{\text {rd }}$ ed. London: Routledge.

Padmanaban R; Bhowmik AK; Cabral P; Zamyatin A; Almegdadi O; Wang S (2017): Modelling Urban Sprawl Using Remotely Sensed Data. A Case Study of Chennai City, Tamilnadu. In Entropy 19 (4), p. 163. DOI: 10.3390/e19040163.

Parnell S; Walawege R (2011): Sub-Saharan African urbanisation and global environmental change. In Global Environmental Change 21 (SUPPL. 1), S12-S20. DOI: 10.1016/j.gloenvcha.2011.09.014.

Perrings C (2010): Biodiversity, Ecosystem Services, and Climate Change. The Economic Problem. World Bank Environmental Department. Washington, DC (Environmental Economics Sieries, 120). Available online at http://projects.mcrit.com/ceara/attachments/article/231/BiodiversityEcosystemsServices_ CC.pdf, checked on 1/9/2020.

Plice MJ (1943): Factors Affecting Soil Color. Progress Report. Oklahoma Academy of Science (Proceedings of the Oklahoma Academy of Science, 23), checked on 5/11/2018. 
Poerwoningsih D; Antariksa; Leksono AS; Hasyim AW (2016): Integrating Visibility Analysis in Rural Spatial Planning. In Procedia - Social and Behavioral Sciences 227, pp. 838-844. DOI: 10.1016/j.sbspro.2016.06.153.

Poss R; Saragoni, H (1992): Leaching of nitrate, calcium and magnesium under maize cultivation on an oxisol in Togo. In Fertilizer Research (33), pp. 123-133, checked on 12/18/2018.

Post WM; Pastor J; Zinke PJ; Stangenberger AG (1985): Global patterns of soil nitrogen storage. In Nature 317 (6038), pp. 613-616. DOI: 10.1038/317613a0.

Pouyat RV; Groffman P; Yesilonis I; Hernandez L (2002): Soil carbon pools and fluxes in urban ecosystems. In Environmental pollution (Barking, Essex: 1987) 116 Suppl 1, S107-18.

Pouyat RV; Szlavecz K; Yesilonis ID; Groffman PM; Schwarz K (2010): Chemical, Physical and Biological Characteristics of Urban Soils. In Jacqueline Aitkenhead-Peterson, Astrid Volder (Eds.): Urban ecosystem ecology, vol. 55. Madison WI: American Society of Agronomy; Crop Science Society of America; Soil Science Society of America (Agronomy monograph, 55), pp. 119-152.

Pribyl DW (2010): A critical review of the conventional SOC to SOM conversion factor. In Geoderma 156 (3-4), pp. 75-83. DOI: 10.1016/j.geoderma.2010.02.003.

R Core Team (2018): R: A Language and Environment for Statistical Computing. Vienna, Austria: R Foundation for Statistical Computing. Available online at https://www.Rproject.org/.

Ramos FT; Dores EC; Weber OLDS; Beber DC; Campelo JH; Maia JC (2018): Soil organic matter doubles the cation exchange capacity of tropical soil under no-till farming in Brazil. In Journal of the science of food and agriculture 98 (9), pp. 3595-3602. DOI: 10.1002/jsfa.8881.

Ricketts TH; Imhoff M (2003): Biodiversity, Urban Areas, and Agriculture. Locating priority ecoregions for conservation. In Conservation ecology 8 (2). Available online at https://www.ecologyandsociety.org/vol8/iss2/art1/.

Ritchie H; Roser M (2020): Urbanization. Our World in Data. Available online at https://ourworldindata.org/urbanization.

Rodrigues M; Pavinato PS; Withers PJA; Teles APB; Herrera WFB (2016): Legacy phosphorus and no tillage agriculture in tropical oxisols of the Brazilian savanna. In The Science of the total environment 542 (Pt B), pp. 1050-1061. DOI: 10.1016/j.scitotenv.2015.08.118.

Roopawula PM; Bhatt BV (Eds.) (2017): Sustainable Peri-village in a potential peri-urban area. National Conference on Recent Research \& Development in Core Disciplines of Engineering. Kontambi, 21-22 April 2017. Available online at https://bvbhatt.com/wpcontent/uploads/2018/04/VIER_RRDCDE-2017_Sustainable-peri-village-in-a-potentialperi-urban-area_Updated.pdf, checked on 1/8/2020.

Rosseel Y (2012): lavaan: An R Package for Structural Equation Modeling. In J. Stat. Soft. 48 (2). DOI: $10.18637 /$ jss.v048.i02.

Roy A (2011): Slumdog cities: rethinking subaltern urbanism. In International Journal of Urban and Regional Research 35 (2), pp. 223-238. DOI: 10.1111/j.1468-2427.2011.01051.x.

Roy ED; Willig E; Richards PD; Martinelli LA; Vazquez FF; Pegorini L; Spera SA; Porder S (2017): Soil phosphorus sorption capacity after three decades of intensive fertilization in 
Mato Grosso, Brazil. In Agriculture, Ecosystems \& Environment 249, pp. 206-214. DOI: 10.1016/j.agee.2017.08.004.

Ryan PC (2014): Environmental and low temperature geochemistry. Chichester, West Sussex, Hoboken, NJ: Wiley Blackwell.

Sanchez PA; Shepherd KD; Soule MJ; Place FM; Buresh RJ; Izac A-M; Mokwunye AU; Kwesiga FR; Ndiritu CG; Woomer PL (1997): Soil Fertility Replenishment in Africa. An Investment in Natural Resource Capital. In Pedro A. Sanchez Roland J. Buresh, Frank Calhoun (Eds.): Replenishing Soil Fertility in Africa. $51^{\text {st }}$ ed. Wisconsin, WI: Soil Science Society of America and American Society of Agronomy (SSSA Special Publication), pp. 146.

Sauer D; Burghardt W (2006): The occurrence and distribution of various forms of silica and zeolites in soils developed from wastes of iron production. In Catena 65 (3), pp. 247-257. DOI: 10.1016/j.catena.2005.11.017.

Schipper LA; Percival HJ; Sparling GP (2004): An approach for estimating when soils will reach maximum nitrogen storage. In soil use manage 20 (3), pp. 281-286. DOI: 10.1079/SUM2004255.

Schleuß U; Wu Q; Blume H-P (1998): Variability of soils in urban and periurban areas in Northern Germany. In Catena 33 (3-4), pp. 255-270. DOI: 10.1016/S03418162(98)00070-8.

Shang C; Tiessen $H$ (2003): Soil organic $C$ sequestration and stabilization in karstic soils of Yucatan. In Biogeochemistry 62 (2), pp. 177-196. DOI: 10.1023/A:1021123728639.

Shen G; Ibrahim AN; Zhu Y; Wang Z; Gong J (2017): Remote sensing of urban growth and landscape pattern changes in response to the expansion of Chongming Island in Shanghai, China. In Geocarto International 32 (5), pp. 488-502. DOI: 10.1080/10106049.2016.1156166.

Simon D; McGregor D; Nsiah-Gyabaah K (2004): The changing urban-rural interface of African cities. Definitional issues and an application to Kumasi, Ghana. In Environment and Urbanization 16 (2), pp. 235-247. DOI: 10.1630/0956247042309856.

Smetak KM; Johnson-Maynard JL; Lloyd JE (2007): Earthworm population density and diversity in different-aged urban systems. In Applied Soil Ecology 37 (1-2), pp. 161-168. DOI: 10.1016/j.apsoil.2007.06.004.

Soares MR; Alleoni LRF; Vidal-Torrado P; Cooper M (2005): Mineralogy and ion exchange properties of the particle size fractions of some Brazilian soils in tropical humid areas. In Geoderma 125 (3-4), pp. 355-367. DOI: 10.1016/j.geoderma.2004.09.008.

International 10390, 2005: Soil Quality - Determination of $\mathrm{pH}$.

Solomon D; Lehmann J; Kinyangi J; Amelung W; Lobe, I; Pell A; Riha S; Ngoze S; Verchots L; Mbugua D; Skjemstad J; Schaefer T (2007): Long-term impacts of anthropogenic perturbations on dynamics and speciation of organic carbon in tropical forest and subtropical grassland ecosystems. In Global Change Biol 13 (2), pp. 511-530. DOI: 10.1111/j.1365-2486.2006.01304.x.

Solomon D; Lehmann J; Mamo T; Fritzsche F; Zech W (2002): Phosphorus forms and dynamics as influenced by land use changes in the sub-humid Ethiopian highlands. In Geoderma 105 (1-2), pp. 21-48. DOI: 10.1016/S0016-7061(01)00090-8. 
Song J; Cai D; Deng J; Wang K; Shen Z (2015): Dynamics of Paddy Field Patterns in Response to Urbanization. A Case Study of the Hang-Jia-Hu Plain. In Sustainability 7 (10), pp. 13813-13835. DOI: 10.3390/su71013813.

Stoorvogel JJ; Smaling EMA (1990): Assessment of soil nutrient depletion in Sub-Saharan Africa: 1983-2000. 28 ${ }^{\text {th }}$ ed. The Winand Staring Centre for Integrated Land, Soil and Water Research. Wageningen, The Netherlands (Nutrient balances per crop and per land use systems, 2), checked on 3/23/2018.

Stoorvogel JJ; Smaling EMA; Janssen BH (1993): Calculating soil nutrient balances in Africa at different scales. In Fertilizer Research 35 (3), pp. 227-235. DOI: 10.1007/BF00750641.

Stow DA; Weeks JR; Shih H-C; Coulter LL; Johnson H; Tsai Y-H; Kerr A; Benza M; Mensah $F$ (2016): Inter-regional pattern of urbanization in southern Ghana in the first decade of the new millennium. In Applied Geography 71, pp. 32-43. DOI: 10.1016/j.apgeog.2016.04.006.

Su S; Wang Y; Luo F; Mai G; Pu J (2014): Peri-urban vegetated landscape pattern changes in relation to socioeconomic development. In Ecological Indicators 46, pp. 477-486. DOI: 10.1016/j.ecolind.2014.06.044.

Tiessen H; Moi JO (2008): Characterization of available P by sequential extraction. In Martin R. Carter, E. G. Gregorich (Eds.): Soil sampling and methods of analysis. $2^{\text {nd }}$ ed. Pinawa Manitoba, Boca Raton FL: Canadian Society of Soil Science; CRC Press, pp. 321-334.

Tiessen H (2005): Phosphorus dynamics in Tropical soils. In T. Sims, A. Sharpley (Eds.): Phosphorus, Agriculture and the Environment. 46 volumes. Madison, WI, pp. 253-262.

Tresch S; Moretti M; Le Bayon R-C; Mäder P; Zanetta A; Frey D; Fliessbach A (2018): A Gardener's Influence on Urban Soil Quality. In Front. Environ. Sci. 6, p. 605. DOI: 10.3389/fenvs.2018.00025.

Turner MG; Gardner RH (2015): Landscape Ecology in Theory and Practice. Second. New York, USA: Springer.

Tuszynski J (2018): caTools. Tools: Moving Window Statistics, GIF, Base64, ROC, AUC, etc. Available online at https://CRAN.R-project.org/package=caTools.

Ubink JM; Quan JF (2008): How to combine tradition and modernity? Regulating customary land management in Ghana. In Land Use Policy 25 (2), pp. 198-213. DOI: 10.1016/j.landusepol.2007.06.002.

UN-Habitat (2004): The Challenge of Slums. Global Report on Human Settlements 2003. In Management of Environmental Quality 15 (3), pp. 337-338. DOI: 10.1108/meq.2004.15.3.337.3.

United Nations Economic Commission for Africa (2014): Contribution to the 2014 United Nations Economic and Social Council (ECOSOC) Integration Segment. United Nations Economic and Social Council.

United Nations, Department of Economic and Social Affairs, Population Division (2014): World Urbanization Prospects. The 2014 Revision, Highlights (ST/ESA/SER.A/352). New York.

United Nations, Department of Economic and Social Affairs, Population Division (2019): World Urbanization Prospects 2018. Highlights (ST/ESA/SER.A/421). New York, checked on 1/8/2020. 
Uuemaa E; Roosaare J; Oja T; Mander A (2011): Analysing the spatial structure of the Estonian landscapes. Which landscape metrics are the most suitable for comparing different landscapes? In Estonian Journal of Ecology 60 (1), p. 70. DOI: 10.3176/eco.2011.1.06.

Uuemaa E; Mander A; Marja R (2013): Trends in the use of landscape spatial metrics as landscape indicators. A review. In Ecological Indicators 28, pp. 100-106. DOI: 10.1016/j.ecolind.2012.07.018.

Venables B; Hornik K; Maechler M (2016): polynom. A collection of functions to implement a class for univariate polynomial manipulations. Available online at https://CRAN.Rproject.org/package=polynom.

Vermeiren K; Adiyia B; Loopmans M; Tumwine FR; van Rompaey A (2013): Will urban farming survive the growth of African cities. A case-study in Kampala (Uganda)? In Land Use Policy 35, pp. 40-49. DOI: 10.1016/j.landusepol.2013.04.012.

Vizzari M; Sigura M (2015): Landscape sequences along the urban-rural-natural gradient: A novel geospatial approach for identification and analysis. In Landscape and Urban Planning 140, pp. 42-55. DOI: 10.1016/j.landurbplan.2015.04.001.

Vodyanitskii YN; Savichev AT (2017): The influence of organic matter on soil color using the regression equations of optical parameters in the system CIE- $\mathrm{L}^{*} \mathrm{a}^{*} \mathrm{~b}^{*}$. In Annals of Agrarian Science 15 (3), pp. 380-385. DOI: 10.1016/j.aasci.2017.05.023.

Vuong TX; Heitkamp F; Jungkunst HF; Reimer A; Gerold G (2013): Simultaneous measurement of soil organic and inorganic carbon. Evaluation of a thermal gradient analysis. In Journal of Soils and Sediments 13 (7), pp. 1133-1140. DOI: 10.1007/s11368013-0715-1.

Wadduwage S; Millington A; Crossman ND; Sandhu H (2017): Agricultural Land Fragmentation at Urban Fringes. An Application of Urban-To-Rural Gradient Analysis in Adelaide. In Land 6 (2), p. 28. DOI: 10.3390/land6020028.

Webster D (2002): On the edge. Shaping the future of Peri-urban East Asia. Stanford, Calif.: Asia/Pacific Research Center (Discussion papers / Asia/Pacific Research Center).

Weihrauch C (2018): Phosphor-Dynamiken in Böden. Grundlagen, Konzepte und Untersuchungen zur räumlichen Verteilung des Nährstoffs. 1. Auflage 2018. Wiesbaden: Springer Fachmedien Wiesbaden GmbH. Available online at http://www.springer.com/.

Wickham H; Francois R; Henry L; Mueller K (2018): dplyr. A grammar of data manipulation. Version 0.7.5. Available online at https://cran.r-project.org/package=dplyr.

Willkomm M; Follmann A; Dannenberg P (2019): Rule-based, hierarchical land use and land cover classification of urban and peri-urban agriculture in data-poor regions with RapidEye satellite imagery: a case study of Nakuru, Kenya. In J. Appl. Rem. Sens. 13 (01), p. 1. DOI: 10.1117/1.JRS.13.016517.

Yankson PWK; Bertrand M (2012): Challenges of Urbanization in Ghana. In The Mobile City of Accra, pp. 25-46.

Yeboah E; Obeng-Odoom F (2010): We are not the only ones to blame. District Assemblies' perspectives on the state of planning in Ghana. In Commonwealth Journal of Local Governance 1996 (7), pp. 78-98.

Yeboah EA (2000): Structural Adjustment and Emerging Urban Form in Accra, Ghana. In Africa Today 47 (2), pp. 61-89. DOI: 10.1353/at.2000.0058. 
Yuan D-G; Zhang G-L; Gong Z-T; Burghardt W (2007): Variations of soil phosphorus accumulation in Nanjing, China as affected by urban development. In J. Plant Nutr. Soil Sci. 170 (2), pp. 244-249. DOI: 10.1002/jpln.200622035.

Zhang MK (2004): Phosphorus Accumulation in Soils Along an Urban-Rural Land Use Gradient in Hangzhou, Southeast China. In Communications in Soil Science and Plant Analysis 35 (5-6), pp. 819-833. DOI: 10.1081/CSS-120030360.

Zhang T (2006): Beyond Metropolis. The Planning and Governance of Asia's Mega-Urban Regions. In Journal of Planning Education and Research 25 (3), pp. 333-334. DOI: 10.1177/0739456X05285897.

Zingore S; Manyame C; Nyamugafata P; Giller KE (2005): Long-term changes in organic matter of woodland soils cleared for arable cropping in Zimbabwe. In Eur J Soil Science 0 (0), 050912034650038-??? DOI: 10.1111/j.1365-2389.2005.00707.x.

Zingore S; Murwira HK; Delve RJ; Giller KE (2007): Soil type, management history and current resource allocation. Three dimensions regulating variability in crop productivity on African smallholder farms. In Field Crops Research 101 (3), pp. 296-305. DOI: 10.1016/j.fcr.2006.12.006.

Zingore S; Delve RJ; Nyamangara J; Giller KE (2008): Multiple benefits of manure. The key to maintenance of soil fertility and restoration of depleted sandy soils on African smallholder farms. In Nutr Cycl Agroecosyst 80 (3), pp. 267-282. DOI: 10.1007/s10705007-9142-2. 